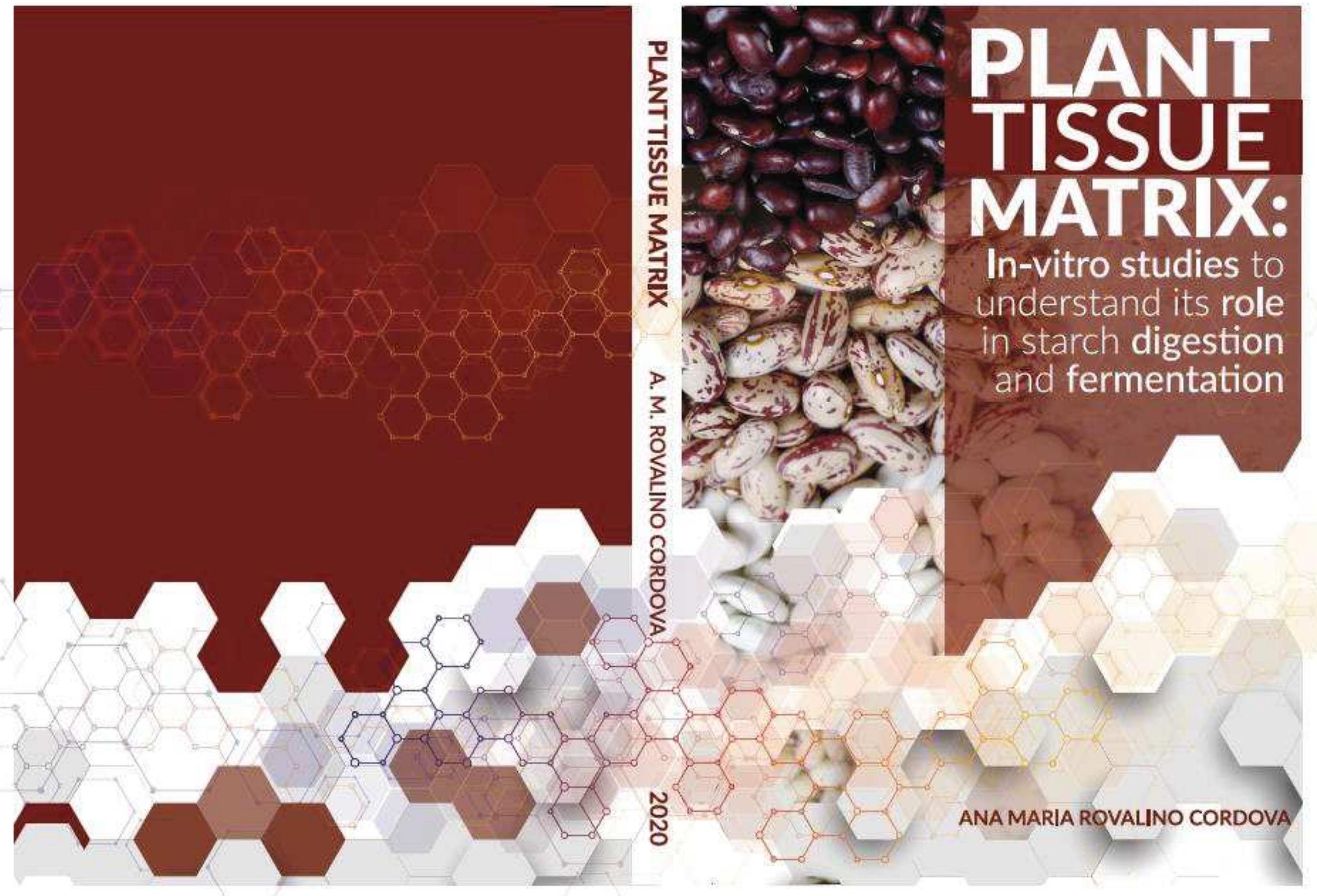




\section{Propositions:}

1. Food structure could be used as a tool to modulate the rate and extent of nutrients digestion. (This thesis)

2. Food composition regulates microbiota's community whereas food structure determines the extent of nutrients fermentation. (This thesis)

3. Nature has all the answers; it is the role of scientists to unveil them.

4. Sustainability should start in a research laboratory.

5. Intelligence can take you far, but motivation will move you further.

6. Humanity has reached a point where the desire of power is stronger than the selfpreservation instinct.

Propositions belonging to the thesis, entitled

Plant tissue matrix: In-vitro studies to understand its role in starch digestion and fermentation

Ana M. Rovalino-Córdova

Wageningen, $17^{\text {th }}$ of April 2020 


\section{Plant tissue matrix: In-vitro studies to understand its role in starch digestion and fermentation}

Ana María Rovalino Córdova 


\section{Thesis Committee}

\section{Promotor}

Prof. Dr V. Fogliano

Professor of Food Quality and Design

Wageningen University \& Research

\section{Co-Promotor}

Dr E. Capuano

Assistant Professor, Food Quality and Design Group

Wageningen University \& Research

\section{Other members}

Prof. Dr H.A. Schols, Wageningen University \& Research

Prof. Dr W.J.J. Gerrits, Wageningen University \& Research

Dr J.J. Mess, Wageningen University \& Research

Dr T Grauwet, KU Leuven, Belgium

This research was conducted under the auspice of the Graduate school VLAG (Advanced studies in Food Technology, Agrobiotechnology, Nutrition and Health Sciences) 


\title{
Plant tissue matrix: In-vitro studies to understand its role in starch digestion and fermentation
}

\author{
Ana María Rovalino Córdova
}

\section{Thesis}

submitted in the fulfilment of the requirements for the degree of doctor at Wageningen University

by the authority of the Rector Magnificus,

$$
\text { Prof. Dr A.P.J. Mol }
$$

in the presence of the

Thesis Committee appointed by the Academic Board

to be defended in public

on Friday $17^{\text {th }}$ of April 2020

at 4 p.m. in the Aula. 


\section{Ana Maria Rovalino Córdova}

Plant tissue matrix: In-vitro studies to understand its role in starch digestion and fermentation, 208 pages.

$\mathrm{PhD}$ thesis Wageningen University, Wageningen, The Netherlands (2020)

With references, with summary in English

ISBN: 978-94-6395-304-7

DOI: https://doi.org/10.18174/513652 
To my grandfather, Luis E. Córdova.

The best mentor I've ever had. $\cos$ 



\section{Table of Contents}

List of abbreviations and symbols

Chapter 1

General Introduction and thesis outline
9

13

33

A closer look to cell structural barriers affecting starch digestibility in beans

Chapter 3

The effect of cell wall encapsulation on macronutrients digestion: a case study in kidney beans

Chapter 4

83

A mechanistic model to study the effect of the cell wall on starch digestion in intact cotyledon cells

Chapter 5

115

Effect of bean structure on microbiota utilization of plant nutrients: an in-vitro study using the simulator of the human intestinal microbial ecosystem (SHIME®)

Chapter 6

In-vitro colonic fermentation of kidney beans depend on cotyledon cells integrity and microbiota adaptation to the diet

Chapter 7

171

General Discussion

Summary

195

Acknowledgements

About the author 



\section{List of abbreviations and symbols}

\begin{tabular}{|c|c|}
\hline$C W$ & Cell walls \\
\hline GI & Glycaemic index \\
\hline ICC & Intact cotyledon cells \\
\hline$M D C$ & Mechanically damaged cells \\
\hline$E D C$ & Enzymatically damaged cells \\
\hline WSP & Water soluble polysaccharides \\
\hline$W I P$ & Water insoluble polysaccharides \\
\hline DMSO & Dimethyl sulfoxide \\
\hline SEM & Scanning electron microscopy \\
\hline$I C W$ & Intact cotyledon walls \\
\hline$E D W$ & Enzymatically damaged walls \\
\hline NSP & Non-starch polysaccharides \\
\hline$B F S$ & Bean flour solution \\
\hline$T C A$ & Trichloroacetic acid \\
\hline$N G P$ & No gastric protease \\
\hline NIP & No intestinal proteases \\
\hline$N P$ & No proteases \\
\hline$N A$ & No amylase \\
\hline$O P A$ & O-phthaldialdehyde \\
\hline$D H$ & Degree of hydrolysis \\
\hline $\mathrm{NH}_{2}(\mathrm{DS})$ & Free amino groups from digested sample \\
\hline $\mathrm{NH}_{2}(t=0)$ & Free amino groups from samples at time 0 of digestion \\
\hline $\mathrm{NH}_{2}$ (Total) & Maximum amount of $\mathrm{NH}_{2}$ present in sample \\
\hline$S D S-P A G E$ & Sodium dodecyl sulphate polyacrylamide gel electrophoresis \\
\hline$F T-I R$ & Fourier transform infrared spectroscopy \\
\hline$R B$ & Raw bean flour \\
\hline
\end{tabular}




\begin{tabular}{|c|c|}
\hline$F S D$ & Fourier self deconvolution \\
\hline$C L S M$ & Confocal laser scanning microscopy \\
\hline$N D$ & Non-digested \\
\hline$W i$ & Spectral weight \\
\hline$A 1$ & Intermolecular aggregates \\
\hline$\beta$ & beta-sheet \\
\hline$\beta-I$ & Intermolecular beta-sheet \\
\hline$R C$ & Random coil \\
\hline$\alpha$ & alpha-helix \\
\hline$T$ & Turn conformations \\
\hline$A 2$ & Intramolecular aggregates \\
\hline FITC & Fluorescein isothyocianate \\
\hline$P_{e}$ & $\alpha$-amylase partition coefficient \\
\hline $\mathrm{Ce}$ & Concentration of $\alpha$-amylase \\
\hline Cs & Concentration of starch hydrolysis products \\
\hline$C e_{b}$ & Concentration of $\alpha$-amylase in the bulk \\
\hline$C s_{b}$ & Concentration of starch hydrolysis products in the bulk \\
\hline$C e_{w}$ & Concentration of $\alpha$-amylase in the cell wall \\
\hline$C e_{i n}$ & Concentration of $\alpha$-amylase within intact cell \\
\hline$C s_{\text {in }}$ & Concentration of starch hydrolysis products within intact cell \\
\hline$C e_{a v}$ & Concentration of $\alpha$-amylase in the combined cell wall ant intact cell compartment \\
\hline$\varphi$ & Volume fraction \\
\hline $1 / k$ & Stagnant layer resistance \\
\hline$D$ & Diffusion coefficient \\
\hline$\delta$ & Cell wall thickness \\
\hline$k d$ & Hindrance coefficient \\
\hline$A$ & Total surface area of intact cotyledon cells \\
\hline$V_{I C}$ & Volume of intact cotyledon cells \\
\hline
\end{tabular}




\begin{tabular}{|c|c|}
\hline$V_{T}$ & Volume of the liquid phase \\
\hline$k_{\text {cat }}$ & Catalytic constant \\
\hline$V_{w}$ & Volume of the cell wall \\
\hline$V_{I N}$ & Volume within intact cotyledon cells \\
\hline$N_{e}$ & Enzyme flux \\
\hline$N_{s}$ & Substrate flux \\
\hline$k$ & Mass transfer coefficient \\
\hline$d_{I C}$ & Intact cotyledon cells diameter \\
\hline$\eta$ & Viscosity \\
\hline$\rho$ & Density \\
\hline$R e_{p}$ & Reinolds number \\
\hline$G a$ & Galilei number \\
\hline$g$ & Gravity constant \\
\hline$k_{B}$ & Boltzmann constant \\
\hline$r_{s}$ & Maltotriose radio \\
\hline$R S$ & Resistant starch \\
\hline$S C F A$ & Short chain fatty acids \\
\hline$B C R$ & Branched chain ratio \\
\hline$A C$ & Ascending colon \\
\hline$T C$ & Transverse colon \\
\hline$D C$ & Descending colon \\
\hline Fuc & Fucose \\
\hline Ara & Arabinose \\
\hline Rha & Rhamnose \\
\hline Gal & Galactose \\
\hline Glc & Glucose \\
\hline$X y l$ & Xylose \\
\hline Man & Mannose \\
\hline
\end{tabular}




\begin{tabular}{|c|c|}
\hline$U A$ & Uronic acid \\
\hline OTU & Operational taxonomic unit \\
\hline D1 & Donor 1 \\
\hline D2 & Donor 2 \\
\hline$S H I M E^{\circledR}$ & Simulator of the human intestinal microbial ecosystem \\
\hline NAICC & Non-adapted bacteria fed with intact cotyledon cells \\
\hline$N A M D C$ & Non-adapted bacteria fed with mechanically damaged cells \\
\hline$A I C C$ & Adapted bacteria fed with intact cotyledon cells \\
\hline$A M D C$ & Adapted bacteria fed with mechanically damaged cells \\
\hline$D M C V$ & Dry matter corrected volume \\
\hline$A_{g}$ & Asymptotic value of gas production \\
\hline$C_{g}$ & Time at which the asymptotic value is reached \\
\hline$B_{g}$ & Switching characteristics of the curve \\
\hline$t$ & Time \\
\hline$R m$ & Maximum rate of gas production \\
\hline$T_{R M}$ & Time at which maximum rate occurred \\
\hline$A A E$ & Acetic acid equivalent \\
\hline$S$ & Structure \\
\hline$C$ & Colon region \\
\hline$B$ & Type of bacteria \\
\hline
\end{tabular}




\section{Chapter 1}

- 1200.

General Introduction and thesis outline 


\subsection{Benefits of consuming edible plant-tissues}

Plant-based foods provides important health and nutritional benefits to the diet. The regular consumption of fruits, vegetables, whole grains, seeds and legumes has been associated with the prevention of cardiovascular diseases and obesity ${ }^{1,2}$. Furthermore, plant-based foods are recommended as a good replacement for other high-energy dense products (e.g. snacks, baked goods) since they confer satiety and satiation due to the large amount of dietary fiber present ${ }^{3}$. In general, these products are good sources of several micro (Fe, $\mathrm{Zn}, \mathrm{Ca}$ ) and macronutrients (protein, starch, fat), sometimes even serving as a primary source of such nutrients to certain segments of the population that, due to ethical or religious reasons, do not consume animalbased products. In this respect, legumes are particularly interesting due to their high protein and starch content that makes them a good substitute for products of animal origin. These two macronutrients are essential components of the diet since they provide energy and are useful for the correct regulation of metabolic processes ${ }^{4}$. Thus, understanding their digestibility and availability when contained within the plant matrix is of great importance and could aid in the development of strategies to modulate their utilization.

\subsection{Physiology of starch and protein digestion}

\subsubsection{Digestion from the mouth to the ileum}

Starch digestion starts in the mouth during bolus formation, where food is mixed with saliva that contains $\alpha$-amylase. The activity of this amylolytic enzyme is not limited to the few minutes of residence in the mouth since it may remain active for several minutes after the bolus have reached the stomach, depending on the kinetics of stomach acidification ${ }^{5}$. However, most of starch digestion and glucose absorption occurs in the small intestine of mammals (Fig. 1-1). In this portion of the digestive system, starch is hydrolysed by pancreatic $\alpha$-amylase, an endohydrolase, that cleaves accessible $\alpha(1-4)$ bonds of the starch molecule ${ }^{6}$. The products formed upon $\alpha$-amylase catalysis are maltose, $\alpha$-limit dextrins and linear oligomers. To be absorbed by the intestinal lumen, they must be further hydrolysed by brush border exo-hydrolases into glucose which is ultimately absorbed by the epithelial cells through active or facilitated transport. The brush border enzymes have the capability of cleaving $\alpha(1-4)$ bonds but also $\alpha$ (1-6) present in $\alpha$-limit dextrins ${ }^{7}$.

As for proteins, their digestion starts in the stomach where pepsin, an aspartic protease, is secreted by chief cells located in the gastric mucosa (Fig. 1-1). Pepsin contains aspartic acid 
residues at the catalytic site that activate water molecules for the hydrolysis of the peptide bonds $^{8}$. Physiologically, pepsin is secreted as a zymogen (pepsinogen) which is later activated by the acidic environment of the gastric juice. This prevents the host tissues from selfdigestion ${ }^{9}$. Pepsin has a broad specificity, with a preference for cleaving peptide bonds between hydrophobic and aromatic amino acids such as phenylalanine, tryptophan and tyrosine ${ }^{8}$. Undigested proteins or peptide fragments produced after pepsin degradation are further digested by trypsin and chymotrypsin in the duodenum and proximal jejunum. Both enzymes are serine proteases that are produced in the pancreas as the zymogens trypsinogen and chymotrypsinogen, respectively. They are endopeptidases which cleave peptide bonds of nonterminal amino acids with specificity towards certain amino acid residues at the scissile peptide bond. In the case of trypsin, its action is limited to hydrolyzing peptides at the site of the basic amino acids arginine and lysine while chymotrypsin acts upon phenylalanine, tryptophan and tyrosine residues ${ }^{10,11}$. Polypeptides produced by trypsin and chymotrypsin are further cleaved into their amino acid constituents by carboxypeptidases and aminopeptidases contained in the pancreatic secretions and dipeptidases present in the intestinal brush border ${ }^{9}$. Ultimately, free amino acids, dipeptides and tripeptides are absorbed by specialized transport proteins in the epithelium. 


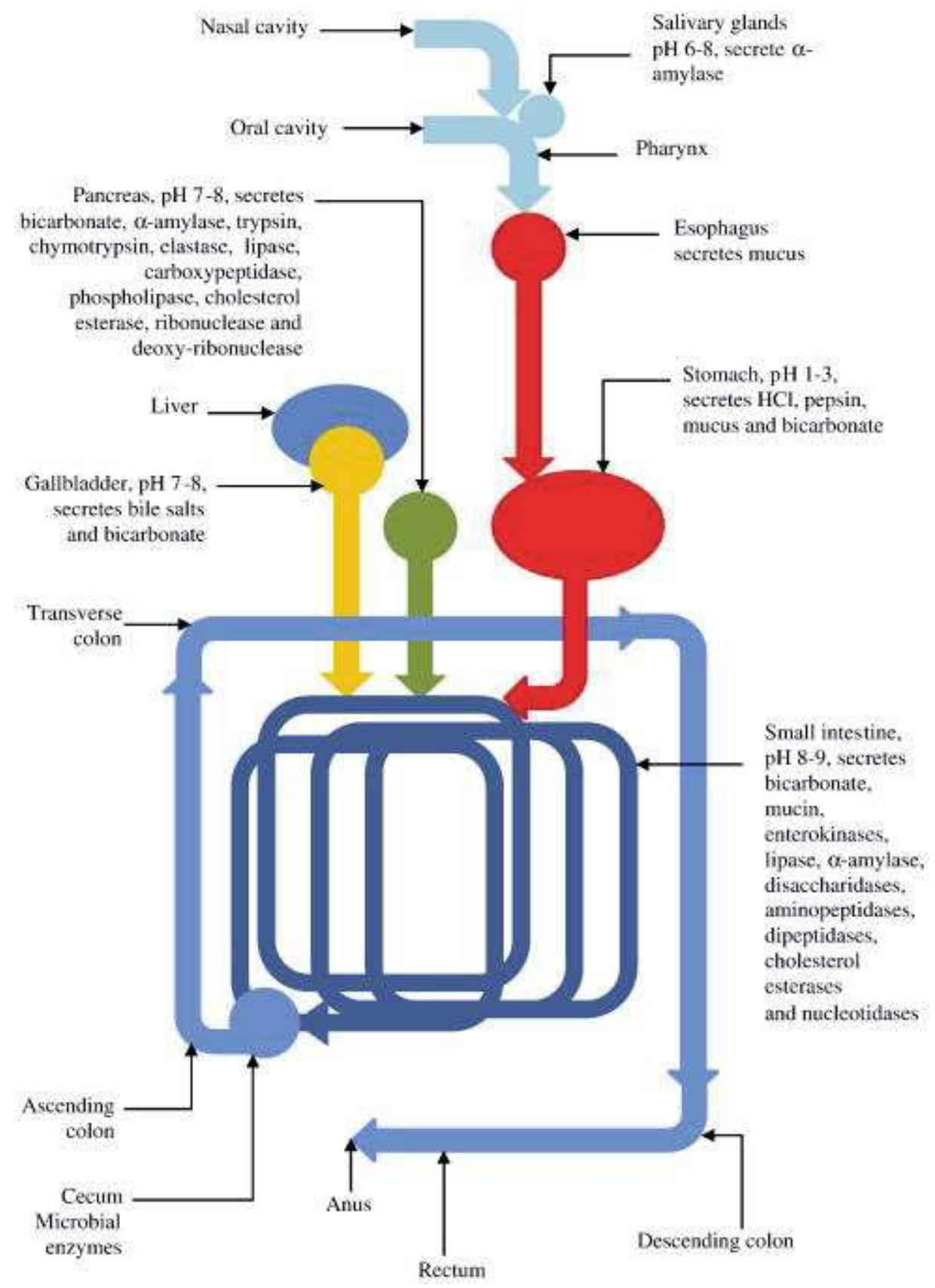

Fig. 1-1. Schematic representation of the digestive tract and the sites of enzyme production and activity ${ }^{12}$. Copyright granted by Elsevier, license number 4711890444977.

\subsubsection{Colonic fermentation}

A substantial amount of nutrients escapes the small intestine undigested. In some cases, this is related to the fact that humans lack specific enzymes needed to degrade them. That is the case of the complex carbohydrates present in plant cell walls which together with resistant starch (RS), are the most abundant source of dietary fibre. The amount of dietary fibre reaching the colon highly depends on the diet and it increases with the amount of plant tissue consumed. 
According to most nutritional guidelines, the intake of dietary fibre should range between 25$35 \mathrm{~g}$ per day ${ }^{13,14}$. Besides carbohydrates, a variable portion of proteins (around 10\% of ingested protein ${ }^{15}$ ), fats and oligosaccharides may escape digestion becoming potential substrates for the microbiota present in the large intestine. The utilization of those undigested nutrients by resident microbiota has been found to influence the host physiology due to the metabolites produced $^{16}$.

The utilization of carbohydrates results in the production of short chain fatty acids (SCFA) and gas $\left(\mathrm{CO}_{2}, \mathrm{CH}_{4}\right.$, and $\left.\mathrm{H}_{2}\right)$. It has been found that, in both humans and pigs, the predominant SCFA produced is acetate, followed by propionate and then butyrate ${ }^{17}$. In general, several health promoting effects have been ascribed to SCFA production such as lowering the $\mathrm{pH}$ of the colon, growth inhibition of pathogenic organisms and maintenance of normal bowel structure and function. More recently, butyrate production has drawn much attention due to its health related properties where the growth inhibition of colon-rectal cancer cells could be the most relevant ${ }^{18}$. Specific substrates, such as RS have been found to stimulate the growth of certain bacterial strains capable of producing higher amounts of butyrate ${ }^{19}$, hence its utilization in the design of functional foods has increased. Furthermore, it has been shown that the presence of RS shifted the utilization of other non-starch polysaccharides (NSP) to more distal parts of the colon ${ }^{20}$. This is of importance since carbohydrate depletion in the distal parts of the gut results in protein fermentation which produces toxic compounds such as ammonia, phenols, amines, thiols and branched chain fatty acids. Experimental evidence is accumulating from animal and in-vitro data, which shows that fermentation of dietary proteins might be one of the factors that increases the risk of colorectal cancer ${ }^{21}$. Fig. 1-2 shows a schematic representation of the bacterial content, substrate availability and optimal $\mathrm{pH}$ of the three portions that constitute the large intestine. 


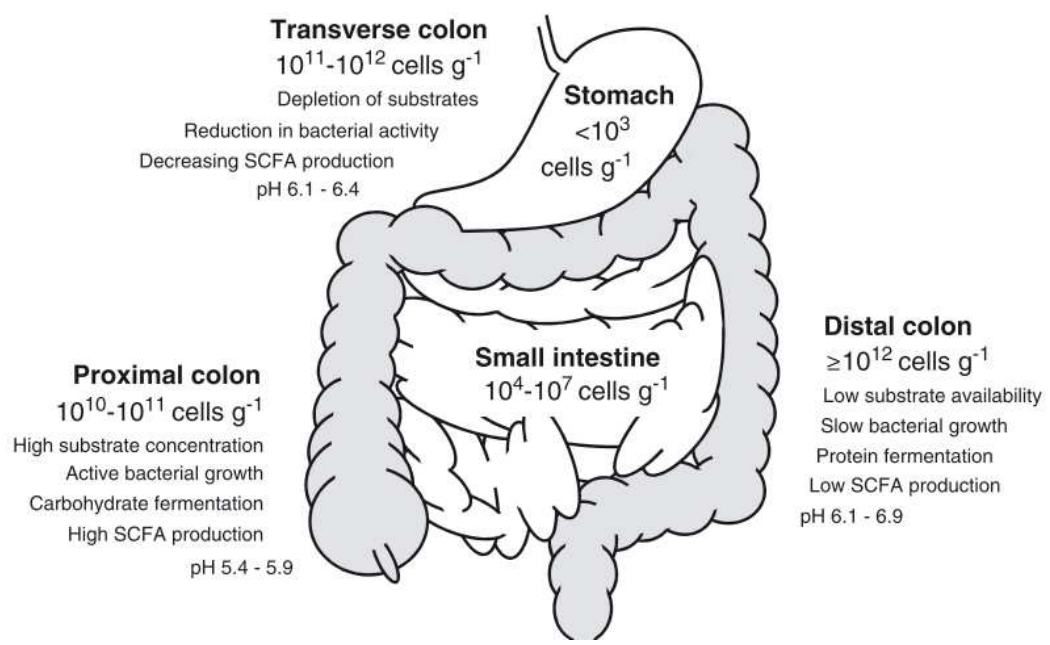

Fig. 1-2. Schematic representation of the bacterial content, substrate availability and SCFA production of the digestive $\operatorname{tract}^{22}$.

\subsection{Factors affecting protein and starch digestibility}

There are two concepts widely used by nutritionists and food scientists to characterize the behaviour of nutrients in the gastrointestinal tract and the fraction that is utilized by the host: bio-availability and bio-accessibility. The former refers to the proportion of an ingested nutrient that is delivered into the blood stream and has to do with the efficiency of absorption and utilization of $\mathrm{it}^{23}$. While the latter refers to the amount of an ingested nutrient that is available for absorption in the gut after digestion ${ }^{24}$. When it comes to macronutrients, such as starch and proteins, their hydrolysis by digestive enzymes into smaller units is the obvious pre-requisite for absorption in the bloodstream. In such cases one better refers to them in terms of digestibility, i.e. the fraction of macronutrient hydrolysed in smaller products by the action of digestive enzymes (amylase for starch and proteases for proteins) that could be either absorbed in the blood stream or available for absorption. Therefore, the proportion of an ingested nutrient that is delivered into the blood stream is more important than the total amount contained in the food.

Starch digestibility has been subject of many research studies due to its huge impact on human health. The clear link between starch digestion and blood glucose levels led to the classification of foods according to their potential to rise post-prandial glycaemia and insulinemic indices ${ }^{25}$. Englyst and Cummings ${ }^{26}$ proposed one of the first systems of starch classification based on its digestion kinetics identifying three types of starches: rapidly digestible, slowly digestible and resistant starch; showing the relationship between the distribution of these three fractions and the corresponding glycaemic index values measured in-vivo. Despite this classification is 
nowadays questioned from a molecular point of view ${ }^{27}$, it represented a useful starting point to relate starch behaviour during digestion to the physiological response observed in-vivo. However, the food properties responsible for those differences remain to be elucidated. In fact, this is still a matter of investigation, but several factors have been found to be important. They are related to food structure (plant tissues ${ }^{28}$ ), physicochemical characteristics of starch granules (amylose: amylopectin ratio, granule size, shape and porosity ${ }^{29}$ ), the presence and interactions with other dietary components (dietary fibre, proteins and polyphenols ${ }^{30}$ ). Perhaps one of the most important factors modulating starch digestibility is related to the extent of granules gelatinization $^{31}$; a thermal process by which native starch granules absorb water and swell losing their crystallinity and structural organization. The extent of gelatinization is affected by the type and amount of starch granules, temperature gradient, shear force and water content ${ }^{32}$. Therefore, high digestibility is achieved in fully gelatinized starch granules while native or crystalline forms of the molecule will result in very low levels of digestion.

The factors affecting protein digestibility are very similar to those of starch and include: its origin and amino acid composition (primary structure), conformational configuration (i.e. secondary and tertiary structure, (un)folded state, aggregation level or cross-linking among individual polypeptides ${ }^{33}$ and interactions with other macronutrients (e.g. dietary fibre) or food components (tannins and other polyphenols, trypsin inhibitors and phytates). Food processing has a large effect on protein digestibility; it has been observed that processes such as germination $^{34}$ or extrusion ${ }^{35}$ could increase protein digestibility due to the reduction of antinutritional factors. In general, heat treatments increase protein digestibility due to the unfolding of the tertiary structure as a consequence of protein denaturation. However, this is not always the case since severe heat treatments can produce protein aggregation or cross-linking as consequence of extensive denaturation and exposure of reactive moieties.

One of the key factors that modulates digestibility and bio-accessibility (and in turn bioavailability) of nutrients is related to the structural properties of the food matrix. Its influence has emerged as one of the most important and intriguing factors since its physical properties could affect enzymatic and chemical processes that occur during digestion ${ }^{23,24}$.

\subsection{Food structure}

Food structure is produced by the interaction and organization of food constituents at multiple spatial scales ${ }^{36}$. Those interactions are responsible for quality, sensorial and nutritional attributes of foods. When food ingredients are mixed, their individual properties will change 
significantly affecting the properties of food. This is due to the heterogeneous nature of the ingredients but also to the processing methods employed. Therefore, a good understanding of the structural aspects of raw materials, their assembly into the food matrix through processing and the interaction forces between them will provide useful information that allow the delivery of tailored functionalities to create specific structural properties ${ }^{37}$. For example, it is possible to extend the shelf life of products by controlling microbial growth due to structural changes in the matrix such as limiting water availability ${ }^{38}$. Or microencapsulating ingredients to provide stability, thermal protection, improving sensorial profile or a delay release of specific compounds ${ }^{39}$.

In general, food structures are complex; they range from intricate self-assembled structures formed by nature (e.g. plant and animal tissues) up to fabricated structures produced as consequence of food processing ${ }^{40}$. The properties of foods perceived by sensory attributes like texture, and taste constitute the macroscopic evidence of the interactions occurring at smaller length scales. This is due to the spatial arrangements of food structural elements, their chemical composition and in a large extent their interactions ${ }^{41}$. Thus, to have a global understanding of the mechanisms that confer a specific macroscopic attribute, food microstructures should be studied thoroughly. A global overview of a food product at different length scales could provide valuable information that will aid in the understanding of its functionality and facilitate the formulation of foods. Fig. 1-3 provides a graphical representation of a staple product, bread, at different length scales to illustrate the diverse levels of structural organization of the constituents in a typical food. At the smallest scale or molecular level, chemical structures of food constituents could be analyzed (e.g. glucose). Moving further to a larger scale or microscopic level, the aggregation of molecules and their assembly into components could be studied such as the ones present in starch granules. While at mesoscopic lengths, interactions between ingredients are assessed ${ }^{42}$ as what happens in gluten network formation in the case of bread. 


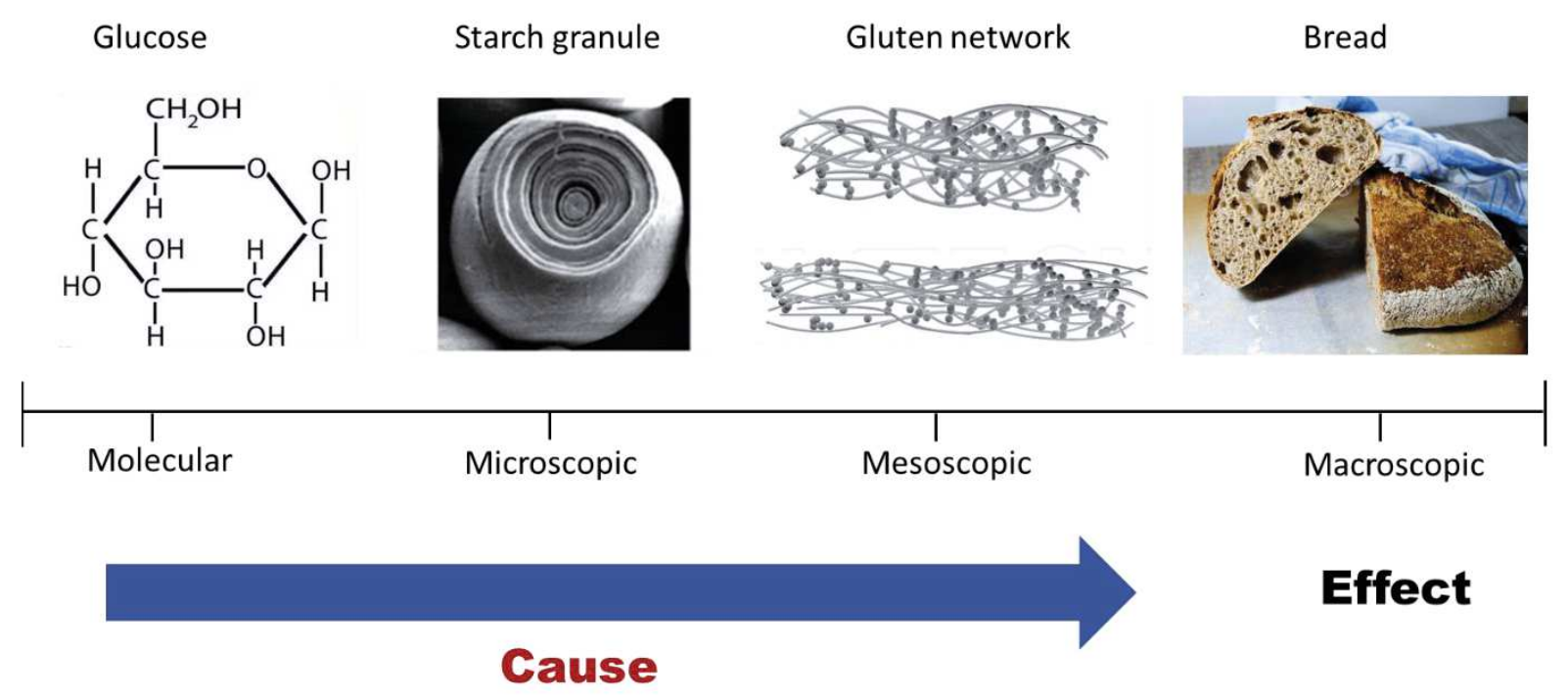

Fig. 1-3. Graphical representation of different levels of organization in a typical food matrix. All the interactions occurring at low length scales (molecular, microscopic and mesoscopic) are responsible for the sensorial attributes perceived at macroscopic scale.

Recently, a new aspect in food structuring research has emerged in which the disassembly of foods is studied. This is of importance as it gives us a better understanding of what happens to food products during consumption. Food perception will not only be affected by this but also its digestion and nutrient uptake by our bodies. By understanding the way in which foods disintegrate during oral processing and gastro-intestinal digestion, one can apply reverse engineering concepts to design foods with optimized digestion of specific nutrients ${ }^{36}$. This in turn could be utilized to produce more tailor-made products to satisfy special needs of vulnerable segments of the population like infants, elderly and people with certain chronic diseases. In this thesis, we will focus on those structural aspects that modulate the digestion of macromolecules (starch and protein) within plant tissues.

\subsubsection{Food structure in nutrition and health}

The relationship between food structure and health has been investigated for several years. One of the earliest studies was performed by Harber and others ${ }^{43}$ when investigating the effect of consuming whole apples on plasma glucose, satiety and serum insulin production. They found that, by removing fiber or physically disrupting apple structure, the three aforementioned parameters changed unfavorably. Since then, several authors had contributed with additional evidence that reinforces the link between structure and nutrition. One of the most important studies that gave concrete evidence about the role of food structure in health is the in-vivo study conducted by Jenkins et al ${ }^{44}$ using whole meal and whole grain breads. The authors were able 
to demonstrate that the glycemic index of patients that consumed whole wheat bread with intact barley kernels was significantly lower compared to a group which consumed bread made of finely milled kernels. This proves that the structure of plant tissues had larger influence in physiological responses than ingredient composition itself ${ }^{45}$.

\subsubsection{Structure of plant-based foods}

The structures that constitute plant-based foods are very diverse: they include tissues that are assembled from molecules with a specific function, for instance fleshy parts that consist of a group of cells able to retain water and confer turgidity or encapsulated embryos that contain starch, proteins and fats ${ }^{46}$. The molecular constituents of plant-tissues, particularly proteins and polysaccharides, are organized into hierarchical structures. The main function of such structures is to confer specific biological functionalities to the living organism, such as providing protection and support to the cell or serving as an energy reservoir ${ }^{47}$. Despite of the variety of structures present in plant-based foods, the continuous network of the cell walls is by far the most important structural feature especially from a nutritional point of view ${ }^{48}$.

Cell walls $(\mathrm{CW})$ are supramolecular structures that provide support and protection to plant cells and regulate communication with the environment. They are mainly composed of non-starch polysaccharides whose molecular composition differs among edible plant tissues. For instance, cereals CW contain cellulose, arabinoxylans, $\beta$-linked glucans, and very low or negligible amounts of pectic polysaccharides and xyloglucans ${ }^{49}$. Legumes, on the other hand, possess a thick and resistant CW predominantly composed of a mixture of cellulose, $\beta$-glucans, xyloglucans and pectins; this last molecule also constitutes the middle lamella that binds two adjacent cells together ${ }^{50}$. The compositional differences between cereal and legumes confers them contrasting mechanical properties. Cereal $\mathrm{CW}$ are thin and easily disintegrate; the structural integrity of the kernel is maintained by the starch/protein "concretion" of the endosperm, combined with the tough surrounding testa or seed coat ${ }^{51}$ (Fig. 1-4A). On the contrary, legumes possess thick $\mathrm{CW}$ and their cytoplasmic matrix fills up the space enclosed within cell membrane with a mixture of starch granules, protein and/or oil bodies (Fig. 1-4B). For starch rich legumes, such as beans and chickpeas, the cytoplasmic matrix is tightly packed by starch granules embedded in a proteinaceous matrix ${ }^{51}$. Bean cells show high resistance to breakage when a mechanical force is applied after cooking. This is due to the solubilization of pectin present in the middle lamella that allows the separation of individual cells maintaining their physical integrity. 
As for fruits and vegetables, their CWs consist mostly of cellulose, hemicellulose and pectin (Fig. 1-4C). During ripening, CW polysaccharides suffer structural changes mainly in pectin but also, to a minor extent, hemicellulose and cellulose material ${ }^{52}$.

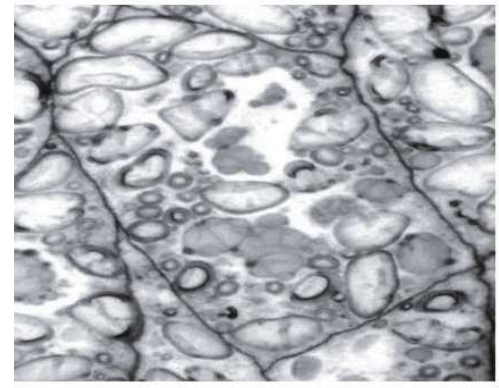

A

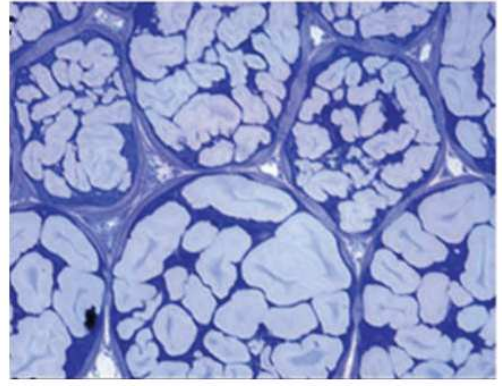

B

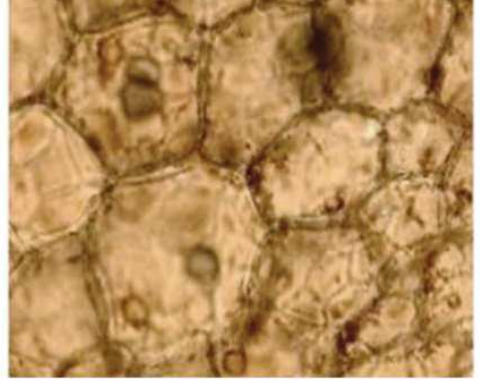

C

Fig. 1-4 Micrographs depicting wheat ${ }^{53}(\mathrm{~A})$, chickpea $^{54}(\mathrm{~B})$ and tomato ${ }^{55}$ (C) cells. Cell walls could be clearly differentiated in the three images as the outer ring that encloses the cytoplasmic matrix that contains proteins, starch (A, B) and carotenoids (C).

The presence of a CW in plant tissues has very important consequences from a nutritional point of view since human digestive enzymes are unable to hydrolyze the polysaccharides present in the $\mathrm{CW}$ that surround macromolecules such as proteins and $\operatorname{starch}^{46}$. Thus, the structure of those systems will act as encapsulating material that will largely determine the bio-accessibility of the nutrients contained within them. Therefore, all processes affecting cellular integrity could also have repercussions in the bio-accessibility of plant nutrients. For instance, grinding or milling will increase the surface area due to particle size reduction facilitating the exposure of intracellular components to digestive fluids ${ }^{56,57}$. This could have beneficial or detrimental implications on health, depending on the type of nutrient considered and on the target population. It has been widely recognized that this is an efficient strategy to increase bioaccessibility especially for cereal matrices.

\subsection{Knowledge gap and research rationale}

The occurrence of a natural barrier in plant tissues (cell walls) that encapsulates starch, proteins and fats has been reported in literature for at least 30 years $^{58}$. This has raised concern regarding the lower digestibility of nutrients entrapped within the $\mathrm{CW}$ of intact plant matrices. Studies using a variety of sources (legumes, cereals, nuts), treatments and particle sizes have described such effects on digestibility as affected by processing and different botanical origins ${ }^{56,59,60}$. Furthermore, efforts have also been made in understanding the resistance of these structures to digestive processes. In-vitro and in-vivo experiments have confirmed the resistance of CW to digestion in those cases where their physical integrity was not compromised before swallowing 
(by cooking or oral processes). Two of the studies that provides conclusive evidence are in-vivo intervention studies using almonds ${ }^{61}$ and wheat endosperms ${ }^{62}$. In both cases, intact cells were recovered in the feces of healthy volunteers or in the effluents from ileostomy patients. Even though these findings provide an important contribution towards understanding the behavior of plant tissues during digestion, several key aspects still remain to be elucidated. One of the most important is related to the role of the $\mathrm{CW}$ as a barrier to pancreatic amylase during small intestinal digestion. Until know, this is still a matter of debate since contradictory information has been generated from studies conducted by different research groups where some describe the $\mathrm{CW}$ as an impermeable barrier to amylase ${ }^{28,63}$. We believe that the lack of a mechanistic explanation about the system is the origin of those discrepancies. Furthermore, the role played by the intracellular matrix of intact cells in modulating macronutrients digestion remains to be elucidated. As for colonic fermentation, even though it is commonly accepted that CW polysaccharides could be fermented by gut microbiota, structural aspects of plant tissues are usually neglected when considering the utilization of its constituents by colonic bacteria. Thus, the role of $\mathrm{CW}$ integrity in modulating colonic fermentation of intracellular nutrients deserves investigation.

This thesis aims at providing a comprehensive description of the main factors affecting digestion and fermentation of intact plant tissues with special attention to $\mathrm{CW}$ permeability and integrity. For this, four main objectives should be achieved:

a) Determine the role of intact $\mathrm{CW}$ in nutrients digestibility in terms of its permeability to digestive enzymes.

b) Provide a mechanistic explanation for the kinetics of digestion of nutrients encapsulated within plant-tissue matrices;

c) Identify the influence of intrinsic factors (besides those of the CW) that could modulate the digestibility of nutrients in plant tissues;

d) Provide insights about the effect of the plant structure, with special reference to CW integrity, on fermentation of intracellular nutrients and $\mathrm{CW}$ by colonic bacteria.

In order to tackle this challenge, isolated cotyledon cells from red kidney beans were used as model systems. 


\subsection{Why using beans as study models?}

Beans, and legumes in general, are a staple food widely consumed in developing countries since it represents a good and cheap alternative for meat proteins. Furthermore, the consumption of this legume in certain areas has been strongly associated with ethnic and cultural background. That is the case of regions like Latin America, where the utilization of beans dates from preColombian civilizations. Beans consumption is strongly rooted and a diversity of preparations have been developed using this legume as main ingredient becoming part of Hispanic traditions ${ }^{64}$. In the last years, several western developed societies are also incorporating beans (and legumes) into their habitual diets. This is due to an increasing trend in reducing the consumption of animal-based products for health and sustainable reasons ${ }^{65}$.

From a health perspective, beans are products with a high nutritional density due to their protein, starch and fibre content. Beans were the first type of foods recognized as having low glycaemic index (GI ${ }^{66}$. Due to this, its consumption has been widely recommended to patients with diabetes and obesity where products with slowly digestible starches are highly preferred. Besides, other health benefits such as reducing the risk of coronary and heart disease together with a decrease in blood pressure have been also associated to bean consumption. This is due to the low amount of saturated fats present in the legume, its high content in dietary fibre (both soluble and insoluble) and the relatively large amount of protein ${ }^{66}$. Furthermore, the biological value of bean proteins is outstanding due to the large amounts of lysine it contains. Beans provide $25 \%$ of the total lysine requirements; this is of particular importance for people consuming plant-based diets ${ }^{67}$. That is why several health organizations encourage a frequent consumption of legumes ${ }^{65}$.

All the health benefits mentioned above make beans an interesting study system. In particular, the relatively low GI of beans deserves special attention since it is intimately related to the unique structural properties of bean cotyledon cells. Moreover, beans (and many other legumes) are typically consumed as whole grains and it has been observed that the structural integrity of bean cells is limitedly affected by thermal treatments such as boiling in excess water, which is their most common method of preparation ${ }^{58}$. This is opposed to what is observed in other sources like cereals that have more brittle and thin cell walls and are normally milled into fine flours before their utilization. Therefore, the strength of the $\mathrm{CW}$ in bean cells facilitates the isolation of individual cells and their manipulation. All in all, beans could serve as a good study 
Chapter 1

model to understand and characterize all of those aspects that modulate the digestibility of starch and proteins contained within an intact plant matrix.

\subsection{Thesis outline}

The influence of food structure on nutrients digestibility has been investigated in the past decades. However, it is still not clear what is the role of the structural aspects of plant tissues in modulating intestinal digestion and fermentation. In this thesis, we aim at getting a better understanding of such mechanisms using red kidney beans as model systems. A multidisciplinary approach is followed that enables to understand the effect of structural aspects on nutrients utilization from the perspective of small and large intestine, where the influence of structural aspects present in kidney beans were tested. A graphical representation of the thesis outline is presented in Fig. 1-5.

In Chapter 2, the role of plant cell walls in starch digestion is described. Cotyledon cells from red kidney beans were isolated and samples with different levels of cell wall integrity were produced by means of enzymatic or mechanic treatments. The influence of cell wall porosity/integrity in the different samples were assessed in terms of starch digestibility. In Chapter 3, the microstructural organization of intact bean cells and its effect on protein and starch digestibility were studied. Interactions between protein and starch as consequence of molecular confinement within the cytoplasmic matrix were related to starch and protein digestibility. The effect of molecular confinement on conformational changes of proteins during heat treatment was also investigated and related to proteins digestibility.

In Chapter 4, a mechanistic mathematical approach was developed to understand the physical and biochemical phenomena responsible of the reduced digestibility of starch confined within intact cotyledon cells. The effect of enzyme diffusion and interactions with cell wall components were characterized and quantified experimentally. Validation of the model was performed using in-vitro digestion data of starch hydrolysis.

Chapter 5 provides insights about the fate of intact cells during large intestinal fermentation using a dynamic in-vitro model (simulator of the human intestinal microbial ecosystem, SHIME $^{\circledR}$ ). The effect of CW entrapment in microbiota utilization of starch was studied. The degree of starch and fiber fermentation in samples with different cell wall integrity levels was investigated. Compositional changes on the microbiota population due to bean cells supplementation were assessed. To complement the insight provided in chapter 5, in Chapter 
6, a batch fermentation system was employed to understand the efficiency of each colon portion when providing equal amounts of substrate. Bean cells integrity after microbiota fermentation was determined by using different microscopy techniques. Furthermore, the impact of microbiota adaptation to bean cells utilization was also investigated.

Finally, Chapter 7 summarizes and integrates the main findings of all the chapters presented in this thesis. A discussion of the main results, its significance and new insights are presented. Furthermore, the scientific challenges and future directions are also outlined.

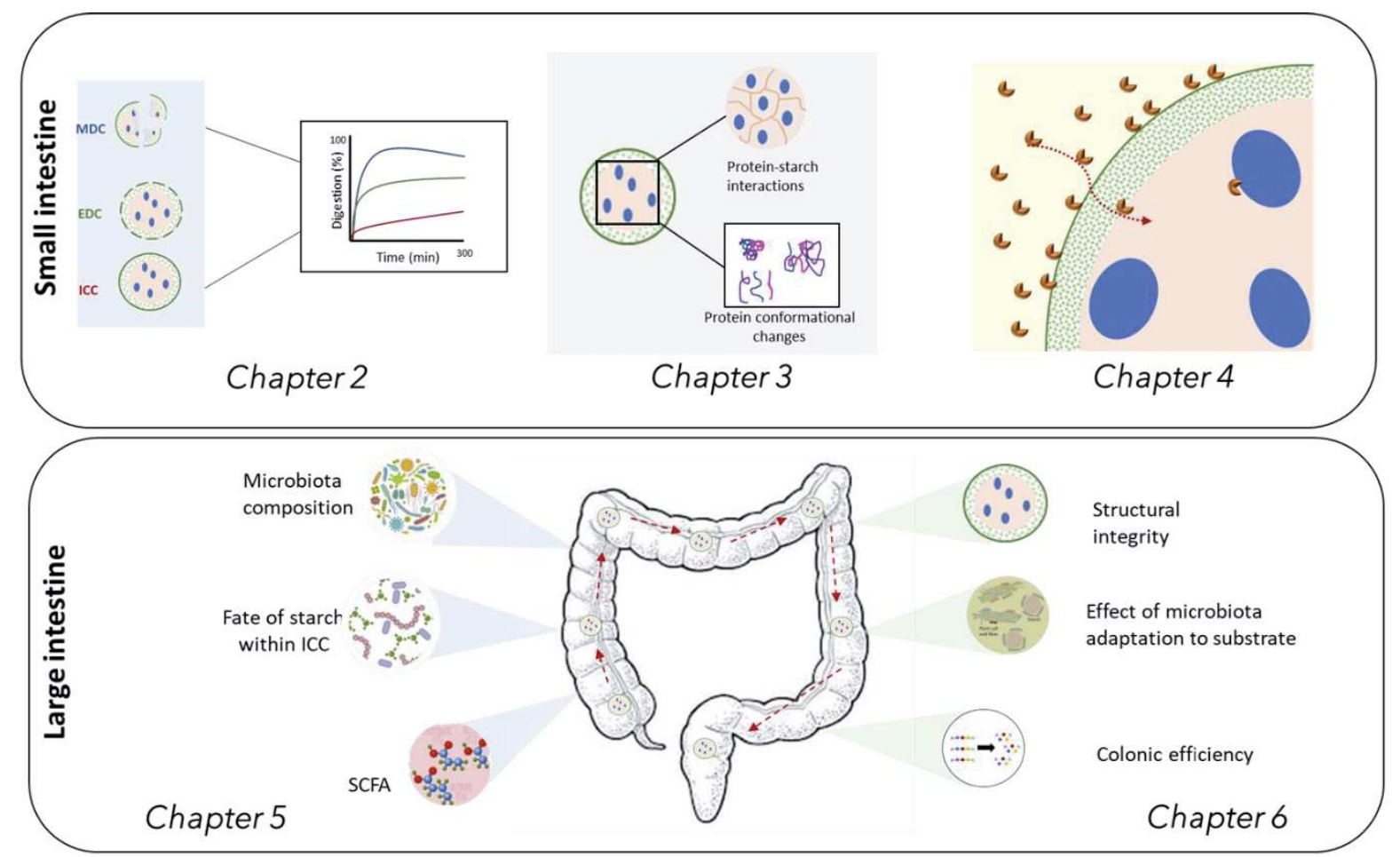

Fig. 1-5. Graphical outline of the chapters contained in this thesis. Chapters 2, 3 and 4 studied the effect of cotyledon cell structure during in-vitro digestion while chapters 5 and 6 focussed on its influence during in-vitro colonic fermentation. $\mathrm{MDC}=$ mechanically damage cells, $\mathrm{EDC}=$ enzymatically damaged cells, $\mathrm{ICC}=$ intact cotyledon cells, $\mathrm{SCFA}=$ short chain fatty acids, colonic efficiency= rate and extent of ICC/MDC fermentation in each colon portion. 


\section{References:}

1. Palafox-Carlos H, Ayala-Zavala JF, González-Aguilar GA. The Role of Dietary Fiber in the Bioaccessibility and Bioavailability of Fruit and Vegetable Antioxidants. J Food Sci. 2011;76(1):6-15.

2. Hu FB. Plant-based foods and prevention of cardiovascular disease: An overview. Am J Clin Nutr. 2003;78(3):544-551.

3. Dhingra D, Michael M, Rajput H, Patil RT. Dietary fibre in foods: A review. J Food Sci Technol. 2012;49(3):255-266.

4. Steffee WP, Goldsmith RS, Pencharz PB, Scrimshaw NS, Young VR. Dietary protein intake and dynamic aspects of whole body nitrogen metabolism in adult humans. Metabolism. 1976;25(3):281-297.

5. Bornhorst GM, Singh RP. Bolus Formation and Disintegration during Digestion of Food Carbohydrates. Compr Rev Food Sci Food Saf. 2012;11(2):101-118.

6. Hasjim J, Lavau GC, Gidley MJ, Gilbert RG. In vivo and in vitro starch digestion: Are current in vitro techniques adequate? Biomacromolecules. 2010;11(12):3600-3608.

7. Dona AC, Pages G, Gilbert RG, Gaborieau M, Kuchel PW. Kinetics of In Vitro Digestion of Starches Monitored by Time-Resolved 1 H Nuclear Magnetic Resonance. 2009:638-644.

8. Bradley, S.G., Antalis, T.M., Bond JS. Proteases in the mammalian digestive system. In: Brix, K., Stocker W, ed. Proteases: Structure and Function. New York: Springer; 2013:373-394.

9. Philipps-Wiemann P. Proteases - general aspects. In: Simoes N, Kumar V, eds. Enzymes in Human and Animal Nutrition. London: Academic Press; 2018:257-266.

10. Di Cera E. Serine proteases. IUBMB Life. 2009;61(5):510-515.

11. Whitaker JR. Proteolytic Enzymes. In: John R. Whitaker, Alphons G. J. Voragen DWSW, ed. Handbook of Food Enzymology. 1st Editio. Boca Raton: Taylor \& Francis Group; 2002.

12. Perera A, Meda V, Tyler RT. Resistant starch: A review of analytical protocols for determining resistant starch and of factors affecting the resistant starch content of foods. Food Res Int. 2010;43(8):1959-1974.

13. Stephen AM, Champ MMJ, Cloran SJ, et al. Dietary Fibre in Europe: Current State of Knowledge on Definitions, Sources, Recommendations, Intakes and Relationships to Health. Vol 30.; 2017.

14. Buttriss JL. Fibre - Need to increase intake according to new recommendations. Nutr Bull. 2015;40(4):291-295.

15. Scott KP, Gratz SW, Sheridan PO, Flint HJ, Duncan SH. The influence of diet on the gut microbiota. Pharmacol Res. 2013;69(1):52-60.

16. Flint HJ, Duncan SH, Scott KP, Louis P. Links between diet, gut microbiota composition and gut metabolism. Proc Nutr Soc. 2014;760:13-22. 
17. Le Leu RK, Brown IL, Hu Y, Morita T, Esterman A, Young GP. Effect of dietary resistant starch and protein on colonic fermentation and intestinal tumourigenesis in rats.

Carcinogenesis. 2007;28(2):240-245.

18. Makki K, Deehan EC, Walter J, Bäckhed F. The Impact of Dietary Fiber on Gut Microbiota in Host Health and Disease. Cell Host Microbe. 2018;23(6):705-715.

19. Makki K, Deehan EC, Walter J, Bäckhed F. The Impact of Dietary Fiber on Gut Microbiota in Host Health and Disease. Cell Host Microbe. 2018;23(6):705-715.

20. Jonathan MC, Haenen D, Souza Da Silva C, Bosch G, Schols HA, Gruppen H. Influence of a diet rich in resistant starch on the degradation of non-starch polysaccharides in the large intestine of pigs. Carbohydr Polym. 2013;93(1):232-239.

21. Windey K, de Preter V, Verbeke K. Relevance of protein fermentation to gut health. Mol Nutr Food Res. 2012;56(1):184-196.

22. Moon JS, Li L, Bang J, Han NS. Application of in vitro gut fermentation models to food components: A review. Food Sci Biotechnol. 2016;25:1-7.

23. Sensoy I. A Review on the Relationship Between Food Structure, Processing, and Bioavailability. Crit Rev Food Sci Nutr. 2014;54(7):902-909.

24. Parada J, Aguilera JM. Food microstructure affects the bioavailability of several nutrients. $J$ Food Sci. 2007;72(2):21-32.

25. Slaughter SL, Ellis PR, Butterworth PJ. An investigation of the action of porcine pancreatic $\alpha-$ amylase on native and gelatinised starches. Biochim Biophys Acta - Gen Subj. 2001;1525(12):29-36.

26. Englyst HN, Kingman SM, Cummings JH. Classification and measurement of nutritionally important starch fractions. Eur J Clin Nutr. 1992;46(2):S33-50.

27. Edwards CH, Warren FJ, Milligan PJ, Butterworth PJ, Ellis PR. A novel method for classifying starch digestion by modelling the amylolysis of plant foods using first-order enzyme kinetic principles. Food Funct. 2014;5:2751-2758.

28. Berg T, Singh J, Hardacre A, Boland MJ. The role of cotyledon cell structure during in vitro digestion of starch in navy beans. Carbohydr Polym. 2012;87(2):1678-1688.

29. Martens BMJ, Gerrits WJJ, Bruininx EMAM, Schols HA. Amylopectin structure and crystallinity explains variation in digestion kinetics of starches across botanic sources in an in vitro pig model. J Anim Sci Biotechnol. 2018;9(1):1-13.

30. Bhattarai RR, Dhital S, Gidley M. Interactions among macronutrients in wheat flour determine their enzymic susceptibility. Food Hydrocoll. 2016;61:415-425.

31. Parada J, Aguilera JM. In vitro digestibility and glycemic response of potato starch is related to granule size and degree of gelatinization. J Food Sci. 2009;74(1):1-5.

32. Copeland L, Blazek J, Salman H, Tang MC. Form and functionality of starch. Food Hydrocoll. 2009;23(6):1527-1534. 
33. Duodu KG, Taylor JRN, Belton PS, Hamaker BR. Factors affecting sorghum protein digestibility. J Cereal Sci. 2003;38(2):117-131.

34. Boye J, Wijesinha-Bettoni R, Burlingame B. Protein quality evaluation twenty years after the introduction of the protein digestibility corrected amino acid score method. Br J Nutr. $2012 ; 108$.

35. Alonso R, Aguirre A, Marzo F. Effects of extrusion and traditional processing methods on antinutrients and in vitro digestibility of protein and starch in faba and kidney beans. Food Chem. 2000;68(2):159-165.

36. Day L, Golding M. Food Structure, Rheology, and Texture. Vol 3. Elsevier; 2016.

37. Joardder MUH, Kumar C, Karim MA. Food structure: Its formation and relationships with other properties. Crit Rev Food Sci Nutr. 2017;57(6):1190-1205.

38. Robins MM, Wilson PDG. Food structure and microbial growth. Trends Food Sci Technol. 1994;5(9):289-293.

39. Đorđević V, Balanč B, Belščak-Cvitanović A, et al. Trends in Encapsulation Technologies for Delivery of Food Bioactive Compounds. Vol 7.; 2014.

40. Morris VJ, Groves K. Introduction. Food Microstruct Microsc Meas Model. 2013.

41. Lundin L, Golding M, Wooster TJ. Understanding food structure and function in developing food for appetite control. Nutr Diet. 2008;65(3):79-85.

42. Scholten E. Composite foods: from structure to sensory perception. Food Funct. 2017;8(2):481-497.

43. Haber GB, Heaton KW, D. M. Depletion and disruption of dietary fibre effects on satiety, plasma glucose and serum-insulin. Lancet. 1977;310(8040):679-682.

44. Jenkins DJA, Wesson V, Wolever TM, et al. Wholemeal versus wholegrain breads: proportion of whole or cracked grain and the glycaemic response. Br Med J. 1988;297(6654):958-960.

45. Fardet A. New hypotheses for the health-protective mechanisms of whole-grain cereals: what is beyond fibre? Nutr Res Rev. 2010;23(01):65-134.

46. Ogawa Y, Donlao N, Thuengtung S, et al. Impact of food structure and cell matrix on digestibility of plant-based food. Curr Opin Food Sci. 2018;19:36-41.

47. Singh H, Ye A, Ferrua MJ. Aspects of food structures in the digestive tract. Curr Opin Food Sci. 2015;3:85-93.

48. Capuano E, Pellegrini N. An integrated look at the effect of structure on nutrient bioavailability in plant foods. $J$ Sci Food Agric. 2019;99(2):493-498.

49. McDougall GJ, Morrison IM, Stewart D, Hillman JR. Plant Cell Walls as Dietary Fibre: Range, Structure, Processing and Function. J Sci Food Agric. 1996;70(2):133-150.

50. Shiga TM, Lajolo FM. Cell wall polysaccharides of common beans (Phaseolus vulgaris L.) composition and structure. Carbohydr Polym. 2006;63(1):1-12. 
51. Do DT, Singh J. Legume Microstructure. Vol 3. Elsevier; 2019.

52. Houben K, Jolie RP, Fraeye I, Van Loey AM, Hendrickx ME. Comparative study of the cell wall composition of broccoli, carrot, and tomato: Structural characterization of the extractable pectins and hemicelluloses. Carbohydr Res. 2011;346(9):1105-1111.

53. Stoger E, Sack M, Nicholson L, Fischer R, Christou P. Recent Progress in Plantibody Technology. Curr Pharm Des. 2005;11(19):2439-2457.

54. Edwards CH, Warren FJ, Campbell GM, et al. A study of starch gelatinisation behaviour in hydrothermally-processed plant food tissues and implications for in vitro digestibility. Food Funct. 2015;6(12):3634-3641.

55. Bot F, Verkerk R, Mastwijk H, Anese M, Fogliano V, Capuano E. The effect of pulsed electric fields on carotenoids bioaccessibility: The role of tomato matrix. Food Chem. 2018;240:415421.

56. Al-Rabadi GJ, Torley PJ, Williams BA, Bryden WL, Gidley MJ. Particle size of milled barley and sorghum and physico-chemical properties of grain following extrusion. J Food Eng. 2011;103(4):464-472.

57. Dhital S, Shrestha AK, Gidley MJ. Relationship between granule size and in vitro digestibility of maize and potato starches. Carbohydr Polym. 2010;82(2):480-488.

58. Würsch P, Vedovo S, Del Koellreutter B. Cell structure and starch nature as key of the digestion rate of starch. Am J Clin Nutr. 1986;43(1):25-29.

59. Mandalari G, Parker ML, Grundy MML, et al. Understanding the effect of particle size and processing on almond lipid bioaccessibility through microstructural analysis: From mastication to faecal collection. Nutrients. 2018;10(2):1-20.

60. Mahasukhonthachat K, Sopade PA, Gidley MJ. Kinetics of starch digestion in sorghum as affected by particle size. J Food Eng. 2010;96(1):18-28.

61. Ellis PR, Kendall CWC, Ren Y, et al. Role of cell walls in the bioaccessibility of lipids in almond seeds. Am J Clin Nutr. 2004;80(3):604-613.

62. Edwards CH, Grundy MM, Grassby T, et al. Manipulation of starch bioaccessibility in wheat endosperm to regulate starch digestion, postprandial glycemia, insulinemia, and gut hormone responses: a randomized controlled trial in healthy ileostomy participants. Am J Clin Nutr. 2015;102(4):791-800.

63. Dhital S, Bhattarai RR, Gorham J, Gidley M. Intactness of cell wall structure controls the in vitro digestion of starch in legumes. Food Funct. 2016;7(3):1367-1379.

64. Leterme P, Carmenza Muũoz L. Factors influencing pulse consumption in Latin America. $\mathrm{Br} J$ Nutr. 2002;88(S3):251-254.

65. Leterme P. Recommendations by health organizations for pulse consumption. Br J Nutr. 2002;88(S3):239-242.

66. Jenkins DJA, Kendall CW, Augustin LS, et al. Effect of Legumes as part of a low glycemic 
Chapter 1

index diet on glycemic control and cardiovascular risk factors in type 2 diabetes mellitus: A randomized controlled trial. Arch Intern Med. 2012;172(21):1-8.

67. Messina V. Nutritional and health benefits of dried beans. Am J Clin Nutr. 2014;100(1):43784428 . 


\section{Chapter 2}

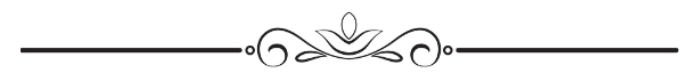

\section{A closer look to cell structural barriers affecting starch digestibility in beans}

This chapter has been published as:

Ana M. Rovalino-Córdova, Vincenzo Fogliano, Edoardo Capuano. (2018) A closer look to cell structural barriers affecting starch digestibility in beans. Carbohydrate Polymers. 181, 994-1002. 
Chapter 2

\section{Abstract}

Isolated bean cells were used to understand the contribution of cell wall and cytoplasmic matrix on starch digestibility. Cotyledon cells were treated enzymatically and mechanically to reduce the level of cell intactness. SEM and chemical characterization revealed that enzymatic treatment modified cell wall thickness and porosity without altering the cytoplasmic matrix, whereas mechanical treatment completely disrupted cell structure. Decreasing cell intactness increased the rate but not the extent of starch digestion in-vitro. It was concluded that cell wall serves as a permeable barrier limiting the access of digestive enzymes. Cytoplasmic matrix, on the other hand, reduced further the accessibility of amylase to starch affecting its hydrolysis rate. In addition, it was proven that cell structural changes, if any, occurring during digestion had no effect on starch hydrolysis. 


\subsection{Introduction}

The beneficial role of legume consumption has been well documented in the past years and associated with the prevention or control of diabetes, obesity, and cardiovascular disorders ${ }^{1-3}$. One of the mechanisms for the health promoting effect of legumes relates to its high dietary fibre (DF) content and relatively low glycaemic index (GI). The latter is influenced by intrinsic and extrinsic factors of foods that alter gastrointestinal motility, the rate of starch digestion and absorption of glucose $e^{4}$. In legumes, cotyledon structure is one of the key factors responsible for low GI. One of the first studies showing such effect dates back to 1971 when Kon, et $\mathrm{al}^{5}$ investigated starch digestibility of beans grinded before and after cooking. They observed that samples grinded after cooking preserved cell intactness. Consequently, starch hydrolysis rate and extent were markedly reduced. Since then, several authors have confirmed this hypothesis ${ }^{6,7}$ and multiple mechanisms have been proposed to explain the effect of cell integrity on starch digestion. For instance, Thorne, et $\mathrm{al}^{8}$ explained that starch entrapment in the cell wall

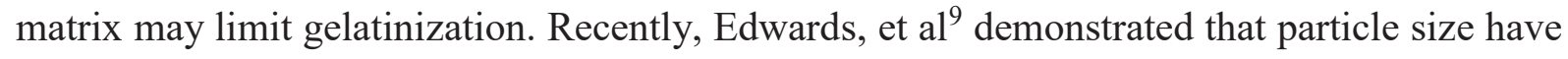
a direct influence in the extent of starch gelatinization in chickpeas. Therefore, it appears that the low GI in legumes is the result of several factors working simultaneously but not all of them have been investigated in detail or given the same importance. That is the case of the cytoplasmic matrix. Starch granules enclosed within intact cells are tightly packed, which considerably reduces starch surface area available to amylases. Studies performed on densely packed matrices, like pasta, have shown an important contribution of compactness in limiting the access and binding of enzymes during digestion ${ }^{10}$. This effect has been briefly addressed for cotyledon cells ${ }^{11}$ but direct evidence has never been shown.

Undoubtedly, cell walls (CW) play a pivotal role in making legumes a low GI food. CW are composed of a complex network of polysaccharides whose function is determined by their specific carbohydrate composition and assembly ${ }^{12}$. Despite of being subject of intensive research, CW net contribution to starch digestibility in beans has not been conclusively assessed. There is not even a consensus whether CW are permeable to digestive enzymes ${ }^{11,13}$. In addition, little is known about the impact of cell wall modifications on starch hydrolysis.

This work aimed at understanding the individual contribution of $\mathrm{CW}$ and cytoplasmic matrix in limiting starch digestibility of beans. For this, cotyledon cells with different levels of structural damage but the same level of starch gelatinization were digested in-vitro. In addition, chemical and physical characterization of damaged cells were performed to identify specific components of the wall that limit starch hydrolysis. 
Chapter 2

We hypothesized that the $\mathrm{CW}$ and cytoplasmic matrix influence starch digestibility in beans. The CW limits the access of digestive enzymes while the cytoplasmic matrix leads to an inefficient interaction between $\alpha$-amylase and starch.

\subsection{Materials and Methods}

\subsubsection{Materials}

Red kidney beans were purchased from the local supermarket (Wageningen, Netherlands) and stored at room temperature.

Pepsin (porcine gastric mucose 4200-4500 U/mg), trypsin (porcine pancreas 1000-2000 U/mg), $\alpha$-chymotrypsin (bovine pancreas $\geq 40 \mathrm{U} / \mathrm{mg}$ ), $\alpha$-amylase (porcine pancreas $700-1400 \mathrm{U} / \mathrm{mg}$ ), amyloglucosidase (aspergillus niger $120 \mathrm{U} / \mathrm{mg}$ ) and Viscozyme ${ }^{\circledR} \mathrm{L}(>100 \mathrm{FBGU} / \mathrm{g})$ were purchased from Sigma-Aldrich Ltd. (St. Louis, MO, USA). Heat stable $\alpha$-amylase (3000 $\mathrm{U} / \mathrm{mL})$, protease (350 tyrosine $\mathrm{U} / \mathrm{mL})$ and amyloglucosidase $(3300 \mathrm{U} / \mathrm{mL})$ were obtained from Megazyme Inc. (Bray, Ireland). All other chemicals were of analytical grade unless stated otherwise.

\subsubsection{Isolation of cotyledon cells}

Cotyledon cells from red kidney beans were isolated according to Dhital, et al ${ }^{13}$ with minor modifications. In short, beans were soaked overnight in ice chilled water followed by manual separation of the seed coat. De-hulled beans were boiled in water (ratio 2:1) for one hour with gentle stirring. Cooked beans were mashed by the use of a mortar and pestle, sieved in a wet sieve shaker and dispersed in sodium azide solution (0.02\%). Intact cotyledon cells (ICC) were used immediately to prevent starch retrogradation or damage caused by prolonged storage.

\subsubsection{Isolation of free starch}

Free starch was obtained by blending $60 \mathrm{~g}$ of previously soaked and de-hulled beans with 60 $\mathrm{mL}$ sodium azide solution $(0.02 \%)$ for 5 min under maximum speed. Blended material was sieved using a laboratory test sieve with mesh size of $70 \mu \mathrm{m}$. Sieved material was collected, mixed with $60 \mathrm{~mL}$ deionized water and brought to boiling temperature with constant stirring. Aluminum foil was used to cover samples and avoid water evaporation. Sample was kept below boiling temperature for $15 \mathrm{~min}$ and subsequently cooled down. 


\subsubsection{Modification of cotyledon cell structure}

\subsubsection{Mechanically damaged cells (MDC)}

Mechanical damage of isolated cotyledon cells was carried out with the method described by Dhital, et $\mathrm{al}^{13}$. A suspension of ICC was mixed by the use of a magnetic stirrer for 24 hours at $1500 \mathrm{rpm}$ until complete cell disruption. Light microscopy was used for visual inspection of cell integrity.

\subsubsection{Enzymatically damaged cells (EDC)}

ICC were treated with a commercial cocktail of cell wall degrading enzymes (Viscozyme ${ }^{\circledR} \mathrm{L}$, Sigma-Aldrich) to disrupt the integrity of the wall. 15 grams of ICC were mixed with $4.84 \mathrm{~mL}$ acetate buffer ( $\mathrm{pH} 5.5$ ) and $168 \mu \mathrm{L}$ Viscozyme ${ }^{\circledR} \mathrm{L}$. Samples were incubated for $1 \mathrm{~h}$ at $44^{\circ} \mathrm{C}$ under constant agitation. Enzymatically damaged cells (EDC) were filtered with cheese cloth and washed several times with deionized water to remove soluble material, cell debris and enzymes. Samples were examined by light microscopy in order to confirm wall damage.

\subsubsection{Dry matter content}

Dry matter content was determined in triplicate by drying a known amount of sample overnight at $105^{\circ} \mathrm{C}$ in an oven to a constant weight.

\subsubsection{Total starch determination}

Starch content in intact and damaged cells (mechanical and enzymatic) was determined by Total Starch Assay Procedure (amyloglucosidase / $\alpha$-amylase method), Megazyme Inc. (Bray, Ireland). Samples were subjected to mechanical disruption before the analysis to avoid underestimation of starch content. For EDC samples, a blank (without amylolytic enzymes) was included in the measurement.

\subsubsection{In-vitro digestion}

A modified version of the protocol from Minekus, et al ${ }^{14}$ was used for running two-phase invitro digestion experiments. During the gastric phase, samples were combined with simulated gastric fluids and pepsin $(2000 \mathrm{U} / \mathrm{mL})$. The $\mathrm{pH}$ was adjusted to 3 with $\mathrm{HCl}$ and the tubes incubated at $37^{\circ} \mathrm{C}$ for 2 hours. For the intestinal phase, gastric chyme was combined with simulated intestinal fluids, trypsin $(100 \mathrm{U} / \mathrm{mL})$, chymotrypsin $(25 \mathrm{U} / \mathrm{mL})$ and pancreatic $\alpha$ - 
amylase $(200 \mathrm{U} / \mathrm{mL})$. The $\mathrm{pH}$ was adjusted to 7 and incubated at $37^{\circ} \mathrm{C}$ for 4 hours. The whole in-vitro experiment lasted 6 hours considering time 0 the moment of pepsin incorporation into the gastric phase. Digestion experiments were conducted inside an incubator to keep the temperature constant. Samples were mixed by the use of a laboratory rotator at constant speed (70 rpm). Aliquots were taken at different time points of gastric and intestinal digestion. Enzymatic reaction was stopped by the addition of absolute ethanol to sample aliquots in a ratio of 4:1 respectively. Samples were left to rest for $30 \mathrm{~min}$ before centrifugation at $4000 \mathrm{x} \mathrm{g}$ for $15 \mathrm{~min}$. Supernatants were collected for futher analysis.

For enzymatic damaged cells, an additional sample was included as a control where no digestive enzymes were incorporated.

\subsubsection{Glucose measurement}

Ethanolic supernatants were incubated with amyloglucosidase for conversion of $\alpha$-amylase products into glucose $\mathrm{e}^{15,16} .0 .1 \mathrm{~mL}$ of supernatant was combined with amyloglucosidase solution $(27 \mathrm{U} / \mathrm{mL})$ in acetate buffer $(\mathrm{pH} 4.8)$ and incubated at $37^{\circ} \mathrm{C}$ for one hour. D-glucose assay procedure (GOPOD FORMAT, K-GLUC 09/14, Megazyme Inc., Bray, Ireland) was used to quantify the amount of glucose present at each time point tested. Glucose content was multiplied by a factor of 0.9 to convert it into the corresponding amount of starch. Results were presented as grams of hydrolysed starch per $100 \mathrm{~g}$ of dry starch. Glucose content in blank sample was quantified and subtracted from EDC.

\subsubsection{Cell wall isolation}

Water soluble (WSP) and insoluble (WIP) polysaccharides were isolated from ICC and EDC following the method of Shiga, et al ${ }^{17}$ with slight modifications. ICC and EDC were subjected to an intense shear stress by the use of a magnetic stirrer for 24 hours. Samples were dispersed in MES-TRIS buffer pH 8.2 and incubated with heat stable $\alpha$-amylase $(3000 \mathrm{U} / \mathrm{mL})$ in a shaking water bath for $30 \mathrm{~min}$ at $98-100^{\circ} \mathrm{C}$. Samples were cooled down to $60^{\circ} \mathrm{C}$ and incubated with protease (350 tyrosine $\mathrm{U} / \mathrm{mL}$ ) for $30 \mathrm{~min}$. The $\mathrm{pH}$ was adjusted to 4.8 ; amyloglucosidase (3300 $\mathrm{U} / \mathrm{mL}$ ) was added and incubated for $30 \mathrm{~min}$ at $60^{\circ} \mathrm{C}$. Suspensions were centrifuged for $15 \mathrm{~min}$ at $4700 \mathrm{x} \mathrm{g}$; the supernatant was collected and brought to $80 \%(\mathrm{v} / \mathrm{v})$ ethanol. Ethanolic mixture was left for precipitation at $-20^{\circ} \mathrm{C}$ for 24 hours. The precipitates were washed three times with ice cold ethanol $(80 \% \mathrm{v} / \mathrm{v})$, suspended in deionized water and freeze dried. This fraction represented water soluble polysaccharides (WSP). 
The pellets obtained after enzymatic hydrolysis were washed at least twice with demineralized water and $0.5 \mathrm{M}$ sodium phosphate buffer ( $\mathrm{pH}$ 7.2). The pellets were subsequently treated twice with a solution of methanol: chloroform $(1: 1 \mathrm{v} / \mathrm{v})$ for $30 \mathrm{~min}$ at $45^{\circ} \mathrm{C}$. DMSO $(90 \%)$ was added, sonicated for $20 \mathrm{~min}$ and centrifuged. Finally, the remaining residue was washed with $90 \%$ DMSO and rinsed with water several times before freeze drying. The material recovered from the indicated treatment constituted the water insoluble polysaccharides (WIP) fraction.

\subsubsection{Neutral monosaccharides and uronic acid composition}

Neutral monosaccharides were measured by gas chromatography after pre-hydrolysis of the samples in $72 \%(\mathrm{w} / \mathrm{w})$ sulfuric acid at $30^{\circ} \mathrm{C}$ for $1 \mathrm{~h}$, hydrolysis in $1 \mathrm{M}$ sulfuric acid at $100^{\circ} \mathrm{C}$ for $3 \mathrm{~h}$, and derivatization of monosaccharides to their alditol acetates with inositol as an internal standard ${ }^{19}$. Uronic acid content in the hydrolysates were analysed using an automated colorimetric m-hydroxydiphenyl assay ${ }^{20}$.

\subsubsection{Microscopy analysis}

Sample microstructure was investigated by light and scanning electron microscopy (SEM). For light microscopy, the samples (ICC, MDC and EDC) were placed in a glass slide with coverslip and visualized under Axioskop 2 plus microscope (Carl Zeiss, Gottingen, Germany). Images were obtained with an AxioCam HRc and AxioVision v3.1 microscope software (Carl-Zeiss, Gottingen, Germany). Samples previously stained with Lugol's iodine solution 5\% (w/v) were also examined to facilitate the identification of starch.

ICC and EDC samples were snap frozen in liquid nitrogen and subsequently freeze dried for SEM analysis. Sample was attached on SEM sample holders using carbon adhesive tabs (EMS, Washington, USA), sputter coated with a $15 \mathrm{~nm}$ thick layer of tungsten (EM SCD 500, Leica, Vienna, Austria) and subsequently analyzed with a field emission scanning electron microscope (Magellan 400, FEI, Eindhoven, Netherlands) with SE detection at $2 \mathrm{kV}$ and $6.3 \mathrm{pA}$. Size measurements were performed using the xT microscospe control software (FEI, Eindhoven, the Netherlands). 
Chapter 2

\subsection{Results and discussion}

\subsubsection{Isolation and modification of cotyledon cell structure}

ICC obtained after isolation of kidney beans had an average size of $100 \mu \mathrm{m}$ and were mainly round in shape. Due to cooking process, individual cells were easily separated without affecting their structural integrity, which was confirmed by light microscopy (Fig. 2-1a, c). ICC was the starting material used for the preparation of MDC and EDC and for this reason; there was no difference in the extent of starch gelatinization between the samples. MDC structure was affected by the mechanical treatment which caused a complete separation of $\mathrm{CW}$ material and cytoplasmic constituents in accordance to what reported by Dhital, et $\mathrm{al}^{13}$.

Light microscopy images (Fig. 2-1b, d) confirmed that the incubation of ICC with Viscozyme ${ }^{\circledR}$ $\mathrm{L}$ altered the structure of the $\mathrm{CW}$. It could be seen that the outer ring, which surrounds the cells in ICC samples, was not visible anymore after the enzymatic treatment. It is important to point out that, despite the visible damage of the wall, cell compact structure was not affected by the treatment. This suggested that not all the CW material was removed.

Several trials were performed using different enzyme concentrations and incubation times to obtain optimal treatment conditions. As a starting point, the method proposed by Guan \& Yao ${ }^{21}$ was used. However, with this relatively severe treatment, the damage of the cell wall was extensive causing a separation between the cell carcass and its content (micrographs not shown). Therefore, a milder treatment was applied reducing the amount of enzyme and the incubation time. 

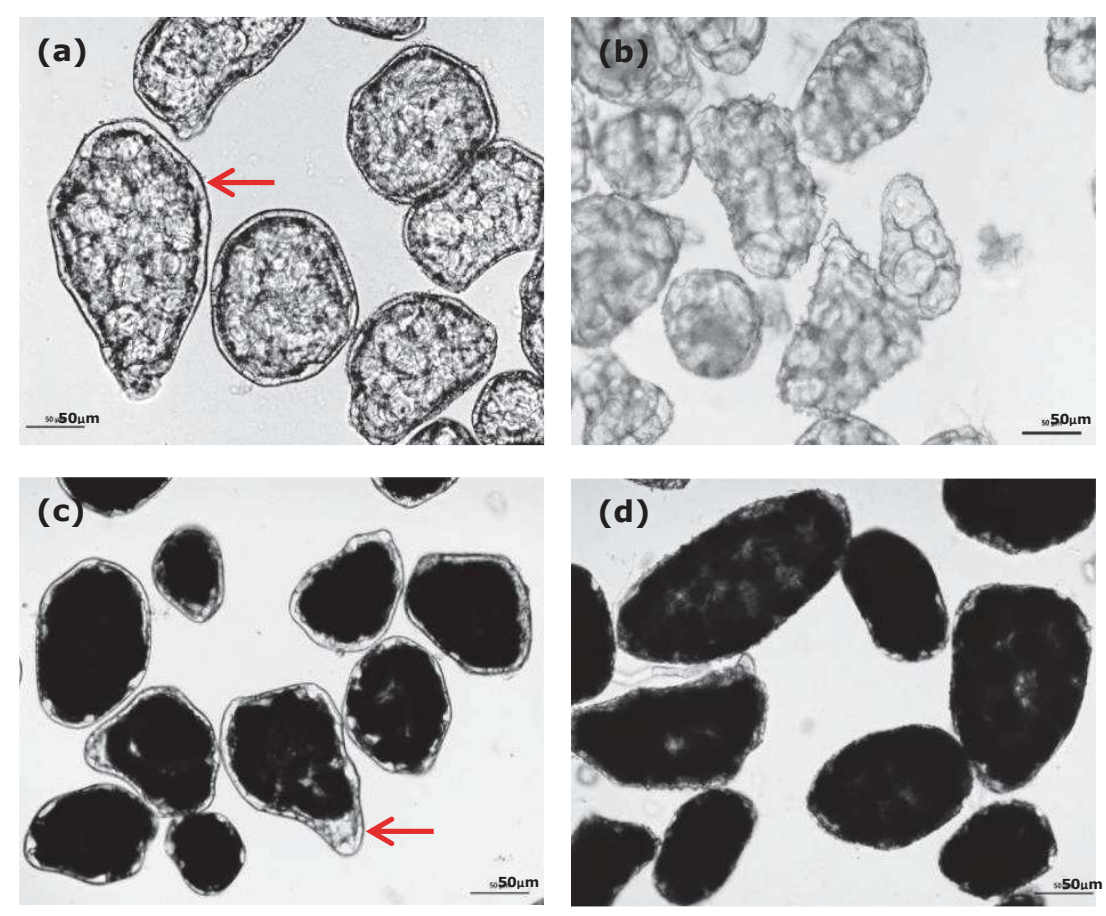

Fig. 2-1. Light micrographs of ICC before (a, c) and after Viscozyme ${ }^{\circledR} \mathrm{L}$ treatment $(b, d)$. Samples were stained with potassium iodide to highlight the presence of starch (c, d). Arrows indicate the presence of the wall in ICC.

Light microscopy provided a general impression of the differences between ICC and EDC. However, a detailed characterization was necessary to determine the extent of EDC CW modification and the role played by the $\mathrm{CW}$ in holding the cytoplasmic matrix together. SEM (Fig. 2-2) was used to compare ICC and EDC CW structure. No cell debris or free starch could be observed (Fig. 2-2a) showing that the protocols employed (isolation and CW degradation) were efficient in obtaining clean and intact samples. When looking in more detail at cells surface (Fig. 2-2b), the effects of the enzymatic treatment were clearly visible on EDC. The surface of the cell was filled with "crates" or "holes" of different sizes as opposed to ICC, which showed a rough surface without any crevices. As an indication of the degree of CW damage, the diameter of several holes was measured giving a size range between 600-3200 nm. These openings were more than 100 times larger than the pores naturally present in the $\mathrm{CW}^{22}$. Furthermore, when taking a closer look at the samples surface (Fig. 2-2c) an homogeneous CW could be observed for ICC, while EDC showed patches with smoother and thinner appearance (where most of the holes were located). This might be an indication of enzymes preference upon specific regions of the cell surface. Consequently, it might not be unreasonable to think that enzymes were more effective in degrading some CW constituents rather than others. In general, legume $\mathrm{CW}$ are assembled as a continuous network of cellulose-xyloglucan in combination with a pectin matrix that serves as filling for the spaces between network 
constituents, increases CW thickness and adds coherence ${ }^{23,24}$. Thus, it could be speculated that $\mathrm{CW}$ in EDC was degraded giving preference to those areas in which its building blocks were less tightly packed.
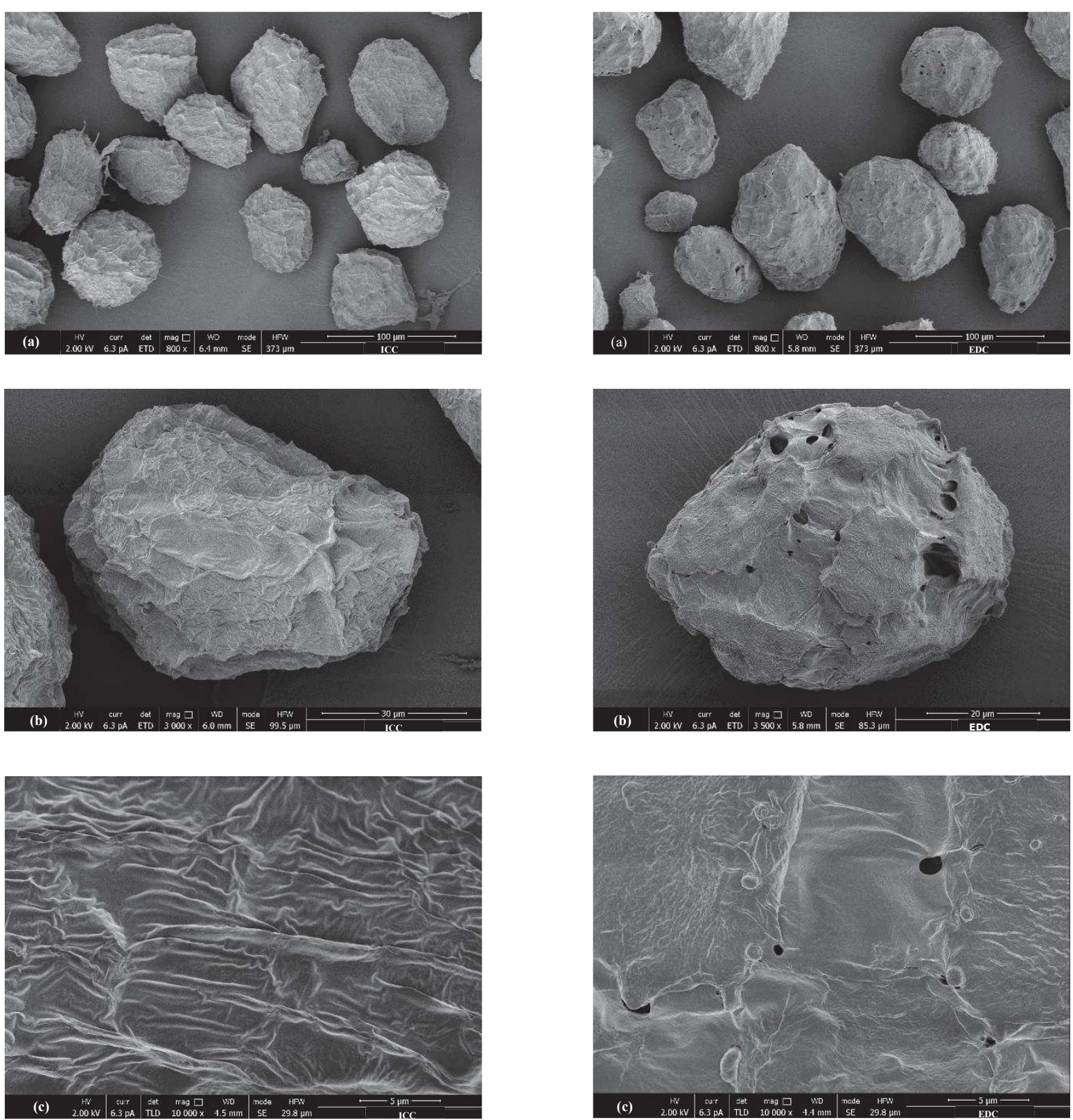

Fig. 2-2. Scanning electron micrographs of ICC (left column) and EDC (right column) from red kidney beans.

SEM technique confirmed that the enzymatic treatment was unable to remove completely the $\mathrm{CW}$. However, it was still capable of producing some changes on its surface without altering the inner structure of the cell.

EDC samples were subjected to preliminary tests in order to check their suitability as experimental material. In-vitro digestion experiments were performed without the addition of 
digestive enzymes as explained in section 2.2.7 Those analyses aimed at determining the amount of glucose in the sample coming from a different source than starch. In addition, starch content of EDC was quantified before and after the digestion experiment. There was no variation in starch content between EDC samples (before and after digestion) even when compared to ICC $(50 \% \mathrm{w} / \mathrm{w})$. This indicates that the enzymes present in Viscozyme ${ }^{\circledR} \mathrm{L}$ were not capable of using starch as substrate which agrees with what previously reported by PerezCarrillo \& Serna-Saldivar (2006).

\subsubsection{Cell wall composition}

Fig. 2-3a summarizes the monosaccharide composition of ICC and EDC related to the CW material recovered from isolation. The main monosaccharides present in both samples were arabinose, glucose, uronic acid and xylose, which accounted more than $90 \%$ of total non-starch polysaccharides (NSP). Similar composition has been reported for kidney beans and other legumes such as mung beans, navy beans and lentils ${ }^{26-29}$. In the present study, lower concentration of uronic acid was found compared to what others have reported. Previous studies were conducted using the entire cotyledon while the present one used isolated cells. Thus, it was reasonable to recover a lower concentration of uronic acid since cell isolation had already solubilized some pectin (D-galacturonic acid polymer and main constituent of middle lamella). 
Chapter 2

(a)

\begin{tabular}{cccccccccc}
\hline \multirow{2}{*}{ Sample } & \multicolumn{8}{c}{ Constituent monosaccharide composition of NSP $(\mu \mathrm{g} / \mathrm{mg})^{\mathrm{a}}$} \\
\cline { 2 - 9 } & Rha & Fuc & Ara & Xyl & Man & Gal & Glc & UA & Total NSP \\
\hline EDW & 2 & 5 & 45 & 15 & 12 & 11 & 168 & 31 & 291 \\
ICW & 4 & 13 & 191 & 42 & 9 & 41 & 130 & 70 & 500 \\
\hline
\end{tabular}

(b)
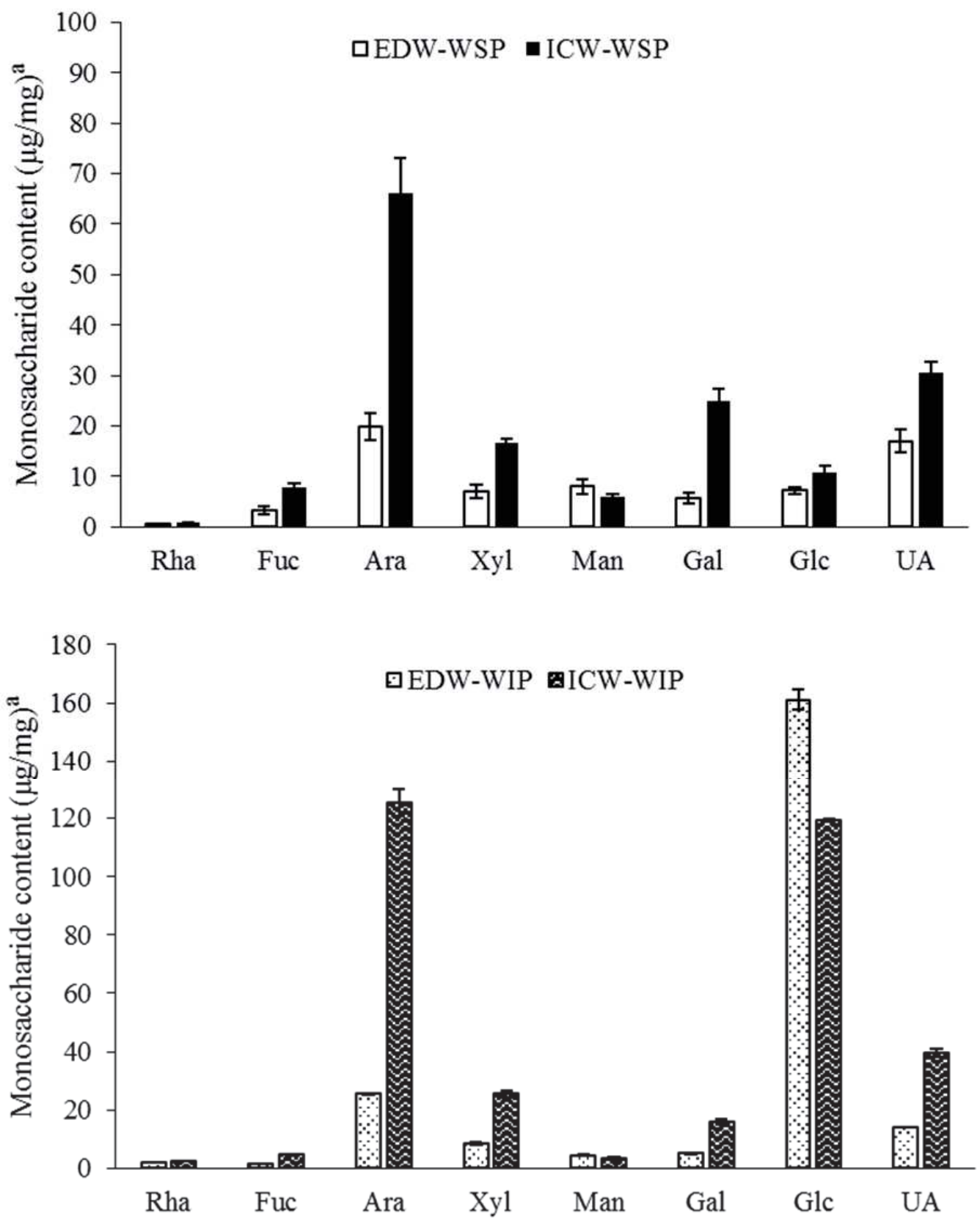

Fig. 2-3. a) Constituent monosaccharide composition and total NSP content of enzymatic damaged walls (EDW) and intact cotyledon walls (ICW) from red kidney beans. b) Monosaccharide content of water-soluble (WSP) and insoluble fraction (WIP) from EDW and ICW. Error bars denote standard deviation of two independent samples. Rha: rhamnose; Fuc: fucose; Ara: arabinose; Xyl: xylose; Man: mannose; Gal: galactose; Glc: glucose; UA: uronic acid.

${ }^{a}$ Expressed as $\mu \mathrm{g} / \mathrm{mg}$ of recovered material. 
The difference in monosaccharide composition between ICW and EDW were compared in Fig. 2-3. A generalized decrease in monosaccharides concentration was evident for EDW. Among all monosaccharide constituents, arabinose and galactose appeared to be mostly affected by enzymatic treatment. Both are building blocks of arabinans and galactans respectively, the socalled "hairy regions" or side chains of pectin rhamnogalacturonan $\mathrm{I}^{30}$. Their specific role in $\mathrm{CW}$ structure is still under investigation, but studies on potato relate galactans to the control of pore size and cotyledon firmness, while arabinans are thought to serve as an anchor of pectin to the rest of the $\mathrm{CW}^{24}$. The loss of both components in EDW highlights their importance since a notable reduction in its content has an impact in $\mathrm{CW}$ integrity and structure.

In addition to the composition, the concentration of NSP in both samples differed notably. After the enzymatic-chemical treatment, the material recovered from ICC contained 50\% NSP as opposed to $29 \%$ (w/w) from EDW. This is an additional indication of the extent of wall damage.

NSPs were separated according to their solubility in water and its sugar constituents quantified (Fig. 2-3b). The highest concentration of monosaccharides was collected in the water insoluble fraction (WIP), representing $80 \%$ of the isolated material from EDW and $70 \%$ for ICW. Nevertheless, the difference among treatments was evident in both the water soluble fraction (WSP) and WIP. In general, higher concentration of sugars were found for ICW in both fractions. However, it is clear from Fig. 2-3 that this is not always the case as for glucose in WIP. Such discrepancy is caused by the enzymatic treatment since the fraction analysed contained only the sugar constituents of undigested NSP. The selective enzymatic hydrolysis of CW polysaccharides increased the relative concentration of the monosaccharide constituents from the less digested NSP. Besides this, no large differences were observed between other EDW soluble and insoluble constituents. Conversely, in ICW glucose, arabinose and xylose were found to be more abundant in WIP.

Viscozyme ${ }^{\circledR} \mathrm{L}$ is a multi-enzyme complex that contains a wide range of carbohydrases including cellulase, $\beta$-glucanase, arabanase, hemicellulase and xylanase ${ }^{31}$. Thus, a substantial degradation of EDW cellulose-hemicellulose backbone was expected. Interestingly, only a limited damage was observed after the enzymatic treatment. This could be caused by the structural architecture of the $\mathrm{CW}$ and the limited time of enzymatic incubation. Consequently, the CW network was partially loosened hindering the contact between the enzyme mix and the cellulose-hemicellulose backbone. As a result, cell structure was prevented from pulling apart 
maintaining its inner compactness while the surface of the cell wall showed some major physical modifications.

Based on the results exposed in this section, it could be speculated that Viscozyme ${ }^{\circledR} \mathrm{L}$ had a high affinity to pectin molecules especially to rhamnogalacturonan side chains (arabinans and galactans). The degradation of pectin could have facilitated the access of the enzymes making other NSP more available. Such degradation caused marked differences in CW structure between EDC and ICC in terms of porosity and CW thickness.

\subsubsection{In-vitro digestion}

\subsubsection{Digestion kinetics of intact, enzymatic and mechanically damaged cotyledon} cells.

In Fig. 2-4, the rate of starch hydrolysis in ICC, MDC and EDC is reported. A sample with free starch was included in the experiment for comparison. All samples showed similar hydrolysis level (70\% ICC and EDC, 77\% MDC and free starch) after 6 hours of in-vitro digestion Fig. 2-4a). Nevertheless, the rate of hydrolysis was higher in samples where cell integrity was compromised. In the case of MDC, 50\% of undigested substrate was observed after 10 minutes of intestinal digestion (Fig. 2-4b). This occurred due to the high accessibility of starch where its depletion was the only limiting factor in the enzymatic reaction.

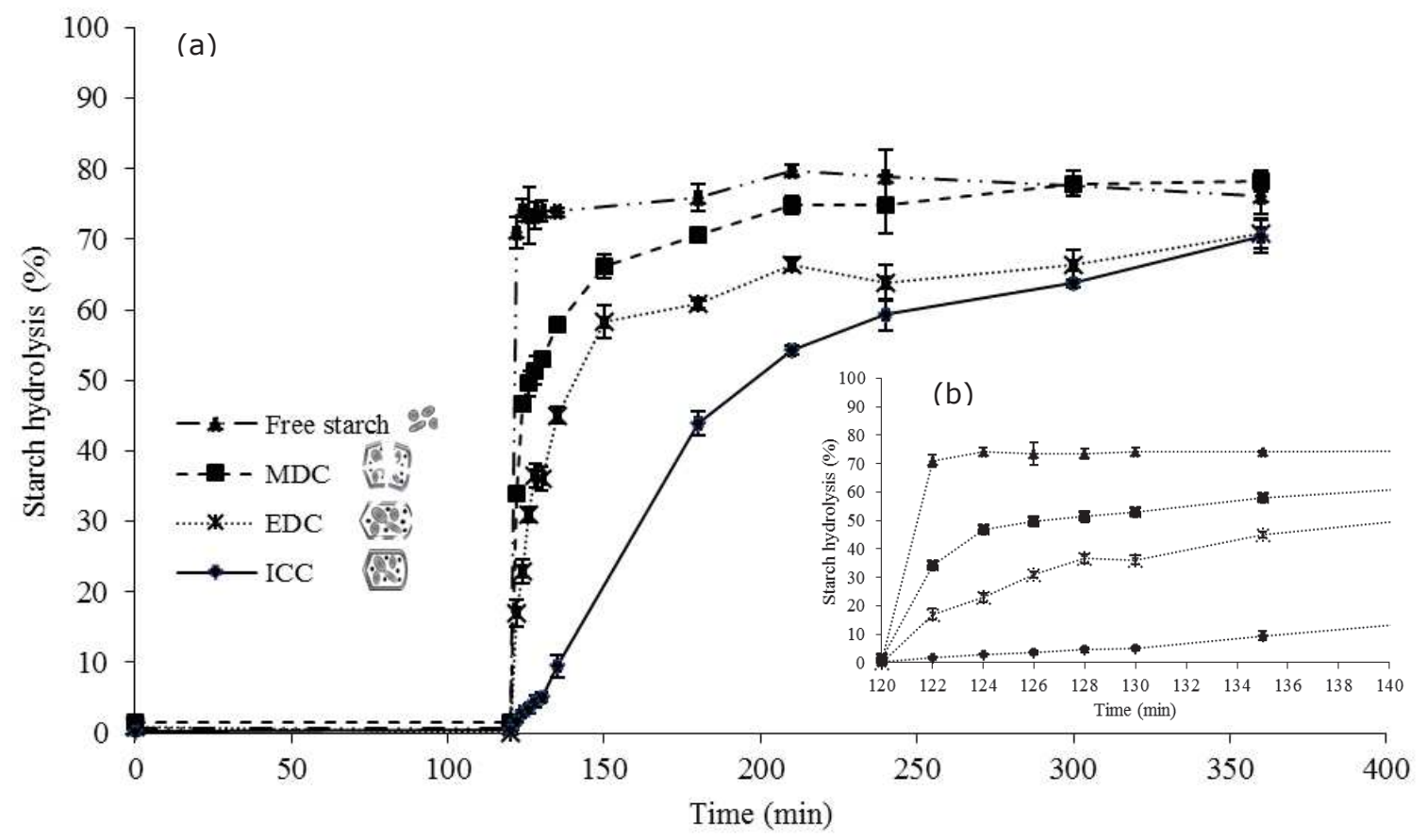

Fig. 2-4. (a) Kinetics of starch hydrolysis from red kidney bean ICC, MDC, EDC and free starch. (b) zoom-in of the first 20 minutes of intestinal digestion. Error bars denote standard deviation of three independent samples. 
On the contrary, in EDC and ICC starch was hydrolysed at a slower pace with approximately $30 \%$ and less than $10 \%$ of starch hydrolysed in the first $10 \mathrm{~min}$ of digestion respectively. This data demonstrates the importance of $\mathrm{CW}$ integrity for the kinetics of starch digestion since a relatively mild damage in the $\mathrm{CW}$ structure has a large impact on the rate of starch hydrolysis. In addition to the barrier effect exerted by the $\mathrm{CW}$, the role of the cytoplasmic matrix in starch digestion deserves attention. Cytoplasmic matrix is referred to as the microstructural organization of cellular constituents where globular starch granules are embedded in a protein matrix. This tightly packed network has consequences on starch hydrolysis by limiting the surface area between enzyme-substrate hindering $\alpha$-amylase diffusion and catalysis. A clear demonstration of this effect is shown in Fig. 2-5, where ICC digestion was conducted in the absence of proteolytic enzymes. The hydrolysis of proteins facilitates the access of $\alpha$-amylase to starch and stressess the importance of intra-cellular packing on starch hydrolysis.

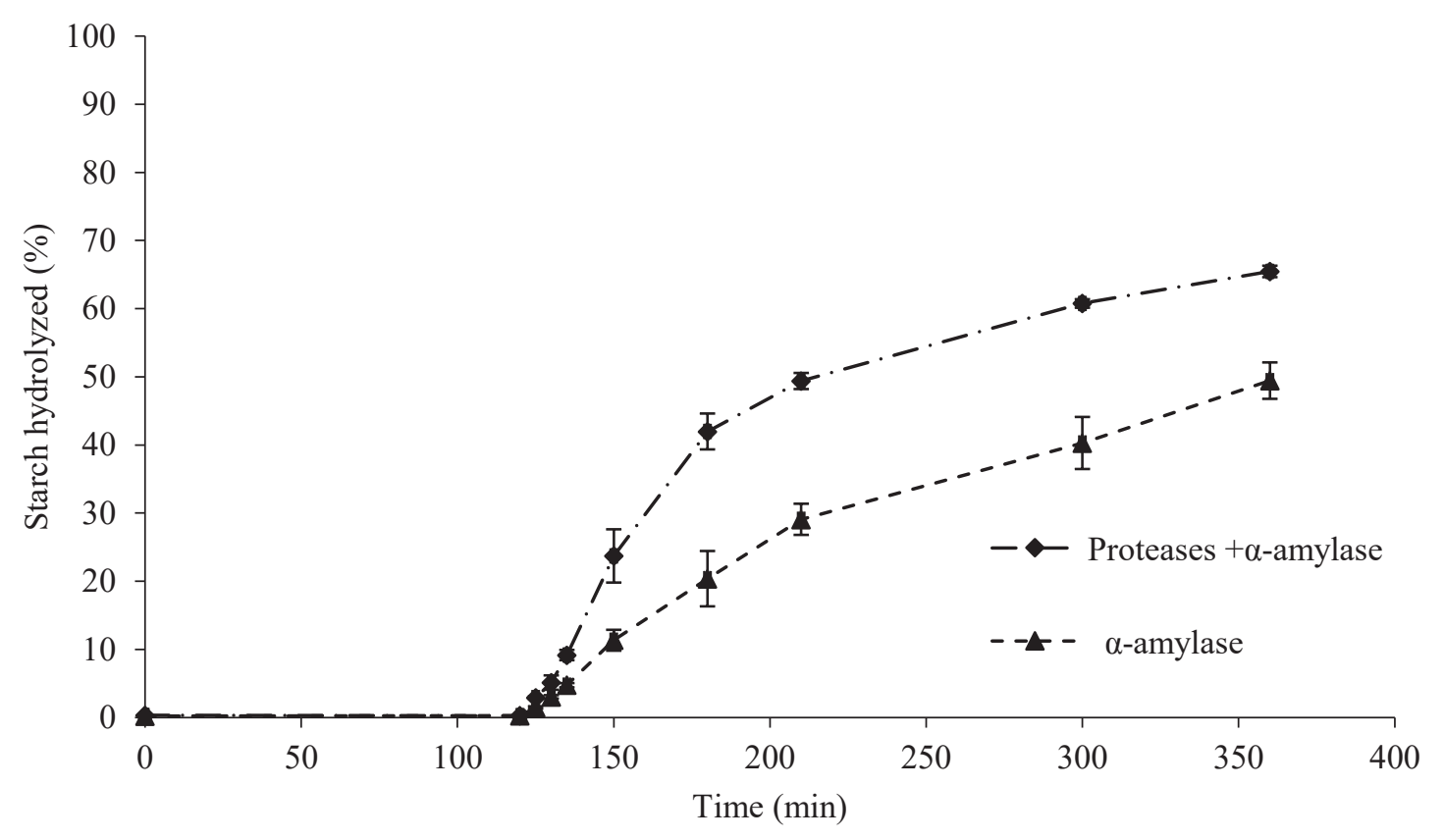

Fig. 2-5. Kinetics of starch hydrolysis from ICC with and without the use of pepsin, trypsin and chymotrypsin during in-vitro digestion. Error bars denote standard deviation of three independent samples.

Legumes were already identified as low GI foods more than 30 years ago. Their contribution to health relies on the ability of reducing the amplitude and duration of postprandial hyperglycaemia ${ }^{8,32,33}$. Until now, this has been entirely attributed to the barrier effect of the $\mathrm{CW}$ sometimes even considered as an impenetrable barrier for digestive enzymes ${ }^{13}$. Based on the results shown, it is clear that the compact organization of the cytoplasmic matrix represent an additional barrier to starch hydrolysis by $\alpha$-amylase. Recently, Bhattarai, et al ${ }^{34}$ observed that 
Chapter 2

binding interactions between amylases and cell wall components could also influence hydrolysis. Such effect is considered negligible in this study, since the in-vitro digestion protocol employed specified the use of higher concentration of $\alpha$-amylase compared to what Bhattarai, et al. utilized.

Our findings show that digestion is a cooperative process and that efficient hydrolysis of one substrate may be affected by the simultaneous hydrolysis of another. This goes in agreement to what Bhattarai, et $\mathrm{al}^{35}$ found for a simplified matrix (wheat flour) where the presence of an intact macronutrient (i.e. protein) hindered starch hydrolysis during digestion.

\subsubsection{Structural integrity of cotyledon cells during in-vitro digestion}

Fig. 2-6 compares the micrographs of ICC, MDC and EDC before, during and after in-vitro digestion. ICC and EDC samples retained their structural integrity throughout the digestion experiment. Additionally, it is apparent from Fig. 2-6 (panels a2, a3) that CW from ICC appeared thicker during digestion. Such increase in CW size might be attributed to osmotic flow of digestive fluids within the cell. Nevertheless, this seems unlikely since samples were already soaked and cooked for a considerable amount of time, enough to reach cells maximum hydrating capacity. If $\mathrm{CW}$ thickening occurred during digestion, MDC CW should have also been affected since no chemical modifications on its composition was produced. Therefore, the most likely explanation for our observation might be that, due to $\mathrm{CW}$ confinement, starch was hydrolysed from the periphery towards the core of the cell. Consequently, the empty space observed between cell cytoplasm and $\mathrm{CW}$ is being formed as digestion proceeds. This could not be observed in EDC possibly because CW modification facilitated the access of proteolytic enzymes which in turn loosened the cytoplasmic matrix increasing the mobility of $\alpha$-amylase within the cells.

Changes in starch content were also visualized by light microscopy. A pronounced decrease in iodine staining intensity was seen for MDC and EDC samples during digestion. This served as an additional indication of the difference in starch hydrolysis rate among the investigated samples. 

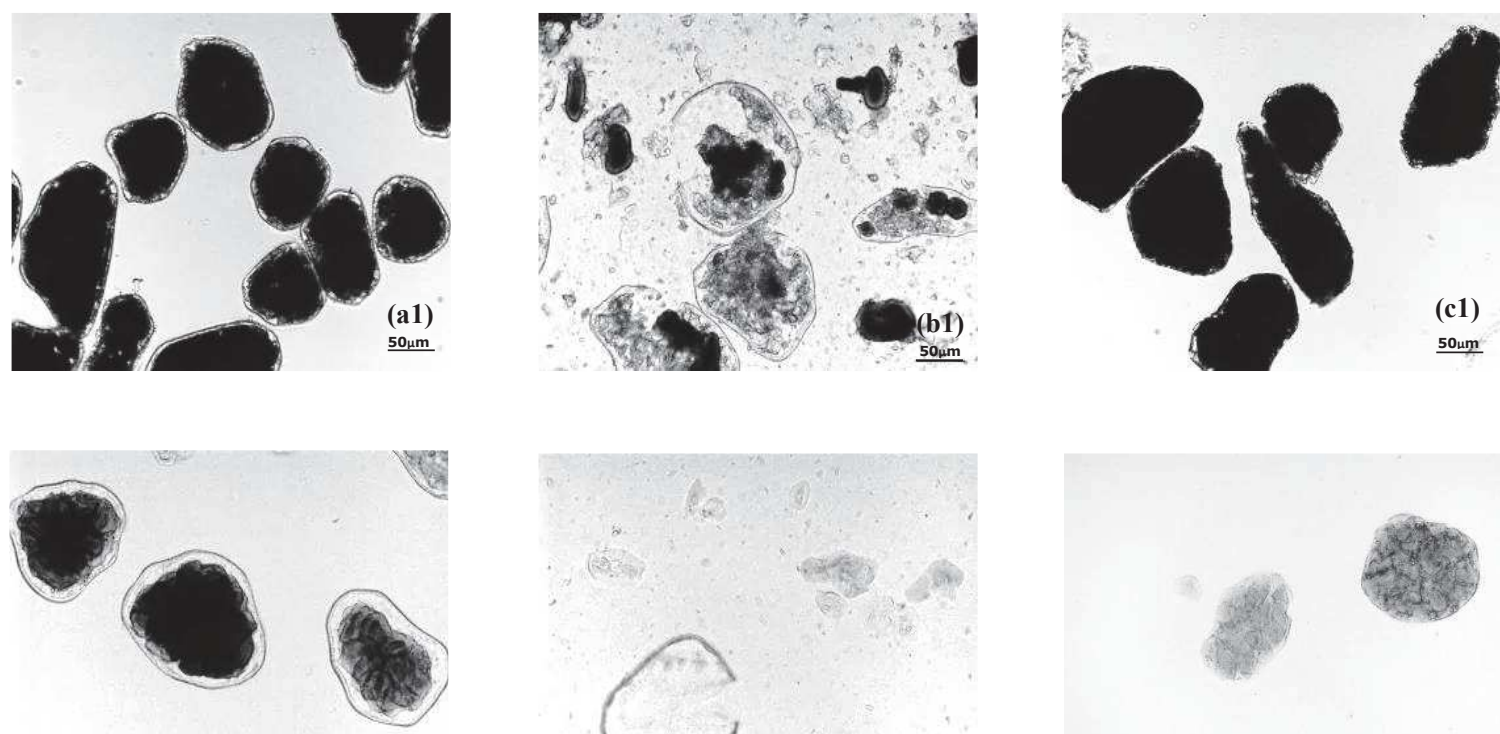

(a2)
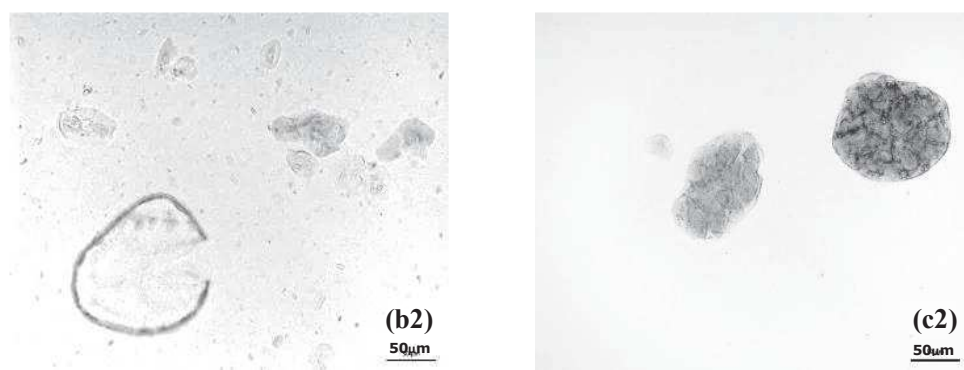

(b2)

(c2)
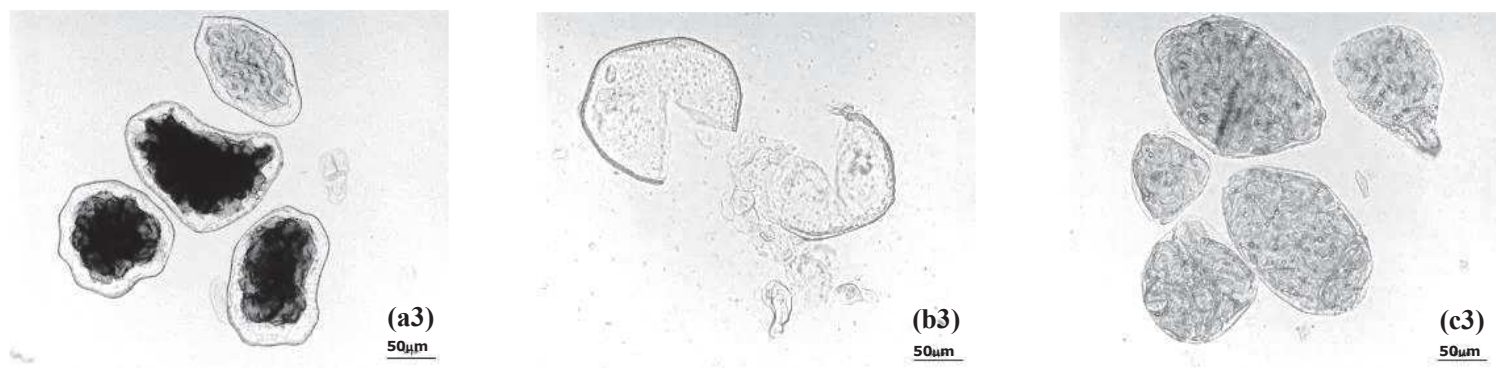

Fig. 2-6. Light microscopy images of ICC (a), MDC (b) and EDC (c) at 0min (1), 150min (2) and 360min (3) of in-vitro digestion. Samples were stained with potassium iodide solution to highlight the presence of starch.

The aforementioned results gave a general impression of sample structure during digestion. Nevertheless, it remained unclear if the mixing conditions used during the in-vitro experiment could damage the physical integrity of ICC. This was the case for Dhital, et al ${ }^{13}$ who reported that isolated cells were damaged when mixed by a magnetic stirrer. To check that, an experiment was designed in which ICC suspended in digestive fluids was rotated overnight using the same speed as the one employed for digestion. After these laps of time, in-vitro digestion was performed and the kinetics of starch hydrolysis measured. ICC sample without pre-mixing was included as a control. Results are reported in Fig. 2-7 and it is evident that both curves behaved identically during digestion. Therefore, the mixing conditions were not altering in any possible way the barrier effect of the $\mathrm{CW}$.

The results presented in this section confirm that starch hydrolysis observed in ICC occurred because of enzyme diffusion through the $\mathrm{CW}$ and not to the physical disruption of it. They also prove that, at least in cooked (and thus fully rehydrated) bean cells, the limited changes in $\mathrm{CW}$ 
structure (chemical and physical) occurring during digestion do not have any significant effect on starch hydrolysis.

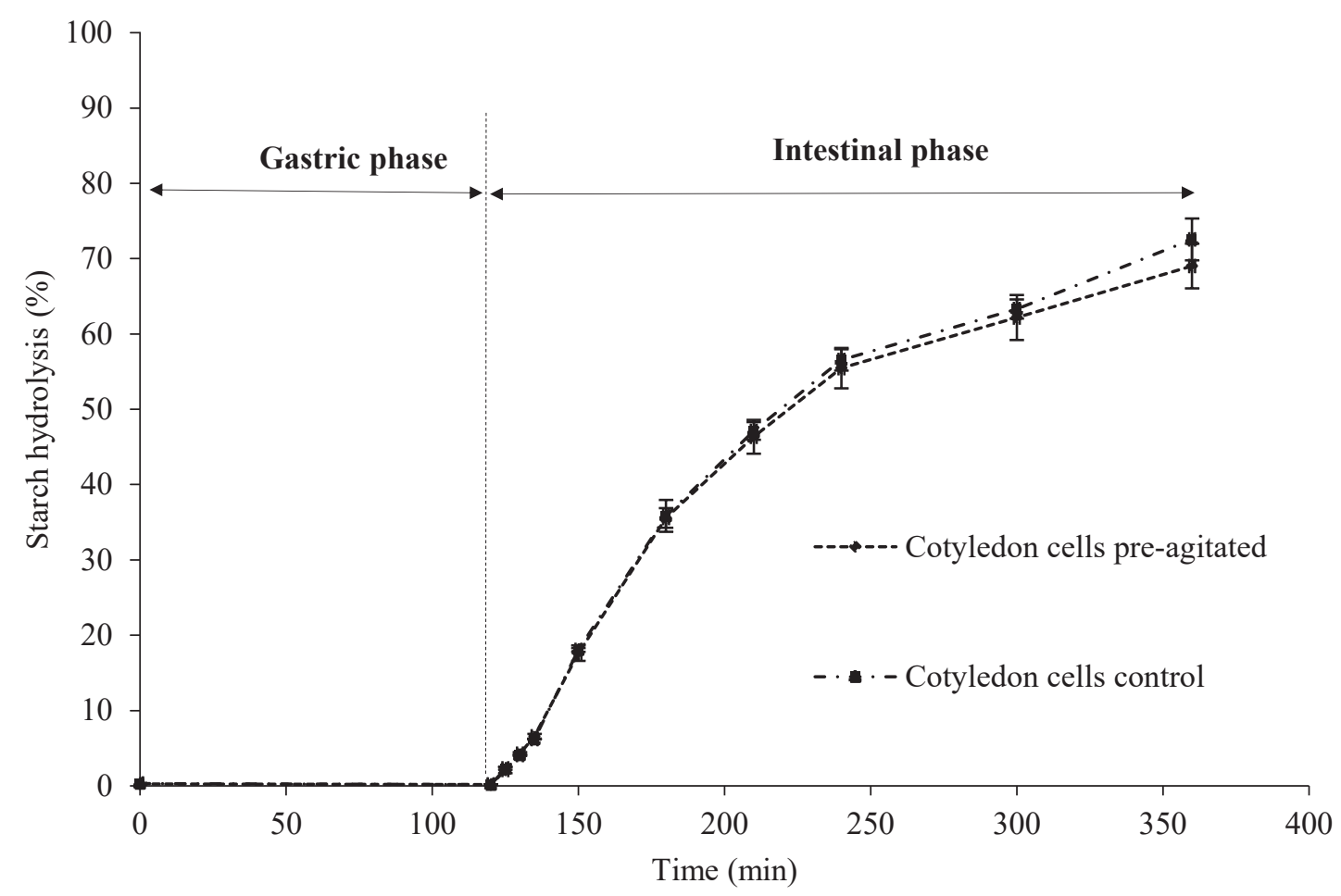

Fig. 2-7. Kinetics of starch hydrolysis from ICC pre-agitated for 12 hours and a control sample (no pre-agitation). Error bars denote standard deviation of three independent samples.

\subsection{Conclusion}

Legume cotyledon cells own a unique ability to decrease the rate of starch hydrolysis during digestion. Understanding the structural features that allow legumes to be a low GI food are of particular interest to scientists and industry, since new strategies could be developed in the formulation of legume-based functional ingredients. In this work, evidence of the mechanisms by which the structural features of beans decrease the rate of starch hydrolysis was provided. The barrier effect exerted by the intact cell wall and the packed cytoplasmic matrix were shown to be key factors in the delay of starch hydrolysis in bean cotyledon cells. Furthermore, this study gave insights about the importance of CW architecture and the influence of specific constituents in modulating $\mathrm{CW}$ permeability to digestive enzymes. This will open the possibility to produce modifications in the cell wall structure for specific applications not only for starch digestibility but also for other nutrients. 
A closer look to cell structural barriers affecting starch digestibility in beans

\subsection{Acknowledgments}

This work was supported by a grant from the Ecuadorian Secretary of Higher Education, Science, Technology and Innovation. 


\section{References}

1. Afshin A, Micha R, Khatibzadeh S, Mozaffarian D. Consumption of nuts and legumes and risk of incident ischemic heart disease, stroke, and diabetes: a systematic review and meta-analysis. Am J Clin Nutr. 2014;100:278-289.

2. Jenkins DJA, Kendall CW, Augustin LS, et al. Effect of Legumes as part of a low glycemic index diet on glycemic control and cardiovascular risk factors in type 2 diabetes mellitus: A randomized controlled trial. Arch Intern Med. 2012;172(21):1-8.

3. Venn BJ, Mann JI. Cereal grains, legumes and diabetes. Eur J Clin Nutr. 2004;58(11):14431461.

4. Jenkins DJA, Kendall CWC, Augustin LSA, et al. Glycemic index: Overview of implications in health and disease. Am Soc Clin Nutr. 2002;76(1):2665-2735.

5. Kon S, Wagner JR, Becker R, Booth AN, Robbins DJ. Optimizing nutrient availability of legume food products. J Food Sci. 1971;36(4):636-639.

6. Würsch P, Vedovo S, Del Koellreutter B. Cell structure and starch nature as key of the digestion rate of starch. Am J Clin Nutr. 1986;43(1):25-29.

7. Tovar J, Bjbrck IM, Asp N. Analytical and Nutritional Implications of Limited Enzymic Availability of Starch in Cooked Red Kidney Beans. J Agric Food Chem. 1990;38(2):488-493.

8. Thorne MJ, Thompson LU, Jenkins DJ. Factors affecting starch digestibility and the glycemic response with special reference to legumes. Am J Clin Nutr. 1983;38(3):481-488.

9. Edwards $\mathrm{CH}$, Grundy MM, Grassby T, et al. Manipulation of starch bioaccessibility in wheat endosperm to regulate starch digestion, postprandial glycemia, insulinemia, and gut hormone responses: a randomized controlled trial in healthy ileostomy participants. Am J Clin Nutr. 2015;102(4):791-800.

10. Zhang B, Dhital S, Gidley MJ. Densely packed matrices as rate determining features in starch hydrolysis. Trends Food Sci Technol. 2015;43(1):18-31.

11. Berg T, Singh J, Hardacre A, Boland MJ. The role of cotyledon cell structure during in vitro digestion of starch in navy beans. Carbohydr Polym. 2012;87(2):1678-1688.

12. McNeil M, Darvill AG, Fry SC, Albersheim P. Structure and function of the primary cell walls of plants. Annu Rev Biochem. 1984;53:625-663.

13. Dhital S, Bhattarai RR, Gorham J, Gidley M. Intactness of cell wall structure controls the in vitro digestion of starch in legumes. Food Funct. 2016;7(3):1367-1379.

14. Minekus M, Alminger M, Alvito $\mathrm{P}$, et al. A standardised static in vitro digestion method suitable for food - an international consensus. Food Funct. 2014;5(6):1113-1124.

15. Dartois A, Singh J, Kaur L, Singh H. Influence of guar gum on the in vitro starch digestibility—Rheological and microstructural characteristics. Food Biophys. 2010;5(3):149160.

16. Monro J, Mishra S, Blandford E, Anderson J, Genet R. Potato genotype differences in 
nutritionally distinct starch fractions after cooking, and cooking plus storing cool. $J$ Food Compos Anal. 2009;22(6):539-545.

17. Shiga TM, Lajolo FM, Filisetti TMCC. Changes in the cell wall polysaccharides during storage and hardening of beans. Food Chem. 2004;84(1):53-64.

18. Shiga TM, Lajolo FM. Cell wall polysaccharides of common beans (Phaseolus vulgaris L.) composition and structure. Carbohydr Polym. 2006;63(1):1-12.

19. Englyst HN, Cummings JH. Simplified method for the measurement of total non-starch polysaccharides by gas-liquid chromatography of constituent sugars as alditol acetates. Analyst. 1984;109(7):937-942.

20. Thibault JF. Automatisation du dosage des substances pectiques par la methode au metahydroxydiphenyl. Leb - Wiss - Technol. 1979;12:247-251.

21. Guan X, Yao H. Optimization of Viscozyme L-assisted extraction of oat bran protein using response surface methodology. Food Chem. 2008;106(1):345-351.

22. Brett CT, Waldron KW. Cell wall architecture and the skeletal role of the cell wall. In: Black B, Charlwood M, eds. Physiology and Biochemistry of Plant Cell Walls. London: Chapman \& Hall; 1996:44-74.

23. Cosgrove DJ. Expansive growth of plant cell walls. Plant Physiol Biochem. 2000;38(1/2):109124.

24. Vincken J, Schols HA, Oomen RJFJ, et al. If homogalacturonan were a side chain of rhamnogalacturonan I. Implications for cell wall architecture. Plant Physiol. 2003;132(4):1781-1789.

25. Perez-Carrillo E, Serna-Saldivar SO. Cell wall degrading enzymes and proteases improve starch yields of sorghum and maize. Starch/Stärke. 2006;58(7):338-344.

26. Champ M, Brillouet JM, Rouau X. Nonstarchy polysaccharides of phaseolus vulgaris, lens esculenta and cicer arietinum seeds. J Agric Food Chem. 1986;34(2):326-329.

27. Bhatty RS. Cooking quality of lentils: the role of structure and composition of cell walls. $J$ Agric Food Chem. 1990;38(2):376-383.

28. Biliaderis CG, Grant DR, Vose JR. Structural characterization of legume starches. Studies on amylose, amylopectin, and beta-limit dextrins. Cereal Chem 58(6),496-502. 1981;58(6):496502.

29. Gooneratne J, Majsaak-Newman G, Robertson JA, Salvendran RR. Investigation of factors that affect the solubility of dietary fiber, as nonstrach polysaccharides, in seed tissues of mung bean (Vigna radiata) and black gram (Vigna mungo). J Agric Food Chem. 1994;42(3):605-611.

30. Oomen RJFJ, Vincken J, Bush MS, et al. Towards unravelling the biological significance of the individual components of pectic hairy regions in plants. In: Voragen F, Schols H, Visser RG., eds. Advances in Pectin and Pectinase Research. Springer Netherlands; 2003:15-34.

31. Fogliano V, Corollaro ML, Vitaglione $\mathrm{P}$, et al. In vitro bioaccessibility and gut biotransformation of polyphenols present in the water-insoluble cocoa fraction. Mol Nutr Food 
Chapter 2

Res. 2011;55(1):S44-55.

32. Jenkins DJA, Wolever TM, Taylor RH, et al. Glycemic index of foods: a physiological basis for carbohydrate exchange. Am J Clin Nutr. 1981;34(3):362-366.

33. Rizkalla SW, Bellisle F, Slama G. Health benefits of low glycaemic index foods, such as pulses, in diabetic patients and healthy individuals. Br J Nutr. 2002;88(S3):255.

34. Bhattarai RR, Dhital S, Wu P, Chen X, Gidley M. Digestion of isolated legume cells in a stomach-duodenum model: three mechanisms limit starch and protein hydrolysis. Food Funct. $2017 ; 8: 2573-2582$.

35. Bhattarai RR, Dhital S, Gidley M. Interactions among macronutrients in wheat flour determine their enzymic susceptibility. Food Hydrocoll. 2016;61:415-425. 


\section{Chapter 3}

$-2000$

\section{The effect of cell wall encapsulation on macronutrients digestion: a case study in kidney beans}

This chapter has been published as:

Ana M. Rovalino-Córdova, Vincenzo Fogliano, Edoardo Capuano. (2019) The effect of cell wall encapsulation on macronutrients digestion: a case study in kidney beans. Food Chemistry. 181, 557-566. 


\section{Abstract}

Cotyledon cells in kidney beans naturally encapsulate starch and proteins limiting the access of digestive enzymes to their substrates. In this study, we investigated the effect of cell wall on bean proteins digestibility and its relationship with starch digestion. Results showed that proteins contained in the cytoplasmic matrix influence the rate at which starch is digested invitro. Confocal laser scanning microscopy revealed that storage proteins in the cytoplasm act as a second encapsulation system preventing starch digestion. This microstructural organization only affected starch since no changes in protein digestion rate or extent were observed due to the presence of starch granules. Fourier transform infrared spectroscopy revealed that cellular entrapment limited protein denaturation induced by thermal treatments. High concentrations of a fraction resistant to digestion were found in proteins that were heated when entrapped within intact cotyledon cells compared to those thermally treated as bean flour. 


\subsection{Introduction}

Beans (Phaseolus vulgaris L.) are an important staple food in many countries around the globe especially in developing regions of Africa and Latin America where it represents a good and cheap source of proteins. Besides proteins, beans provide carbohydrates (starch and dietary fibre), vitamins, minerals and low fat content ${ }^{1}$ to the diet. The consumption of beans and legumes in general, has been associated with the prevention of chronic disorders such as cardiovascular diseases and diabetes. Even though there is strong epidemiological evidence that supports this statement, the mechanisms by which these favourable properties take place is still lacking $^{2}$. The health benefits associated with the consumption of beans are related to the low glycaemic index, which has been attributed to the dietary fibre present in legumes. However, legumes also have structural peculiarities that might play an important role in the way they are digested. In bean cotyledon cells, starch and proteins are surrounded by thick cell walls. Together, proteins and starch form a well-organized cytoplasmic matrix while a mixture of indigestible non-starch polysaccharides (cellulose, pectin, hemicellulose) constitute the building blocks from which the cell wall is made. Several studies have given insights about the importance of these cellular structures in digestion ${ }^{3}$. In a previous study ${ }^{4}$, we showed that intact cotyledon cells from kidney beans delay the rate of starch hydrolysis in-vitro. In the same study, it was also observed that the protein matrix (that embeds starch) is also important for modulating starch digestibility.

Bean proteins consist of water-soluble albumins and salt soluble globulins. The latter one, also named phaseolin or vicilin, is the major storage protein in beans representing $40-50 \%$ of the total seed protein. Phaseolin is an oligomeric protein consisting of three types of similar sub units, $\alpha, \beta$ and $\gamma$ (397, 411 and 412 amino acid residues respectively) with a molecular weight distribution ranging from 43 to $53 \mathrm{kDa}^{5}$. From a nutritional point of view, this protein contains low sulphur amino acids and is poorly digested thus resulting in a limited nutritive value in raw conditions $^{6}$. Several factors like the presence of lectins, phytic acid and polyphenols in the bean matrix possibly contributed to protein limited digestibility ${ }^{7}$. However, in-vitro studies have indicated that the high resistance of phaseolin to the attack of proteolytic enzymes is the main contributor for limited protein digestion in beans ${ }^{8}$. This is particularly the case when raw phaseolin is digested, while thermal treatments have been found to be effective in improving drastically its digestibility. However, scarce information is available regarding the effect of cellular entrapment on protein digestibility as it happens in beans. 
Interactions among macronutrients as consequence of structural entrapment have been also observed to influence digestibility. A well-known example could be found in pasta, where the digestibility of starch is delayed due to matrix compactness and the gluten network formed by proteins ${ }^{9}$. Nothing has been said about the repercussions that protein digestibility has in the degradation of starch also confined within intact cells of legumes.

This study aims at understanding the effects of cellular confinement in protein digestibility of kidney beans. Furthermore, the changes in starch digestibility due to the degradation of the protein matrix will also be explored. We hypothesize that the cellular entrapment of proteins within intact cotyledon cells has an impact in its digestibility rate and extent. Due to the structural organization of the cotyledon cells, the changes in protein digestibility are also expected to influence the way starch is degraded in-vitro.

\subsection{Materials and methods}

\subsubsection{Materials}

Red kidney beans were purchased from the local supermarket (Wageningen, Netherlands) and stored at room temperature.

Pepsin (porcine gastric mucose 3200-4500 U/mg), trypsin (porcine pancreas 1000-2000 U/mg), $\alpha$-chymotrypsin (bovine pancreas $\geq 40 \mathrm{U} / \mathrm{mg}$ ), $\alpha$-amylase (porcine pancreas 700 -1400 U/mg), amyloglucosidase (from aspergillus Niger, $120 \mathrm{U} / \mathrm{mg}$ ), protease Flavourzyme ${ }^{\circledR}$ (from aspergillus oryzae, $\geq 500 \mathrm{U} / \mathrm{g}$ ) and serine proteinase inhibitor Pefabloc ${ }^{\circledR} \mathrm{SC}$ were purchased from Sigma-Aldrich Ltd. (St. Louis, MO, USA). Heat stable $\alpha$-amylase (3000 U/mL), and amyloglucosidase $(3300 \mathrm{U} / \mathrm{mL})$ were obtained from Megazyme Inc. (Bray, Ireland). NuPAGE ${ }^{\circledR}$ 4-12\% Bis-Tris Gels, MOPS running buffer and LDS sample buffer for SDS-PAGE analysis were provided by Thermo fisher scientific (Van Allen Way Carlsbad, CA, USA). Blue ray prestained protein ladder (9-180 kDa) was purchased from Jena Bioscience (Jena, Germany). All other chemicals were of analytical grade unless stated otherwise.

\subsubsection{Isolation of cotyledon cells}

Isolation of cotyledon cells was carried out as described before ${ }^{4}$. In short, previously soaked and de-hulled beans were boiled in water (ratio 2:1) for $1 \mathrm{~h}$ with gentle stirring. After cooling to room temperature, cooked beans were mashed by the use of a mortar and pestle and then fractionated in a vibratory sieve shaker. Sample retained in a sieve with mesh size of $90 \mu \mathrm{m}$ 
correspond to intact cotyledon cells (ICC) and was the fraction utilized in this study. ICC were dispersed in sodium azide solution $(0.02 \%)$ to prevent microbiological spoilage and used immediately to prevent starch retrogradation.

\subsubsection{Mechanically damaged cells}

Mechanical damaged cells (MDC) were obtained after the physical disruption of ICC following the procedure described in detail in a previous work ${ }^{4}$. Briefly, a suspension of ICC in sodium azide solution $(0.02 \%)$ was mixed by the use of a magnetic stirrer for $24 \mathrm{~h}$ at $1500 \mathrm{rpm}$ until complete cell breakage.

\subsubsection{Bean flour solution}

Soaked and de-hulled beans were dried at $40^{\circ} \mathrm{C}$ until achieving a moisture content of $10 \%$ prior to milling and sieving (mesh size $70 \mu \mathrm{m}$ ). Sieved bean flour was used for preparing an aqueous suspension with a protein concentration of $6.25 \mathrm{mg} / \mathrm{mL}$ in demineralized water. Bean flour solution (BFS) was boiled for 30 min with constant stirring; cooled to room temperature and used immediately to prevent sample spoilage ${ }^{10}$.

\subsubsection{Dry matter content}

Dry matter content was determined in triplicate by placing the sample in an oven at $105^{\circ} \mathrm{C}$ overnight until reaching a constant weight.

\subsubsection{In-vitro digestion}

Two-phase in-vitro digestion experiments were carried based on the harmonized INFOGEST protocol as described by Rovalino-Córdova, et $\mathrm{al}^{4}$ with some modifications. Samples were combined with simulated gastric fluids and pepsin $(2000 \mathrm{U} / \mathrm{mL})$. The $\mathrm{pH}$ was adjusted to 3 with $\mathrm{HCl}$ and the tubes incubated at $37^{\circ} \mathrm{C}$ for $2 \mathrm{~h}$ to complete gastric digestion. For the intestinal phase, gastric chyme was combined with simulated intestinal fluids, trypsin $(100 \mathrm{U} / \mathrm{mL})$, chymotrypsin $(25 \mathrm{U} / \mathrm{mL})$ and pancreatic $\alpha$-amylase $(100 \mathrm{U} / \mathrm{mL})$. The $\mathrm{pH}$ was adjusted to 7 and incubated at $37^{\circ} \mathrm{C}$ for $4 \mathrm{~h}$. Samples were mixed by the use of a laboratory rotator at constant speed $(70 \mathrm{rpm})$ throughout the whole experiment. Aliquots were taken at different time points of gastric and intestinal digestion.

Amylase and protease activity were stopped by the use of absolute ethanol and $15 \%$ trichloroacetic acid (TCA) respectively. In both cases, the addition of the reagent to sample 
Chapter 3

aliquot was in a ratio of $4: 1$. Samples were left to rest for $30 \mathrm{~min}$ before centrifugation at $4000 \mathrm{~g}$ for $15 \mathrm{~min}$. Supernatants were collected for further analysis.

The influence of individual enzymes in the rate and extent of starch or protein digestion was tested. For this purpose, in-vitro digestion was conducted in the absence of either pepsin in the gastric phase (NGP), trypsin and chymotrypsin in the intestinal phase (NIP), all proteases (NP) or $\alpha$-amylase in the intestinal phase (NA). Enzymes were replaced by the addition of simulated fluids in order to keep the ratio between sample: digestive fluids constant.

\subsubsection{Determination of starch hydrolysis}

$0.1 \mathrm{~mL}$ of ethanolic supernatant was combined with amyloglucosidase solution $(27 \mathrm{U} / \mathrm{mL})$ in acetate buffer $0.1 \mathrm{M}(\mathrm{pH} 4.8)$ and incubated at $37^{\circ} \mathrm{C}$ for $1 \mathrm{~h}$. The amount of glucose present at each time tested was quantified by D-glucose assay procedure (GOPOD FORMAT, K-GLUC 09/14, Megazyme Inc., Bray, Ireland). A factor of 0.9 was used to convert glucose into the corresponding amount of starch hydrolysed. Results were presented as grams of hydrolysed starch / 100 g of dry starch.

\subsubsection{Total starch}

Starch content was determined by Total Starch Assay Procedure (amyloglucosidase / $\alpha$-amylase method), Megazyme Inc. (Bray, Ireland). Prior the determination, samples were mechanically disrupted to avoid underestimation of the starch content ${ }^{4}$.

\subsubsection{Determination of protein hydrolysis}

TCA diluted samples were subjected to an additional enzymatic treatment with exo-peptidase $\left(\right.$ Flavourzyme $^{\circledR}$ ) in order to quantify the degree of protein hydrolysis. $0.05 \mathrm{~mL}$ of sample was combined with a solution of Flavourzyme ${ }^{\circledR}$ in phosphate buffer $(\mathrm{pH} 8)$. The enzyme-substrate ratio (E/S) utilized was $100 \mathrm{LAPU}$ (leucine aminopeptidase unit) /g protein as suggested by Clemente, et $\mathrm{al}^{11}$. Samples were incubated at $50^{\circ} \mathrm{C}$ for $1 \mathrm{~h}$. Enzyme inactivation was obtained after heat treatment $\left(85^{\circ} \mathrm{C}\right)$ for $10 \mathrm{~min}$. The concentration of free amino groups $\left(\mathrm{NH}_{2}\right)$ in digested samples was determined using the $o$-phthaldialdehyde method (OPA $)^{12}$.

Non-digested samples were hydrolysed by the use of $\mathrm{HCl}$ in order to estimate the total content of $\mathrm{NH}_{2}$ groups present in ICC, MDC and BFS. For this, samples were combined with $\mathrm{HCl} 6 \mathrm{M}$ $(5 \mathrm{mg}$ protein $/ \mathrm{mL} \mathrm{HCl})$ and incubated at $110^{\circ} \mathrm{C}$ for $24 \mathrm{~h}^{13}$. Free amino groups were quantified by OPA.

Page $\mid 60$ 


\subsubsection{Calculation of protein degree of hydrolysis}

Degree of Hydrolysis (DH) was estimated by the following equation:

$$
D H(\%)=\frac{\left(N H_{2(D S)}-N H_{2(t=0)}\right)}{N H_{2(\text { Total })}-N H_{2(t=0)}} \times 100
$$

Where:

$\mathrm{NH}_{2}(\mathrm{DS})=$ Free amino groups from digested sample

$\mathrm{NH}_{2}(\mathrm{t}=0)=$ Free amino groups from samples at time 0 of digestion

$\mathrm{NH}_{2}$ (Total) $=$ Maximum amount of $\mathrm{NH}_{2}$ present in sample

\subsubsection{Nitrogen content by Dumas combustion method}

Nitrogen content in samples was determined according to Dumas method using a flash EA 1112 NC analyser (Thermo fisher scientific Inc., Waltman, USA) following the manufacturers protocol. Samples were combusted using helium as a carrier gas. D-methionine was used for constructing the calibration curve and cellulose as a control. Nitrogen content in the sample was converted to protein by the use of 6.25 as conversion factor.

\subsubsection{Protein extraction}

The remainder of protein left in the pellet after digestion was extracted using a modified version of the method described by Aboubacar, et $\mathrm{al}^{14}$. After digestion, samples were centrifuged to separate the pellet from the supernatant. Enzyme inactivation (of both, pellet and supernatant) was performed by the addition of pefabloc ${ }^{\odot}$ until reaching a concentration of $5 \mathrm{mM}$ in the final mixture $^{15}$. Subsequently, pellets were mixed with sodium tetraborate buffer $0.0125 \mathrm{M}$ (pH 10) containing 1\% SDS (w/v) and 2\% 2-mercaptoethanol (v/v). Protein was extracted for $1 \mathrm{~h}$ at room temperature and centrifuged at $7500 \mathrm{~g}$ for $10 \mathrm{~min}$. The extraction was repeated twice using the same conditions. Samples were freeze-dried; protein concentration was estimated by Dumas combustion method. Undigested samples were also included in the analysis as matter of comparison. Prior to protein extraction, ICC samples were subjected to intense mechanic stirring as described in section 3.2.3. to break down cell structure and facilitate protein solubilisation. 


\subsubsection{Sodium dodecyl sulphate polyacrylamide gel electrophoresis (SDS-PAGE)}

SDS-PAGE was performed under non-reducing conditions. A mixture consisting of protein extract $(2 \mu \mathrm{L})$, sample buffer $(5 \mu \mathrm{L})$ and MilliQ water $(15 \mu \mathrm{L})$ was centrifuged at $2000 \mathrm{~g}$ for 2 $\mathrm{min}$ and subsequently heated $\left(70^{\circ} \mathrm{C}\right)$ for $10 \mathrm{~min}$. Protein concentration was adjusted to the same level in all samples $(4 \mathrm{mg} / \mathrm{mL})$. Samples were loaded into each well of a 4-12\% Bis-Tris Gel. Protein ladder $(9-180 \mathrm{kDa})$ was added to a specific well in each gel and used for molecular weight calibration. Electrophoresis was ran at $200 \mathrm{~V}$ in MOPS buffer for approximately $50 \mathrm{~min}$. Subsequently, gels were washed several times with water and stained with Coomassie Blue (R$250)$ followed by destaining in washing buffer $(10 \%$ absolute ethanol and $7.5 \%$ glacial acetic acid). The gels were analysed by Image Lab software ${ }^{\mathrm{TM}}$ (Bio-Rad Laboratories, California, USA).

\subsubsection{Confocal laser scanning microscopy (CLSM)}

ICC microstructure of non-digested, gastric and intestinal digested samples was visualized using a Zeiss 510 inverted microscope (Carl Zeiss microscopy, Oberkochen, Germany). For this, samples were stained with calcoflour white and rhodamine B to highlight the presence of the cell wall and protein matrix respectively. Samples were stained with the amount of dye necessary to achieve a final concentration of $0.005 \%$ rhodamine B and $0.01 \%$ calcoflour white and left overnight to assure complete dye diffusion and homogeneity. Samples were excited using an argon laser at $405 \mathrm{~nm}$ and $543 \mathrm{~nm}$ for calcoflour white and rhodamine B respectively. Images were taken using $20 \times$ (N.A. 0.5) and $40 \times$ (N.A. 1.3 oil immersion) objective lenses. Micrographs were analysed by the use of Zen blue 2.3 edition software (Carl Zeiss microscopy, Oberkochen, Germany).

\subsubsection{Fourier transform infrared (FT-IR) spectroscopy}

Information about protein secondary structure was obtained by using FT-IR. For this, ICC, MDC and BFS were snap frozen in liquid nitrogen immediately after they were prepared and lyophilized. Subsequently, samples were grinded, sieved (mesh size 70 $\mu \mathrm{m}$ ) and stored inside a desiccator until FT-IR analysis was performed. A sample of raw bean flour (RB) was also analysed as a control. Spectra were obtained by measuring samples in the mid-infrared region (4000-350 $\mathrm{cm}^{-1}$ ), at a resolution of $4 \mathrm{~cm}^{-1}$ with 32 scans in a Bruker Tensor 27 (Bruker Optics, Ettlingen, Germany). Data collection was done by OPUS 7.0 software (Bruker Optics, Ettlingen, Germany). The region of interest in this study was $1600-1700 \mathrm{~cm}^{-1}$ (amide I band). 
Data analysis was performed using Origin $1 \mathrm{ab}^{\circledR}$ software (Northampton, MA, USA) and following the procedure of Carbonaro, et $\mathrm{al}^{16}$ with some modifications. In short, Fourier self deconvolution (FSD), second derivative (SD) and Gaussian curve fitting procedures were used for peak separation. FSD and SD were employed for determining peak frequencies. The ratio between the integrated intensity of each Gaussian component with the area of the whole amide I band were used to determine the relative spectral weight of each constituent peak. The maximum number of components found in the deconvoluted spectra was not higher than $\mathrm{N}=7$ in order to avoid correlation between the band constituents. Identification of the spectral ranges for protein secondary structures was done by using previous studies as reference ${ }^{16-18}$. The peak frequency range of the seven bands investigated were: intermolecular aggregates (A1) 1610$1615 \mathrm{~cm}^{-1}$, intermolecular $\beta$-sheet ( $\beta$-I) $1620-1630 \mathrm{~cm}^{-1}, \beta$-sheet $(\beta) 1630-1640 \mathrm{~cm}^{-1}$, random coil (RC) 1640-1648 $\mathrm{cm}^{-1}, \alpha$-helix ( $\alpha$ ) 1648-1658 $\mathrm{cm}^{-1}$, turns in the $\beta$-sheet (T) $1658-1670 \mathrm{~cm}^{-}$ ${ }^{1}$ and intramolecular aggregates (A2) $1670-1695 \mathrm{~cm}^{-1}$.

\subsection{Results and Discussion}

\subsubsection{Starch and protein degree of hydrolysis}

Fig. 3-1a shows the amount of starch hydrolysed during digestion of intact bean cells under standard conditions (all proteases present) and when gastric (NGP), intestinal (NIP) or all proteolytic enzymes (NP) were not incorporated in the simulated digestion experiment. As it can be seen, around $60 \%$ of starch was digested in intact bean cells when all proteases were included, in accordance to what previously reported by us ${ }^{4}$. However, the amount of digested starch was considerably lower when one or more digestive proteases were excluded from the digestion experiment, clearly proving that proteins represent an additional barrier to starch hydrolysis by pancreatic amylase. This was particularly evident in NP conditions where the level of starch hydrolysis represents only $50 \%$ of what obtained for samples that were digested with all proteases. Nevertheless, this $32 \%$ of starch hydrolysis found for NP sample showed that about one third of the starch present in ICC was directly accessible to $\alpha$-amylase despite of the protein matrix intactness. 
a)
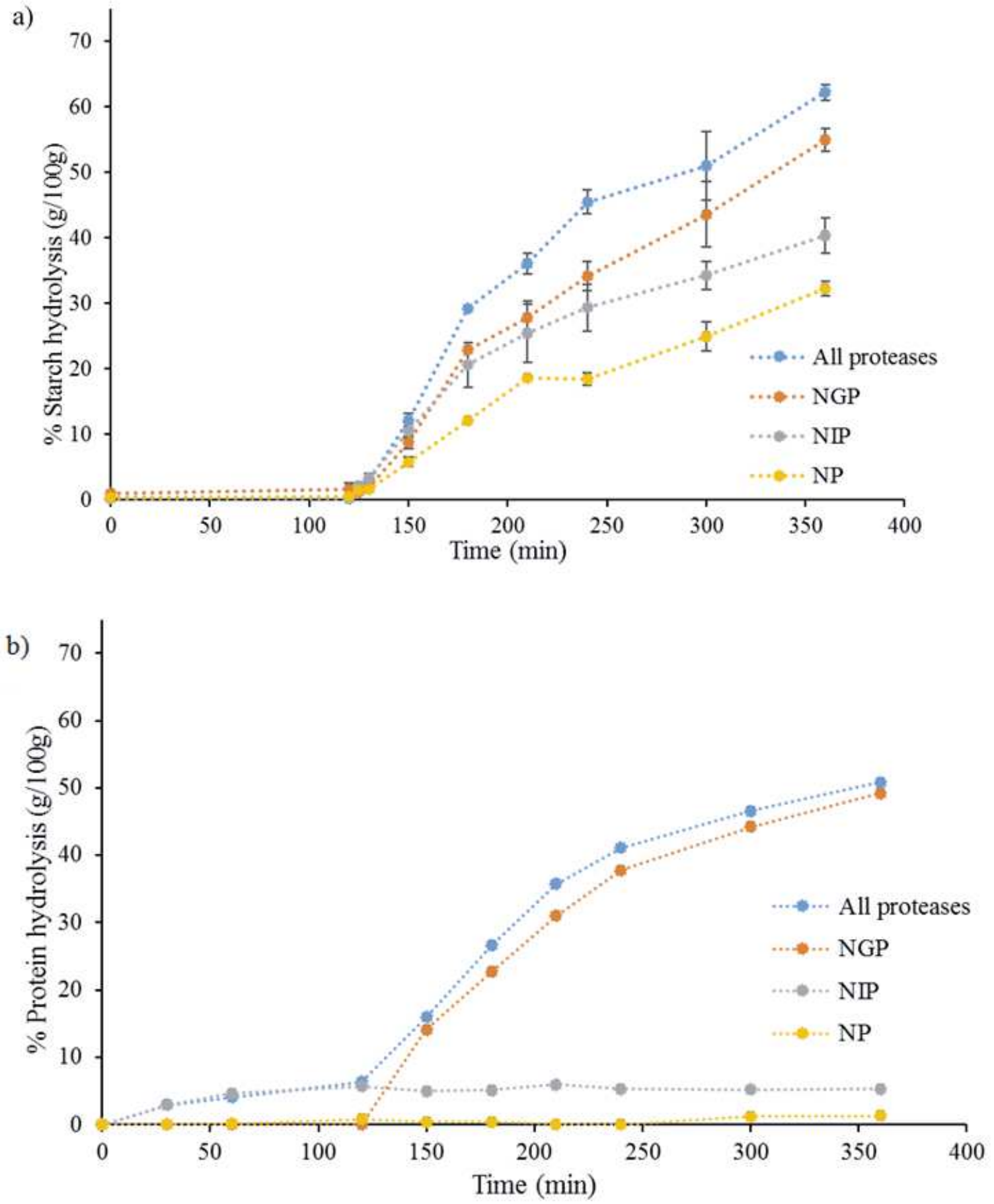

Fig. 3-1. Red kidney bean intact cotyledon cell (ICC) starch (a) and protein (b) hydrolysis as function of time during gastric and intestinal in-vitro digestion. Values are mean \pm SD of three independent samples. Sample with all digestive enzymes were included as a control (All proteases). NP: no proteases, NIP: no intestinal proteases, NGP: no gastric proteases.

When considering the role that gastric and intestinal proteases play in starch digestion, it is evident that the later ones are more efficient since the increment in starch degradation was 3 times larger than with the solely use of pepsin (Fig. 3-1a). These results are related to the effectiveness of enzymes in degrading protein (Fig. 3-1b). Trypsin and chymotrypsin are 
capable of hydrolysing $49 \%$ of protein after 360 min of in-vitro digestion, whereas pepsin only degrades $5 \%$ of the total protein available.

Such differences are possibly due to enzymatic specificity, mode of action and conformational state of proteins. Pepsin is an aspartic protease that has a broad specificity with preference in cleaving peptide bonds between hydrophobic aromatic acids such as phenylalanine, tryptophan and tyrosine ${ }^{19}$. On the contrary, trypsin and chymotrypsin are serine proteases that cleave polypeptide chains at C-terminal basic amino acids (Arginine, Lysine) or large hydrophobic residues (Phenylalanine, Tryptophan, Tyrosine) respectively ${ }^{20,21}$. From a nutritional point of view, red kidney beans (and beans in general) are poor in sulphur containing amino acids and tryptophan but they still have considerable amounts of glutamic and aspartic acid, lysine, leucine, arginine, phenylalanine and methionine ${ }^{22}$. Therefore, the most abundant amino acids present in kidney beans are substrate for trypsin activity making evident why the intestinal phase is more efficient in degrading proteins during in-vitro digestion. In addition, the strong similarities between pepsin and chymotrypsin cleaving sites might explain the lack of an increment in protein degradation when the three proteases are included in the digestion experiment ${ }^{5}$.

Moreover, it is important to mention that our in-vitro digestion protocol only made use of endoproteases for protein digestion cleaving only peptide bonds within the protein molecule ${ }^{23}$. The peptides released during in-vitro digestion were initially quantified by OPA and clear differences were observed between our treatments (data not shown). However, the degree of protein hydrolysis we obtained was in all cases lower than $25 \%$, more than $50 \%$ lower compared to what reported by other authors and unrealistically low compared to the degree of protein hydrolysis achieved in-vivo ${ }^{8}$. Such discrepancy was due to the fact that most of the invitro digestion experiments found in literature used pancreatin during the intestinal phase. The proteases present in pancreatin include enzymes (or their zymogens) such as trypsin, chymotrypsin, elastase and carboxypeptidases, these last ones being exo-peptidases attacking the terminal amino acid (either aromatic, neutral, acidic or basic) of a peptide molecule depending on its specificity $\left(\mathrm{A}_{1}, \mathrm{~A}_{2}, \mathrm{~B}_{1} \text { and } \mathrm{B}_{2}\right)^{24}$ ensuring a complete hydrolysis of dietary proteins. Since OPA method detects the adducts formed by the combination of $\alpha$-amino groups (released during hydrolysis), o-phthaldialdehyde and $\beta$-mercaptoethanol it was clear that the lack of exo-peptidase in our experiments was underestimating the actual degree of protein hydrolysis obtained with trypsin and chymotrypsin. 
A new set of experiments was designed in order to include an exo-peptidase that allowed us to obtain comparable values for protein hydrolysis (Fig. 3-1b). In our study we used Flavouryzme $^{\circledR}$, an enzyme preparation derived from Aspergillus oryzae that is commonly used for industrial and research applications. Merz, et $\mathrm{al}^{25}$ characterized the enzymatic mixture and identified eight enzymes from which two were aminopeptidases. As could be seen in section 3.2.9, Flavourzyme ${ }^{\circledR}$ incubation was performed upon the digests supernatant in order to achieve a complete conversion of the peptides generated by pancreatic proteases into amino acids. We decided to apply this extra exo-peptidase step on the supernatants rather than incorporating the exo-peptides during the digestion experiment to avoid further protein degradation by other enzymes present in the cocktail. Preliminary trials were carried out to standardize the experimental protocol and rule out the possibility that free amino groups deriving from flavourzyme autolysis could give rise to higher and incorrect digestibility values (data not shown). It is important to mention that the incorporation of this extra incubation step did not change the relative difference nor the trend in the degree of protein hydrolysis that we initially obtained between the treatments used in in this study.

The kinetics of protein digestion obtained in our investigation are in line to those described by Montoya, et $\mathrm{al}^{26}$ using beans that differed in their phaseolin type. In none of the cases, the digestibility values found by these authors was higher than $61 \%$ after $240 \mathrm{~min}$ of in-vitro digestion. Similar results were observed by Zia-ur, et $\mathrm{al}^{27}$ when digesting samples from red kidney beans. However, other studies in which protein digestibility exceeded $80 \%$ were also found. It is likely that the nature of this discrepancy relies in the different sample microstructure utilized during those studies, given that they employed bean flour ${ }^{28}$ and sometimes even protein fractions for their digestibility experiments ${ }^{29}$.

Fig. 3-1a highlights the major role that protein plays in delaying the degradation of starch. This could be well exemplified by the results obtained when pepsin was used as the only proteolytic enzyme. As discussed earlier, only 5\% of proteins were degraded due to the action of gastric protease, however, this seemingly small proportion of protein hydrolysed produced a $20 \%$ increment in the amount of starch digested after $360 \mathrm{~min}$ of the in-vitro experiment. This evidence suggests that the physiological relevance of pepsin is more to facilitate starch degradation than to initiate the digestion of proteins that can be done very efficiently by intestinal proteases. 
The cytoplasmic matrix consists of a compact structure made of protein bodies and starch granules that may hinder the access of digestive enzymes to their corresponding substrates. From the above data, it was clear that the presence of proteins restrained starch digestibility. However, it remained unclear if the digestion of proteins was somehow affected by the presence of starch. Hence, an in-vitro digestion experiment was conducted without the addition of $\alpha$ amylase. No differences were found in protein kinetic profile between samples digested with and without the addition of alpha amylase (Fig. 3A-1). These results indicate that the access of digestive proteases to the protein bodies is not hindered by the presence of starch.

Previous studies have investigated how the presence of protein interferes in the digestibility of $\operatorname{starch}^{30,31}$ and, in most of the cases, the interactions between both macronutrients mutually affects their digestibility. For instance, Wong, et $\mathrm{al}^{32}$ showed that protein-starch interactions in sorghum influence the digestibility of both nutrients. The abundance of disulphide bonds and protein bodies tightly associated with starch was assumed to cause low digestibility. In kidney beans, this is less probable due to the lower amount of sulphur amino acid content, possibly leading to a less compact cytoplasmic structure and higher surface area in contact with proteases. Contrary to what described by other authors, in this study, the interactions between protein and starch (as consequence of molecular confinement within the cytoplasm) does not affect both macromolecules digestion in the same way. Thus, it could be inferred that for kidney beans, the microstructural organization of starch granules and protein bodies within the cytoplasmic matrix is one of the main factors that aids in the delay of starch hydrolysis. We believe that protein bodies might form a sort of protective layer appearing as an extra encapsulation system for starch granules. As consequence, when the physical entrapment formed by proteins was compromised by the use of proteases, the kinetics of starch hydrolysis changed among the treatments. This could be explained by the fact that the diffusion of amylase was facilitated when the protein matrix was partially degraded giving as consequence a change in the reaction kinetics. However, an active binding of amylase to bean proteins could not be ruled out as an additional factor that might contribute in the delay of starch digestion as indicated by $\mathrm{Yu}$, et $\mathrm{al}^{33}$ on barley proteins. Furthermore, it is worth noticing that the kinetic curves for starch digestion depicted in Fig. 3-1 do not reach a plateau value despite of the extensive hydrolysis treatment they were exposed to. In our previous work ${ }^{4}$, we have shown that around $30 \%$ of the starch present in ICC is resistant to hydrolysis. This indicates that in NGP, NIP and NP there is still a portion of starch that could be utilized by alpha amylase but its hydrolysis is delayed due to the presence of the protein matrix. The observed dissimilarities 


\section{Chapter 3}

in digestion kinetics mostly reflect differences in the rate of digestion rather than the formation of starch fractions resistant to digestion ${ }^{34}$.

CLSM was employed to visualize ICC microstructure before, during and after in-vitro digestion. The micrographs, reported in Fig. 3-2, clearly show the structural organization of ICC components due to the staining of the cell wall (light blue) and the protein matrix (red). Starch granules were left unstained but their presence could still be distinguished as black spots embedded inside the protein network. As can be seen in Fig. 3-2, no large differences could be identified between undigested (micrographs 3-2 a, d) and gastric digested samples (micrographs $\mathrm{b}, \mathrm{e})$. In both cases, the protein matrix that surrounds starch granules remains largely unchanged. This goes in line with the low protein digestibility values obtained after gastric digestion as explained earlier. However, when comparing the microstructure of ICC after gastro-intestinal digestion, it was not surprising to observe large changes in the protein matrix that showed a decrease in colour intensity and a reduction in the area stained in red (micrograph 3-2 $\mathrm{f}$ ), suggesting that the protein network has shrunken. In general, a less dense cytoplasmic matrix could be appreciated due to the increasing amounts of dark spots that it contained. An empty space formed between the cell wall and the protein network (not identified in undigested samples) could be observed. The changes in ICC microstructure showed by CLSM are in agreement with the extent of protein hydrolysis found at the different stages of in-vitro digestion and discussed previously. We consider both as complementary information that contributes toward the understanding of how proteins (and starch) are hydrolysed. 

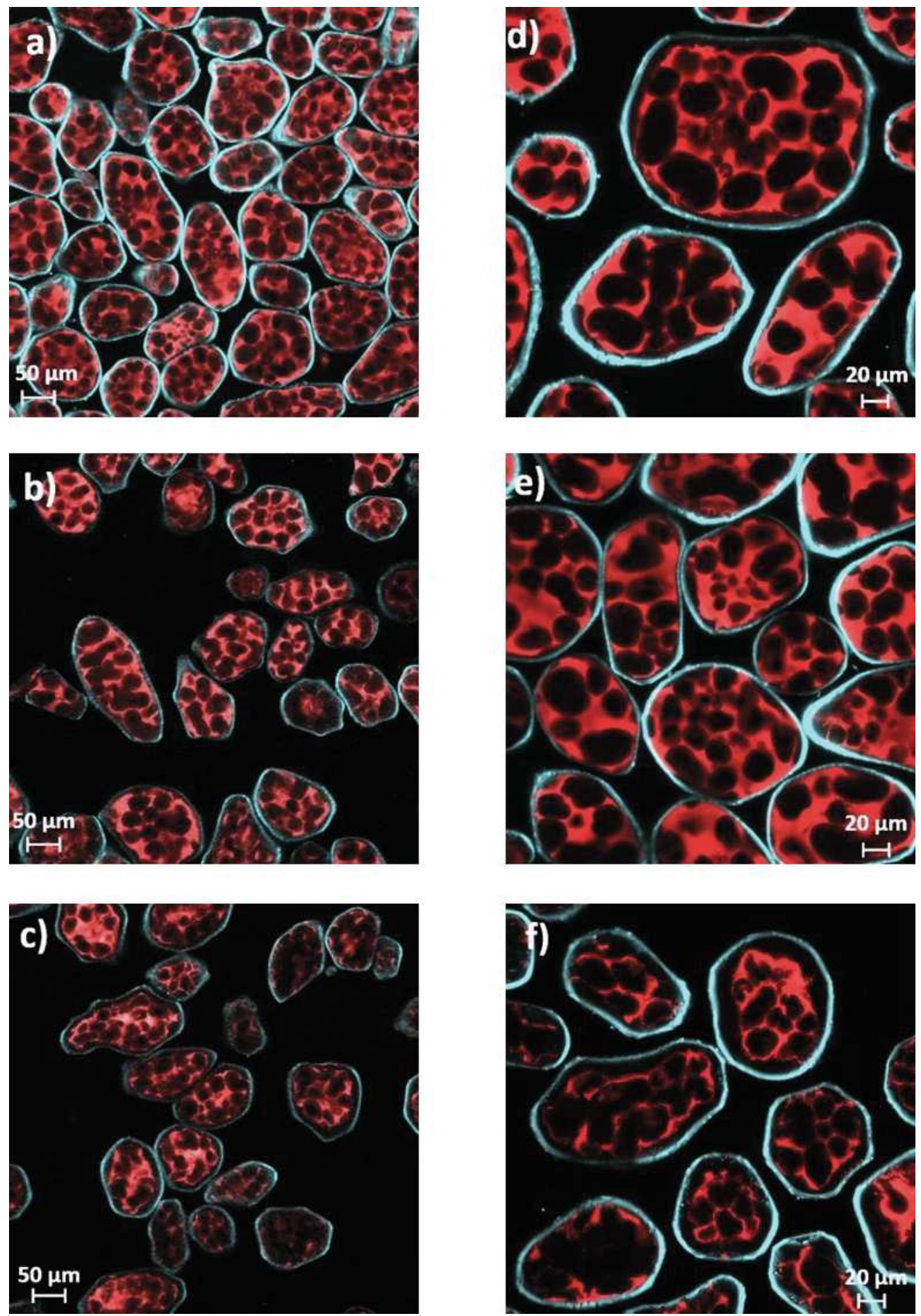

Fig. 3-2. CLSM images of undigested ICC (a, d), after $2 \mathrm{~h}$ of gastric digestion (b, e) and at the end of gastrointestinal in-vitro digestion (c, f). Protein bodies were stained in red and cell walls in light blue. Micrographs a, b and $\mathrm{c}$ were taken using 20x objective lens while $\mathrm{d}$, e, and $\mathrm{f} 40 \mathrm{x}$.

In addition, it is important to mention that CLSM micrographs demonstrate, once again, that cotyledon cells retained their integrity during in-vitro digestion, since no loss of intracellular material was evident, and no visible changes could be identified in the cell walls of ICC.

As demonstrated before, the protein matrix is one of the factors that modulates the rate of starch hydrolysis. However, it is very difficult to discriminate between its net contribution and the one 
provided by the barrier effect of the cell walls. In an attempt to differentiate between these two variables, ICC was incubated with proteases for $20 \mathrm{~h}$ prior the incorporation of $\alpha$-amylase. The objective of this pre-treatment was to hydrolyse completely the protein matrix in order to study the digestion kinetics of starch granules encapsulated within intact cells but without the protective protein layer. When $\alpha$-amylase was incorporated (Fig. 3-3a), the rate of starch digestion in proteases pre-treated ICC was higher in the first minutes compared to control ICC and eventually levelled up until reaching $60 \%$ of hydrolysis (as described in standard digestion conditions). The increment observed in the rate of starch hydrolysis at the initial stages of digestion demonstrate the barrier effect exerted by the protein layers on starch digestion. A quantitative assessment of its net effect compared to that exerted by the cell wall was not possible due to an incomplete digestion of proteins in our samples despite of the extensive proteolytic treatment. The amount of protein hydrolysed after $20 \mathrm{~h}$ was quantified and only $50 \%$ of protein was digested. These results are comparable to those previously obtained using standard digestion conditions ( $6 \mathrm{~h}$ incubation) indicating that only a marginal increase in the degree of protein hydrolysis was achieved upon additional incubation of ICC with proteolytic enzymes. 
a)

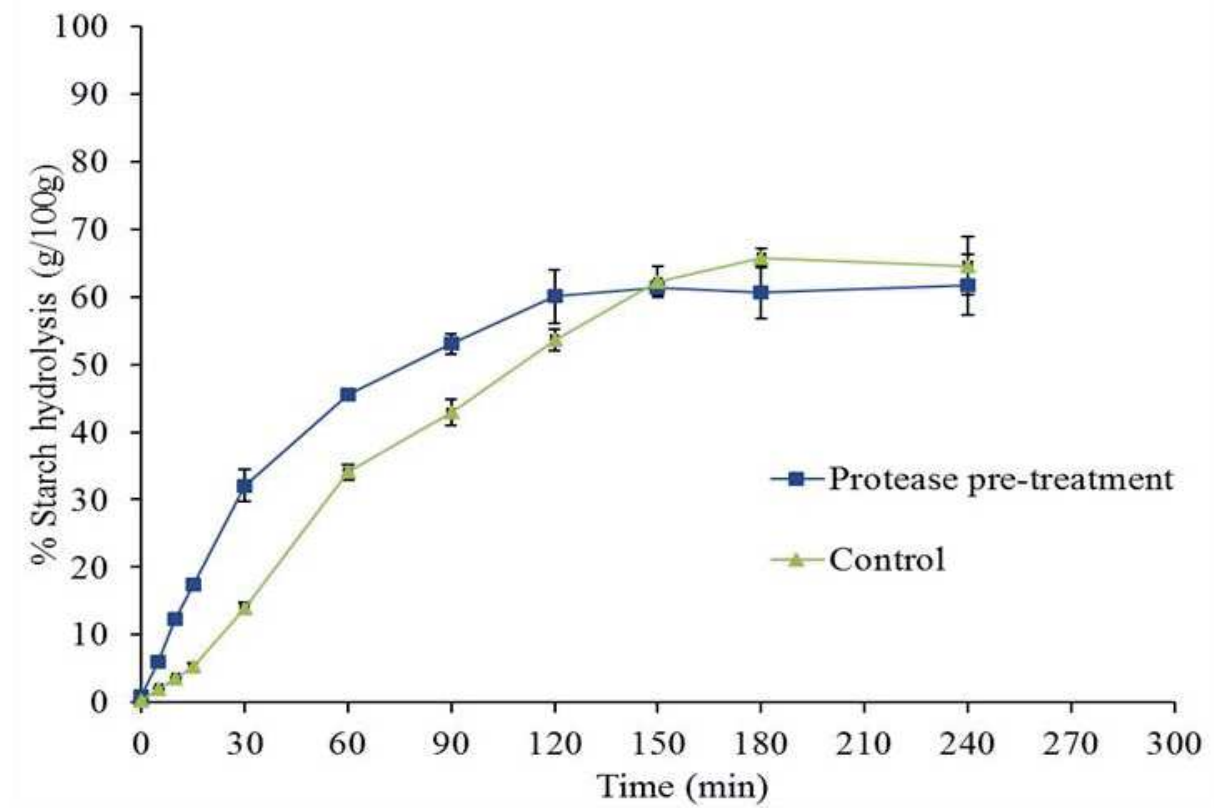

b)
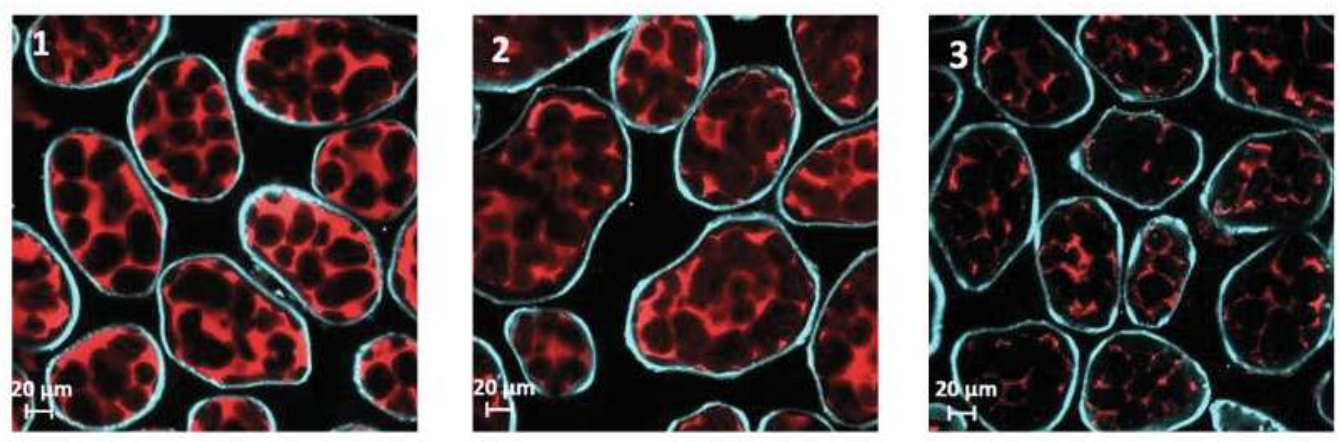

Fig. 3-3. a) Kinetics of starch hydrolysis during in-vitro intestinal digestion of red kidney beans ICC after $20 \mathrm{~h}$ of protease incubation (protease pre-treated). First time point (time zero) was taken immediately after the addition of $\alpha$-amylase into the sample mixture. Error bars denote standard deviation of three independent samples. Red kidney beans ICC without protease pre-treatment were included as a control. b) CLSM of non-digested ICC (1), protease pre-treated ICC (2) and protease pre-treated ICC samples after digestion with $\alpha$-amylase for $6 \mathrm{~h}$ (3). Micrographs were taken using 40x objective lens, red colour highlights the presence of protein bodies while light blue that of the cell wall.

CLSM micrographs taken after protease pre-treatment (Fig. 3-3b) resemble those shown previously and further confirm the incomplete protein hydrolysis after $20 \mathrm{~h}$ digestion. Overall, it is clear that the incomplete hydrolysis found for proteins is not related to an insufficient time for proteolytic activity. There seems to be other factors involved that contribute into the resistance of proteins towards digestion, which were investigated and discussed in the next sections.

\subsubsection{Influence of cell intactness on protein hydrolysis}

Cotyledon cells intactness have a great influence on the rate of starch digestion ${ }^{4}$, but its effect on protein degradation has rarely been addressed ${ }^{35}$. Fig. 3-4 compares the protein hydrolysis 
kinetics of intact cotyledon cells (ICC), mechanically damaged cells (MDC) and bean flour solution (BFS) along 360 min of in-vitro digestion. When comparing ICC with MDC, an increase in the rate of hydrolysis could be observed for MDC especially in the gastric phase (the amount of protein hydrolysed is more than twice of what obtained for ICC). However, as digestion proceeds, the amount of protein hydrolysed eventually levels up reaching around 50\% of digestion at the end of the experiment in both cases. This behaviour resembles what we previously described for starch digestibility and highlights the importance of the cell wall and cytoplasmic compactness in limiting the accessibility of enzymes to their substrates.

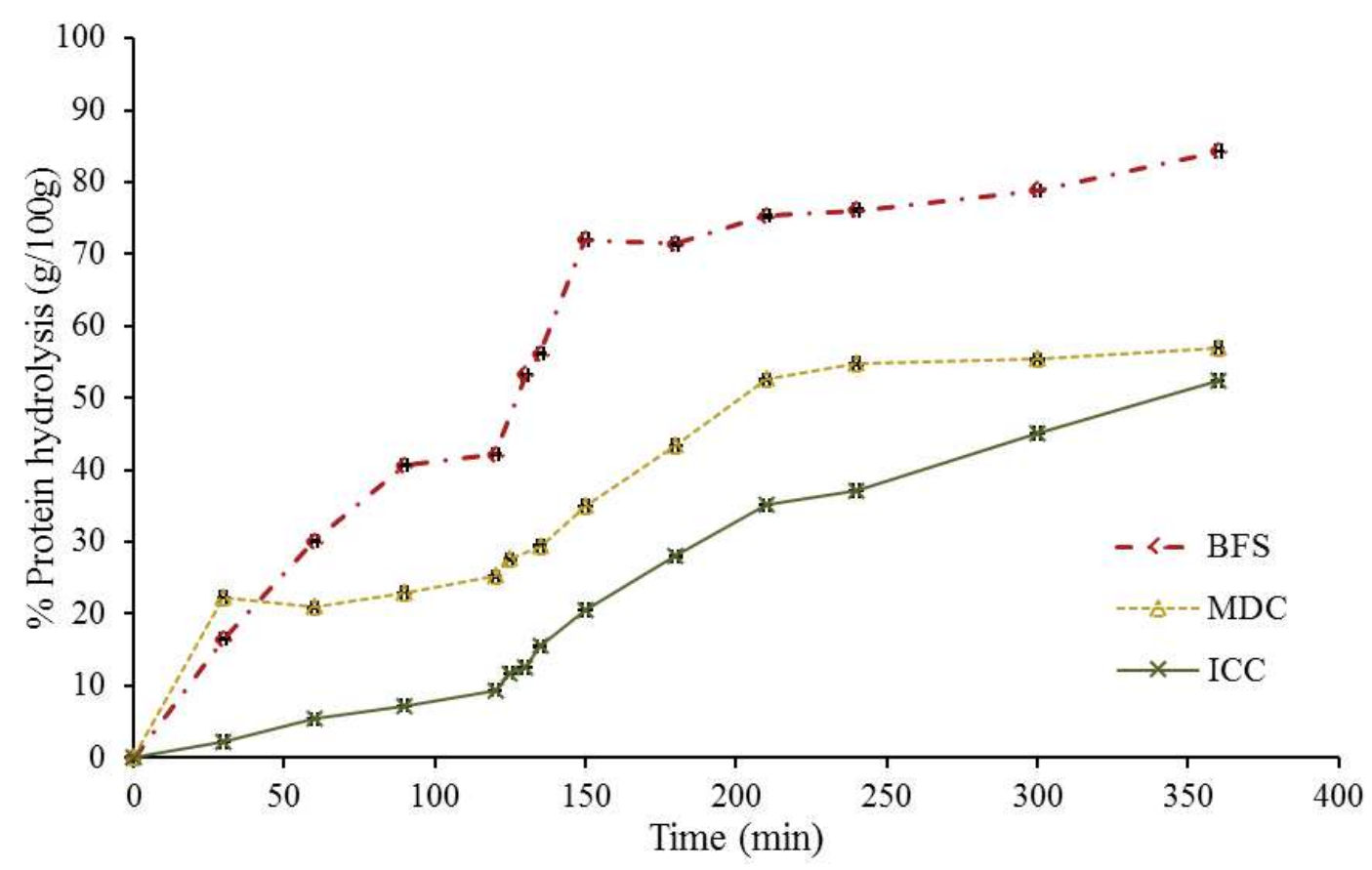

Fig. 3-4. Kinetics of protein hydrolysis from red kidney bean intact cotyledon cells (ICC), mechanically damaged cells (MDC) and bean flour solution (BFS). First 120 min represent gastric phase, the subsequent time points correspond to intestinal digestion. Error bars denote standard deviation of three independent samples.

Striking differences were found when comparing the behaviour of BFS with MDC. This was unexpected because of the negligible barrier effect of the cell wall and the comparable accessibility of digestive enzymes to bean proteins in both samples. However, BFS degree of hydrolysis $(80 \%)$ was always higher to that found for MDC (56\%) throughout the whole invitro experiment. Therefore, we believe that besides the physical constraints provided by ICC there are other factors that might play a role in limiting protein digestibility. The origin of such discrepancy might have taken place during sample preparation (sections 3.2.3, 3.2.4). For MDC, beans were cooked prior the isolation and mechanical damage of the cotyledon cells; while in BFS beans were first milled and then cooked. Therefore, the level of protein denaturation between these samples might not be the same. The molecular confinement within 
a tightly packed cytoplasm and the cell wall presence could have limited proteins water uptake and unfolding resulting in an incomplete denaturation when proteins are heated when still entrapped within the cells. This was not the case for BFS since proteins were free of any physical boundary, solubilized into the medium and directly exposed to heat during cooking. Hence, these results may indicate that cell intactness is not only important during digestion by acting as a physical barrier between proteases and proteins, but it might also influence the effect of thermal treatments on protein structure.

This might be of particular importance for proteins present in the samples used in this study. Phaseolin, the main protein fraction in kidney beans, is known to be resistant to hydrolysis in raw conditions ${ }^{36}$. We believe that the tight packing inside ICC limits the degree of protein denaturation affecting its digestibility. This structural constraint might also have an impact in the extent of starch gelatinization and indeed, it has been suggested that molecular confinement (as experienced in the cytoplasmic environment of an intact legume cell) can change the gelatinization behaviour of starch by limiting water absorption and degree of swelling ${ }^{37}$. In our previous study ${ }^{4}$, we determined that structural differences in ICC produced changes in starch digestibility rate but not in the extent at which starch was digested. Such behaviour could not be identified in the case of proteins, since large differences in the extent of digestion were found in samples with different structural characteristics. All together, this evidence indicates that the physical entrapment represents a large constraint for proteins digestibility associated to the stability of its molecular conformation.

\subsubsection{Protein size distribution and secondary structure}

Fig. 3-5 shows the SDS-page protein profile of the supernatant (left) and pellet (right) from BFS, MDC and ICC. Bands between 41-53 kDa indicate the presence of phaseolin in nondigested (ND) samples of both the pellet and supernatant fractions. MDC and ICC shared the same non-digested sample since prior conducting SDS-page experiment, cotyledon cells were broken to loosen all the protein they contained. Therefore, ND was included only once in the gel (Lane 5 in both gels). Large molecular weight proteins could be observed in all ND samples being more evident the ones in BFS of the supernatant fraction. Those protein fragments belong to the aggregates formed as consequence of protein denaturation. When looking at the protein profile of all digested samples supernatant, bands at approximately 14, 22 and $35 \mathrm{kDa}$ were identified. The former one represents the smallest polypeptide size that could be obtained after the degradation of phaseolin by digestive (proteolytic) enzymes ${ }^{7}$. While $22 \mathrm{kDa}$ could make 
reference to degradation products that are the characteristic fingerprint of an incomplete digestion of phaseolin as it occurred in experiments conducted using this raw globulin ${ }^{5}$. Furthermore, it is also possible that these fragments are the product of partially digested aggregates formed after heat treatment as they were also observed when a non-fully denatured phaseolin was digested ${ }^{36}$. The bands appearing at around $35 \mathrm{kDa}$ might belong to pepsin since this molecular weight was stated as the size of the enzyme in the manufacturer's product information sheet and they are visible in the gastric phase of all the digested samples. In addition, a band at $53 \mathrm{kDa}$ was visible only for ICC and to a lesser extent in MDC, possibly belonging to phaseolin. As mentioned earlier, phaseolin structure consists of three subunits that are similar in their backbone conformation and sequence homology. However, Montoya, et $\mathrm{al}^{26}$ observed that the subunit with molecular weight of $53 \mathrm{kDa}$ ( $\alpha$-phaseolin) was less susceptible to trypsin hydrolysis. This was attributed to differences in thermal stability, surface hydrophobicity, solubility and heat induced associations among the subunit. On the other hand, it has also been shown that phaseolin susceptibility to hydrolysis increases with heat treatment $^{26,38}$ probably due to structural changes and higher accessibility to proteolytic enzymes. Such effect could be clearly observed in BFS since its high digestibility and the absence of $\alpha$-phaseolin band indicates that the heat treatment applied was more efficient in denaturing the protein present in kidney beans.
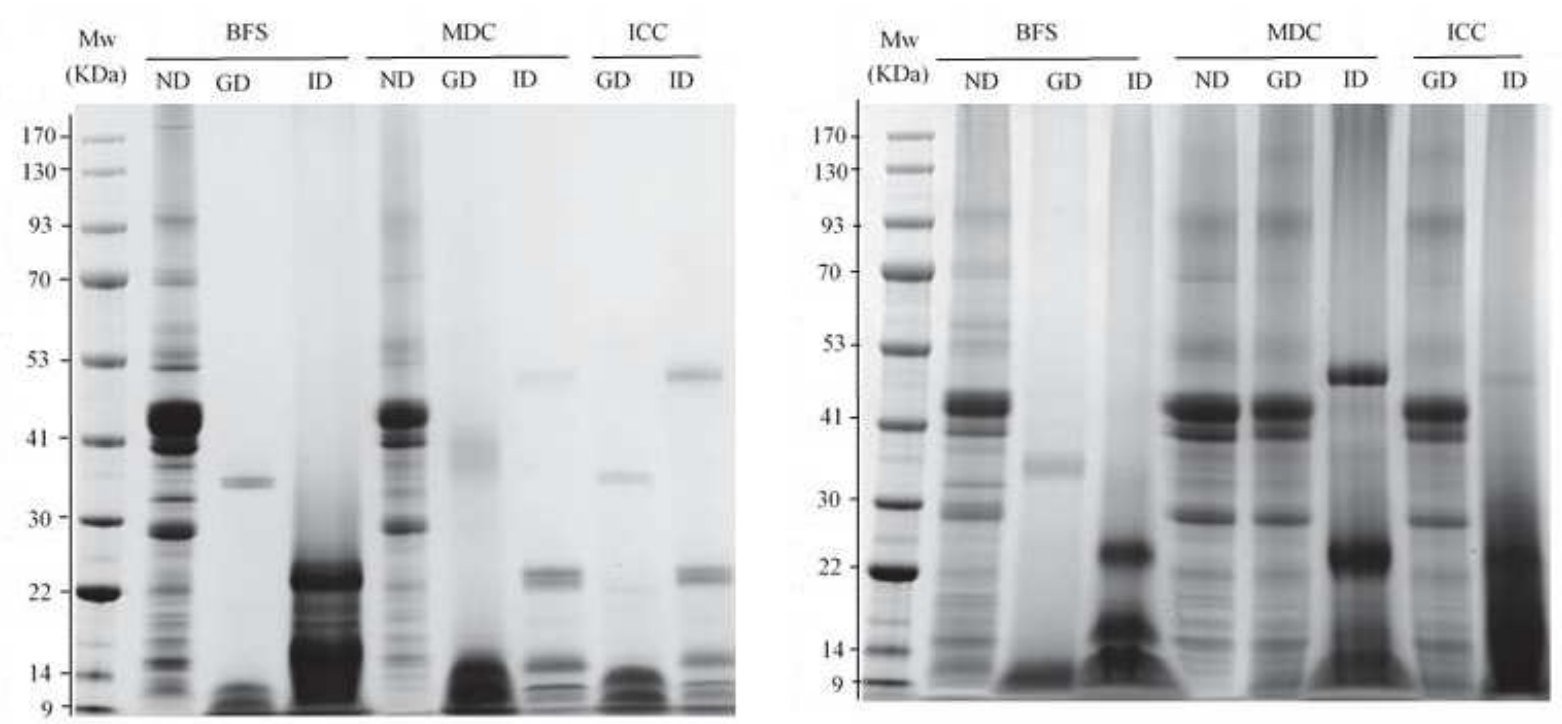

Fig. 3-5. SDS-page protein profile of the supernatant (left panel) and pellet (right panel) from BFS, MDC and ICC before digestion (ND), after $2 \mathrm{~h}$ of gastric digestion (GD) and $6 \mathrm{~h}$ of gastro-intestinal digestion (ID). Molecular weight markers $(\mathrm{Mw})$ are present in lane 1 of each gels.

Regarding the proteins left in the pellet (Fig. 3-5 right panel), it is evident that for MDC and ICC no differences could be distinguished between ND and gastric digested samples, 
confirming the results previously discussed about pepsin digestibility. Carbonaro, et al ${ }^{39}$ performed an in-vivo study using rats and found high amounts of undigested protein remaining in the stomach content of the rodents after feeding them raw common bean globulins. The absence of phaseolin band in BFS after gastric digestion demonstrates that the treatment applied facilitated the utilization of proteins by the digestive enzymes. As for the intestinal phase, the only band remaining (from phaseolin) was that of $53 \mathrm{kDa}$ in MDC and ICC as found in the supernatant. Smaller polypeptides ( 22 and $\leq 14 \mathrm{kDa})$ were also visible in the pellet of the three treatments indicating proteolytic activity of the enzymes during digestion.

FT-IR was conducted on undigested BFS, MDC and ICC to determine the changes in amide I spectra as consequence of the treatments applied (Fig. 3-6). In general, legume proteins structure is characterized by a high content of $\beta$-sheet conformation and a relatively low amount of $\alpha$-helix as could be seen in the spectra belonging to raw bean (RB) sample. The relative spectral weights $(\mathrm{Wi})$ of RB deconvoluted spectra are in agreement with what Carbonaro, et al ${ }^{16}$ described with $\beta$-sheet $(0.50)$ as the main component from amide I band, followed by $\alpha$-helix (0.15) and in minor extent intramolecular aggregates (0.19), turn conformations (0.09) and intermolecular aggregates (0.07). Heat treatment, as expected, changed the ratio between amide I components, where BFS showed the most notable differences compared to RB. In the former, the disappearance of $\alpha$-helix and the formation of RC structures were the most notable modifications. $\mathrm{RC}$ has been related to an increment in digestibility due to its unstructured nature typical of denatured proteins ${ }^{17}$. This peak was also found in MDC and ICC but in a minor extent since the spectral weight of BFS was twice the size than the one present in the aforementioned samples.

Carbonaro, et $\mathrm{al}^{16}$ also showed that protein digestibility did not involve those regions in which amino acids were arranged in $\beta$-sheet structures showing a negative correlation between the concentration of these structures and food digestibility values. Due to the heat treatment applied, no $\beta$-sheet peak could be identified in BFS, MDC and ICC but $\beta$-I band was detected instead. This peak (formed upon the disappearance of $\beta$-sheet) has been found to provide even more resistance to proteolysis than $\beta$-sheet itself due to protein aggregation with a very stable conformation. The concentration of $\beta$-I band in MDC and ICC was higher than that found for BFS $(0.28,0.37$, and 0.17 respectively). Those structural differences contribute in the understanding of the limited protein digestibility found in MDC and ICC compared to that of BFS. The remainder peaks that constitute amide I band had no remarkable differences among the samples and no direct correlation has been described between them and protein digestibility. 

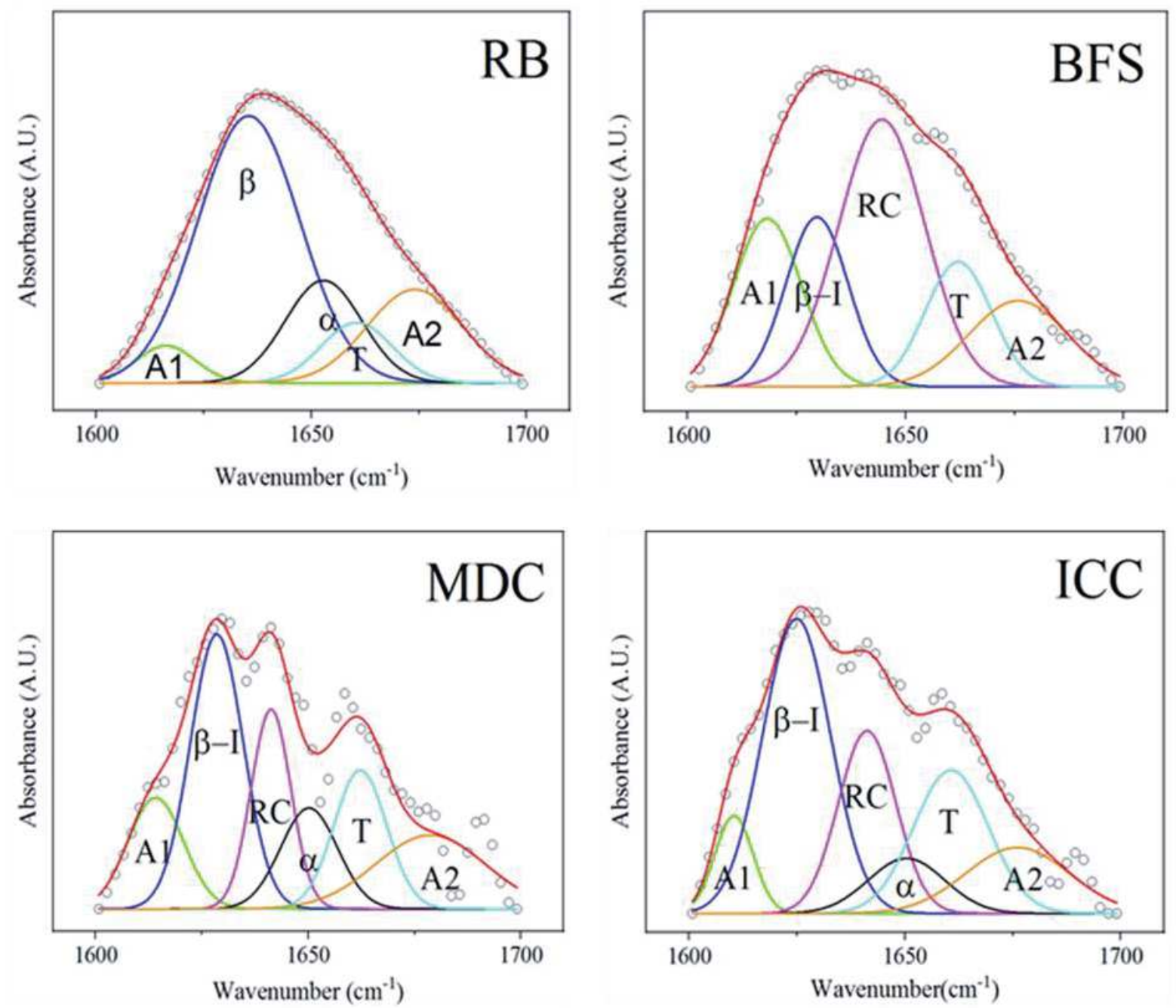

Fig. 3-6. Amide I band and its spectra deconvolution with Gaussian contribution of RB, BFS, MDC and ICC. A1: intermolecular aggregates, $\beta$ : beta-sheet, $\beta$-I: intermolecular beta-sheet, RC: random coil, $\alpha$ : alpha-helix, T: turn conformations, A2: intramolecular aggregates.

The results presented by FT-IR provide important insights in the role that intact cells molecular confinement has for protein denaturation. In fact, the large resemblance between the peak constituents of MDC and ICC demonstrate that the presence of the cell wall during cooking is determinant in the conformational organization of proteins, given that cell wall breakage after heat treatment has no large impact in the distribution of amide I constituents. The data presented in Fig. 3-6 provides evidence that changes in protein structure upon thermal treatments depend on the environment that surrounds proteins, i.e. food microstructure. Even though it has already been reported that protein stability to denaturation increases under conditions of molecular crowding or confinement ${ }^{40}$, this study demonstrates for the first time the indirect effect that this differential response to thermal treatment has on protein digestibility. What is more, results presented here may also explain some apparent inconsistencies among previous studies. Studies have been done where different heat treatment processes were investigated, and in some 
cases, it has been observed a higher resistance to digestion in samples after more intense thermal treatments. Unfortunately, for these experiments sample preparation has been disregarded and comparisons have been made between samples with different structural characteristics. There is evidence showing that cotyledon cells in beans are highly resistant to harsh treatments such as autoclaving. Berg, et $\mathrm{al}^{41}$ demonstrated that autoclaving navy beans at $121^{\circ} \mathrm{C}$ for $15 \mathrm{~min}$ did not damage the cotyledon cell structure or its ability to delay starch digestion. In our study, we have observed that cell wall disruption after heat treatment has negligible impact in the conformational organization of protein secondary structure. The evidence presented in this investigation highlights the importance of sample preparation and the pivotal role of food structure.

\subsection{Conclusion}

The present study demonstrate the influence of cellular entrapment in the digestibility of proteins in-vitro. Limited protein digestibility was observed for samples with intact cellular structures. Our findings indicate that the impact of intact cell encapsulation goes beyond its barrier function that limits the contact of digestive enzymes with its substrate. Cellular confinement also plays an important role during sample preparation and it determines the extent at which molecules are affected by processing treatments. In addition, it was demonstrated that protein digestion has a direct impact in the way that starch is hydrolysed: an incomplete protein degradation results in less starch being utilized in the intestinal phase during digestion.

The results presented in this study contributed to unravel the importance of food structure during processing and on the extent of macronutrient digestion. By understanding the way in which the building blocks that constitute a food matrix interact, it is possible to modulate the rate and extent at which those products become available to the human body.

\subsection{Acknowledgments}

We thank Wensi Song and Erik Meulenbroeks for their contribution in performing part of the experimental work for this study.

This research was supported by a grant from the Ecuadorian Secretary of Higher Education, Science, Technology and Innovation. 


\section{References}

1. Anderson JW, Smith BM, Washnock CS. Cardiovascular and renal benefits of dry bean and soybean intake. Am J Clin Nutr. 1999;70(3):464-474.

2. Williams PG, Grafenauer SJ, O'Shea JE. Cereal grains, legumes, and weight management: A comprehensive review of the scientific evidence. Nutr Rev. 2008;66(4):171-182.

3. Edwards CH, Warren FJ, Campbell GM, et al. A study of starch gelatinisation behaviour in hydrothermally-processed plant food tissues and implications for in vitro digestibility. Food Funct. 2015;6(12):3634-3641.

4. Rovalino-Córdova AM, Fogliano V, Capuano E. A closer look to cell structural barriers affecting starch digestibility in beans. Carbohydr Polym. 2018;181:994-1002.

5. Jivotovskaya A V., Senyuk VI, Rotari VI, Horstmann C, Vaintraub IA. Proteolysis of Phaseolin in Relation to Its Structure. J Agric Food Chem. 1996;44(12):3768-3772.

6. Montoya CA, Gomez AS, Lallès JP, Souffrant WB, Beebe S, Leterme P. In vitro and in vivo protein hydrolysis of beans (Phaseolus vulgaris) genetically modified to express different phaseolin types. Food Chem. 2008;106(3):1225-1233.

7. Deshphande SS, Nielsen SS. In vitro enzymatic hydrolysis of phaseolin, the major storage protein of Phaseolus vulgaris L. J Food Sci. 1987;52(5):1326-1329.

8. Liener IE, Thompson RM. In vitro and in vivo studies on the digestibility of the major storage protein of the navy bean ( Phaseolus vulgaris )*. Plant foods Hum Nutr. 1980;30:13-25.

9. Zou W, Sissons M, Warren FJ, Gidley MJ, Gilbert RG. Compact structure and proteins of pasta retard in vitro digestive evolution of branched starch molecular structure. Carbohydr Polym. 2016;152:441-449.

10. Chávez-Murillo CE, Veyna-Torres JI, Cavazos-Tamez LM, de la Rosa-Millán J, SernaSaldívar SO. Physicochemical characteristics, ATR-FTIR molecular interactions and in vitro starch and protein digestion of thermally-treated whole pulse flours. Food Res Int. 2018;105:371-383.

11. Clemente A, Vioque J, Sánchez-Vioque R, Pedroche J, Bautista J, Millán F. Protein quality of chickpea (Cicer arietinum L.) protein hydrolysates. Food Chem. 1999;67(3):269-274.

12. Nielsen PM, Petersen D, Dambmann C. Improved Method for Determining Food Protein Degree of Hydrolysis. J Food Sci. 2001;66(5):642-646.

13. Torres J, Rutherfurd SM, Muñoz LS, Peters M, Montoya CA. The impact of heating and soaking on the in vitro enzymatic hydrolysis of protein varies in different species of tropical legumes. Food Chem. 2016;194:377-382.

14. Aboubacar A, Axtell JD, Huang CP, Hamaker BR. A rapid protein digestibility assay for identifying highly digestible sorghum lines. Cereal Chem. 2001;78(2):160-165.

15. Egger L, Ménard O, Delgado-Andrade $\mathrm{C}$, et al. The harmonized INFOGEST in vitro digestion method: From knowledge to action. Food Res Int. 2016;88:217-225. 
16. Carbonaro M, Maselli P, Nucara A. Relationship between digestibility and secondary structure of raw and thermally treated legume proteins: A Fourier transform infrared (FT-IR) spectroscopic study. Amino Acids. 2012;43(2):911-921.

17. Carbonaro M, Maselli P, Dore P, Nucara A. Application of Fourier transform infrared spectroscopy to legume seed flour analysis. Food Chem. 2008;108(1):361-368.

18. Meng G, Ma CY, Phillips DL. Raman spectroscopic study of globulin from Phaseolus angularis (red bean). Food Chem. 2003;81(3):411-420.

19. Bradley, S.G., Antalis, T.M., Bond JS. Proteases in the mammalian digestive system. In: Brix, K., Stocker W, ed. Proteases: Structure and Function. New York: Springer; 2013:373-394.

20. Di Cera E. Serine proteases. IUBMB Life. 2009;61(5):510-515.

21. Hornbuckle WE, Tennant BC. Gastrointestinal function. In: Kaneko, J.J., Bruss, M.L., Harvey JW, ed. Clinical Biochemistry of Domestic Animals. 5th edtion. San Diego: Academic Press; 1997:367-406.

22. Pusztai A, Clarke EMW, King TP, Stewart JC. Nutritional evaluation of kidney beans (phaseolus vulgaris): Chemical composition, lectin content and nutritional value of selected cultivars. J Sci Food Agric. 1979;30(9):843-848.

23. Philipps-Wiemann P. Proteases — general aspects. In: Simoes N, Kumar V, eds. Enzymes in Human and Animal Nutrition. London: Academic Press; 2018:257-266.

24. Whitcomb DC, Lowe ME. Human pancreatic digestive enzymes. Dig Dis Sci. 2007;52(1):1-17.

25. Merz M, Eisele T, Berends P, et al. Flavourzyme, an Enzyme Preparation with Industrial Relevance: Automated Nine-Step Purification and Partial Characterization of Eight Enzymes. $J$ Agric Food Chem. 2015;63(23):5682-5693.

26. Montoya CA, Leterme P, Victoria NF, et al. Susceptibility of phaseolin to in vitro proteolysis is highly variable across common bean varieties (Phaseolus vulgaris). $J$ Agric Food Chem. 2008;56(6):2183-2191.

27. Zia-ur-Rehman, Salariya AM. The effects of hydrothermal processing on antinutrients, protein and starch digestibility of food legumes. Int J Food Sci Technol. 2005;40(7):695-700.

28. Alonso R, Aguirre A, Marzo F. Effects of extrusion and traditional processing methods on antinutrients and in vitro digestibility of protein and starch in faba and kidney beans. Food Chem. 2000;68(2):159-165.

29. Rubio LA, Grant G, Caballé C, A. M-A, Pusztai A. High in-Vivo (Rat) Digestibility of Faba Bean (Vicia-Faba), Lupin (Lupinus-Angustifolius) and Soya Bean (Glycine-Max) Soluble Globulins. J Sci Food Agric. 1994;66(3):289-292.

30. Singh J, Dartois A, Kaur L. Starch digestibility in food matrix: a review. Trends Food Sci Technol. 2010;21(4):168-180.

31. Kim EHJ, Petrie JR, Motoi L, et al. Effect of structural and physicochemical characteristics of the protein matrix in pasta on in vitro starch digestibility. Food Biophys. 2008;3(2):229-234. 
32. Wong JH, Lau T, Cai N, et al. Digestibility of protein and starch from sorghum (Sorghum bicolor) is linked to biochemical and structural features of grain endosperm. J Cereal Sci. 2009;49(1):73-82.

33. $\mathrm{Yu} \mathrm{W}$, Zou W, Dhital S, et al. The adsorption of $\alpha$-amylase on barley proteins affects the in vitro digestion of starch in barley flour. Food Chem. 2018;241:493-501.

34. Dhital S, Warren FJ, Butterworth PJ, Ellis PR, Gidley MJ. Mechanisms of starch digestion by $\alpha$-amylase-Structural basis for kinetic properties. Crit Rev Food Sci Nutr. 2017;57(5):875892.

35. Bhattarai RR, Dhital S, Wu P, Chen X, Gidley M. Digestion of isolated legume cells in a stomach-duodenum model: three mechanisms limit starch and protein hydrolysis. Food Funct. 2017;8:2573-2582.

36. Nielsen S. Degradation of bean proteins by endogenous and exogenous proteases. A review. Cereal Chem. 1988;65(5):435-442.

37. Edwards $\mathrm{CH}$, Grundy MM, Grassby T, et al. Manipulation of starch bioaccessibility in wheat endosperm to regulate starch digestion, postprandial glycemia, insulinemia, and gut hormone responses: a randomized controlled trial in healthy ileostomy participants. Am J Clin Nutr. 2015;102(4):791-800.

38. Nielsen S, Hermodson MA, Paul Scott M, Deshpande SS. Comparative digestibility of legume storage proteins. J Agric Food Chem. 1988;36(5):896-902.

39. Carbonaro M, Grant G, Cappelloni M, Pusztai A. Perspectives into factors limiting in vivo digestion of legume proteins: Antinutritional compounds or storage proteins? J Agric Food Chem. 2000;48(3):742-749.

40. Eggers DK, Valentine JS. Molecular confinement influences protein structure and enhances thermal protein stability. Protein Sci. 2001;10:250-261.

41. Berg T, Singh J, Hardacre A, Boland MJ. The role of cotyledon cell structure during in vitro digestion of starch in navy beans. Carbohydr Polym. 2012;87(2):1678-1688. 


\section{Appendix 3}

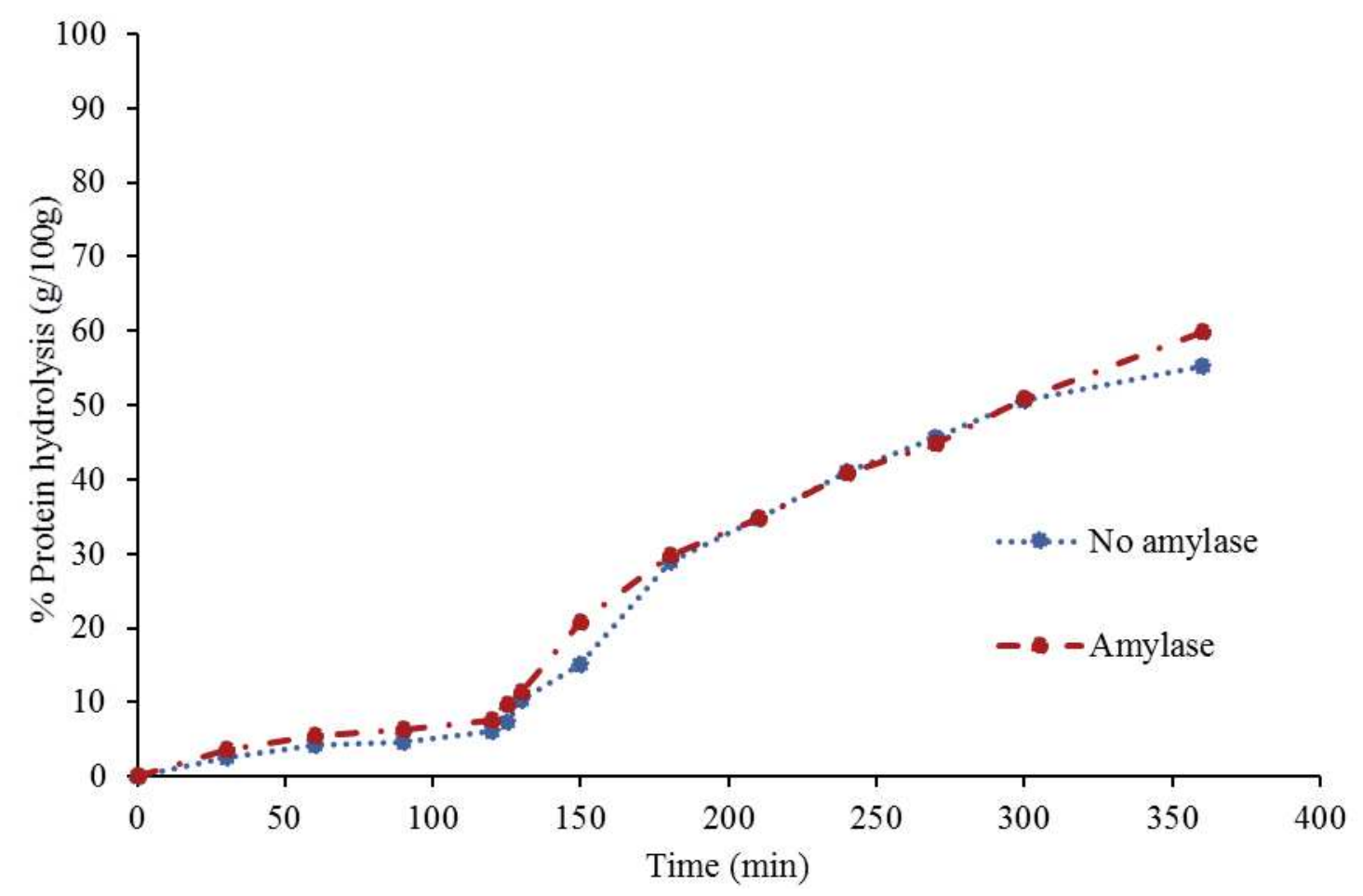

Fig. 3-A1 Kinetics of protein hydrolysis during digestion of red kidney beans intact cotyledon cells (ICC) with and without addition of $\alpha$-amylase in the intestinal phase. First 120 minutes represent gastric phase, the subsequent time points correspond to intestinal digestion. Error bars denote standard deviation of three independent samples. 



\section{Chapter 4}

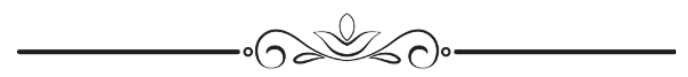

\section{A mechanistic model to study the effect of the cell wall on starch digestion in intact cotyledon cells}

This chapter is based on:

Ana M. Rovalino-Córdova, Victor Aguirre-Montesdeoca, Edoardo Capuano. A mechanistic model to study the effect of the cell wall on starch digestion in intact cotyledon cells. Submitted for publication. 
Chapter 4

\section{Abstract}

The role of the plant matrix is recognized as the main factor restricting starch digestibility in beans, nevertheless the exact mechanism behind this process has not been elucidated yet. In this study, we developed a mechanistic model, which describes the main physical and biochemical phenomena that play a role in starch digestion in intact cotyledon cells. It was found that starch entrapped in intact cells could only be hydrolysed after the diffusion of enzymes through the cell wall. This process is limited by the pores naturally present in the cell wall and the adsorption of $\alpha$-amylase to the cell wall surface. Both factors restrict the number of enzymes available for starch hydrolysis within the cells. The model was validated with in-vitro starch digestion data giving very accurate results. The proposed approach provides new information to understand the digestibility of starch, and possibly other macronutrients, in complex food matrices. 


\subsection{Introduction}

Starch is the primary carbohydrate produced by plants as energy storage and one of the main macronutrients in human diet ${ }^{1}$. Due to the primary role of starch in nutrition, substantial research has been conducted in order to understand the factors affecting its hydrolysis during gastro-intestinal digestion. Several factors have been found to affect starch digestion, from which food structure could be considered as one of the most relevant ${ }^{2}$.

One of the best examples showing the importance of food structure in starch digestion are legumes, a type of food with a relatively low glycaemic index. This has been confirmed by invitro studies, which indicate a slow digestion kinetics of starch in beans ${ }^{3}$. In a recent publication from our group ${ }^{4}$, we confirm those results and further demonstrate that the limited starch digestibility in beans was due to the restricted passage of $\alpha$-amylase through the cell wall $(\mathrm{CW})$. Even though this information gives us some insights about the low glycaemic index of legumes, further research is still needed to understand the mechanisms behind this effect.

In the past few years, several researchers have postulated the use of models in an attempt to describe the mechanisms that govern starch hydrolysis. For instance, Goñi, et $\mathrm{al}^{5}$ developed a model to explain starch granules digestibility in raw and cooked conditions. Later on, Al Rabadi, et $\mathrm{al}^{6}$, Edwards, et $\mathrm{al}^{7}$ and Mahasukhonthachat, et $\mathrm{al}^{8}$ proposed mathematical models to estimate the level of starch digestion in grains taking into account differences in particle size. These models were all of empirical nature and used only kinetic parameters, assuming that the only factors affecting starch hydrolysis were related to the enzymatic conversion of starch. This might be the case for simplified systems such as free starch granules, but when studying complex food matrices other aspects such as (enzyme) transport phenomena should also be considered. To the best of our knowledge, no mechanistic studies have been proposed so far, in which starch hydrolysis in complex food matrices is explained considering both enzyme kinetics and transport phenomena.

Other interactions such as the binding affinity between digestive enzymes and dietary fibre components might also play an important role 9 . In a recent study, Dhital, et al ${ }^{10}$ demonstrated that $\alpha$-amylase can bind to cellulose and bran fibre, thus serving as an inhibitor for amylolysis. This was further confirmed by Bhattarai, et $\mathrm{al}^{11}$ when observing a reduction in hydrolysis of 
Chapter 4

isolated starch due to the presence of cell wall material. The real impact of such interactions in a system where starch is entrapped within a cell wall matrix has never been described before.

The aim of this study is to provide insight about the mechanisms behind the low digestibility of starch in beans. A mathematical mechanistic model, which incorporates equilibrium thermodynamics, transport phenomena and enzyme kinetics, was developed in order to understand the complex interaction between the different parameters involved in starch hydrolysis. We hypothesize that the hindered diffusion of $\alpha$-amylase through the pores of the $\mathrm{CW}$ can be explained by the synergistic effect between steric factors and interactions with the CW components.

\subsection{Materials and methods}

\subsubsection{Materials}

Red kidney beans were purchased from the supermarket (Wageningen, Netherlands) and stored at room temperature. Pepsin (porcine gastric mucose 3200-4500 U/mg), trypsin (porcine pancreas 1000-2000 U/mg), $\alpha$-chymotrypsin (bovine pancreas $\geq 40 \mathrm{U} / \mathrm{mg}$ ), $\alpha$-amylase (porcine pancreas 700-1400 U/mg), amyloglucosidase (from aspergillus Niger, $120 \mathrm{U} / \mathrm{mg}$ ), were purchased from Sigma-Aldrich Ltd. (St. Louis, MO, USA). All other chemicals were of analytical grade and purchased from Sigma-Aldrich Ltd unless stated otherwise.

\subsubsection{Sample preparation}

Intact cotyledon cells (ICC) from red kidney beans were isolated following the procedure described by Rovalino-Córdova ${ }^{4}$.

\subsubsection{In-vitro digestion experiments}

In-vitro digestion was carried out using a modified version of the protocol developed by Minekus, et al ${ }^{12}$. Briefly, ICC were gastric digested by the addition of simulated fluids ( $\mathrm{pH} 3$ ) and pepsin. The resulting gastric chyme was combined with intestinal fluids (SIF), trypsin, chymotrypsin, $\alpha$-amylase and incubated for $4 \mathrm{~h}$ at $\mathrm{pH}$. The temperature was kept constant at $37^{\circ} \mathrm{C}$ throughout the whole experiment. In this study, all experiments were performed using substantially lower concentration of $\alpha$-amylase than what normally employed in conventional in-vitro digestion experiments. This was done to ensure that the amount of substrate was always in excess so that the reaction velocity was nearly that of $\operatorname{Vmax}^{13}$. Samples were collected at different time points for determining the kinetics of starch hydrolysis and measure enzyme 
concentration. In order to stay within the range of maximum reaction velocity, only a small fraction of the substrate (no more than $5 \%$ ) should be consumed ${ }^{13}$. Therefore, only those time points that fulfilled this requirement were considered for the analysis.

In a second set of experiments, in-vitro digestion at different enzyme concentrations $(0.3,1,5$, 10 and $25 \mathrm{U} / \mathrm{mL}$ ) was conducted to determine the partition coefficient between the $\mathrm{CW}$ and the aqueous phase. Samples were incubated for $20 \mathrm{~h}$ to ensure equilibrium between both phases. Other experimental conditions remained constant as the ones described above. $\alpha$-amylase concentration was quantified as described in the following sections.

\subsubsection{Quantification of starch hydrolysis}

Aliquots taken from in-vitro digestion were further hydrolysed with amyloglucosidase as described by Rovalino-Córdova, et $\mathrm{al}^{4}$ and the corresponding glucose concentration was quantified by GOPOD method following the manufacturer's instructions (Megazyme Inc. Bray, Ireland).

\subsection{5. $\alpha$-amylase concentration}

Enzyme concentration (in the bulk and ICC) was quantified after in-vitro digestion using a modified version of alpha amylase assay procedure (Ceralpha method) Megazyme, Inc. (Bray, Ireland). After incubation, tubes were opened and the supernatant was separated from ICC using a Falcon $^{\mathrm{TM}}$ cell strainer (mesh size $70 \mu \mathrm{m}$ ). The cells collected were weighed and re-suspended in SIF in a ratio 1:7 respectively. This suspension was left overnight under stirring conditions to break down the cells. Enzyme concentration was determined by combining $0.1 \mathrm{~mL}$ of sample with Amylase HR reagent and incubating at $40{ }^{\circ} \mathrm{C}$ for $20 \mathrm{~min}$. Subsequently, the reaction was stopped by the addition of $1.5 \mathrm{~mL}$ of stopping reagent ( $20 \%$ tri-sodium phosphate solution, $\mathrm{pH}$ 11). The absorbance was read at $400 \mathrm{~nm}$ against distilled water. A calibration curve was constructed by plotting alpha amylase concentration versus absorbance. This curve was linear over the concentration range $0-25 \mu \mathrm{g} / \mathrm{mL}$. A linear regression was fitted for quantitation. All time points tested were performed in duplicates.

\subsection{6. $\alpha$-amylase fluorescent labelling}

Alpha amylase was fluorescently labelled using the FluoroTag ${ }^{\mathrm{TM}}$ Conjugation Kit from SigmaAldrich (St. Louis, MO, USA) according to the manufacturer's instructions with minor modifications. Briefly, the enzyme was combined with FITC in a molar ratio of 1:10 
respectively. The sample was incubated for $2 \mathrm{~h}$ at room temperature avoiding light exposure. Unbound FITC was separated from the conjugated fraction by a Sephadex gel filtration column (G-25M) using PBS buffer $\mathrm{pH}$ 7.4. Conjugated enzyme fractions were pooled, aliquoted and frozen $^{14}$. The Fluorescein / Protein molar ratio (F/P) calculated for the conjugate formed was 2.05 .

\subsubsection{Confocal laser scanning microscopy (CLSM)}

CLSM micrographs were obtained following the procedure described by Rovalino-Córdova, et $\mathrm{al}^{4}$.

\subsubsection{Mathematical modelling approach}

A mechanistic dynamic model based on Fick's law was developed for enzyme diffusion within ICC, and subsequently for the diffusion of starch hydrolysis products from the inner part of ICC towards the exterior liquid phase (bulk). Considering the high affinity of the enzyme to the cell wall components ${ }^{10}$, the measurement of $\alpha$-amylase partition coefficient $\left(P_{e}\right)$ allowed us to incorporate the effect of enzyme adsorption in the model. Moreover, besides the resistance exerted by the $\mathrm{CW}$, the effect of the stagnant layer in proximity to the $\mathrm{CW}$ was included in the model by using film theory. Fig. 4-1 shows a schematic view of the concentration profiles for the enzyme $(\mathrm{Ce})$ and starch hydrolysis products $(\mathrm{Cs})$.
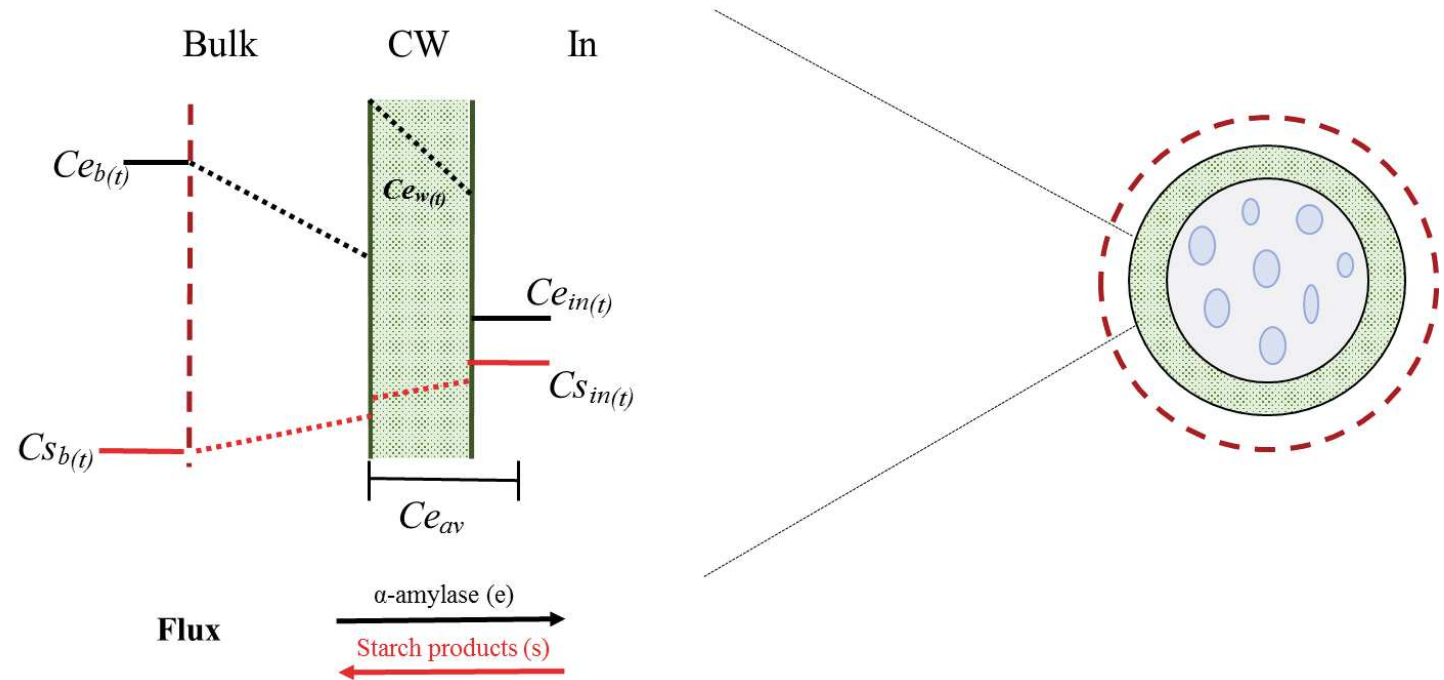

Fig. 4-1. Schematic representation of $\alpha$-amylase diffusion through the stagnant layer and cell wall, and the exit of the hydrolysis products towards the bulk phase. Dotted lines represent the concentration gradient through the stagnant layer and cell wall. The dashed red line indicates the stagnant layer. $\mathrm{Ce}_{\mathrm{b}}=$ enzyme concentration in bulk; $\mathrm{Cs}_{\mathrm{b}}=$ substrate concentration in bulk; $\mathrm{Ce}_{\mathrm{w}}=$ enzyme concentration in $\mathrm{CW} ; \mathrm{Ce}_{\mathrm{in}}=$ enzyme concentration within ICC; $\mathrm{Cs}_{\mathrm{in}}=$ substrate concentration within ICC; $\mathrm{Ce}_{\mathrm{av}}=$ Enzyme concentration in the combined $\mathrm{CW}+\mathrm{ICC}$ compartment. 
Since the enzyme concentration in the wall $\left(C e_{w}\right)$ and inside ICC $\left(C e_{i n}\right)$ could not be measured separately, an average of them is considered in the model $\left(C e_{a v}\right)$, which represents the measured concentration in the pellet of intact cells. Eq.1 shows this relation in which $\varphi$ stands for volume fraction.

$$
C e_{a v}=C e_{w} \varphi_{w}+C e_{i n} \varphi_{i n}
$$

Considering that, by definition, the partition coefficient $P_{e}$ is the ratio of the concentration of a compound in two immiscible phases (aqueous and cell wall) at equilibrium, we can state:

$$
P_{e}=\frac{C e_{w(e q)}}{C e_{b(e q)}}=\frac{C e_{w(e q)}}{C e_{i n(e q)}}
$$

By combining Eq. 1 and Eq. 2 and considering that $C e_{w(t)} \approx P_{e} C e_{i n(t)}$, we obtain the following relation which express $C e_{i n}$ as a function of $C e_{a v}$ at any time:

$$
C_{i n(t)}=\frac{C e_{a v(t)}}{P_{e} \varphi_{w}+\varphi_{i n}}
$$

The dynamic model is represented by a system of four differential equations (Eq.4-Eq.7), which together with Eq.3 are sufficient to represent the entire dynamic system. These equations represent the change in the concentration of the enzyme and hydrolysis products $(C s)$ over time. Eq.4, Eq.5 and Eq.7 have a comparable structure, in which two terms can be distinguished at the right hand side: the resistance (first bracket) and the driving force for diffusion (second bracket). The former is the sum of the stagnant layer resistance, represented by $1 / k$, and the resistance of the $\mathrm{CW}\left(1 /\left(D / \delta P_{e} k d\right)\right)$, which is a more complex term that includes the diffusion coefficient $(D)$, the thickness of the cell wall $(\delta)$, the partition coefficient $\left(P_{e}\right)$ and the hindrance coefficient $(k d)$. The driving force, on the other hand, is the difference of the concentration in the bulk and inside ICC. Evidently, equilibrium is obtained once these two concentrations reach equal values. In Eq. 4-7, $A$ stands for the total area of the surface of ICC, while $V_{I C}$ and $V_{T}$ are the volume of ICC and the liquid phase respectively. On the other hand, Eq. 6 contains the aforementioned structure with one additional term, which represents the production rate of the hydrolysates. A detailed explanation about the derivation of this set of differential equations could be found in the appendix. Likewise, the calculation of the mass transfer coefficient $k$ for the enzyme and the product is also detailed there.

$$
\frac{\mathrm{dCe}_{\mathrm{av}}}{\mathrm{dt}}=\left(\frac{1}{\mathrm{k}_{\mathrm{e}}}+\frac{1}{\frac{\mathrm{D}_{\mathrm{e}}}{\delta} \mathrm{P}_{\mathrm{e}} \mathrm{kd}_{\mathrm{e}}}\right)^{-1}\left(\mathrm{Ce}_{\mathrm{b}}-\mathrm{Ce}_{\mathrm{in}}\right) \frac{\mathrm{A}}{\mathrm{V}_{\mathrm{IC}}}
$$




$$
\begin{aligned}
& \frac{d C e_{b}}{d t}=-\left(\frac{1}{k_{e}}+\frac{1}{\frac{D_{e}}{\delta} P_{e} k d_{e}}\right)^{-1}\left(C e_{b}-C e_{i n}\right) \frac{A}{V_{T}} \\
& \frac{\mathrm{dC} s_{\text {in }}}{\mathrm{dt}}=\mathrm{k}_{\mathrm{cat}} \mathrm{Ce}_{\mathrm{in}}-\left(\frac{1}{\mathrm{k}_{\mathrm{s}}}+\frac{1}{\frac{\mathrm{D}_{\mathrm{s}}}{\delta} \mathrm{P}_{\mathrm{s}} \mathrm{kd}}\right)^{-1}\left(\mathrm{Cs}_{\mathrm{in}}-C \mathrm{~s}_{\mathrm{b}}\right) \frac{\mathrm{A}}{\mathrm{V}_{\mathrm{IC}}} \\
& \frac{\mathrm{dC} \mathrm{s}_{\mathrm{b}}}{\mathrm{dt}}=\left(\frac{1}{\mathrm{k}_{\mathrm{s}}}+\frac{1}{\frac{\mathrm{D}_{\mathrm{s}}}{\delta} \mathrm{P}_{\mathrm{s}} \mathrm{kd}_{\mathrm{s}}}\right)^{-1}\left(\mathrm{Cs}_{\mathrm{in}}-\mathrm{Cs}_{\mathrm{b}}\right) \frac{\mathrm{A}}{\mathrm{V}_{\mathrm{T}}}
\end{aligned}
$$

The model assumes that all ICCs have the same size and spherical shape, uniform CW thickness and pore size. In order to simplify the kinetics of the enzymatic reaction, all experiments were performed under excess substrate concentration allowing us to assume that Vmax conditions were met. It is also assumed that local equilibrium takes place at the interface between water and the CW. The parameters used for the resolution of the model are presented in Table 4-1.

Table 4-1. Parameters utilized for the resolution of the mathematical model.

\begin{tabular}{l|l|l}
\hline Parameter & Value & Reference \\
\hline$\alpha$-amylase diffusion in water & $8.05 \times 10^{-11}\left(\mathrm{~m}^{2} . \mathrm{s}^{-1}\right)$ & Meyer, E.H., \& Bernferld, (1947) \\
$\alpha$-amylase products (DP3) diffusion in water & $5.94 \times 10^{-10}\left(\mathrm{~m}^{2} . \mathrm{s}^{-1}\right)$ & Sano \& Yamamoto, (1993) \\
ICC diameter & $100 \times 10^{-6}(\mathrm{~m})$ & Rovalino-Córdova et al., (2018) \\
Molecular weight $\alpha$-amylase & $56000\left(\mathrm{~g} \cdot \mathrm{mol}^{-1}\right)$ & Edwards et al., (2014) \\
Pore diameter ICC & $5.5 \times 10^{-9}(\mathrm{~m})$ & Brett \& Waldron, (1996) \\
ICC density & $1.12 \times 10^{3}\left(\mathrm{Kg}_{\mathrm{m}} \mathrm{m}^{-3}\right)$ & Determined experimentally by volume displacement \\
Cell wall thickness & $2 \times 10^{-6}(\mathrm{~m})$ & McEwen, Dronzek, \& Bushuk, (1974) \\
\hline
\end{tabular}

\subsubsection{Turnover number (kcat) determination}

The reaction kinetics are represented in our model by Kcat. This parameter was calculated upon starch hydrolysis of ICC samples whose structural integrity was previously disrupted to determine the catalytic action of enzymes without having the structural constraints exerted by the CW. For this purpose, ICC were mixed for $24 \mathrm{~h}$ using a magnetic stirrer at high speed rate as described by Rovalino-Córdova, et $\mathrm{al}^{4}$. Structural disruption of the cells was confirmed by 
visual inspection under a light microscope. Hereinafter these samples will be referred as mechanically damaged cells (MDC).

MDC was enzymatically hydrolyzed at different $\alpha$-amylase concentrations $(0.03 \mathrm{U} / \mathrm{mL}$, $0.3 \mathrm{U} / \mathrm{mL}, 1 \mathrm{U} / \mathrm{mL}$ ). These concentrations were at least 2 orders of magnitude lower than what normally used when conducting in-vitro digestion experiments in order to ensure an excess of substrate as described in section 4.2.3. Starch quantification was performed (section 4.2.4) and only those time points, in which less than $5 \%$ of starch was hydrolyzed, were considered for $k_{\text {cat }}$ determination. $k_{\text {cat }}$ was calculated from Eq. 6 considering that in this case there were no structural barriers affecting the enzyme kinetics, therefore:

$$
k_{\text {cat }}=\frac{\frac{d s_{\text {in }}}{d t}}{C e_{\text {in }}}=\frac{\mu m \text { moles }(\text { of } S \rightarrow P) \times \text { min }^{-1} \times m L^{-1}}{\mu \text { moles of } \alpha-\text { amylase } \times m L^{-1}}
$$

The results obtained for kcat at different $\alpha$-amylase concentrations are detailed in the appendix section.

\subsubsection{0. $\alpha$-amylase partition coefficient}

For determining the partition coefficient an adsorption isotherm of $\alpha$-amylase binding to ICC was constructed using enzyme concentration data at equilibrium conditions. The calculation was done assuming that at equilibrium conditions both the bulk and the inner part of ICC have the same enzyme concentration $\left(C e_{b(e q)}=C e_{i n(e q)}\right)$ as schematically represented in Fig. 4-2. Moreover, for this calculation it was also assumed that the concentration of enzyme and hydrolysis products were homogeneous within ICC (no internal gradients). By definition, the partition coefficient could be calculated upon the ratio of the enzyme concentration in two immiscible phases (Eq.2), therefore, it was necessary to first determine the concentration of the enzyme in the CW. 


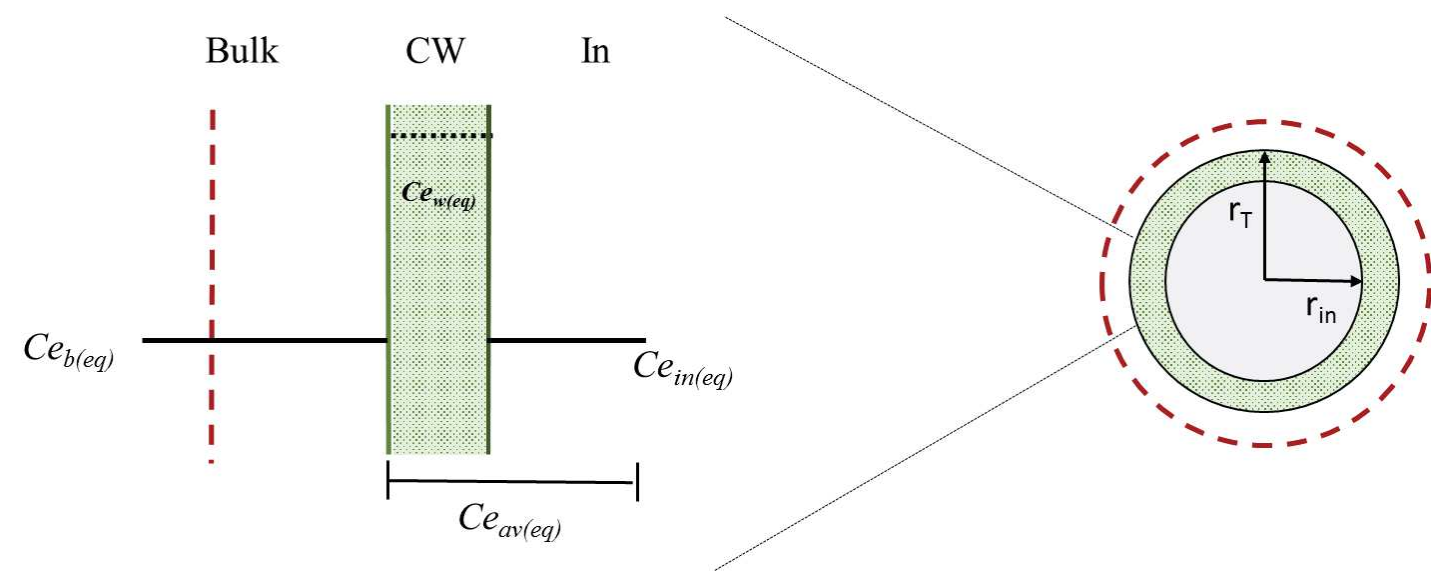

Fig. 4-2. Schematic representation of $\alpha$-amylase concentration at equilibrium conditions (left side). Radio of total ICC $\left(\mathrm{r}_{\mathrm{T}}\right)$ and the inner part of it without taking into account the CW $\left(\mathrm{r}_{\text {in }}\right)$ (right side). Red dashed line represents the stagnant layer and the black dotted line enzyme concentration in the $\mathrm{CW}$. $\mathrm{Ce}_{\mathrm{b}}=$ enzyme concentration in bulk; $\mathrm{Ce}_{\mathrm{w}}=$ enzyme concentration in $\mathrm{CW} ; \mathrm{Ce}_{\mathrm{in}}=$ enzyme concentration within ICC; $\mathrm{Ce}_{\mathrm{av}}=$ Enzyme concentration in the combined CW + ICC compartment.

Since $C e_{a v}$ is the added contribution of the enzyme concentration in the $\mathrm{CW}$ and within ICC, a mass balance was proposed to determine the concentration of $\alpha$-amylase in the $\mathrm{CW}$ :

$$
\begin{gathered}
C e_{w} \times V_{w}+C e_{i n} \times V_{i n}=C e_{a v} \times V_{I C} \\
\frac{C e_{w} \times V_{w}}{V_{I C}}+\frac{C e_{i n} \times V_{i n}}{V_{I C}}=\frac{C e_{a v} \times V_{I C}}{V_{I C}} \\
\frac{C e_{w} \times \emptyset_{w}}{V_{I C}}+\frac{C e_{i n} \times\left(1-\emptyset_{w}\right)}{V_{I C}}=C e_{a v}
\end{gathered}
$$

Where $V_{w}, V_{\text {in }}$ and $V_{\text {ICC }}$ represent the volume of CW, within ICC and total volume $\left(V_{w}+V_{\text {in }}\right)$ respectively. The only unknown parameter from Eq.9 is $\mathrm{Vw}$ since it is assumed that at equilibrium conditions $C e_{b(e q)}=C e_{i n(e q)} ; \mathrm{V}_{\mathrm{IC}}$ and $\mathrm{V}_{\text {in }}$ were calculated from ICC diameter and $\mathrm{CW}$ thickness information found in literature $\left(100 \mu \mathrm{m}^{4} ; 2 \mu \mathrm{m}{ }^{19}\right.$ respectively) and $\mathrm{Ce}_{\mathrm{av}}$ was determined experimentally. All the terms in Eq.9 were divided by $\mathrm{V}_{\text {IC }}$ to express $\mathrm{V}_{\mathrm{w}}$ as a volume fraction which was calculated as follows:

$$
\emptyset_{w}=\frac{V_{I C}-V_{\text {in }}}{V_{I C}}=\frac{r_{I C}^{3}-r_{i n}^{3}}{r_{I C}^{3}}=1-\frac{r_{i n}^{3}}{r_{I C}^{3}}
$$

After obtaining $\alpha$-amylase concentration in the $\mathrm{CW}$, the partition coefficient was calculated from Eq.2. 


\subsection{Results and discussion}

In this study, we propose a mathematic model to unravel the mechanism behind the low digestibility of starch in ICC. As determined in a previous publication ${ }^{4}$, starch confined in ICC could be hydrolysed by $\alpha$-amylase despite cells preserving their structural intactness during digestion. This implies that the enzyme needs to diffuse through the $\mathrm{CW}$ before getting in contact with starch granules. As consequence, enzymatic hydrolysis takes place within ICC and the products of starch digestion diffuse out of the cell towards the bulk phase after hydrolysis. We consider that the complex mechanism behind starch hydrolysis in ICC is due to the simultaneous action of several factors that will be discussed in detail in this section.

\subsubsection{Enzyme transport within ICC}

Equations 1 and 2 describe the change in enzyme concentration of ICC $\left(C e_{a v}\right)$ and the bulk $\left(\mathrm{Ce}_{b}\right)$, where the former increases and the later decreases as digestion proceeds. The system of differential equations was solved by using several parameters found in literature and reported in Table 4-1. However, other parameters like $P_{e}$ had to be determined experimentally in order to describe accurately the conditions present in the system. As described in section 4.2.3, different $\alpha$-amylase concentrations were utilized to obtain the partition coefficient. ICC was extensively digested to provide the enzyme enough time $(\sim 20 \mathrm{~h})$ to diffuse within ICC until reaching equilibrium concentrations in the supernatant and pellet prior quantification and construction of the adsorption isotherm (Fig. 4-3). As seen in Fig. 4-3 a linear behaviour in enzyme concentration between the bulk and ICC was found independently from the initial amylase concentration used. This indicates a direct relation between $\alpha$-amylase concentration in the bulk and its affinity with the CW. Due to the low concentration of enzyme utilized in this study, a saturation of $\mathrm{CW}$ binding sites was not achieved which resulted in a linear behaviour of the isotherm. We are aware that at higher enzyme concentrations the adsorption isotherm will eventually reach a plateau due to saturation of the binding sites present in the $\mathrm{CW}$. The analysis of those concentrations was not reported since they were out of the scope of this study. 


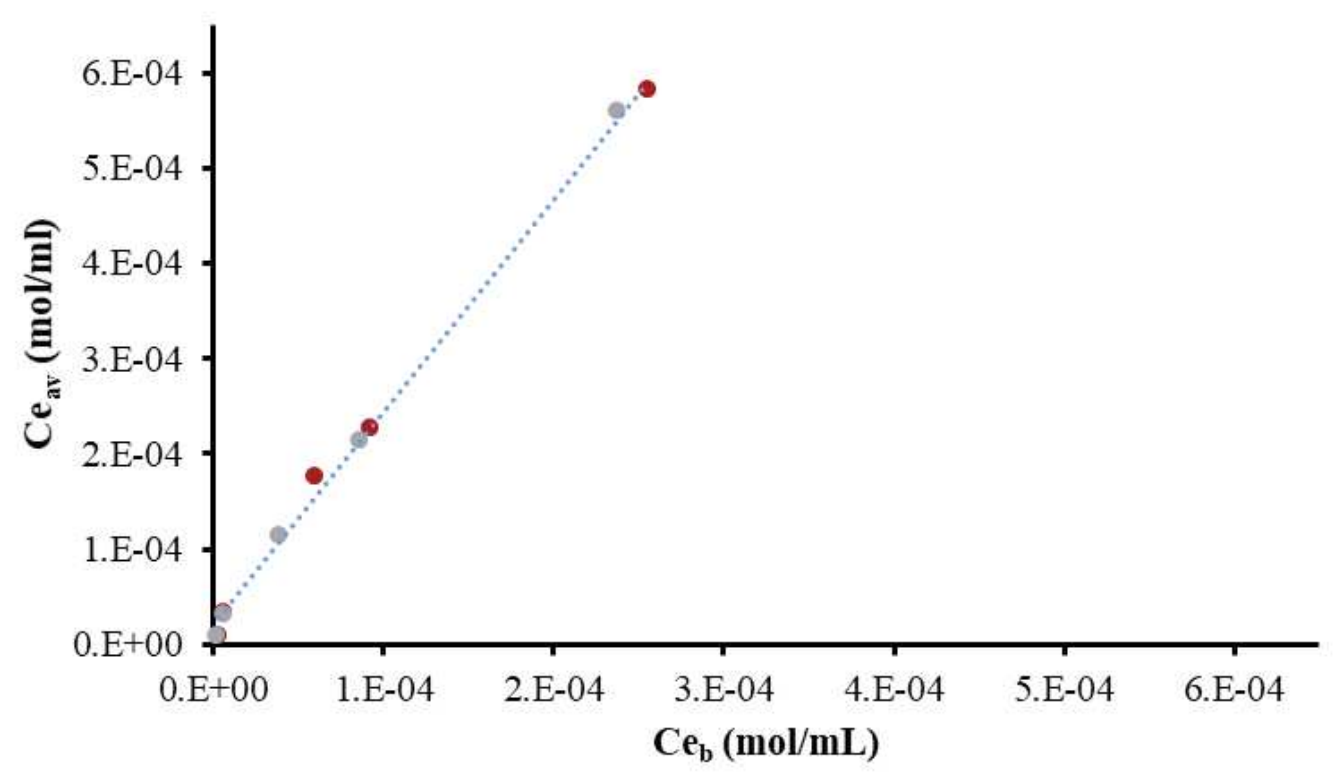

Fig. 4-3. Adsorption isotherm of $\alpha$-amylase into cell walls of ICC at equilibrium conditions. Circles represent the experimental measurement, each colour being an independent set of samples, dotted line depict the trend line of the analysis. Note the slope $>1$ is an indication of the interaction between $\alpha$-amylase and the CW.

The enzyme hindrance coefficient $k d_{\mathrm{e}}$ represents the resistance of mass transfer through the CW and normally occurs due to the interactions between the diffusing molecule and the pores ${ }^{20}$. In this study, the enzyme hindrance coefficient $\left(k d_{e}\right)$ was obtained by fitting the model to in-vitro digestion data that quantified enzyme concentration in the bulk phase over time (Fig. 4-4). A value of $1.23 \times 10^{-5}$ (dimensionless number) for the hindrance coefficient at an enzyme concentration of $0.3 \mathrm{U} / \mathrm{mL}$ was obtained. $k d_{e}$ was also calculated at other enzyme concentrations and values of the same order of magnitude were obtained (data not shown). The $k d_{e}$ value obtained in this study is considered very low compared to the results of other authors who have investigated the diffusion of proteins through different food matrices. That is the case of Fardet, et $\mathrm{al}^{21}$ who studied the diffusion of BSA through protein network of pasta. They found a twofold reduction in the diffusion of BSA in comparison to its behaviour in pure aqueous solvent. $K d_{e}$ value obtained by our model decreases the diffusion of $\alpha$-alpha amylase by five orders of magnitude showing a great difference to what the aforementioned authors have found. We believe that the cause of such discrepancy is the structural difference between pasta and ICC. In pasta, the gluten network has a porosity ranging from $0.3-30 \mu \mathrm{m}$ while porosity of the $\mathrm{CW}$ in ICC ranges from 3.5-5.5 $\mathrm{nm}$. Considering that the cell wall porosity allows the passage of proteins of around $50 \mathrm{KDa}^{18}$, it is reasonable to have a higher hindrance coefficient since this value generally becomes significant when the diffusing molecule and the pore size are of comparable $\operatorname{size}^{20}$. Diffusion studies performed in highly constricted pores (such as the ones 
present in ICC) using synthetic membranes, indicate that $k d$ was more than four orders of magnitude smaller than when proteins are diffusing in free solutions ${ }^{22}$. Furthermore, it is known that the reduction in transport through constricted pores is caused by two phenomena: hydrodynamic effects and equilibrium partitioning. The former refers to the frictional drag of the molecules while the later relates to steric effects and electrostatic interactions ${ }^{22}$. We believe that these two phenomena also explain the relative low hindrance value that our model calculated for the diffusion of amylase through cell wall pores. In first place, both enzyme and CW pore size have dimensions of the same order of magnitude already creating important limitations for free (and fast) diffusion. In addition to this, the interactions between the CW and $\alpha$-amylase limits further its diffusion. Dhital, et $\mathrm{al}^{10}$ reported the inhibition of $\alpha$-amylase by cellulose and bran fibre, demonstrating a strong and rapid binding interaction between these two components. Such interaction was also present in our study and could be clearly identified when plotting the concentration of enzyme present in the bulk and ICC during in-vitro digestion. As depicted in Fig. 4-4, after $1 \mathrm{~h}$ of hydrolysis, the concentration of $\alpha$-amylase in ICC was remarkably higher than the one found in the bulk, a clear indication that an adsorption mechanism was taking place. If no adsorption phenomena had taken place, $\alpha$-amylase concentration in both phases would have been comparable when reaching equilibrium. This adsorption process occurred in all samples tested, independently of the enzyme concentration employed.

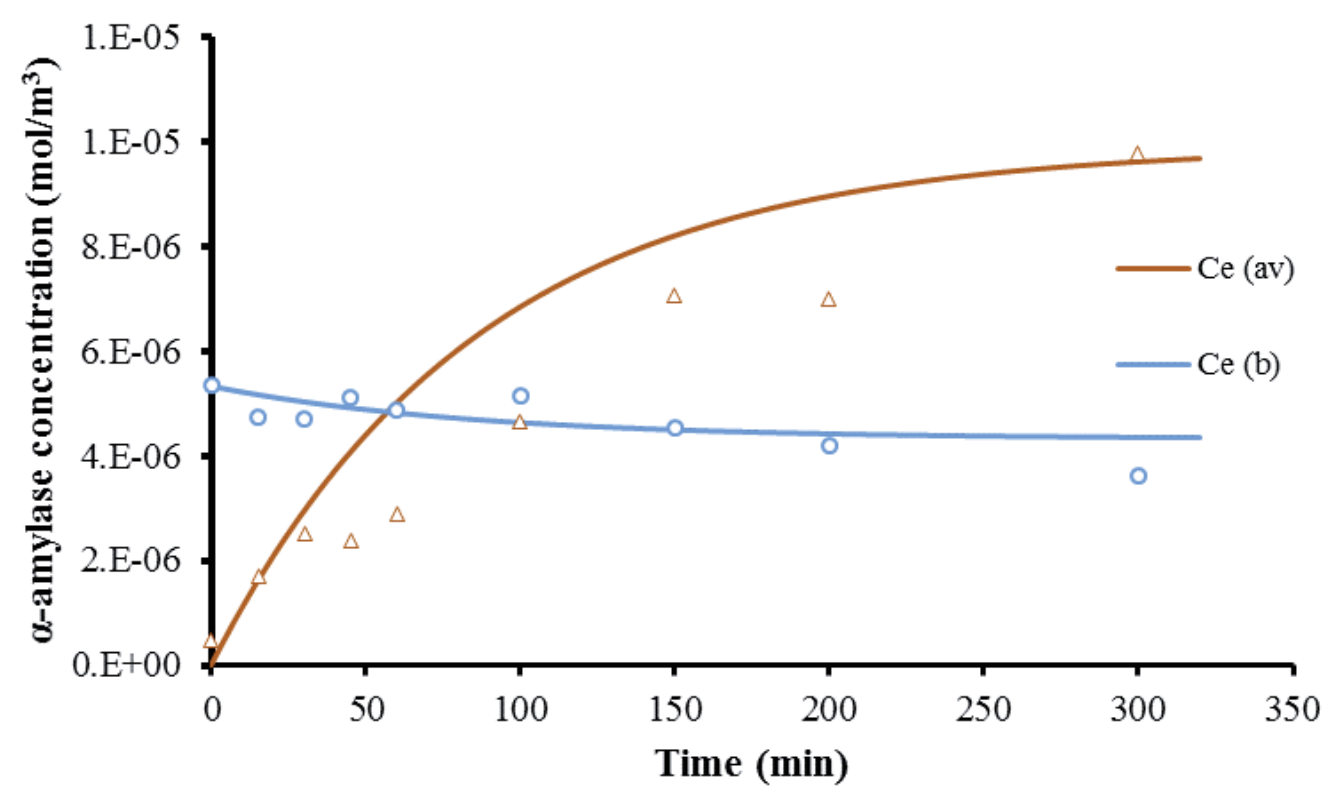

Fig. 4-4. Average $\alpha$-amylase concentration in ICC $\left(\mathrm{Ce}_{\mathrm{av}}\right)$ and bulk phase $\left(\mathrm{Ce}_{\mathrm{b}}\right)$ as a function of time. Lines represent the change in enzyme concentration predicted by the model. Open symbols denote data collected experimentally for each of the phases. 
The partition and hindrance coefficient reflect the combined effect of enzyme diffusion through constricted pores in ICC and the adsorption of $\alpha$-amylase to $\mathrm{CW}$ components. The hindrance to diffusion due to pore size limitations are attributable to a combination of particle-wall hydrodynamic interactions and steric restrictions. The former depends on the particle proximity to the $\mathrm{CW}$ so any force that influences its position affects them. Even when considering those forces negligible, the finite size of the solute restricts its access to the region near the $\mathrm{CW}$ affecting its flux ${ }^{23}$.

Furthermore, from Fig. 4-4 it is evident that adsorption also has a tremendous impact in the amount of enzyme that diffuses inside ICC. This phenomena is dependent on enzyme concentration since it has been found that cellulose has a limited number of binding sites for the enzyme to attach ${ }^{10}$. Therefore, at very low enzyme concentrations, the $\mathrm{CW}$ material will deplete the enzyme from the solution causing a larger effect in starch hydrolysis. This might be the most plausible explanation of the discrepancy in the degree of starch hydrolysis reported by different research groups when studying starch digestibility in intact bean cells.

Fig. 4-5 depicts CLSM micrographs of ICC digestion by a fluorescently labelled $\alpha$-amylase. These images are a qualitative evidence of the diffusion of $\alpha$-amylase through the $\mathrm{CW}$. During early stages of digestion, the presence of alpha amylase could be identified in the outer periphery of ICC, whereas as digestion proceeds the enzyme starts diffusing towards the core of the cell until starch granules were clearly stained by the fluorescent dye. These results are in agreement with those found by Pallares Pallares, et $\mathrm{al}^{24}$ when studying the effect of different thermal treatments on starch digestibility. 

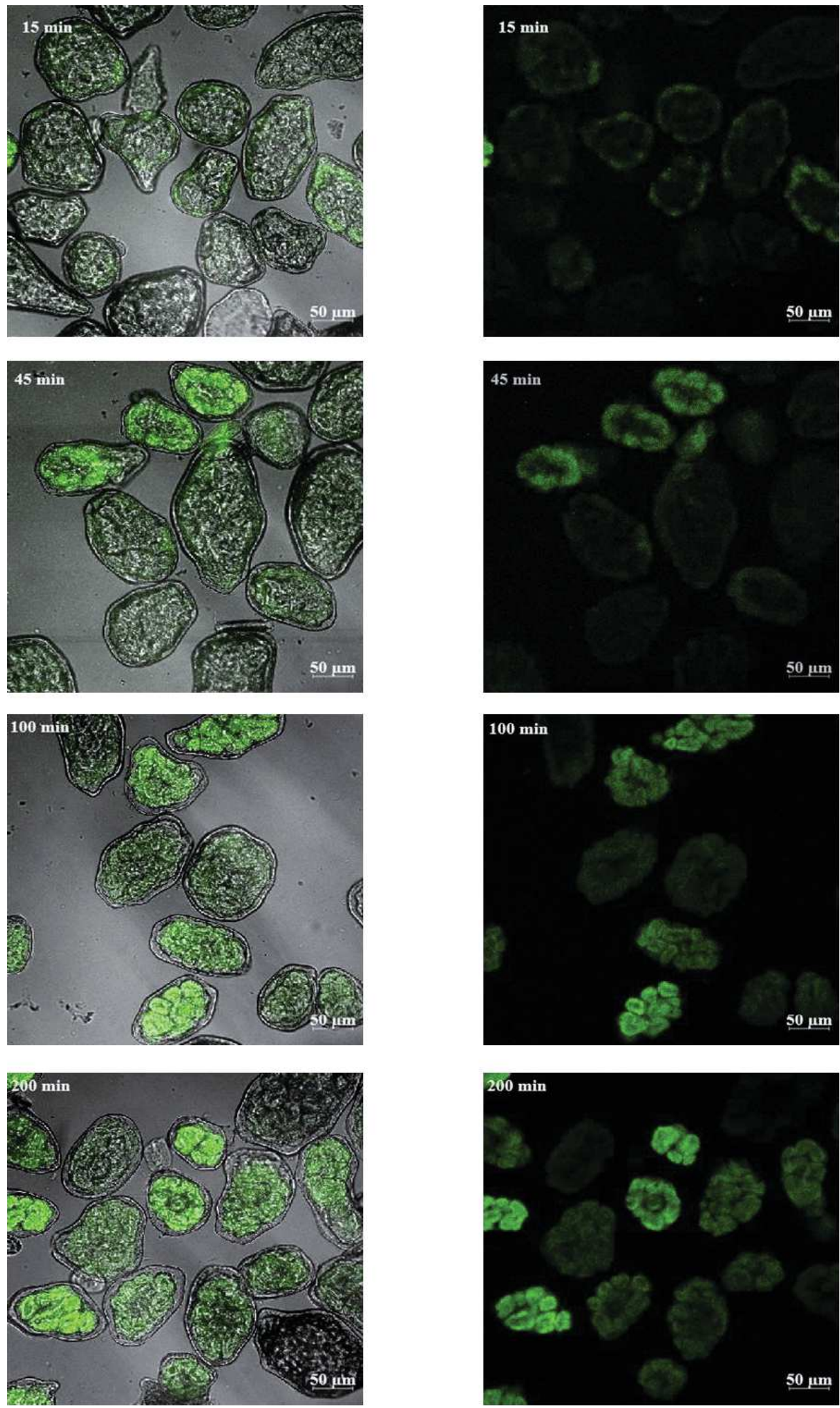

Fig. 4-5. CLSM micrographs of fluorescently-labelled $\alpha$-amylase at 15, 45, 100 and 200 min of in-vitro digestion. Right column depicts fluorescent channel and left column an overlaid visualization between fluorescent and bright field channels to facilitate the localization of the enzyme within ICC. 
Chapter 4

Furthermore, in Eq.4 and Eq.5 the effect of the stagnant layer is also taken into account to describe the system. This layer is an additional diffusion barrier immediately adjacent to the $\mathrm{CW}$, next to a region of slow laminar flow in which convection due to stirring do not cause any significant mixing of the solution and only diffusion takes place ${ }^{25}$. Stirring conditions will modify the thickness of the stagnant layer, hence reducing its influence during diffusion. In our study, mixing conditions were applied to all treatments trying to resemble what is normally occurring during digestion. We found that the resistance opposed by the stagnant layer $\left(k e^{-1}\right)$ was 2000 times smaller compared to what obtained for the $\mathrm{CW}\left(\left(D / \delta P_{e} k d\right)^{-1}\right)$. Therefore, we can state that due to the characteristics of the system described in this study, the stagnant layer has a very limited effect in delaying the diffusion of $\alpha$-amylase through the CW. The impact of this layer could be more relevant in other systems with higher viscosities as occurring due to the presence of soluble dietary fibres or reduced mixing conditions ${ }^{26}$.

\subsubsection{Starch hydrolysis within ICC}

As described before, $\alpha$-amylase needs to overcome adsorption and diffusion restrictions imposed by the $\mathrm{CW}$ in order to hydrolyse starch. Due to the nature of those interactions, the average concentration $\left(C e_{a v}\right)$ of $\alpha$-amylase measured experimentally in ICC does not reflect the amount of enzymes that were able to penetrate the CW. Instead, this concentration also included those enzymes adsorbed by the surface of the cell that were not actively involved in starch hydrolysis. Based on the mathematical model, we were able to determine and quantify the amount of enzymes that were able to penetrate the $\mathrm{CW}$ and as consequence capable of hydrolysing starch. As it could be seen in Fig. 4-6, the concentration of $\alpha$-amylase shows an asymptote behaviour that has a slow increase in the first minutes of digestion, followed by an exponential rise and ending in a plateau with no further increment in enzyme concentration. In the first $30 \mathrm{~min}$ of digestion, the amount of $\alpha$-amylase present within ICC was $25 \%$ of the amount originally present in the bulk. As enzyme concentration reached a plateau, this value increased up to $3.98 \times 10^{-6} \mathrm{~mol} / \mathrm{m}^{3}$ within ICC, that is, $75 \%$ of what originally present in the bulk. Since only a fraction of the enzymes can "work" upon starch degradation, the low digestibility values found for starch in legumes is a logical outcome. 


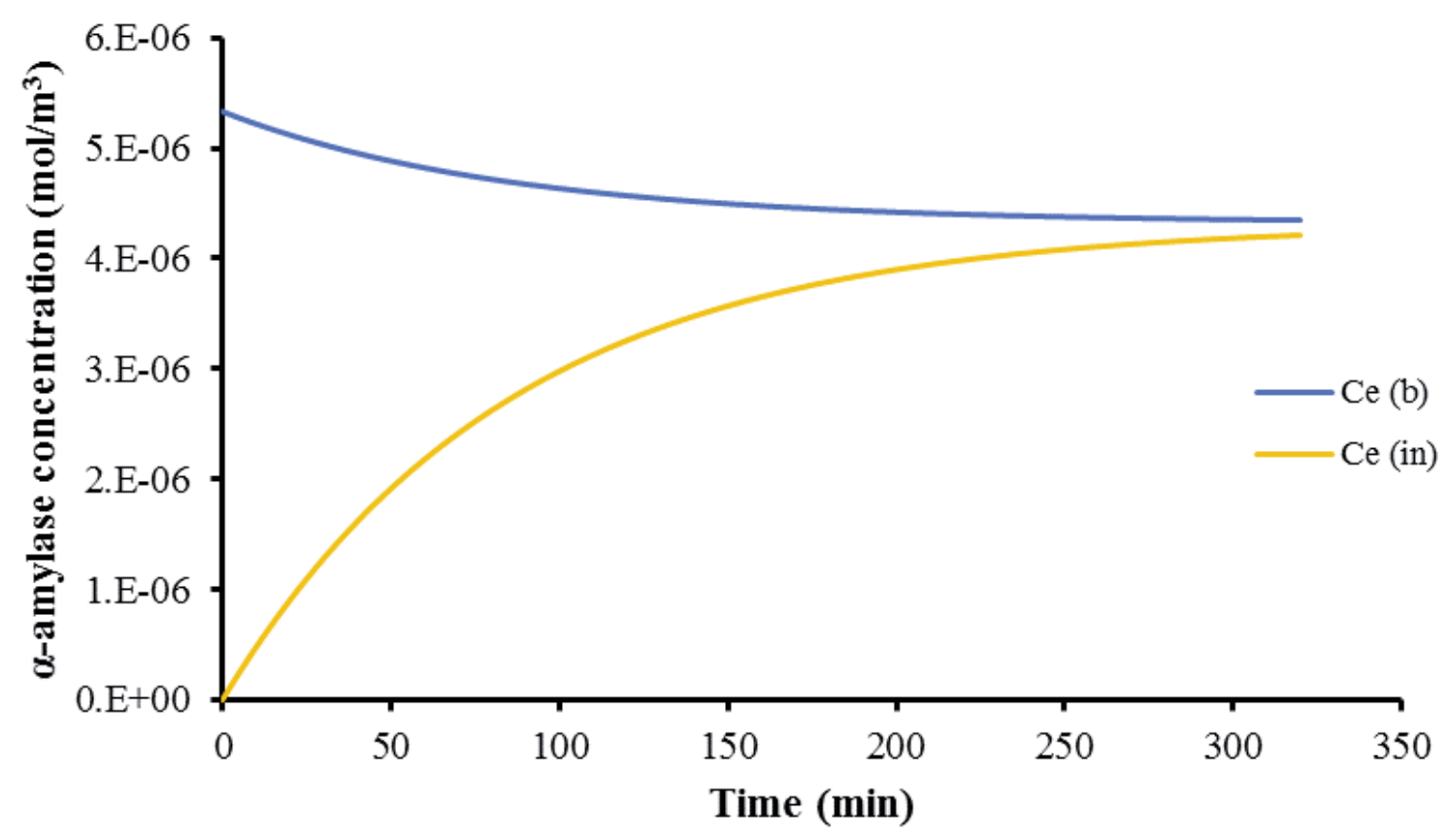

Fig. 4-6. Model calculation of the increase in $\alpha$-amylase concentration within ICC (Ce $\left.\mathrm{e}_{\text {in }}\right)$ as a function of time. Changes in enzyme concentration in the bulk $\left(\mathrm{Ce}_{\mathrm{b}}\right)$ are also included for comparison.

It is important to mention that in the present model, enzyme kinetics was calculated when less than $5 \%$ of the total starch was consumed (velocity similar to Vmax). In this situation, the reaction velocity is at its maximum level due to an excess of substrate that allows all the active sites of the enzyme to be complexed ${ }^{27}$. For this study, we determined that at $0.3 \mathrm{U} / \mathrm{mL}$, the system remained at this condition until $200 \mathrm{~min}$ of intestinal incubation allowing us to model starch hydrolysis for a considerable amount of time. We are aware that these enzymatic concentrations do not resemble the physiological environment; however, the transport of enzyme through the $\mathrm{CW}$ is independent of the concentration used and the model perfectly represents the mechanism of the system. We used lower amounts of enzyme due to experimental reasons since at larger enzyme concentrations the diffusion process will occur very fast making it impossible to quantify experimentally. Additionally, it allowed us to simplify the mathematic representation of starch hydrolysis in the model. When using high enzyme concentrations its ratio with the substrate will change moving the reaction velocity away from Vmax. At this stage other factors such as product inhibition and substrate exhaustion might also play a role in the kinetics of hydrolysis ${ }^{28}$.

In order to represent starch hydrolysis for our experimental conditions, it was necessary to determine the catalytic constant of the reaction $\left(k_{c a t}\right)$. This constant reflects enzyme accessibility to susceptible glycosidic linkages and the influence of structural constraints that might hinder starch hydrolysis ${ }^{28}$. For ICC, the presence of the cytoplasmic matrix (i.e. other starch granules 
Chapter 4

and protein bodies) represented a structural constraint that could influence starch kinetics. For this reason, mechanically damaged cells (MDC) were used as substrate to reflect as consistently as possible the properties of ICC without the $\mathrm{CW}$ entrapment. By doing so, we ensured that the enzyme could work at a velocity similar to Vmax but still considering the influence of the cytoplasmic matrix that was otherwise impossible to be determined independently. We obtained experimentally a $k_{\text {cat }}$ value of $3.2 \times 10^{4} \mathrm{~min}^{-1}$, which is considerably small to what normally reported for isolated starch $\left(1.6 \times 10^{5} \mathrm{~min}^{-1}\right)^{28}$. Most likely, such discrepancy occurred since the cytoplasmic matrix effect is included in our catalytic constant where the presence of proteins have also been found to affect starch hydrolysis due to the binding of $\alpha$-amylase to insoluble proteins $^{29}$. Furthermore, it is important to highlight that starch in MDC was hydrolysed despite of the presence of $\mathrm{CW}$ material. It has been previously found that the nature of the interactions between $\alpha$-amylase and the CW is non-active site mediated ${ }^{10}$.

\subsubsection{Diffusion of starch hydrolysis products towards the bulk phase: model validation}

As starch digestion proceeds, the products formed by enzymatic hydrolysis will diffuse through the $\mathrm{CW}$ due to the generation of a concentration gradient between ICC and the bulk phase. From literature it is known that $\alpha$-amylase produces small dextrins being maltotriose one of the most abundant ${ }^{30}$. This was further confirmed by HPAEC-PAD analysis performed at different time points during in-vitro digestion (Appendix Fig. 4-A2). Therefore, only maltotriose was considered as starch degrading products to facilitate the construction of the model. In addition to this, the only parameter considered to influence the diffusion through the $\mathrm{CW}$ pores was the size of the molecule $(0.55 \mathrm{~nm}$ radius $)$. Due to the lack of electric charges in the oligomers formed upon starch hydrolysis, electrical interactions with the $\mathrm{CW}$ components can be ruled out. As consequence, the passage of starch hydrolysates towards the bulk phase will occur at a much faster rate than what observed for $\alpha$-amylase. The hindrance coefficient estimated for maltotriose, $\mathrm{kd}_{\mathrm{s}}$, was four orders of magnitude larger than what found for $\alpha$-amylase $\left(\mathrm{kd}_{\mathrm{e}}\right)$.

The products of starch hydrolysis that diffused through the CW were quantified experimentally and used to validate the model. As seen in Fig. 4-7, the amount of oligomers predicted by the model goes in accordance to what determined experimentally after starch hydrolysis. This provides strong evidence that supports our theory about the mechanism by which starch is hydrolysed in beans. The limited starch hydrolysis in legumes has been described before by several authors $3,4,24$; however, this is the first time that a mechanistic explanation is provided giving insights about the phenomena responsible for the reduced starch digestion in these 
complex systems. In particular, our model provides a mechanistic explanation to the lag phase and the apparent sigmoidal kinetics that is observed for starch digestion in intact bean cells $s^{4,31}$ which is produced by the building up of the enzyme concentration in the intracellular compartment.

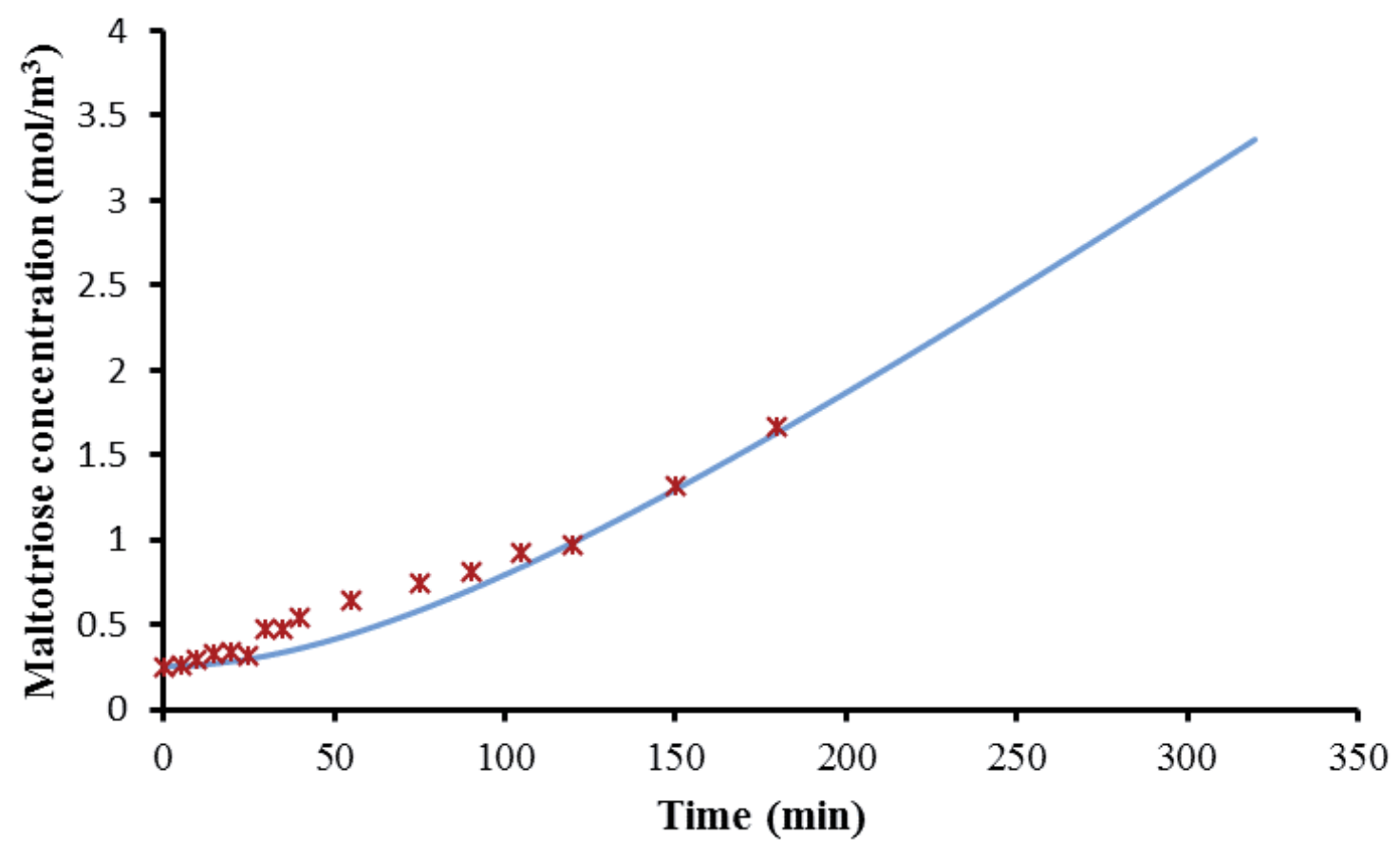

Fig. 4-7. Starch hydrolysis products in the bulk phase during in-vitro digestion of ICC. Continuous line represents the model prediction, red crosses represent the data obtained experimentally.

\subsection{Conclusion}

The consumption of plant based diets and whole grain foods has been increasing over the last years. Therefore, understanding how those complex matrices are digested should be of great concern for food scientists and industry. Due to the paucity of models that can quantitatively account for the effect of food matrix on nutrients digestion, this study proposed a mechanistic approach designed to investigate the physical and kinetic factors involved in the reduced starch digestibility of beans. It was found that the constricted pores present in the $\mathrm{CW}$ matrix and the adsorption interactions with $\alpha$-amylase were the most determinant factors that cause a delay in starch hydrolysis. Consequently, the concentration of amylase within ICC was always lower than the concentration of enzyme present in the system. By this, it was shown that the CW function goes beyond serving as a mere physical barrier that encapsulates starch. This structure also has the ability to adsorb enzymes towards its surface reducing the amount of available enzymes for hydrolysis. We believe that the knowledge gathered by this investigation is of significant relevance and helps to understand the complexity of the food matrix and its 
Chapter 4

implications in hydrolysis. Finally, the outcome of this research has wider implications than starch digestibility in beans. Other macronutrients encapsulated in different legume sources or plant-based matrices could follow similar hydrolysis mechanisms since all digestive enzymes may be affected in a comparable way by the presence of the CW.

\subsection{Acknowledgments}

We thank Erik Meulenbroeks and Wageningen Light Microscopy Centre for the help with the analysis of the samples by confocal laser scanning microscopy.

This work was supported by a grant from the Ecuadorian Secretary of Higher Education, Science, Technology and Innovation. 


\section{References}

1. Singh J, Dartois A, Kaur L. Starch digestibility in food matrix: a review. Trends Food Sci Technol. 2010;21(4):168-180.

2. Parada J, Aguilera JM. Review: starch matrices and the glycemic response. Food Sci Technol Int. 2011;17:187-204.

3. Berg T, Singh J, Hardacre A, Boland MJ. The role of cotyledon cell structure during in vitro digestion of starch in navy beans. Carbohydr Polym. 2012;87(2):1678-1688.

4. Rovalino-Córdova AM, Fogliano V, Capuano E. A closer look to cell structural barriers affecting starch digestibility in beans. Carbohydr Polym. 2018;181:994-1002.

5. Goñi I, Garcia-Alonso A, Saura-Calixto F. A starch hydrolysis procedure to estimate glycemic index. Nutr Res. 1997;17(3):427-437.

6. Al-Rabadi GJS, Gilbert RG, Gidley MJ. Effect of particle size on kinetics of starch digestion in milled barley and sorghum grains by porcine alpha-amylase. J Cereal Sci. 2009;50(2):198-204.

7. Edwards CH, Warren FJ, Milligan PJ, Butterworth PJ, Ellis PR. A novel method for classifying starch digestion by modelling the amylolysis of plant foods using fi rst-order enzyme kinetic principles. Food Funct. 2014:1-8.

8. Mahasukhonthachat K, Sopade PA, Gidley MJ. Kinetics of starch digestion in sorghum as affected by particle size. J Food Eng. 2010;96(1):18-28.

9. Isaksson G, Lundquist I, Ihse I. Effect of Dietary Fiber on Pancreatic Enzyme Activity In Vitro: The Importance of Viscosity, pH, Ionic Strength, Adsorption, and Time of Incubation. Gastroenterology. 1982;82(5):918-924.

10. Dhital S, Gidley MJ, Warren FJ. Inhibition of $\alpha$-amylase activity by cellulose: Kinetic analysis and nutritional implications. Carbohydr Polym. 2015;123:305-312.

11. Bhattarai RR, Dhital S, Wu P, Chen X, Gidley M. Digestion of isolated legume cells in a stomach-duodenum model: three mechanisms limit starch and protein hydrolysis. Food Funct. 2017;8:2573-2582.

12. Minekus M, Alminger M, Alvito $\mathrm{P}$, et al. A standardised static in vitro digestion method suitable for food - an international consensus. Food Funct. 2014;5(6):1113-1124.

13. Segel IH. Enzyme Kinetics Behaviour and Analysis of Rapid Equilibrium and Steady State Enzyme Systems. (Sons JW\&, ed.). California: Wiley classics libary; 1993. 
Chapter 4

14. Dhital S, Warren FJ, Zhang B, Gidley MJ. Amylase binding to starch granules under hydrolysing and non-hydrolysing conditions. Carbohydr Polym. 2014;113:97-107.

15. Meyer KH, E.H. F, Bernferld B. Molecular Weight of $\alpha$-Amylase. Nature. 1947;160(4078):899.

16. Sano Y, Yamamoto S. Mutual Diffusion Coefficient of Aqueous Sugar Solutions. J Chem Eng Japan. 1993;26(6):633-636.

17. Edwards CH, Warren FJ, Milligan PJ, Butterworth PJ, Ellis PR. A novel method for classifying starch digestion by modelling the amylolysis of plant foods using first-order enzyme kinetic principles. Food Funct. 2014;5:2751-2758.

18. Brett CT, Waldron KW. Cell wall architecture and the skeletal role of the cell wall. In: Black B, Charlwood M, eds. Physiology and Biochemistry of Plant Cell Walls. London: Chapman \& Hall; 1996:44-74.

19. McEwen TJ, Dronzek BL, Bushuk W. A scanning electron microscope study of fababean seed. Cereal Chem. 1974;51:750-757.

20. Ford DM, Glandt ED. Steric hindrance at the entrances to small pores. J Memb Sci. 1995;107(1-2):47-57.

21. Fardet A, Hoebler C, Djelveh G, Barry JL. Restricted Bovine Serum Albumin Diffusion through the Protein Network of Pasta. J Agric Food Chem. 1998;46(11):4635-4641.

22. Robertson BC, Zydney AL. Hindered protein diffusion in asymetric ultrafiltration membranes with highly constricted pores. J Memb Sci. 1990;49:287-303.

23. Dechadilok P, Deen WM. Hindrance factors for diffusion and convection in pores. Ind Eng Chem Res. 2006;45(21):6953-6959.

24. Pallares Pallares A, Alvarez Miranda B, Truong NQA, et al. Process-induced cell wall permeability modulates the: In vitro starch digestion kinetics of common bean cotyledon cells. Food Funct. 2018;9(12):6544-6554.

25. Barry PH, Diamond JM. Effects of unstirred layers on membrane phenomena. Physiol Rev. 1984;64(3):763-872.

26. Dhital S, Dolan G, Stokes JR, Gidley MJ. Enzymatic hydrolysis of starch in the presence of cereal soluble fibre polysaccharides. Food Funct. 2014;5(3):579.

27. Dona AC, Pages G, Gilbert RG, Kuchel PW. Digestion of starch: In vivo and in vitro kinetic 
models used to characterise oligosaccharide or glucose release. Carbohydr Polym.

2010;80(3):599-617.

28. Butterworth PJ, Warren FJ, Ellis PR. Human $\alpha$-amylase and starch digestion: An interesting marriage. Starch - Stärke. 2011;63(7):395-405.

29. Yu W, Zou W, Dhital S, et al. The adsorption of $\alpha$-amylase on barley proteins affects the in vitro digestion of starch in barley flour. Food Chem. 2018;241:493-501.

30. Banks W, Greenwood CT, Khan KM. Studies on starch degrading enzymes. Part XIV. The multiple forms of porcine pancreatic alpha amylase. Carbohydr Res. 1971;19:233-242.

31. Pallares Pallares A, Loosveldt B, Karimi SN, Hendrickx M, Grauwet T. Effect of processinduced common bean hardness on structural properties of in vivo generated boluses and consequences for in vitro starch digestion kinetics. Br J Nutr. 2019;122(4):388-399. 
Chapter 4

\section{Appendices 4}

\section{Diffusion of enzyme and products in and out of ICC}

Due to affinity/adsorption of the enzyme to cell wall components, the concentration of $\alpha$ amylase will be different in the cell wall $\left(C e_{w}\right)$ and inside the intact cell $\left(C e_{i n}\right)^{1}$. These 2 concentrations could not be measured separately; therefore, we defined $C e_{a v}$, as the average of the aforementioned concentrations, and corresponds to the concentration of the pellet of intact cells after centrifugation.

The increase of $C e_{a v}$ in time can be represented by Eq.A1, in which $N_{e}$ is the enzyme flux due to diffusion, $A$ is the total surface area of the intact cells and $V_{I C}$ their total volume.

$$
\frac{d C e_{a v}}{d t}=N_{e}(t) \frac{A}{V_{I C}}
$$

In the same way, the reduction in the concentration of $\alpha$-amylase in the bulk $\left(C e_{b}\right)$ could be represented by Eq. A2, in which V is the volume of the bulk phase.

$$
\frac{d C e_{b}}{d t}=-N_{e}(t) \frac{A}{V}
$$

The transport of the hydrolysates could be represented in a similar fashion. The only addition is a production term representing the hydrolysis rate inside the intact cell $\left(k_{c a t} C e_{i n}\right)$. Thus, the change in concentration of the hydrolysis products inside ICC $\left(C s_{i n}\right)$ and in the bulk $\left(C s_{b}\right)$ were expressed as shown in Eq. A3 and A4, in which $N_{s}$ represents the flux of the hydrolysis products from ICC towards the bulk.

$$
\begin{aligned}
& \frac{d C s_{\text {in }}}{d t}=k_{c a t} C e_{\text {in }}-N_{s}(t) \frac{A}{V_{I C}} \\
& \frac{d C s_{b}}{d t}=N_{s}(t) \frac{A}{V}
\end{aligned}
$$

The enzymes diffuse through two 'layers'. The first one is the stagnant layer located just outside the surface of the cell wall. Here, according to film theory, convection due to stirring does not 
occur and only diffusion takes place (Fig. 4-A1) ${ }^{2}$. The second layer is the cell wall, in which diffusion is hindered due to constriction and electrical interactions. Therefore, it is necessary to multiply the enzyme diffusion coefficient $\left(D_{e}\right)$ by a correction factor $\left(K d_{e}\right)$ commonly known as hindrance factor.

Considering the concentrations as depicted in Figure 4-A1, one flux equation per component can be written using Fick's law for each layer. Eq. A5 and A6 correspond to the enzyme diffusion through the stagnant layer and cell wall respectively. Notice that the same $N_{e}$ applies for both layers.

$$
\begin{aligned}
& N_{e}=D_{e} \frac{\left(C e_{b}-C e_{b i}\right)}{Z} \\
& N_{e}=D_{e} k d_{e} \frac{\left(C e_{w i}-C e_{w j}\right)}{\delta}
\end{aligned}
$$
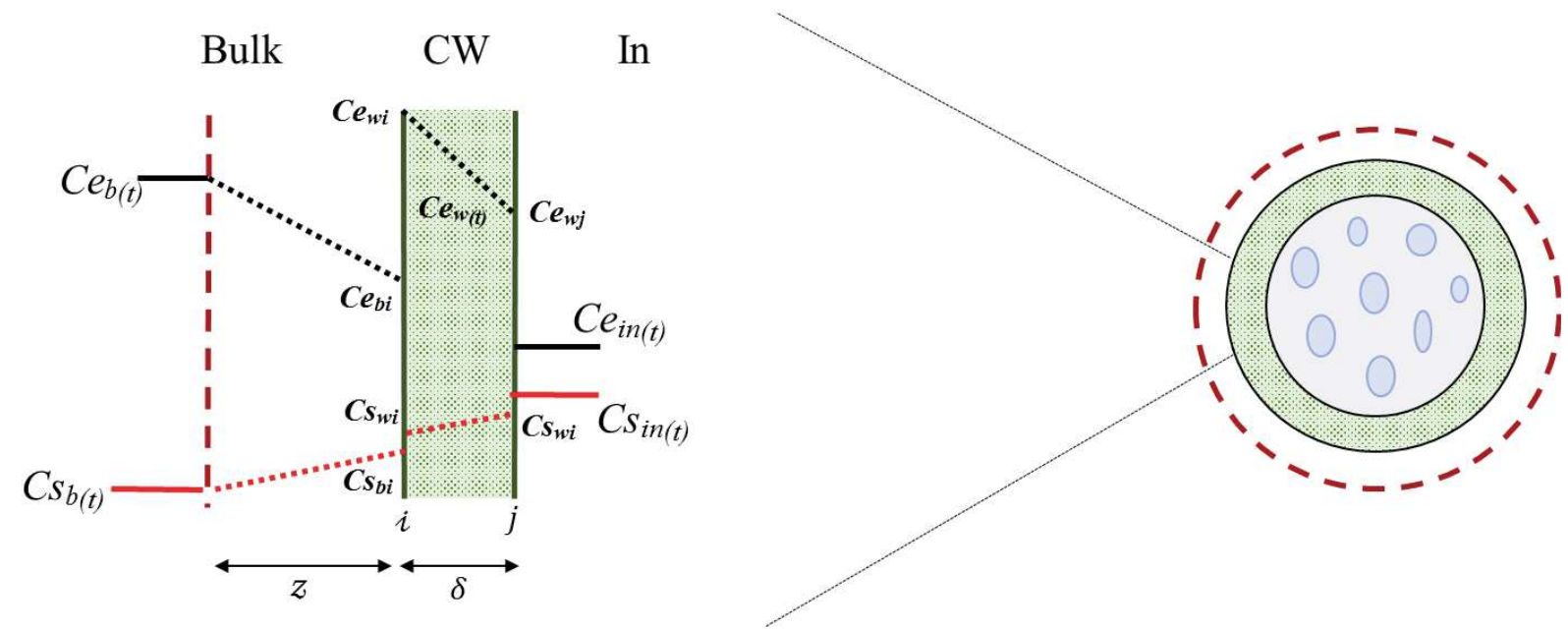

Fig. 4-A1. Schematic representation of $\alpha$-amylase concentration profiles $(\boldsymbol{e})$ and starch hydrolysis products $(\boldsymbol{s})$ across the stagnant layer $(\mathbf{z})$ and cell wall $(\boldsymbol{\delta})$. The scheme includes the concentration in the bulk of the phases and in the interphases $(\boldsymbol{i}$ and $\boldsymbol{j})$.

We define a partition coefficient $P$, which is the ratio of the concentration of a component at equilibrium in two contiguous phases. Since in this case, we assume local equilibrium at the interface, we obtain:

$$
P_{e}=\frac{C e_{w(e q)}}{C e_{b(e q)}}=\frac{C e_{w(e q)}}{C e_{i n(e q)}}=\frac{C e_{w i}}{C e_{b i}}=\frac{C e_{w j}}{C e_{i n}}
$$




\section{Chapter 4}

Notice that we assume that the inner phase and the bulk phase are similar. Thus, the same enzyme partition coefficient, $P_{e}$, describes the equilibrium between the cell wall and bulk, and between the cell wall and the inside part of the intact cell.

Additionally, we can define the external mass transfer coefficient $k$ as follows:

$$
k_{e}=\frac{D_{e}}{Z}
$$

Considering the definition of $P_{e}$ and $k_{e}$, we can rewrite Eq. A5 and A6:

$$
\begin{aligned}
& N_{e}\left(\frac{1}{k_{e}}\right)=\left(C e_{b}-\frac{C e_{w i}}{P_{e}}\right) \\
& N_{e}\left(\frac{1}{\frac{D_{e} k d_{e} P_{e}}{\delta}}\right)=\left(\frac{C e_{w i}}{P_{e}}-C e_{i n}\right)
\end{aligned}
$$

By summing Eq. A9 and A10, we can obtain an expression for $N_{e}$ as function of $C e_{b}$ and $C e_{i n}$.

$$
N_{e}=\left(\frac{1}{k_{e}}+\frac{1}{\frac{D_{e} k d_{e} P_{e}}{\delta}}\right)^{-1}\left(C e_{b}-C e_{i n}\right)
$$

By defining $P_{S}$ and $k_{S}$ and following a similar approach as done with the enzyme, an equivalent expression could be obtained for the products of hydrolysis.

$$
N_{s}=\left(\frac{1}{k_{s}}+\frac{1}{\frac{D_{s} k d_{s} P_{s}}{\delta}}\right)^{-1}\left(C s_{i n}-C s_{b}\right)
$$

By replacing $\mathrm{N}_{\mathrm{e}}$ and $\mathrm{N}_{\mathrm{s}}$ (Eq. A11 and A12) in Eq. A1-A4 a set of differential equations could be obtained. They represent the change in concentration of enzymes and products in the system during starch hydrolysis.

$$
\frac{\mathrm{dCe}_{\mathrm{av}}}{\mathrm{dt}}=\left(\frac{1}{\mathrm{k}_{\mathrm{e}}}+\frac{1}{\frac{\mathrm{D}_{\mathrm{e}}}{\delta} \mathrm{P}_{\mathrm{e}} \mathrm{kd} \mathrm{e}_{\mathrm{e}}}\right)^{-1}\left(\mathrm{Ce}_{\mathrm{b}}-\mathrm{Ce}_{\mathrm{in}}\right) \frac{\mathrm{A}}{\mathrm{V}_{\mathrm{IC}}}
$$




$$
\begin{aligned}
& \frac{d C e_{b}}{d t}=-\left(\frac{1}{k_{e}}+\frac{1}{\frac{D_{e}}{\delta} P_{e} k d_{e}}\right)^{-1}\left(C e_{b}-C e_{i n}\right) \frac{A}{V_{T}} \\
& \frac{\mathrm{dCs}_{\mathrm{in}}}{\mathrm{dt}}=\mathrm{k}_{\mathrm{cat}} \mathrm{Ce}_{\mathrm{in}}-\left(\frac{1}{\mathrm{k}_{\mathrm{s}}}+\frac{1}{\frac{\mathrm{D}_{\mathrm{s}}}{\delta} \mathrm{P}_{\mathrm{s}} \mathrm{kd}_{\mathrm{s}}}\right)^{-1}\left(\mathrm{Cs}_{\mathrm{in}}-C \mathrm{~s}_{\mathrm{b}}\right) \frac{\mathrm{A}}{\mathrm{V}_{\mathrm{IC}}} \\
& \frac{\mathrm{dC \textrm {s } _ { \mathrm { b } }}}{\mathrm{dt}}=\left(\frac{1}{\mathrm{k}_{\mathrm{s}}}+\frac{1}{\frac{\mathrm{D}_{\mathrm{s}}}{\delta} \mathrm{P}_{\mathrm{s}} \mathrm{kd}_{\mathrm{s}}}\right)^{-1}\left(\mathrm{Cs}_{\mathrm{in}}-\mathrm{Cs}_{\mathrm{b}}\right) \frac{\mathrm{A}}{\mathrm{V}_{\mathrm{T}}}
\end{aligned}
$$

\section{Calculation of $k, P$ and $K$}

Although the mass transfer coefficient is defined as $k=D / z$, it cannot be calculated in this way since $z$ is unknown. $k$ is calculated using the following empirical expression obtained by Brian and Hales for freely moving particles with low Reynolds number ${ }^{3}$.

$$
k=\frac{D}{d_{I C}} \sqrt{4+1.21\left(\frac{R e_{p} \eta_{l}}{\rho_{l} D}\right)^{0.67}}
$$

In which $d_{I C}$ corresponds to the diameter of ICC, while $\eta_{l}$ and $\rho_{l}$ are the viscosity and density of the surrounding liquid (water) at the experimental temperature.

For the calculation of Reynolds $\left(R e_{p}\right)$ and Galilei number $(G a)$ we used the following expressions, in which $g$ corresponds to the gravity constant, and $\rho_{I C C}$ the density of the particle, in this case the density of ICC, which was found to be $1200 \mathrm{~kg} / \mathrm{m}^{3}$.

$$
\begin{aligned}
& R e_{p}=G a / 18 \\
& G a=\frac{g d_{I C}^{3} \rho_{l}\left(\rho_{I C C}-\rho_{l}\right)}{\eta_{l}{ }^{2}}
\end{aligned}
$$

Since the enzyme is a charged molecule, electrical interactions (adsorption) is expected to take place inside the cell wall ${ }^{1}$. Thus, besides the steric exclusion due to its size, more mechanisms affect its diffusion inside ICC. Consequently, an upfront estimation of $P_{e}$ and $K d_{e}$ is not possible. On the other hand, the hydrolysis products are neutral dextrins, for which the only mechanism affecting its diffusion through the cell wall is steric exclusion ${ }^{4}$. In this case, $P_{S}$ and 
Chapter 4

$K d_{s}$ can be estimated by approximating these molecules to a spherical geometry and by considering the cell wall pores to be cylindrical.

The first step was to find the radius of DP3 dextrin $\left(r_{s}\right)$ by using Stokes-Einstein equation in which $k_{B}$ is the Boltzmann constant.

$$
r_{s}=\frac{k_{B} T}{6 \pi \eta_{l} D_{s}}
$$

The diffusion coefficient of the dextrin could be obtained as function of its molecular weight as obtained by Sano and Yamamoto ${ }^{5}$.

$$
D_{S}=\frac{T}{9.5 \cdot 10^{13} M w_{S}^{1 / 3} \eta_{H 2 O}}
$$

The following equations are normally used in membrane science to calculate $P$ and $K d$ for neutral spherical molecules ${ }^{6}$ :

$$
\begin{aligned}
& P_{s}=\left(1-\lambda_{s}\right)^{2} \\
& \lambda_{s}=\frac{r_{s}}{r_{p}} \\
& K d=\frac{H}{P_{S}} \\
& H(\lambda)=1+\frac{9}{8} \lambda \ln _{\lambda}-1.56034 \lambda+0.528155 \lambda^{2}+1.91521 \lambda^{3} \\
& -2.81903 \lambda^{4}+0.270788 \lambda^{5}+1.10115 \lambda^{6} \\
& -0.435933 \lambda^{7}
\end{aligned}
$$

\section{High performance anion-exchange chromatography (HPAEC-PAD)}

The chain length distribution of starch hydrolysis by $\alpha$-amylase was qualitatively assessed by high performance anion exchange chromatography with pulsed amperometric detection (HPAEC-PAD). Hydrolysed samples were centrifuged at $4000 \mathrm{x} g$ for $15 \mathrm{~min}$ after which the 
supernatant and pellet were separated. Supernatants were collected and diluted in water until reaching a concentration of $1 \mathrm{mg} / \mathrm{mL}$. Samples were filtered with $0.45 \mu \mathrm{m}$ PFTE filter prior injection. HPAEC-PAD system comprised a CarboPac PA-1 column $(2 \times 250 \mathrm{~mm})$ equipped with an electrochemical detector (Thermo Fisher Scientific, Breda, The Netherlands). Eluents $\mathrm{A}, \mathrm{B}$ and $\mathrm{C}$ consisted of water, $100 \mathrm{mM} \mathrm{NaOH}$ and $0.5 \mathrm{M} \mathrm{NaOAc}$ respectively. A flow rate of $0.25 \mathrm{~mL} \mathrm{~min}^{-1}$ was applied, and the column equilibrated with $20 \mathrm{mM} \mathrm{NaOH}$. Elution was performed by mixing eluent $\mathrm{A}, \mathrm{B}$ and $\mathrm{C}$ as follows: $0 \mathrm{~min},(80: 20: 0) ; 5 \mathrm{~min},(80: 20: 20) ; 60 \mathrm{~min}$, (20:20:60); $60.1 \mathrm{~min},(80: 20: 0) ; 75 \mathrm{~min},(80: 20: 0)$. Glucose, maltotriose, maltopentahose and maltoheptaose were used as standards for peak identification. The data was analysed in Chromeleon software, version 7.2 (Dionex Corporation, Sunnyvale, CA, USA).

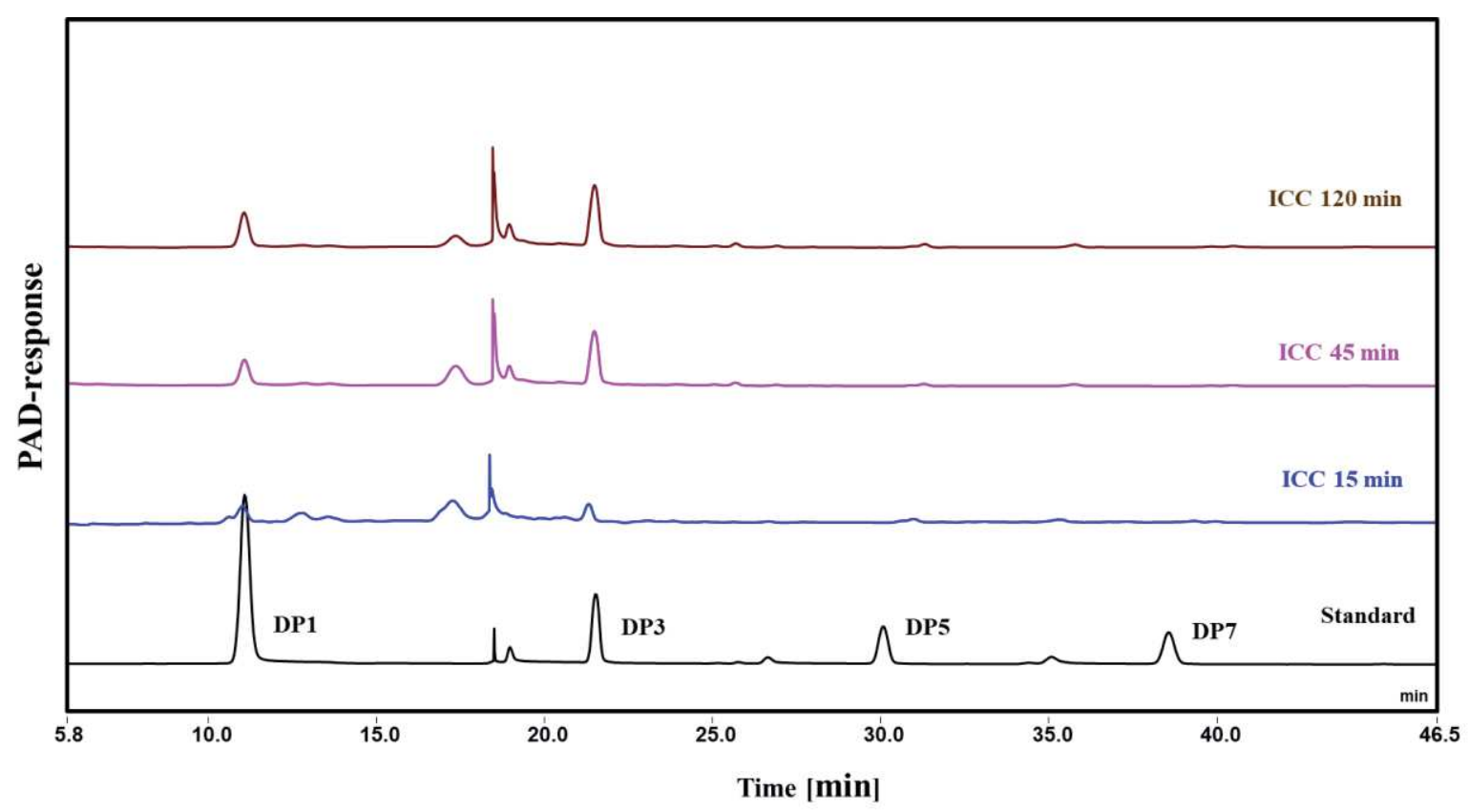

Fig. 4-A2. High performance anion exchange chromatography (HAPEC) patterns of starch hydrolysis in ICC after 15, 45 and 150 min of in-vitro digestion. Degree of polymerization (DP) are indicated in the standard as reference.

\section{Catalytic constant determination $\left(\boldsymbol{k}_{\text {cat }}\right)$}

The catalytic constant was determined using mechanically damaged cells (MDC) as substrate. Samples were hydrolysed in-vitro following the guidelines of Minekus, et $\mathrm{al}^{7}$ with some modifications. Briefly, samples were subjected to gastric digestion with pepsin for $30 \mathrm{~min}$ and subsequently the $\mathrm{pH}$ was increased up to 7 for intestinal incubation. Trypsin, chymotrypsin and alpha amylase were incorporated in the system and the samples where hydrolysed for up to 80 min. Different $\alpha$-amylase concentrations were utilized $(0.03,0.3$ and $1 \mathrm{U} / \mathrm{mL})$ for starch hydrolysis. Aliquots where taken at different time points during digestion, incubated with 
amyloglucosidase and the products of digestion quantified by GOPOD method as described by Rovalino-Córdova, et $\mathrm{al}^{8}$. Samples were expressed as mmol of maltotriose per Litre and the percentage of starch consumed at each time point was calculated. The data points where starch was hydrolysed less than $5 \%$ were selected for $k_{\text {cat }}$ calculation. The formula employed for $k_{\text {cat }}$ quantification expresses the number of moles of substrate transformed per minute per mole of enzyme (units per $\mu$ mole of enzyme).

$$
k_{\text {cat }}=\frac{\operatorname{Vmax}}{[E]_{t}}=\frac{\mu \operatorname{moles}(S \rightarrow P) \times \min ^{-1}}{\mu \operatorname{moles}(\text { of } E) \times m L^{-1}}=\min ^{-1}
$$

Where the numerator was calculated from the slope of the linear portion of the curve that represents starch hydrolysis versus time and the denominator the concentration of enzyme utilized in the experiment.

$$
\alpha-\text { amylase }=0.03 \mathrm{U} / \mathrm{mL}
$$
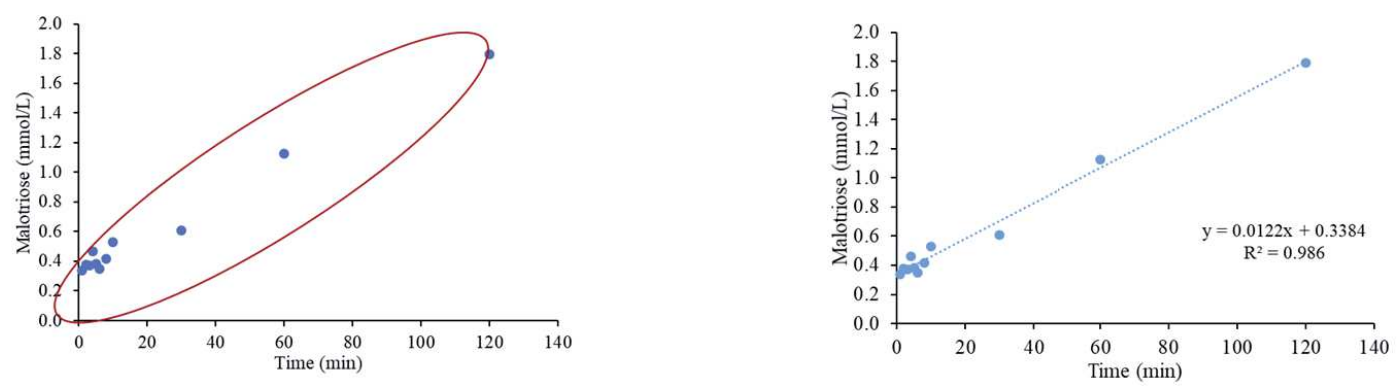

Sample 1
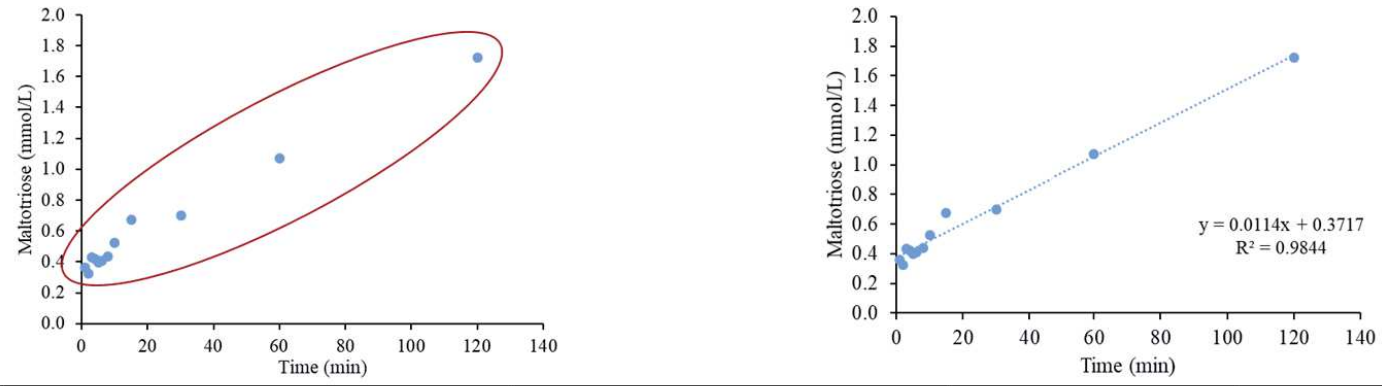

\begin{tabular}{|c|c|c|c|}
\hline & Sample 1 & Sample 2 & \\
\hline Slope & 0.0122 & 0.0114 & $\mathrm{mmol} / \mathrm{L} . \mathrm{min}$ \\
\hline$[\mathrm{E}] \mathrm{t}$ & $3.29 \mathrm{E}-07$ & $3.29 \mathrm{E}-07$ & $\mathrm{mmol} / \mathrm{L}$ \\
\hline $\mathrm{kp}$ & $3.7 . \mathrm{E}+04$ & $3.5 . \mathrm{E}+04$ & $\mathrm{~min}-1$ \\
\hline
\end{tabular}

Fig. 4-A3. kcat determination using $0.03 \mathrm{U} / \mathrm{mL}$ of $\alpha$-amylase. Left column indicates the time points selected for analysis which showed a linear relationship between product formation and time. All the time points selected in the analysis satisfied the condition of having less than $5 \%$ of the total starch hydrolysed. 


\section{$\alpha-$ amylase $=0.3 \mathrm{U} / \mathrm{mL}$}
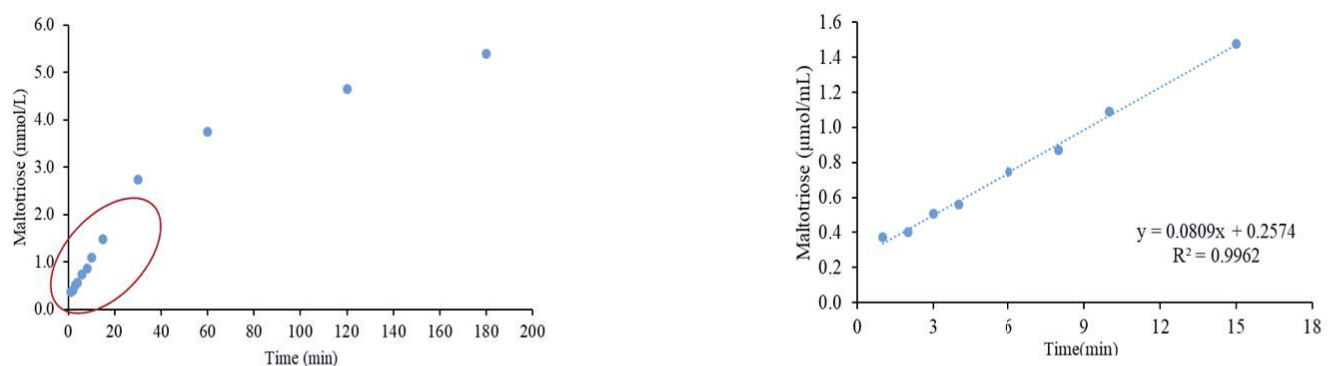

Sample 1
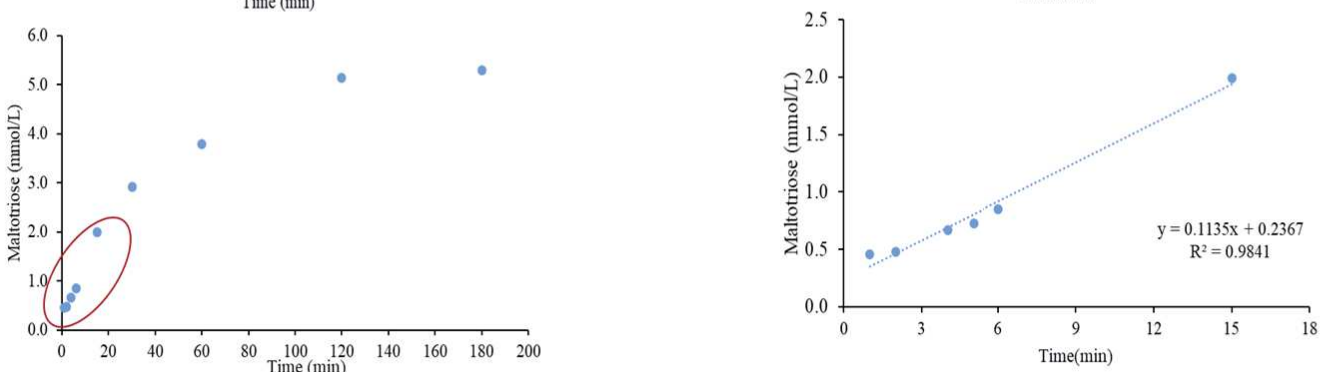

Sample 2

\begin{tabular}{|c|c|c|c|}
\hline & Sample 1 & Sample 2 & \\
\hline Slope & 0.0809 & 0.1135 & $\mathrm{mmol} / \mathrm{L} . \mathrm{min}$ \\
\hline$[\mathrm{E}] \mathrm{t}$ & $3.29 \mathrm{E}-06$ & $3.29 \mathrm{E}-06$ & $\mathrm{mmol} / \mathrm{L}$ \\
\hline $\mathrm{kp}$ & $2.5 . \mathrm{E}+04$ & $3.5 . \mathrm{E}+04$ & $\mathrm{~min}-1$ \\
\hline
\end{tabular}

Fig. 4-A4. kcat determination using $0.3 \mathrm{U} / \mathrm{mL}$ of $\alpha$-amylase. Left column indicates the time points selected for analysis which showed a linear relationship between product formation and time. All the time points selected in the analysis satisfied the condition of having less than $5 \%$ of the total starch hydrolysed. 


\section{$\alpha-$ amylase $=1 \mathrm{U} / \mathrm{mL}$}
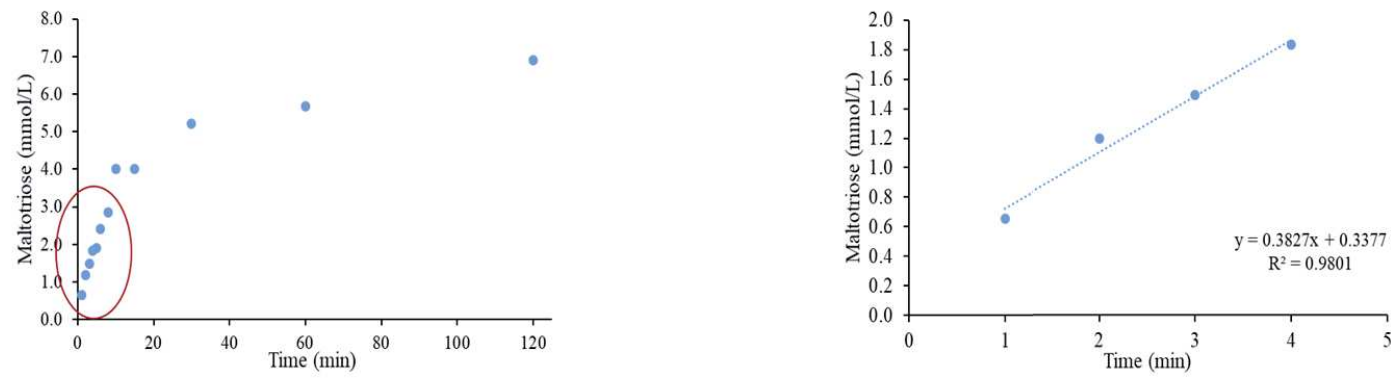

Sample 1
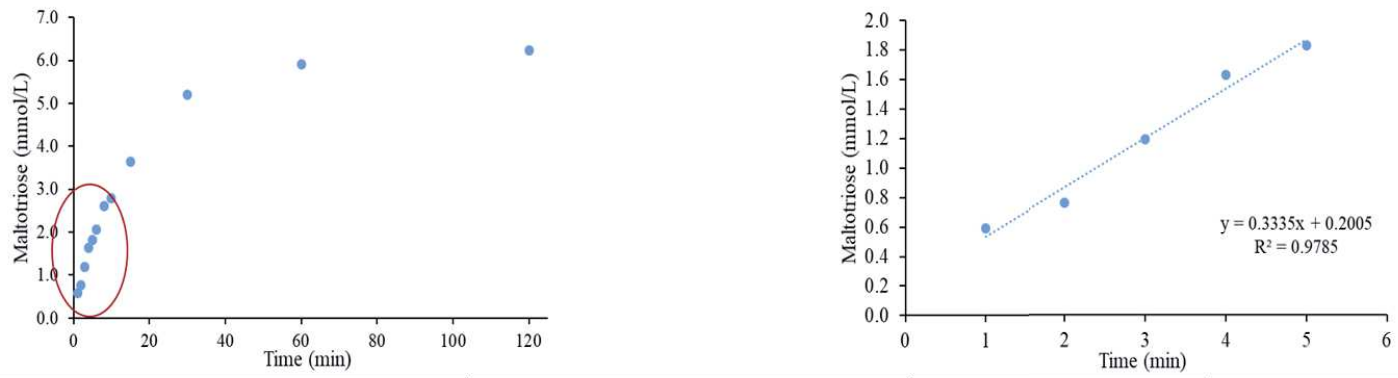

Sample 2

\begin{tabular}{|c|c|c|c|}
\hline & Sample 1 & Sample 2 & \\
\hline Slope & 0.3827 & 0.3335 & mmol/L.min \\
\hline$[E] t$ & $1.10 E-05$ & $1.10 E-05$ & $\mathrm{mmol} / \mathrm{L}$ \\
\hline $\mathrm{kp}$ & $3.5 . \mathrm{E}+04$ & $3.0 . \mathrm{E}+04$ & $\mathrm{~min}-1$ \\
\hline
\end{tabular}

Fig. 4-A5. kcat determination using $1 \mathrm{U} / \mathrm{mL}$ of $\alpha$-amylase. Left column indicates the time points selected for analysis which showed a linear relationship between product formation and time. All the time points selected in the analysis satisfied the condition of having less than $5 \%$ of the total starch hydrolysed.

\section{References:}

1. Dhital S, Gidley MJ, Warren FJ. Inhibition of $\alpha$-amylase activity by cellulose: Kinetic analysis and nutritional implications. Carbohydr Polym. 2015;123:305-312.

2. Riet K van't, Tramper J. Basics Bioreactor Design. Wageningen: Marcel Dekker, Inc.; 1991.

3. Brian PLT, Hales HB. Effects of transpiration and changing diameter on heat and mass transfer to spheres. AIChE J. 1969;15(3):419-425.

4. Aguirre Montesdeoca V, Bakker J, Boom RM, Janssen AEM, Van der Padt A. Ultrafiltration of non-spherical molecules. J Memb Sci. 2019;570-571:322-332.

5. Sano Y, Yamamoto S. Mutual Diffusion Coefficient of Aqueous Sugar Solutions. J Chem Eng Japan. 1993;26(6):633-636.

6. Dechadilok P, Deen WM. Hindrance factors for diffusion and convection in pores. Ind Eng Chem Res. 2006;45(21):6953-6959.

7. Minekus M, Alminger M, Alvito $\mathrm{P}$, et al. A standardised static in vitro digestion method suitable for food - an international consensus. Food Funct. 2014;5(6):1113-1124.

8. Rovalino-Córdova AM, Fogliano V, Capuano E. A closer look to cell structural barriers affecting starch digestibility in beans. Carbohydr Polym. 2018;181:994-1002. 


\section{Chapter 5}

026

\section{Effect of bean structure on microbiota utilization of plant nutrients: an in-vitro study using the simulator of the human intestinal microbial ecosystem $\left(\mathrm{SHIME}^{\circledR}\right)$}

This chapter is based on:

Ana M. Rovalino-Córdova, Vincenzo Fogliano, Edoardo Capuano. Effect of bean structure on microbiota utilization of plant nutrients: an in-vitro study using the simulator of the human intestinal microbial ecosystem (SHIME®). Submitted for publication. 


\section{Abstract}

Colonic fermentation of starch provides health benefits for the host. However, physical characteristics of the food matrix could limit the availability of starch and other dietary fibres for microbiota utilization. In this study, the influence of food structural aspects was studied by using cotyledon cells from red kidney beans with different levels of cellular integrity. In-vitro colonic fermentation was conducted in the simulator of the human intestinal microbial ecosystem $\left(\mathrm{SHIME}^{\circledR}\right)$ where the utilization of starch and other non-starch polysaccharides was investigated along the three colon regions. Results indicate that plant cell integrity modulates nutrient utilization by gut microbiota where higher amounts of starch were delivered to distal regions of the colon in intact samples. Other dietary fibre constituents, such as pectin, were also differentially fermented depending on the level of cellular integrity. Moreover, bean supplementation produced changes in microbiota population favouring the proliferation of Bifidobacterium species. 


\subsection{Introduction}

Colonic fermentation of carbohydrates provides beneficial physiological effects for human health ${ }^{1}$. Non-digestible polysaccharides, commonly known as dietary fibre, are the primary source of carbon and energy for gut microbiota which favours bacterial diversity ${ }^{2}$, production of gas, organic acids and short chain fatty acids (SCFA) $)^{3,4}$. Therefore, changes in the quantity and type of carbohydrates consumed in the diet will influence bacterial population and the metabolic products formed by their metabolism ${ }^{5}$. It has been found that dietary fibres are not equally fermented by the gut microbiota and a hierarchic order is followed where simple sugar, oligosaccharides and starch are preferred over soluble and insoluble non-starch polysaccharides $(\mathrm{NSP})^{6}$. Differences in solubility, size, chemical structure and types of linkages within the fibres are the main factors responsible of those preferences ${ }^{1}$.

Due to this, special attention has been payed to resistant starch (RS), i.e. the portion of starch (or its hydrolysis products) that escapes digestion and reach the large intestine. Several health benefits are associated with the fermentation of RS, the most relevant being related to a higher production of butyric acid, which has been associated to the improvement of bowel health against ulcerative colitis and colon cancer $^{7-10}$. The resistance of starch to small intestinal digestion has been attributed to several causes: physical entrapment by cell wall polymers, (crystalline) structure of the starch granule, retrogradation, chemical modification or crosslinking ${ }^{11}$. Therefore, the amount of RS in the diet will vary depending on food composition, structure and the cooking methods applied.

Beans, and legumes in general, possess structural and compositional characteristics that has deserved the attention of many scientists in the last years. Legumes are mainly composed of carbohydrates (500-700 g. $\mathrm{kg}^{-1}$ dry basis) a fraction of which is undigested in the small intestine thereby becoming substrate for colonic fermentation ${ }^{4}$. Those fractions include RS, poly- and oligosaccharides that exert beneficial effects for the gut health ${ }^{12}$. Colonic fermentation studies conducted with legumes using human and animal inoculum revealed that their indigestible fraction increases butyric acid concentration ${ }^{4,10}$ and produces changes in bacterial population ${ }^{5}$. However, most of these studies were performed using bean powders instead of intact plant tissues thereby neglecting the influence of the food matrix. In legumes this is of particular importance since the cell wall matrix (which encapsulates starch and proteins) has a great influence in macronutrients digestion ${ }^{13}$. We believe that the structural integrity of bean cells could have a great impact on microbial fermentation of RS and other bean components. To the 
best of our knowledge, the fermentation of NSP within a complex cell wall matrix (CW) and its impact on RS utilization by microbiota has not been fully addressed. Only few studies that used intact legume structures were conducted employing fermentation models that were not able to differentiate between the three portions of the colon ${ }^{14}$.

This study aims at unravelling the fate of intact cotyledon cells (ICC) from red kidney beans and RS utilization along the large intestinal tract using the simulated human intestinal microbial ecosystem (SHIME $\left.{ }^{\circledR}\right)$. We hypothesize that due to cell wall entrapment RS could be fermented slower and more distally compared to a sample wherein this natural encapsulation was lost. The integrity of bean cells could also trigger changes in microbiota population along the three portions of the large intestine.

\subsection{Experimental section}

\subsubsection{Materials}

Red kidney beans were purchased from the local supermarket (Wageningen, Netherlands). All other reagents were of analytical grade and purchased from Sigma Aldrich (St. Louis MO, USA) unless stated otherwise.

\subsubsection{Preparation of intact and mechanically damaged cells}

Intact cotyledon cells (ICC) were isolated from red kidney beans according to the protocol described by Rovalino-Cordova, et $\mathrm{al}^{13}$. In short, soaked beans were cooked for $1 \mathrm{~h}$ in boiling water and subsequently mashed with the use of a mortar and pestle. Bean cells were isolated by the use of a wet sieve shaker; samples retained in a sieve with a mesh size of $70 \mu \mathrm{m}$ were collected and used for further analysis. Mechanically damaged cells (MDC) were obtained by stirring ICC for $24 \mathrm{~h}$ at high speed rate (1500rpm). Cell disruption was confirmed by the use of a light microscope as indicated by Rovalino-Cordova et $\mathrm{al}^{13}$.

\subsubsection{Simulator of the human intestinal microbial ecosystem $\left(S H I M E^{\circledR}\right)$ model}

SHIME $^{\circledR}$ system (PRODIGEST, Belgium) was employed to mimic large intestinal fermentation. This reactor comprise a series of double jacketed vessels connected in sequence that mimic the human gastrointestinal tract (Fig. 5-1). The temperature of all vessels was kept constant at $37^{\circ} \mathrm{C}$ with a total retention time of $72 \mathrm{~h}$ and anaerobiosis ensured by daily nitrogen flushing of the head space $(10 \mathrm{~min})^{15}$. In this study, the samples were only subjected to colonic fermentation; therefore, they were not treated with simulated gastric or pancreatic juices. Three 
separate vessels were used to represent the ascending (AC) (pH 5.60-5.90), transverse (TC) (pH 6.15-6.40) and descending (TC) $(\mathrm{pH}$ 6.60-6.90) colon and the $\mathrm{pH}$ of each vessel was kept constant by the use of automated $\mathrm{pH}$ controllers ${ }^{16}$. Experimental setup started by stabilizing faecal inoculum in each of the three vessels representing AC, TC and DC colon respectively as described by Koper, et $\mathrm{al}^{17}$. Two healthy volunteers of Caucasian ethnicity, non-smokers, aged between 25-35 years old with no history of antibiotic treatment for at least 6 months before stool collection were recruited as donors. Bacterial inoculum was left for stabilization (basal period) in the SHIME ${ }^{\circledR}$ system for ten days prior the start of the treatment. During this time, bacteria were fed three times per day with a carbohydrate rich medium $\left[1.2 \mathrm{~g} \mathrm{~L}^{-1}\right.$ arabinogalactan, $2.0 \mathrm{~g} \mathrm{~L}^{-1}$ pectin, $0.5 \mathrm{~g} \mathrm{~L}^{-1}$ xylan, $0.4 \mathrm{~g} \mathrm{~L}^{-1}$ glucose, $3.0 \mathrm{~g} \mathrm{~L}^{-1}$ yeast extract, 1.0 $\mathrm{g} \mathrm{L}^{-1}$ special peptone, $3.0 \mathrm{~g} \mathrm{~L}^{-1}$ mucin, $0.5 \mathrm{~g} \mathrm{~L}^{-1}$ 1-cysteine- $\mathrm{HCl}$, and $4.0 \mathrm{~g} \mathrm{~L}^{-1} \operatorname{starch}^{17}$ ] enabling the microbial community to adapt to the environmental conditions of the different colon vessels. After the stabilization period, the system was fed three times per day for 12 consecutive days with a mixture of a carbohydrate-based medium that contained all the components previously mentioned except for starch that was replaced by the addition of either ICC or MDC. The ratio of bean cells and medium employed was 60:40 respectively to preserve as consistently as possible the initial feed concentration. Samples were taken from each vessel every three days by withdrawing an aliquot that did not exceed $10 \%$ of the content in each vessel. These aliquots were always taken at the same time of the day, i.e. before the start of the second feeding. Immediately after sampling, aliquots were centrifuged (10 min, $2000 \mathrm{x} \mathrm{g})$, the pellet and supernatant separated and frozen at $-20^{\circ} \mathrm{C}$ until further use. The same procedure was followed for each of the two biological replicates used in this study. 
Chapter 5

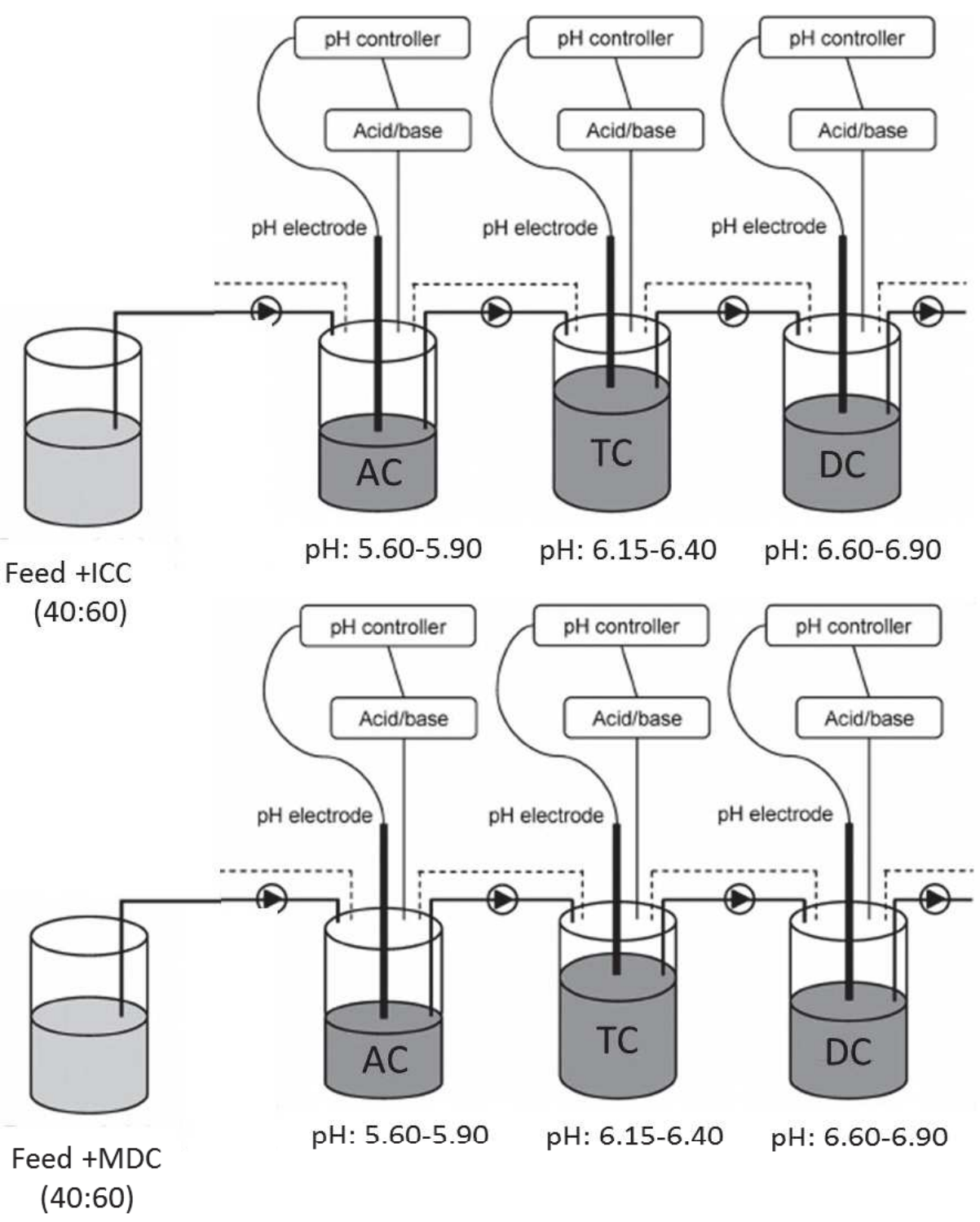

Fig. 5-1. Schematic representation of the SHIME ${ }^{\circledR}$ system. Feed + sample (ICC, MDC) was pumped to the vessels representing the ascending (AC), transverse (TC) and descending (DC) colon. Temperature $\left(37^{\circ} \mathrm{C}\right), \mathrm{pH}$ and anaerobiosis was automatically controlled.

\subsubsection{Total starch analysis}

The pellets collected at different time points were freeze dried and the amount of starch present was quantified by using Total Starch Kit from Megazyme, Inc. (Bray, Ireland) following the manufacturers guidelines. For ICC, structure was disrupted by mechanical shear force prior freeze-drying as described by Rovalino-Cordova et al ${ }^{13}$. The samples were expressed as grams of starch per $100 \mathrm{~g}$ of unfermented feed. 


\subsubsection{Non-starch polysaccharides (NSP) extraction}

Unfermented NSP were extracted following the protocol described by Jonathan, et al. ${ }^{9}$ with minor modifications. Briefly, ICC (previously broken by shear force) and MDC fermentation pellets were freeze dried and subsequently enzymatically degraded with $\alpha$-amylase $(0.5 \mathrm{~h})$ protease $(0.5 \mathrm{~h})$ and amyloglucosidase $(1.5 \mathrm{~h})$ to hydrolyse remnant starch and proteins from the matrix. Total NSP were extracted by precipitation with acidified absolute ethanol, $85 \%$ acidified ethanol, absolute ethanol and acetone in a sequential order followed by centrifugation (1500 x g, $10 \mathrm{~min}$ ). Excess acetone was removed by placing samples in a water bath at $75^{\circ} \mathrm{C}$ and further overnight drying at $50^{\circ} \mathrm{C}$ in an incubator. The dried samples were analysed for monosaccharide composition. NSP from unfermented ICC was also extracted for comparison.

\subsubsection{Constituent monosaccharide composition}

Constituent monosaccharide composition of extracted NSP were analysed following the procedures of Gouveia et $\mathrm{al}^{18}$ with minor modifications. In short, cell wall $(\mathrm{CW})$ material was hydrolysed in $72 \%$ sulphuric acid $(\mathrm{w} / \mathrm{w})$ for $1 \mathrm{~h}$ at $30^{\circ} \mathrm{C}$ and further diluted with water until a concentration of $1 \mathrm{M}$ of the acid was obtained. This mixture was incubated further for $3 \mathrm{~h}$ at $100^{\circ} \mathrm{C}$ and subsequently cooled in ice and centrifuged ( $\left.3000 \mathrm{x} \mathrm{g}, 15 \mathrm{~min}\right)$. The $\mathrm{pH}$ was adjusted with barium carbonate until a clear magenta colour was obtained. The mixture was filtered in a $0.45 \mu \mathrm{m}$ PTFE filter and the monomeric sugar constituents analysed by high performance anion exchange chromatography (HPAEC) using a ICS-3000 ion chromatography HPLC system equipped with a CarboPac PA-1 column $(2 \times 250 \mathrm{~mm})$ in combination with a CarboPac PA guard column $(2 \times 25 \mathrm{~mm})$ and pulsed amperometric detector (Dionex, Sunnyvale, USA). A flow rate of $0.3 \mathrm{mLmin}^{-1}$ was used and the column was equilibrated with water. Elution was performed by mixing eluent A $(500 \mathrm{mM} \mathrm{NaOH}), \mathrm{B}(150 \mathrm{mM} \mathrm{NaOH})$ and $\mathrm{C}\left(\mathrm{H}_{2} \mathrm{O}\right)$ in the following ratios: $0 \mathrm{~min}(0: 0: 100) ; 53 \mathrm{~min}(0: 0: 100) ; 63 \min (00: 100: 0) ; 63.1 \min (100: 0: 0) 78$ $\min (100: 0: 0) ; 83 \min (0: 0: 100) ; 100 \min (0: 0: 100)$. Monomer detection was possible after post column addition of $0.5 \mathrm{M} \mathrm{NaOH}\left(0.1 \mathrm{~mL} \cdot \mathrm{min}^{-1}\right)$. L-Rhamnose, L-fucose, D-mannose, Larabinose, D-glucose, D-xylose, D-galactose, D-glucuronic and D-galacturonic acid (SigmaAldrich) were used as standards for identification. All analyses were performed in duplicate.

\subsubsection{Microbial analysis}

Genomic DNA isolation, bacterial 16s rRNA gene (V3-V4) PCR amplification and library preparation was performed by BaseClear (Leiden, The Netherlands). Paired-end sequence reads 
Chapter 5

were collapsed into pseudo-reads using sequence overlap with USEARCH version 9.2. Classification of these pseudo-reads was performed based on the results of alignment with SNAP version 1.2.23 against the RDP database for bacterial organisms, while fungal organisms were classified using the UNITE ITS gene database. Further analysis and statistics were performed using the online Microbiome Analyst tool (www.microbiomeanalys.ca), with filtering steps: minimal count 4 , prevalence $10 \%$ and removal of $2 \%$ standard deviation. Statistical analysis was performed by comparing MDC, ICC and a control sample in which microbiota was fed with a commercial diet.

\subsubsection{Short chain fatty acids (SCFA)}

Fermented supernatants were centrifuged $\left(9000 \mathrm{x} \mathrm{g}, 5 \mathrm{~min}, 4^{\circ} \mathrm{C}\right)$, filtered $(15 \mathrm{~mm} 0.2 \mu \mathrm{m} \mathrm{RC}$ filter) and combined with an internal standard (2-ethylbutyric acid in $0.3 \mathrm{M} \mathrm{HC}$ and $0.9 \mathrm{M}$ oxalic acid) for SCFA quantification. Solutions of acetic, propionic, butyric, valeric, iso-butyric and iso-valeric acids were prepared for identification and quantification. The measurement was performed using a Shimadzu GC-2014 gas chromatograph (Kyoto, Japan) equipped with a Flame-ionization gas detector (FID), a capillary fatty acid-free Stabil wax-DA column $(1 \mu \mathrm{m} x$ $0.32 \mathrm{~mm} \times 30 \mathrm{~m}$ ) (Restek, Bellefonte, PA, USA) and a split injector. The carrier gas was nitrogen and the temperature of the injector and detector were 100 and $250{ }^{\circ} \mathrm{C}$ respectively ${ }^{19}$. The ratio between branched and linear fatty acids, indicated as branched-chain ratio (BCR) and the total SCFA production was calculated according to Warren, et $\mathrm{al}^{14}$.

\subsubsection{Statistical analyses}

Repeated measures analysis of variance was conducted using the GLM procedure (SAS 9.4 for Windows, Cary, NC, USA). Significant differences between treatments and days of fermentation were tested using Tukey's studentized range test.

\subsection{Results and discussion}

Bean samples with identical composition but different structural properties (intact - ICC and mechanically damaged - MDC cells) were fermented for 12 days using a semi-dynamic invitro fermentation model. 


\subsubsection{Changes in starch fermentation due to structural characteristics of the matrix}

Fig. 5-2 depicts the amount of unfermented starch in each colon portion after 3, 6, 9 and 12 days of in-vitro colonic fermentation. These time points were selected for sampling since the residence time in the $\mathrm{SHIME}^{\circledR}$ system (i.e. the effective residence time of a sample in the system) is $72 \mathrm{~h}^{16}$. As seen in the figure, AC was the portion with the highest levels of unfermented starch, followed by TC and DC independently of the treatment considered (ICC, MDC). However, a clear difference in starch utilization between the two samples was observed. For ICC samples, large amounts of unfermented starch were recovered in AC during the first 6 days of fermentation, where nearly $30 \%$ of the feed collected was constituted by starch. As fermentation progressed, the amount of starch utilized by the microbiota increased considerably until $15 \%$ of the unfermented pellet was identified as starch. This pattern was not observed for MDC samples where a relatively constant amount of unfermented starch (approximately 10\%) was collected throughout the 12 days of fermentation. In general, ICC always contained higher levels of unfermented starch compared to MDC in the three colon regions. However, a significant difference between the treatments (ICC and MDC) was only found in the AC during the first six days of colonic fermentation $(p<0.05)$. Furthermore, in the TC and DC the concentration of unfermented starch remained relatively constant during the 12 days of fermentation independently of the treatment studied. It is important to mention that in both samples starch had the same degree of gelatinization since thermal treatments were applied to intact cotyledons before disrupting cellular integrity. Therefore, the differences observed in starch utilization are only related to the structural properties of the bean cells, i.e. their level of integrity. Similar results were obtained by Rose, et al. ${ }^{20}$ when studying the effect of starch encapsulation in alginate beads. In that study the authors found that when starch was entrapped in an alginate matrix there was a decrease in the rate of starch fermentation compared to free starch granules. 

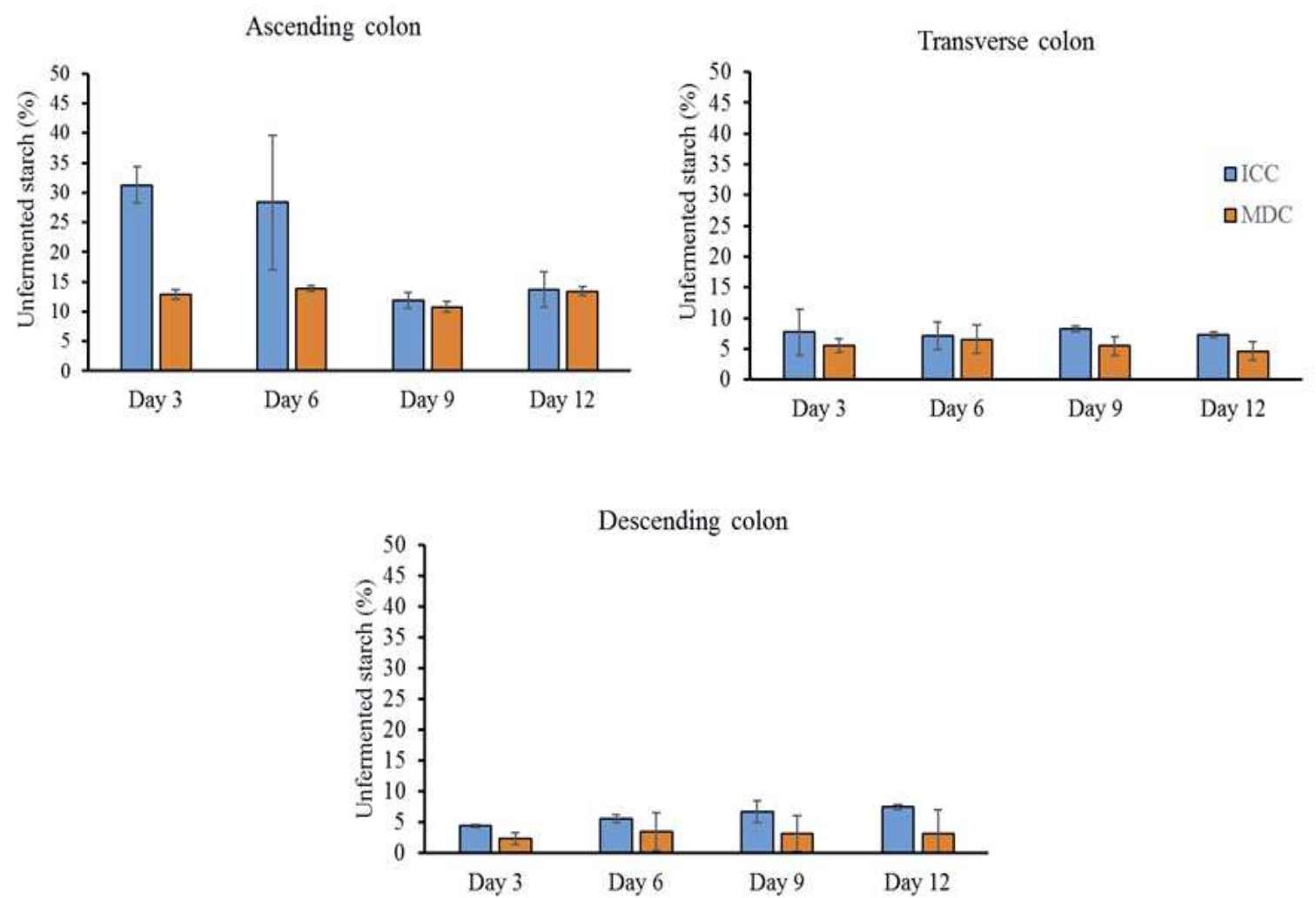

Fig. 5-2. Unfermented starch content in ICC and MDC in ascending, transverse and descending colon after 3, 6, 9 and 12 days of in-vitro fermentation in the $\mathrm{SHIME}^{\circledR}$ system. Error bars denote standard deviation of two biological donors.

The SHIME ${ }^{\circledR}$ is a semi-dynamic fermentation model that is used to represent the different portions of the digestive system. In this model, a homogeneous distribution is ensured in the vessels by the use of a magnetic stirrer. Even though the integrity of ICC can be affected by the application of mechanical force, in this study the particle size distribution of fermented samples was not affected by stirring (data not shown). This was probably due to the low mixing rates applied (100 rpm) compared to those normally used for CW disruption (1400rpm). Therefore, this indicates that in ICC, microbiota accessibility to starch was restricted by the presence of CW material and the lower fermentability found (compared to MDC) could be related to this effect. The mechanism employed by the microbiota to ferment entrapped starch is not clear yet; however, due to the pore size diameter of the $\mathrm{CW}\left(6 \mathrm{~nm}\right.$ on average $\left.{ }^{21}\right)$ it is unlikely that micrometre range bacteria could diffuse through $\mathrm{CW}$ and ferment starch. Even though the isolation procedure to obtain ICC may increase CW porosity, it is unlikely that this change facilitates the access to bacteria. Hence, it is possible that starch fermentation in ICC follows a similar mechanism as observed during small intestinal digestion ${ }^{22}$ i.e. enzymes diffuse through the $\mathrm{CW}$ matrix to hydrolyse starch and the products formed upon digestion exit the cells to be further utilized by the microbiota. Further research is needed to confirm this 
hypothesis where microscopy techniques could be employed to provide information on the colonization of entrapped starch and the apparent porosity of ICC CW. This is important because the composition and metabolic activity of bacterial communities colonizing food particles and carbohydrate substrates is different from communities dispersed in a liquid phase environment ${ }^{23}$. One may speculate that bacteria and its metabolism involved in starch utilization would be different according to its accessibility for microbiota. Moreover, Fig. 5-2 also shows that a portion of starch in ICC and MDC remains unfermented despite of the extensive fermentation treatment provided. Further research is needed to understand if a portion of starch resistant to fermentation exists, due e.g. to structural aspects of the molecule or if this is an artefact of the in-vitro model utilized.

\subsubsection{Fermentation of cell wall constituents is linked to structural integrity of cotyledon cells}

In order to identify if cellular integrity influences the fermentability of $\mathrm{CW}$ constituents, monosaccharide composition was analysed in the three colon regions at the beginning and at the end (after 3 and 12 days) of colonic fermentation (Table 5-1). During the first 3 days of fermentation, the total amount of carbohydrates present was higher in MDC than ICC in each of the three colon regions (13\% higher in AC, $26 \%$ in TC and $60 \%$ in DC). This trend could be explained when considering the results obtained for starch fermentation since the amount of unfermented starch in ICC was 2 times higher than what recovered for MDC. Therefore, it seems that the lower availability of starch in ICC directed bacterial metabolism towards CW utilization. After 12 days of fermentation, this trend was maintained for the AC where larger differences were observed between the two treatments (32\%) and to a minor extent for the TC (7\%). However, for DC the opposite was observed since the amount of CW constituents recovered for ICC were higher than those of MDC (22\%).

Differences were also observed when comparing the total carbohydrates present in the colon regions within each treatment. In the case of ICC, the ascending colon had twice as much $\mathrm{CW}$ constituents than the TC and four times more than the DC after 3 days of fermentation. However, after 12 days of fermentation, no differences were observed between the amount of total carbohydrates present in the AC and TC. While for DC, an opposite trend was found since higher amounts of CW constituents were collected (14\%) at the end of fermentation compared to what found for the ascending colon. Based on the data showed in Table 5-1, we could infer that the long-term feeding with beans increased proximal bacteria efficiency in using NSP since 
there was an increase of $32 \%$ in the amount of $\mathrm{CW}$ constituents utilized by the microbiota after 12 days of fermentation. This was not the case for the other two colon segments since almost no variation in the total carbohydrates content was observed for TC while in the DC there was an important reduction in the amount of fermented material (65\%). We could infer that as AC colon became more efficient in utilizing the substrate available, lower amounts of fermentable material were available for the microbiota present in the distal sections of the colon. This could be the main reason why the efficiency of the aforementioned colon sections is reduced.

In the case of MDC, the $\mathrm{AC}$ was the colonic portion with the higher amounts of total carbohydrates present. The proximal region had 30\% more CW constituents than the TC and $40 \%$ more than the DC. However, contrary to what occurred in ICC, this trend remained constant in both time points analysed. Regarding the changes in fermentation in each colon section, after 12 days of diet exposure the amount of sugar constituents decreased by $13 \%$ in the $\mathrm{AC}, 16 \% \mathrm{TC}$ and $11 \%$ in the $\mathrm{DC}$. These results indicate that for MDC, the prolonged fermentation time allowed bacteria to adapt and degrade $\mathrm{CW}$ constituents even further in each colon region especially considering that the extent of starch fermentation in these samples remained relatively constant throughout the experiment. Furthermore, the reduction of $\mathrm{CW}$ constituents obtained for MDC in the three colon regions rules out the possibility that the higher concentration of total carbohydrates collected in the distal region of ICC are due to artefacts of the in-vitro system employed (sample accumulation).

Table 5-1. Constituent monosaccharide composition of total non-starch polysaccharides present in ICC and MDC after 3 and 12 days of colonic fermentation. Unfermented sample (control) was also analysed for comparison purposes.

\begin{tabular}{|c|c|c|c|c|c|c|c|c|c|c|c|}
\hline & \multirow[b]{2}{*}{ Colon } & \multirow[b]{2}{*}{ Day } & \multicolumn{9}{|c|}{$\mathrm{w} / \mathrm{w} \%$} \\
\hline & & & Fuc & Ara & Rha & Gal & Glc & Xyl & Man & UA & Total \\
\hline \multirow[t]{3}{*}{ Control } & & & $0.98^{ \pm 0.00}$ & $12.13^{ \pm 0.30}$ & $0.40^{ \pm 0.00}$ & $2.44^{ \pm 0.01}$ & $21.59^{ \pm 0.38}$ & $4.41^{ \pm 0.05}$ & $1.04^{ \pm 0.11}$ & $1.46^{ \pm 0.01}$ & $44.44^{ \pm 0.65}$ \\
\hline & $\mathrm{AC}$ & 3 & $0.88^{ \pm 0.21}$ & $10.85^{ \pm 4.95}$ & $0.11^{ \pm 0.00}$ & $3.54^{ \pm 0.17}$ & $18.3^{ \pm 1.75}$ & $4.13^{ \pm 0.61}$ & $0.74^{ \pm 0.04}$ & $1.81^{ \pm 0.16}$ & $40.35^{ \pm 5.85}$ \\
\hline & & 12 & $0.91^{ \pm 0.00}$ & $0.18^{ \pm 0.00}$ & $0.10^{ \pm 0.00}$ & $2.95^{ \pm 0.90}$ & $18.45^{ \pm 4.84}$ & $2.64^{ \pm 1.90}$ & $1.00^{ \pm 0.33}$ & $1.49^{ \pm 0.57}$ & $27.62^{ \pm 6.07}$ \\
\hline \multirow[t]{6}{*}{ ICC } & $\mathrm{TC}$ & 3 & $0.12^{ \pm 0.08}$ & $3.14^{ \pm 1.86}$ & $1.04^{ \pm 0.33}$ & $2.96^{ \pm 0.64}$ & $9.91^{ \pm 4.83}$ & $1.43^{ \pm 0.02}$ & $4.13^{ \pm 2.11}$ & $0.68^{ \pm 0.08}$ & $23.83^{ \pm 5.13}$ \\
\hline & & 12 & $0.00^{ \pm 0.00}$ & $0.00^{ \pm 0.00}$ & $0.07^{ \pm 0.00}$ & $2.80^{ \pm 1.10}$ & $19.56^{ \pm 3.71}$ & $0.65^{ \pm 0.01}$ & $1.31^{ \pm 0.15}$ & $0.42^{ \pm 0.00}$ & $25.06^{ \pm 2.36}$ \\
\hline & DC & 3 & $0.03^{ \pm 0.00}$ & $0.54^{ \pm 0.00}$ & $0.60^{ \pm 0.01}$ & $1.41^{ \pm 0.52}$ & $2.57^{ \pm 1.61}$ & $0.20^{ \pm 0.08}$ & $5.39^{ \pm 0.11}$ & $0.43^{ \pm 0.01}$ & $11.15^{ \pm 2.77}$ \\
\hline & & 12 & $0.00^{ \pm 0.00}$ & $0.00^{ \pm 0.00}$ & $0.18^{ \pm 0.00}$ & $2.93^{ \pm 0.77}$ & $25.55^{ \pm 4.38}$ & $0.69^{ \pm 0.04}$ & $2.05^{ \pm 0.64}$ & $0.60^{ \pm 0.08}$ & $32.00^{ \pm 4.12}$ \\
\hline & $\mathrm{AC}$ & 3 & $0.49^{ \pm 0.04}$ & $10.75^{ \pm 0.16}$ & $0.33^{ \pm 0.00}$ & $3.15^{ \pm 0.93}$ & $27.26^{ \pm 2.14}$ & $3.27^{ \pm 0.19}$ & $1.00^{ \pm 0.35}$ & $0.20^{ \pm 0.00}$ & $46.44^{ \pm 1.56}$ \\
\hline & & 12 & $0.37^{ \pm 0.09}$ & $4.94^{ \pm 2.26}$ & $0.12^{ \pm 0.05}$ & $2.73^{ \pm 0.71}$ & $28.07^{ \pm 0.41}$ & $2.59^{ \pm 0.18}$ & $1.39^{ \pm 0.48}$ & $0.31^{ \pm 0.18}$ & $40.48^{ \pm 1.97}$ \\
\hline \multirow[t]{4}{*}{ MDC } & $\mathrm{TC}$ & 3 & $0.20^{ \pm 0.00}$ & $0.45^{ \pm 0.01}$ & $0.33^{ \pm 0.00}$ & $2.38^{ \pm 0.82}$ & $25.24^{ \pm 8.01}$ & $1.62^{ \pm 0.23}$ & $2.18^{ \pm 0.74}$ & $0.00^{ \pm 0.00}$ & $32.39^{ \pm 6.70}$ \\
\hline & & 12 & $0.20^{ \pm 0.04}$ & $0.20^{ \pm 0.03}$ & $0.26^{ \pm 0.20}$ & $2.82^{ \pm 1.08}$ & $20.37^{ \pm 9.07}$ & $1.54^{ \pm 0.09}$ & $1.76^{ \pm 0.82}$ & $0.00^{ \pm 0.00}$ & $27.13^{ \pm 8.51}$ \\
\hline & DC & 3 & $0.15^{ \pm 0.02}$ & $0.23^{ \pm 0.04}$ & $0.25^{ \pm 0.00}$ & $2.22^{ \pm 0.74}$ & $19.83^{ \pm 12.04}$ & $1.53^{ \pm 0.06}$ & $4.01^{ \pm 1.16}$ & $0.00^{ \pm 0.00}$ & $28.20^{ \pm 10.22}$ \\
\hline & & 12 & $0.19^{ \pm 0.08}$ & $0.14^{ \pm 0.00}$ & $0.32^{ \pm 0.24}$ & $2.68^{ \pm 1.41}$ & $18.11^{ \pm 10.19}$ & $1.38^{ \pm 0.17}$ & $2.16^{ \pm 0.81}$ & $0.00^{ \pm 0.00}$ & $24.97^{ \pm 9.10}$ \\
\hline
\end{tabular}

ICC: intact cotyledon cells, MDC, mechanically damaged cells, AC: Ascending colon, TC: transverse colon; DC: descending colon, Fuc: fucose, Ara: arabinose, Rha: rhamnose, Gal, galactose, Glc: glucose, Xyl: xylose, Man: mannose, UA: Uronic acids. Superscripts indicate the standard deviation of two biological replicates. 
Regarding the utilization of individual CW constituents, structural characteristics of the samples (ICC, MDC) provided changes in the fermentability of the molecules present in the $\mathrm{CW}$. The most important differences observed were related to the arabinose, uronic acid and glucose content. During the first 3 days of fermentation, arabinose was degraded in the three colon portions of both ICC and MDC where the latter showed higher consumption of the monosaccharide. However, after 12 days of fermentation, most of the arabinose present in ICC was consumed in the $\mathrm{AC}$ colon depleting the system of this molecule. This was not observed in MDC since even though a decrease in the amount of arabinose was observed in the AC, the presence of this compound could still be detected in the other two colon regions. As for uronic acid, microbiota was able to degrade this compound completely in MDC while in ICC this was not achieved despite of the long incubation period. Both arabinose and uronic acid are constituents of pectin from which the former is part of the building blocks of the so-called hairy regions of rhamnogalacturonan $\mathrm{I}^{24}$ while the latter is the backbone of homogalacturonan which is the main type of pectin present in cell walls ${ }^{25}$. Studies conducted in rats have shown that pectin is highly utilized by colonic microbiota, however structural aspects of the molecule such as its degree of methylation could affect the rate of fermentation ${ }^{26}$. We are aware that arabinose, xylose and galactose were not only supplied in the diet as ICC or MDC constituents since they were also part of the commercial feed. Therefore, is it possible that some of the NSP collected during sampling do not belong to bean cells. The experimental design used in this study could not provide a distinction between both sources. However, it could still be seen that structural properties of the samples provided differences in substrate utilization independently of their origin. As for glucose, it could be observed that during the first 3 days of fermentation microbiota present in the TC and DC degraded this CW constituent extensively in ICC samples compared to what observed for MDC. Nevertheless, after 12 days of treatment the amount of glucose fermentation decreased considerably in ICC probably due to higher extent of fermentation of other CW constituents. This was not observed for MDC since even though glucose reduction was not extensive, a decreasing trend in its concentration was observed throughout these 12 days of treatment. Furthermore, it is important to mention that the monosaccharides degraded to a higher extent in both ICC and MDC are the main constituents present in beans $\mathrm{CW}^{24}$. The results obtained in our study are in accordance to those found by van $\operatorname{Laar}^{27}$, et al which showed that pectin or pectin related sugars (arabinose, uronic acid) were fermented faster than cellulose in isolated CW from peas, faba and soya beans. 
In the present study, we have demonstrated that besides NSP molecular characteristics, structural aspects of the food matrix modulate the way in which its constituents are fermented. It has been already reported that isolated soluble polysaccharides are fermented faster compared to when they occur in complex supramolecular assembly as $\mathrm{CW}^{28}$. Here we hypothesized that by increasing the surface area after the application of mechanical force, microbiota had more access to other CW constituents (e.g. pectin) that are normally interlinked in the tight network of undamaged cells. This effect would be similar to the increase in the fermentation rate observed upon reduction of NSP particle size, e.g. an increase in the available sites for enzymatic attack ${ }^{27}$.

Studies have revealed that the fermentation of fibres when present in a mixture is delayed due to a hierarchical utilization of them by gut microbiota ${ }^{9,29}$. Therefore, when fast-fermenting substrates such as RS and pectins are present, the utilization of other NSP are delayed to more distal portions of the colon ${ }^{9,30}$. However, in none of these studies the effect of food microstructure has been considered. Our study is one of the few that illustrates the importance of food structure in modulating microbiota utilization of plant tissue constituents when present in a matrix.

\subsubsection{Diversity of microbiota communities as a response to ICC and MDC treatments}

Samples from the different colon vessels of the SHIME ${ }^{\circledR}$ after ICC and MDC treatment were analysed in terms of alpha and beta diversity at OTU level in order to identify if cellular integrity produced changes in sample richness, evenness (Shannon index) and abundance (beta diversity index) (Fig. 5-3). Microbiota taken before the application of the bean treatment was also included in the analysis to assess the effect of bean supplementation (control). No statistical significance was observed in the Shannon index between ICC, MDC and control, indicating no differences in terms of the number of species and the uniformity of the population size of each of them. On the contrary, a significant difference was observed in the beta diversity when comparing MDC, ICC and the control $(\mathrm{p}<0.001)$. This showed that different microbial species were present after bean diet supplementation. Legumes ability to modulate microbial population has already been described in literature. These changes have been found to be favourable for gut health due to the proliferation of probiotic species probably due to the high amount of dietary fibre (including RS) present in legumes ${ }^{5,12}$. Furthermore, it is interesting to observe that for beta diversity ICC samples from the two biological donors were clustered 
together with MDC of donor 1, while the samples belonging to donor 2 were more distant from the group.
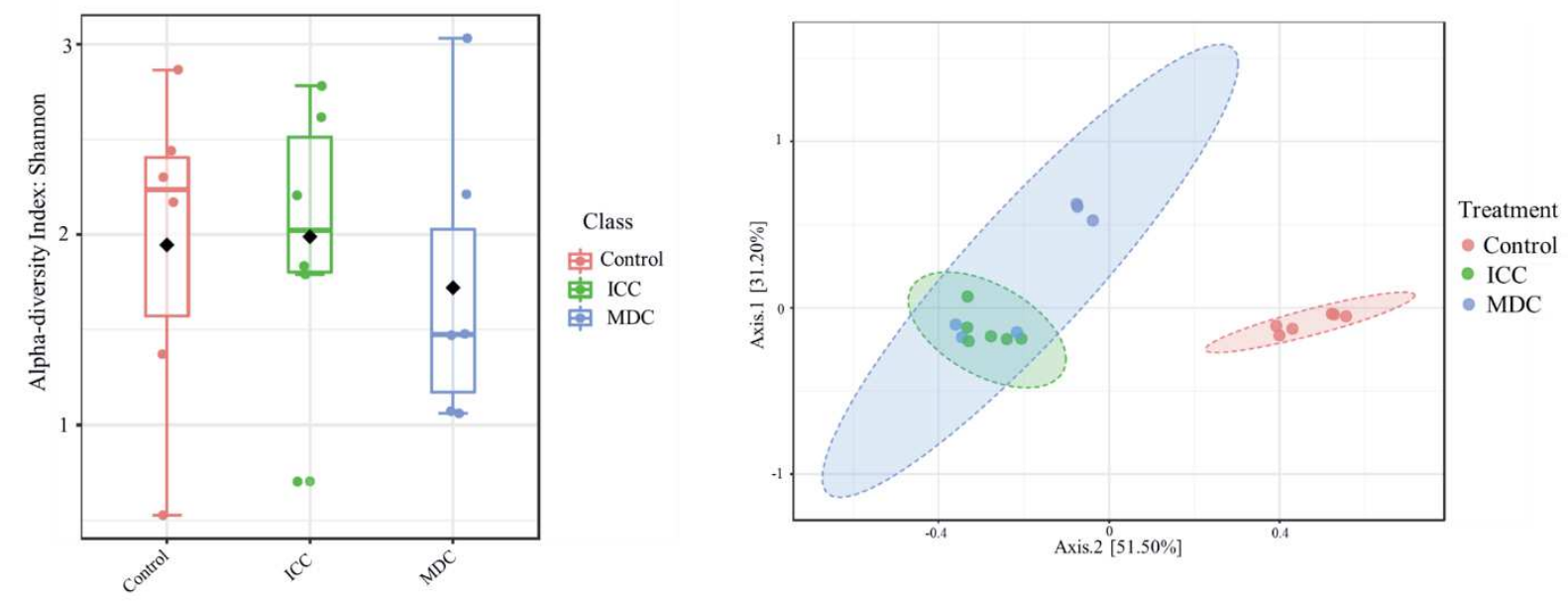

Fig. 5-3. Alpha (left) and beta (right) diversity at OTU level, using the Bray-Curtis PCoA index indicating the effects of treatment (control, ICC, MDC) on the overall microbial composition.

\subsubsection{Changes in microbiota composition due to samples structural properties}

Fig. 5-4 depicts the relative microbial abundance of ICC, MDC and control in the three colon portions after 12 days of in-vitro colonic fermentation. Large differences were evident between the microbial distribution of the control compared to the bean treatments in all colon sections. In the control, the most abundant phylum present was Firmicutes, while after the treatments with bean supplementation the most abundant phylum was Actinobacteria. Even though microbiota composition varies according to several factors from which the diet is one of the most important, it is generally accepted that in adults the phyla Bacteroidetes and Firmicutes usually dominate the microbiome, whereas Actinobacteria, Proteobacteria and Verrucomicrobia are generally present in minor proportions ${ }^{31}$. Larger differences were also found between the two biological donors especially in the $\mathrm{AC}$ where the microbiota distribution was not even similar for the control diets. When comparing the effect of bean cell structure in changes on microbiota distribution, ICC sample showed lower abundance of Actinobacteria in the AC and TC for donor 1, while in the DC both samples showed similar levels of this phylum. This trend was not followed in donor 2 where the amount of Actinobacteria was very similar between both samples and in some cases, ICC showed a slight increase in its relative abundance. 
Donor 1
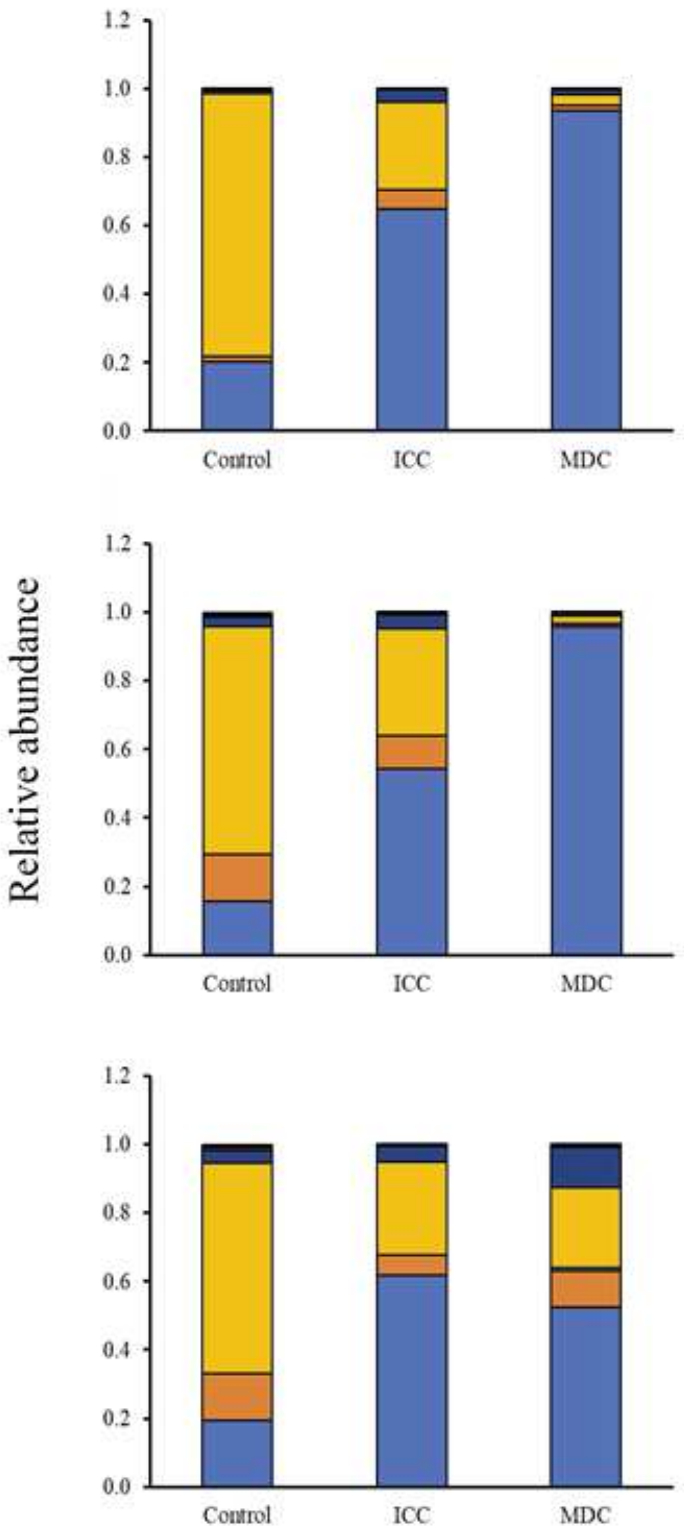

$\square$ Actinobacteria

$\square$ Firmicutes

- Proteobacteria

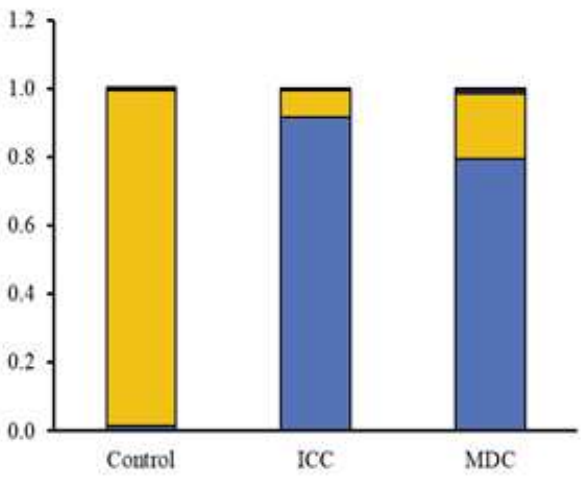

竞

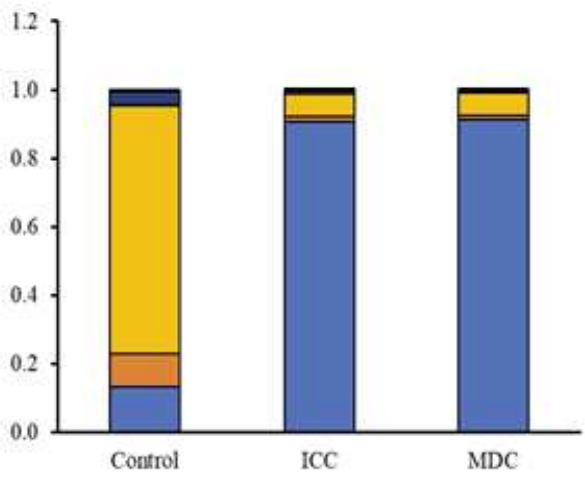

馬

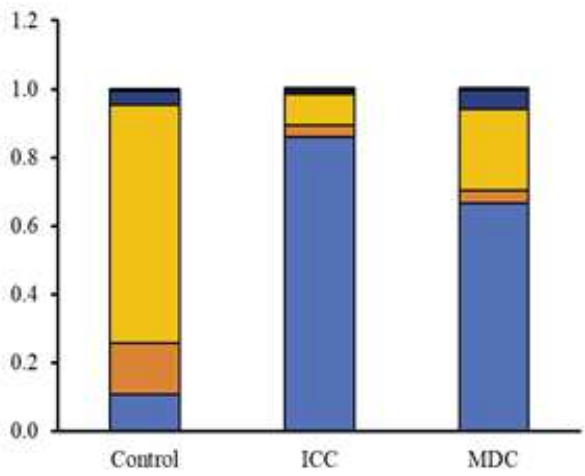

.

Fig. 5-4. Relative abundance of 16 rRNA sequencing at phylum level after 12 days of ICC or MDC supplementation in the ascending, transverse and descending colon for two biological replicates. Control indicates 16 rRNA sequencing of samples prior the start of the treatments for comparison.

In order to identify the differences in microbial composition between samples, Fig. 5-5 depicts a bar graph indicating microbiota abundance of all samples at family level in all colon regions. A table with a detail information about the relative abundance in all samples is also included in 
the appendix (Table 5A-1, 2,3). Larger differences were observed in the microbiota present in the control compared to that of ICC and MDC. In general, it can be seen that after treatment with ICC and MDC Bifidobacteriaceae was the most abundant family present while for the control Selenomonadaceae was the most prevalent one. This was the case for all colon regions and biological replicates. When looking at the species with higher abundance within these families it was found that Bifidobacterium adolescentis was the bacterial specie present at higher relative abundance after ICC treatment in all colon regions and biological donors. On the other hand, after MDC treatment, $B$. adolescentis was the specie with higher abundance in donor 1 while $B$. longum was the predominant one in the case of donor 2 . The genus Bifidobacterium is long considered the hallmark probiotic genus and has been found to confer positive health benefits to the human host and have been used to prevent various gastrointestinal disorders such as diarrhoea and inflammatory bowel disease ${ }^{32}$. The abundance of this genus declines with the age of the host where changes in the type of dominant species have also been observed $^{33}$. In infants, B. bifidum and B. longum are the dominant species while B. longum and B. adolescentis dominate the adult gut microbiota ${ }^{34}$. The high prevalence of Bifidobacterium found in our study goes in accordance to an in-vivo research conducted by Fernando et $\mathrm{al}^{5}$ who demonstrated that chickpea supplementation produced a shift in faecal microbial population where Bifidobacterium species was present in high concentrations. As for the control sample Megamonas funiformis was found as the strain with higher abundance in all the colon regions. This bacterial strain is able to utilize several monosaccharides from which arabinose, glucose and xylose are the most relevant ${ }^{35,36}$. 


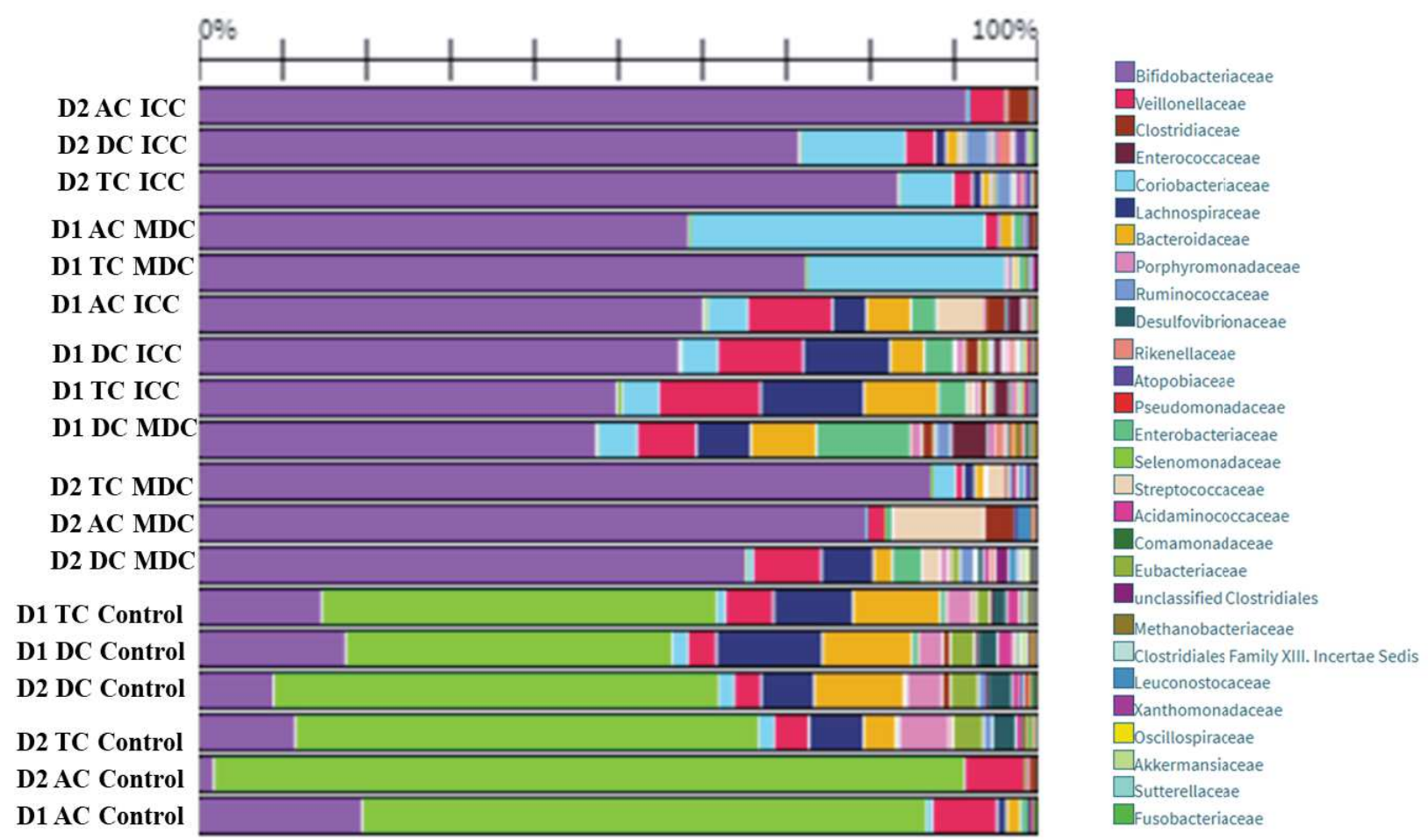

Fig. 5-5. Bar graph of the 16S RNA microbial analysis at family level in the ascending, transverse and descending colon in ICC and MDC for two biological replicates (D1, D2). A control sample was included where microbiota was fed with a commercial feed that contained isolated starch. Colour code indicates difference in microbiota abundance in all samples analysed. $\mathrm{AC}=$ ascending colon; $\mathrm{TC}=$ transverse colon; $\mathrm{DC}=$ descending colon.

Microbial species differ in their substrate preferences, therefore the balance of species in the gut could be modulated by the selective consumption of nutrients to trigger the proliferation and persistence of specific strains ${ }^{37}$. In the present study, we have shown that bean consumption (independently of its structural properties) produce changes in the microbial population in the gut. Even though changes in the structural properties of the samples did not confer larger differences in the type of microbiota present at family level, it seems that cell intactness increased the abundance of bacterial species in proximal portions of the colon that were otherwise not detectable. That is the case of Bacteroides cellulosilyticus who was only found in the DC of MDC and control while in ICC its presence was detected also in the TC. This type of bacteria are known for degrading cellulose present in plant cell walls ${ }^{38}$. It seems like the presence of the $\mathrm{CW}$ triggers the proliferation of bacteria that are able to produce $\mathrm{CW}$ degrading enzymes.

\subsubsection{SCFA content}

The concentration of SCFA produced at different days of colonic fermentation is shown in Table 5-2. In this table, the concentration of SCFA present in the basal diet (prior bean cells 
supplementation) is also included for comparison. As it can be seen, higher amounts of SCFA were observed for acetate and butyrate in ICC and MDC while propionate decreased at the later stages of fermentation in all colon regions. In most cases, the concentration of SCFA upon treatment with MDC showed significantly higher levels during the first 3 days of fermentation compared to ICC. This could be due to the higher substrate accessibility where structural damage of bean cells facilitated the access of colonic microbiota. However, in the later stages of fermentation the concentration of SCFA in ICC reached the same level than those in MDC samples. When comparing the concentration of SCFA after 12 days of fermentation with those of the basal diet, it could be seen that in all cases bean cell supplementation (independently of its structural integrity) showed higher amounts of acetate, propionate and butyrate. Furthermore, it was also observed that during the early stages of fermentation, ICC samples had lower SCFA concentration comparted to MDC. This trend was not constant throughout the 12 days of fermentation since at the end of the in-vitro experiment the amount of SCFA in both treatments (ICC, MDC) was very similar. Furthermore, the concentration of butyrate in ICC and MDC reached similar values than those obtained for propionate after 12 days of fermentation. This is interesting since in general terms the concentration of SCFA follows the order acetate $>$ propionate $>$ butyrate. It is possible that the presence of Bifidobacterium strains in both ICC and MDC are partly responsible for the high amount of butyrate produced. During carbohydrate fermentation, Bifidobacterium produce acetate and lactate which in turn could be converted into butyrate by other bacteria species through cross-feeding interactions ${ }^{34}$.

Moreover, it could also be observed that after 12 days of bean supplementation, the ratio between branched and linear SCFA showed a significant difference compared to the basal diet indicating microbiota preference to carbohydrate fermentation since branched fatty acids have been associated with protein degradation. 
Table 5-2. SCFA concentration $(\mathrm{mmol} / \mathrm{L})$ in the ascending, transverse and descending colon at different days of treatment with ICC and MDC.

\begin{tabular}{|c|c|c|c|c|c|c|c|}
\hline & & \multicolumn{3}{|c|}{ ICC } & \multicolumn{3}{|c|}{ MDC } \\
\hline & & Ascending & Transverse & Descending & Ascending & Transverse & Descending \\
\hline \multirow{5}{*}{ Acetate } & Basal & $17.28 \pm 5.50^{\mathrm{a}}$ & $31.00 \pm 7.50^{\mathrm{ab}}$ & $37.38 \pm 1.82^{b}$ & $18.27 \pm 6.70^{\mathrm{a}}$ & $34.17 \pm 3.44^{\mathrm{a}}$ & $36.64 \pm 7.96^{\mathrm{ab}}$ \\
\hline & $3^{\text {rd }}$ day & $19.27 \pm 2.61^{\mathrm{a}^{*}}$ & $18.49 \pm 4.68^{\mathrm{a}^{*}}$ & $27.08 \pm 3.80^{\mathrm{a}^{*}}$ & $26.88 \pm 1.92^{\mathrm{a}^{*}}$ & $33.50 \pm 5.82^{\mathrm{a}^{*}}$ & $33.26 \pm 2.43^{\mathrm{a}^{*}}$ \\
\hline & $6^{\text {th }}$ day & $29.57 \pm 0.97^{\mathrm{b}^{*}}$ & $37.75 \pm 2.04^{\mathrm{bc}}$ & $32.96 \pm 4.00^{\mathrm{ab}}$ & $38.92 \pm 4.10^{\mathrm{b}^{*}}$ & $36.03 \pm 2.62^{\mathrm{a}}$ & $37.86 \pm 9.49^{\mathrm{ab}}$ \\
\hline & $9^{\text {th }}$ day & $36.50 \pm 2.41^{b}$ & $44.71 \pm 7.94^{\mathrm{c}}$ & $53.75 \pm 3.97^{c}$ & $40.10 \pm 3.80^{\mathrm{b}}$ & $52.00 \pm 8.01^{\mathrm{b}}$ & $43.32 \pm 2.30^{\mathrm{ab}}$ \\
\hline & $12^{\text {th }}$ day & $35.53 \pm 4.75^{\mathrm{b}}$ & $39.34 \pm 7.15^{\mathrm{bc}}$ & $48.77 \pm 4.97^{c}$ & $37.85 \pm 0.88^{\mathrm{b}}$ & $33.29 \pm 4.29^{\mathrm{a}}$ & $52.26 \pm 10.58^{\mathrm{b}}$ \\
\hline \multirow{5}{*}{ Propionate } & Basal & $12.42 \pm 1.66^{\mathrm{a}}$ & $17.15 \pm 3.15^{\mathrm{a}}$ & $22.25 \pm 0.74^{\mathrm{a}}$ & $16.12 \pm 2.95^{\mathrm{a}}$ & $21.78 \pm 2.41^{\mathrm{a}}$ & $20.90 \pm 2.91^{\mathrm{a}}$ \\
\hline & $3^{\text {rd }}$ day & $2.62 \pm 0.85^{\mathrm{b}}$ & $6.65 \pm 1.73^{\mathrm{b}^{*}}$ & $15.82 \pm 2.19^{b}$ & $3.62 \pm 1.74^{\mathrm{b}}$ & $12.11 \pm 1.23^{\mathrm{b}^{*}}$ & $18.42 \pm 4.88^{\mathrm{ab}}$ \\
\hline & $6^{\text {th }}$ day & $2.13 \pm 1.12^{b}$ & $6.61 \pm 0.60^{\mathrm{b}}$ & $7.61 \pm 0.62^{\mathrm{c}^{*}}$ & $1.13 \pm 0.57^{b}$ & $8.41 \pm 2.40^{\mathrm{bc}}$ & $12.27 \pm 2.06^{\mathrm{bc}^{*}}$ \\
\hline & $9^{\text {th }}$ day & $1.62 \pm 0.29^{b}$ & $6.03 \pm 1.23^{\mathrm{b}}$ & $8.88 \pm 0.50^{c}$ & $1.03 \pm 0.28^{b}$ & $9.26 \pm 0.41^{\mathrm{bc}}$ & $8.90 \pm 1.92^{\mathrm{c}}$ \\
\hline & $12^{\text {th }}$ day & $1.50 \pm 0.34^{\mathrm{b}}$ & $5.47 \pm 1.36^{\mathrm{b}}$ & $8.79 \pm 0.99^{c}$ & $0.87 \pm 0.29^{b}$ & $6.31 \pm 1.15^{\mathrm{c}}$ & $11.46 \pm 1.96^{\mathrm{c}}$ \\
\hline \multirow{5}{*}{ Butyrate } & Basal & $1.37 \pm 0.31^{\mathrm{a}}$ & $2.61 \pm 0.67^{\mathrm{a}}$ & $3.55 \pm 0.80^{\mathrm{a}}$ & $0.75 \pm 0.47^{\mathrm{a}}$ & $1.63 \pm 0.13^{\mathrm{a}}$ & $2.69 \pm 0.93^{\mathrm{a}}$ \\
\hline & $3^{\text {rd }}$ day & $2.74 \pm 1.12^{\mathrm{ab}}$ & $1.74 \pm 0.26^{\mathrm{a}^{*}}$ & $4.02 \pm 1.62^{\mathrm{a}}$ & $4.02 \pm 0.15^{b}$ & $4.06 \pm 0.33^{\mathrm{ab}^{*}}$ & $5.03 \pm 1.38^{\mathrm{ab}}$ \\
\hline & $6^{\text {th }}$ day & $6.47 \pm 2.43^{\mathrm{bc}}$ & $6.59 \pm 2.34^{\mathrm{ab}}$ & $5.35 \pm 2.48^{\mathrm{a}}$ & $7.41 \pm 0.65^{\mathrm{c}}$ & $6.73 \pm 1.81^{b c}$ & $7.61 \pm 1.43^{\mathrm{bc}}$ \\
\hline & $9^{\text {th }}$ day & $8.27 \pm 1.99^{c}$ & $9.32 \pm 3.82^{b}$ & $10.81 \pm 3.17^{\mathrm{b}}$ & $8.89 \pm 1.50^{\mathrm{c}}$ & $10.55 \pm 1.33^{\mathrm{cd}}$ & $9.74 \pm 3.39^{\mathrm{cd}}$ \\
\hline & $12^{\text {th }}$ day & $8.24 \pm 2.09^{c}$ & $8.67 \pm 3.25^{\mathrm{b}}$ & $10.88 \pm 2.85^{\mathrm{b}}$ & $7.46 \pm 0.59^{c}$ & $8.53 \pm 2.59^{\mathrm{d}}$ & $13.22 \pm 1.75^{\mathrm{d}}$ \\
\hline \multirow{5}{*}{ Total } & Basal & $31.07 \pm 7.02^{\mathrm{ab}}$ & $50.76 \pm 11.28^{a}$ & $63.19 \pm 2.93^{\mathrm{a}}$ & $35.14 \pm 9.68^{\mathrm{ab}}$ & $57.58 \pm 5.76^{\mathrm{ac}}$ & $60.23 \pm 11.77^{\mathrm{a}}$ \\
\hline & $3^{\text {rd }}$ day & $24.63 \pm 2.96^{\mathrm{a}^{*}}$ & $26.88 \pm 6.28^{\mathrm{b}^{*}}$ & $46.92 \pm 2.04^{\mathrm{a}^{*}}$ & $34.52 \pm 2.57^{\mathrm{a}^{*}}$ & $49.67 \pm 5.61^{\mathrm{ab}^{*}}$ & $56.71 \pm 5.56^{\mathrm{a}^{*}}$ \\
\hline & $6^{\text {th }}$ day & $38.18 \pm 0.01^{b c^{*}}$ & $50.95 \pm 3.83^{\mathrm{a}}$ & $45.91 \pm 6.93^{\mathrm{b}^{*}}$ & $47.45 \pm 3.72 \mathrm{a}^{\mathrm{b}^{*}}$ & $51.17 \pm 5.10^{\mathrm{ab}}$ & $57.74 \pm 6.97^{\mathrm{a}^{*}}$ \\
\hline & $9^{\text {th }}$ day & $46.38 \pm 3.26^{\mathrm{c}}$ & $60.06 \pm 12.87^{\mathrm{a}}$ & $73.45 \pm 6.11^{\mathrm{b}}$ & $50.02 \pm 4.23^{\mathrm{b}}$ & $71.81 \pm 7.48^{\mathrm{c}}$ & $61.96 \pm 5.47^{\mathrm{a}}$ \\
\hline & $12^{\text {th }}$ day & $45.26 \pm 5.80^{\mathrm{bc}}$ & $53.49 \pm 11.45^{\mathrm{a}}$ & $68.44 \pm 7.64^{b}$ & $46.17 \pm 1.79^{\mathrm{ab}}$ & $48.12 \pm 8.00^{\mathrm{b}}$ & $76.93 \pm 12.37^{\mathrm{a}}$ \\
\hline \multirow{5}{*}{ BCR } & Basal & $0.072 \pm 0.022^{\mathrm{a}}$ & $0.055 \pm 0.024^{\mathrm{a}}$ & $0.081 \pm 0.017^{\mathrm{a}}$ & $0.068 \pm 0.027^{\mathrm{a}}$ & $0.086 \pm 0.007^{\mathrm{a}}$ & $0.072 \pm 0.006^{\mathrm{a}}$ \\
\hline & $3^{\text {rd }}$ day & $0.052 \pm 0.008^{\mathrm{ab}}$ & $0.007 \pm 0.001^{b}$ & $0.017 \pm 0.005^{b}$ & $0.064 \pm 0.030^{\mathrm{ab}}$ & $0.007 \pm 0.001^{b}$ & $0.014 \pm 0.004^{b}$ \\
\hline & $6^{\text {th }}$ day & $0.029 \pm 0.007^{b c}$ & $0.007 \pm 0.001^{\mathrm{b}}$ & $0.010 \pm 0.003^{b}$ & $0.023 \pm 0.009^{b}$ & $0.007 \pm 0.001^{b}$ & $0.010 \pm 0.002^{b c}$ \\
\hline & $9^{\text {th }}$ day & $0.023 \pm 0.010^{\mathrm{c}}$ & $0.004 \pm 0.001^{\mathrm{b}}$ & $0.005 \pm 0.001^{b}$ & $0.022 \pm 0.013^{\mathrm{b}}$ & $0.004 \pm 0.001^{b}$ & $0.006 \pm 0.002^{c}$ \\
\hline & $12^{\text {th }}$ day & $0.024 \pm 0.008^{c}$ & $0.005 \pm 0.001^{\mathrm{b}}$ & $0.006 \pm 0.002^{b}$ & $0.022 \pm 0.011^{\mathrm{b}}$ & $0.005 \pm 0.001^{\mathrm{b}}$ & $0.005 \pm 0.002^{\mathrm{c}}$ \\
\hline
\end{tabular}

Different upper-case letters in the same column indicate statistical difference to the Tukey test $(\mathrm{p}<0.05)$. Data represent the mean of two donors, \pm indicate standard deviation of the biological replicates. At each time point and colon region, * indicate statistical significance between ICC and MDC.

\subsection{Concluding remarks}

In the present study, we have showed that plant cell integrity modulates nutrient utilization by gut microbiota. Higher amounts of starch were delivered to the distal parts of the colon in bean samples where an intact CW matrix was present. NSP constituents of the CW were also differentially fermented in samples depending on their structural properties. Furthermore, bean cell supplementation produced remarkable changes in microbial population with a large increase in the abundance of Bifidobacterium species after the bean treatments. However, structural changes between bean samples did not produce large differences in the microbial population. The evolution of SCFA concentration suggests that the main changes produced by structural properties are related to the differential utilization of the substrates available and those differences disappear upon long-term supplementation. Therefore, microstructural 
properties of food systems could be used as a strategy to modulate colonic fermentation but the efficacy of such strategy on the long term needs to be further explored.

\subsection{Acknowledgments}

We thank Erik Meulenbroeks for his technical support while conducting the SHIME ${ }^{\circledR}$ experiments.

This research was supported by a grant from the Ecuadorian Secretary of Higher Education, Science, Technology and Innovation. 


\section{References}

1. Sonnenburg ED, Sonnenburg JL. Starving our microbial self: The deleterious consequences of a diet deficient in microbiota-accessible carbohydrates. Cell Metab. 2014;20(5):779-786.

2. Sonnenburg ED, Smits SA, Tikhonov M, Higginbottom SK, Wingreen NS, Sonnenburg JL. Diet-induced extinctions in the gut microbiota compound over generations. Nature. 2016;529(7585):212-215.

3. Slavin J. Fiber and prebiotics: Mechanisms and health benefits. Nutrients. 2013;5(4):14171435.

4. Hernández-Salazar M, Osorio-Diaz P, Loarca-Piña G, Reynoso-Camacho R, Tovar J, BelloPérez LA. In vitro fermentability and antioxidant capacity of the indigestible fraction of cooked black beans (Phaseolus vulgaris L.), lentils (Lens culinaris L.) and chickpeas (Cicer arietinum L.). J Sci Food Agric. 2010;90(9):1417-1422.

5. Fernando WMU, Hill JE, Zello GA, Tyler RT, Dahl WJ, Van Kessel AG. Diets supplemented with chickpea or its main oligosaccharide component raffinose modify faecal microbial composition in healthy adults. Benef Microbes. 2010;1(2):197-207.

6. Bach Knudsen KE. Microbial Degradation of Whole-Grain Complex Carbohydrates and Impact on Short-Chain Fatty Acids and Health. Adv Nutr. 2015;6(2):206-213.

7. Nugent AP. Health properties of resistant starch. Nutr Bull. 2005;30(1):27-54.

8. Umu ÖCO, Frank JA, Fangel JU, et al. Resistant starch diet induces change in the swine microbiome and a predominance of beneficial bacterial populations. Microbiome. 2015;3(1):115.

9. Jonathan MC, Haenen D, Souza Da Silva C, Bosch G, Schols HA, Gruppen H. Influence of a diet rich in resistant starch on the degradation of non-starch polysaccharides in the large intestine of pigs. Carbohydr Polym. 2013;93(1):232-239.

10. Henningsson ÅM, Margareta E, Nyman GL, Björck IME. Content of short-chain fatty acids in the hindgut of rats fed processed bean ( Phaseolus vulgaris ) flours varying in distribution and content of indigestible carbohydrates. Br J Nutr. 2001;86(3):379-389.

11. Flint HJ, Scott KP, Duncan SH, Louis P, Forano E. Microbial degradation of complex carbohydrates in the gut. Gut Microbes. 2012;3(4).

12. Clemente A, Olias R. Beneficial effects of legumes in gut health. Curr Opin Food Sci. 2017;14:32-36.

13. Rovalino-Córdova AM, Fogliano V, Capuano E. A closer look to cell structural barriers affecting starch digestibility in beans. Carbohydr Polym. 2018;181:994-1002.

14. Warren FJ, Fukuma NM, Mikkelsen D, et al. Food Starch Structure Impacts Gut Microbiome Composition. mSphere. 2018;3(3):1-13.

15. Van De Wiele T, Boon N, Possemiers S, Jacobs H, Verstraete W. Inulin-type fructans of longer degree of polymerization exert more pronounced in vitro prebiotic effects. $J$ Appl Microbiol. 
2007;102(2):452-460.

16. Molly K, Vande Woestyne M, Verstraete W. Development of a 5-step multi-chamber reactor as a simulation of the human intestinal microbial ecosystem. Appl Microbiol Biotechnol. 1993;39:254-258.

17. Koper JEB, Loonen LMP, Wells JM, Troise AD, Capuano E, Fogliano V. Polyphenols and Tryptophan Metabolites Activate the Aryl Hydrocarbon Receptor in an in vitro Model of Colonic Fermentation. Mol Nutr Food Res. 2019;63(3):1-9.

18. Gouveia JD, Ruiz J, van den Broek LAM, et al. Botryococcus braunii strains compared for biomass productivity, hydrocarbon and carbohydrate content. J Biotechnol. 2017;248:77-86.

19. Guo B, Oliviero T, Fogliano V, Ma Y, Chen F, Capuano E. Gastrointestinal bioaccessibility and colonic fermentation of fucoxanthin from the extract of the microalga Nitzschia laevis. $J$ Agric Food Chem. 2019.

20. Rose DJ, Keshavarzian A, Patterson JA, Venkatachalam M, Gillevet P, Hamaker BR. Starchentrapped microspheres extend in vitro fecal fermentation, increase butyrate production, and influence microbiota pattern. Mol Nutr Food Res. 2009;53:121-130.

21. Brett CT, Waldron KW. Cell wall architecture and the skeletal role of the cell wall. In: Black B, Charlwood M, eds. Physiology and Biochemistry of Plant Cell Walls. London: Chapman \& Hall; 1996:44-74.

22. Rovalino-Córdova AM, Fogliano V, Capuano E. The effect of cell wall encapsulation on macronutrients digestion: A case study in kidney beans. Food Chem. 2019;286:557-566.

23. Leitch ECMW, Walker AW, Duncan SH, Holtrop G, Flint HJ. Selective colonization of insoluble substrates by human faecal bacteria. Environ Microbiol. 2007;9(3):667-679.

24. Oomen RJFJ, Vincken J, Bush MS, et al. Towards unravelling the biological significance of the individual components of pectic hairy regions in plants. In: Voragen F, Schols H, Visser RG., eds. Advances in Pectin and Pectinase Research. Springer Netherlands; 2003:15-34.

25. Voragen AGJ, Coenen GJ, Verhoef RP, Schols HA. Pectin, a versatile polysaccharide present in plant cell walls. Struct Chem. 2009;20(2):263-275.

26. Dongowski G, Lorenz A, Proll J. The Degree of Methylation Influences the Degradation of Pectin in the Intestinal Tract of Rats and In Vitro. J Nutr. 2002;132(7):1935-1944.

27. van Laar H, Tamminga S, Williams BA, Verstegen MW. Fermentation of the endosperm cell walls of monocotyledon and dicotyledon plant species by faecal microbes from pigs. Anim Feed Sci Technol. 2000;88(1-2):13-30.

28. Mikkelsen D, Gidley MJ, Williams BA. In vitro fermentation of bacterial cellulose composites as model dietary fibers. J Agric Food Chem. 2011;59(8):4025-4032.

29. Tuncil YE, Nakatsu CH, Kazem AE, et al. Delayed utilization of some fast-fermenting soluble dietary fibers by human gut microbiota when presented in a mixture. J Funct Foods. 2017;32:347-357. 
30. Tian L, Scholte J, Borewicz K, et al. Effects of pectin supplementation on the fermentation patterns of different structural carbohydrates in rats. Mol Nutr Food Res. 2016;60(10):22562266.

31. Lozupone CA, Stombaugh JI, Gordon JI, Jansson JK, Knight R. Diversity, stability and resilience of the human gut microbiota. Nature. 2012;489(7415):220-230.

32. Callaghan AO, Sinderen D Van. Bifidobacteria and Their Role as Members of the Human Gut Microbiota. Front Microbiol. 2016;7:1-23.

33. Turroni F, Foroni E, Pizzetti P, et al. Exploring the Diversity of the Bifidobacterial Population in the Human Intestinal Tract $\square$. Appl Environ Microbiol. 2009;75(6):1534-1545.

34. Rivière A, Selak M, Lantin D, Leroy F, Vuyst L De. Bifidobacteria and Butyrate-Producing Colon Bacteria : Importance and Strategies for Their Stimulation in the Human Gut. Front Microbiol. 2016;7(June):1-21.

35. Sakon H, Nagai F, Morotomi M, Tanaka R. Sutterella parvirubra sp. nov. and Megamonas funiformis sp. nov. isolated from human faeces. Int J Syst Evol Microbiol. 2008;58:970-975.

36. Paepe K De, Kerckhof F, Verspreet J, Courtin CM, Wiele T Van De. Inter-individual differences determine the outcome of wheat bran colonization by the human gut microbiome. Environ Microbiol. 2017;19(8):3251-3267.

37. Koropatkin NM, Cameron EA, Martens EC. How glycan metabolism shapes the human gut microbiota. Nat Rev Microbiol. 2012;10:323-335.

38. Chassard C, Delmas E, Bernalier-donadille A. The cellulose-degrading microbial community of the human gut varies according to the presence or absence of methanogens '. Microbiol Ecol. 2010;74:205-2013. 


\section{Appendices 5}

Table 5-A1. 16S RNA microbial analysis at family level in the ascending colon for ICC and MDC of two biological replicates. A control sample was included where microbiota was given a commercial feed that contained isolated starch.

\begin{tabular}{|c|c|c|c|c|c|c|}
\hline \multirow[b]{3}{*}{ Family } & \multicolumn{6}{|c|}{ Relative Abundance } \\
\hline & \multicolumn{3}{|c|}{ Donor 1} & \multicolumn{3}{|c|}{ Donor 2} \\
\hline & Control & ICC & MDC & Control & ICC & $\mathrm{MDC}$ \\
\hline Acidaminococcaceae & $0.44 \%$ & $0.36 \%$ & $0.00 \%$ & $0.04 \%$ & $0.00 \%$ & $0.00 \%$ \\
\hline Alcaligenaceae & $0.00 \%$ & $0.01 \%$ & $0.00 \%$ & $0.00 \%$ & $0.00 \%$ & $0.00 \%$ \\
\hline Aspergillaceae & $0.00 \%$ & $0.00 \%$ & $0.01 \%$ & $0.00 \%$ & $0.00 \%$ & $0.00 \%$ \\
\hline Bacillaceae & $0.04 \%$ & $0.09 \%$ & $0.04 \%$ & $0.00 \%$ & $0.01 \%$ & $0.03 \%$ \\
\hline Bacteroidaceae & $1.62 \%$ & $5.27 \%$ & $1.57 \%$ & $0.01 \%$ & $0.01 \%$ & $0.00 \%$ \\
\hline Bifidobacteriaceae & $19.32 \%$ & $59.94 \%$ & $58.30 \%$ & $1.66 \%$ & $91.43 \%$ & $79.38 \%$ \\
\hline Brucellaceae & $0.01 \%$ & $0.00 \%$ & $0.00 \%$ & $0.00 \%$ & $0.00 \%$ & $0.00 \%$ \\
\hline Clostridiaceae & $0.07 \%$ & $2.50 \%$ & $0.32 \%$ & $0.90 \%$ & $2.81 \%$ & $3.62 \%$ \\
\hline Comamonadaceae & $0.77 \%$ & $0.41 \%$ & $0.02 \%$ & $0.00 \%$ & $0.13 \%$ & $0.10 \%$ \\
\hline Coriobacteriaceae & $0.00 \%$ & $4.72 \%$ & $35.12 \%$ & $0.00 \%$ & $0.00 \%$ & $0.00 \%$ \\
\hline Enterobacteriaceae & $0.99 \%$ & $3.01 \%$ & $1.33 \%$ & $0.43 \%$ & $0.19 \%$ & $0.79 \%$ \\
\hline Enterococcaceae & $0.00 \%$ & $1.86 \%$ & $0.91 \%$ & $0.00 \%$ & $0.34 \%$ & $0.03 \%$ \\
\hline Erwiniaceae & $0.01 \%$ & $0.01 \%$ & $0.00 \%$ & $0.02 \%$ & $0.00 \%$ & $0.00 \%$ \\
\hline Eubacteriaceae & $0.00 \%$ & $0.01 \%$ & $0.00 \%$ & $0.00 \%$ & $0.00 \%$ & $0.00 \%$ \\
\hline Fabaceae & $0.00 \%$ & $0.00 \%$ & $0.00 \%$ & $0.00 \%$ & $0.01 \%$ & $0.00 \%$ \\
\hline Lachnospiraceae & $1.19 \%$ & $4.12 \%$ & $0.11 \%$ & $0.01 \%$ & $0.03 \%$ & $0.01 \%$ \\
\hline Lactobacillaceae & $0.09 \%$ & $0.16 \%$ & $0.02 \%$ & $0.02 \%$ & $0.10 \%$ & $0.03 \%$ \\
\hline Leuconostocaceae & $0.00 \%$ & $0.00 \%$ & $0.00 \%$ & $0.00 \%$ & $0.00 \%$ & $1.99 \%$ \\
\hline Listeriaceae & $0.00 \%$ & $0.01 \%$ & $0.00 \%$ & $0.00 \%$ & $0.00 \%$ & $0.00 \%$ \\
\hline Microbacteriaceae & $0.00 \%$ & $0.00 \%$ & $0.00 \%$ & $0.00 \%$ & $0.00 \%$ & $0.02 \%$ \\
\hline Morganellaceae & $0.01 \%$ & $0.08 \%$ & $0.03 \%$ & $0.00 \%$ & $0.00 \%$ & $0.00 \%$ \\
\hline Nocardiaceae & $0.00 \%$ & $0.00 \%$ & $0.00 \%$ & $0.00 \%$ & $0.00 \%$ & $0.08 \%$ \\
\hline Paenibacillaceae & $0.00 \%$ & $0.14 \%$ & $0.00 \%$ & $0.00 \%$ & $0.02 \%$ & $0.00 \%$ \\
\hline Prevotellaceae & $0.00 \%$ & $0.00 \%$ & $0.00 \%$ & $0.00 \%$ & $0.02 \%$ & $0.01 \%$ \\
\hline Pseudomonadaceae & $0.00 \%$ & $0.06 \%$ & $0.06 \%$ & $0.09 \%$ & $0.06 \%$ & $0.05 \%$ \\
\hline Peptostreptococcaceae & $0.00 \%$ & $0.01 \%$ & $0.00 \%$ & $0.00 \%$ & $0.00 \%$ & $0.00 \%$ \\
\hline Porphyromonadaceae & $0.00 \%$ & $0.01 \%$ & $0.00 \%$ & $0.00 \%$ & $0.00 \%$ & $0.00 \%$ \\
\hline Ruminococcaceae & $0.00 \%$ & $0.01 \%$ & $0.00 \%$ & $0.00 \%$ & $0.02 \%$ & $0.02 \%$ \\
\hline Selenomonadaceae & $67.13 \%$ & $0.53 \%$ & $0.04 \%$ & $89.40 \%$ & $0.14 \%$ & $0.02 \%$ \\
\hline Sphingobacteriaceae & $0.00 \%$ & $0.04 \%$ & $0.00 \%$ & $0.00 \%$ & $0.01 \%$ & $0.00 \%$ \\
\hline Streptococcaceae & $0.00 \%$ & $5.78 \%$ & $0.00 \%$ & $0.00 \%$ & $0.01 \%$ & $10.90 \%$ \\
\hline Sutterellaceae & $0.08 \%$ & $0.00 \%$ & $0.00 \%$ & $0.00 \%$ & $0.00 \%$ & $0.00 \%$ \\
\hline Unclassified & $0.38 \%$ & $0.28 \%$ & $0.12 \%$ & $0.06 \%$ & $0.08 \%$ & $0.08 \%$ \\
\hline unclassified Actinobacteria & $0.01 \%$ & $0.07 \%$ & $0.03 \%$ & $0.00 \%$ & $0.00 \%$ & $0.00 \%$ \\
\hline unclassified Burkholderiales & $0.00 \%$ & $0.05 \%$ & $0.01 \%$ & $0.00 \%$ & $0.01 \%$ & $0.00 \%$ \\
\hline unclassified Gammaproteobacteria & $0.01 \%$ & $0.02 \%$ & $0.02 \%$ & $0.01 \%$ & $0.00 \%$ & $0.01 \%$ \\
\hline Veillonellaceae & $7.66 \%$ & $10.07 \%$ & $1.67 \%$ & $7.23 \%$ & $4.29 \%$ & $2.26 \%$ \\
\hline Xanthomonadaceae & $0.00 \%$ & $0.10 \%$ & $0.10 \%$ & $0.00 \%$ & $0.05 \%$ & $0.37 \%$ \\
\hline
\end{tabular}


Table 5-A2. 16S RNA microbial analysis at family level in the transverse colon for ICC and MDC of two biological replicates. A control sample was included where microbiota was given a commercial feed that contained isolated starch.

\begin{tabular}{|c|c|c|c|c|c|c|}
\hline \multirow[b]{3}{*}{ Family } & \multicolumn{6}{|c|}{ Relative abundance } \\
\hline & \multicolumn{3}{|c|}{ Donor 1} & \multicolumn{3}{|c|}{ Donor 2} \\
\hline & Control & ICC & $\mathrm{MDC}$ & Control & $\mathrm{ICC}$ & $\mathrm{MDC}$ \\
\hline Acidaminococcaceae & $1.38 \%$ & $0.48 \%$ & $0.01 \%$ & $0.75 \%$ & $0.06 \%$ & $0.06 \%$ \\
\hline Akkermansiaceae & $0.60 \%$ & $0.11 \%$ & $0.00 \%$ & $0.00 \%$ & $0.00 \%$ & $0.00 \%$ \\
\hline Atopobiaceae & $0.00 \%$ & $0.00 \%$ & $0.00 \%$ & $0.00 \%$ & $0.83 \%$ & $0.97 \%$ \\
\hline Bacillaceae & $0.01 \%$ & $0.12 \%$ & $0.00 \%$ & $0.01 \%$ & $0.01 \%$ & $0.01 \%$ \\
\hline Bacteroidaceae & $10.39 \%$ & $8.84 \%$ & $0.57 \%$ & $3.82 \%$ & $0.88 \%$ & $1.08 \%$ \\
\hline Bifidobacteriaceae & $14.53 \%$ & $49.66 \%$ & $72.29 \%$ & $11.38 \%$ & $83.21 \%$ & $87.20 \%$ \\
\hline Brucellaceae & $0.01 \%$ & $0.01 \%$ & $0.00 \%$ & $0.00 \%$ & $0.00 \%$ & $0.00 \%$ \\
\hline Caulobacteraceae & $0.01 \%$ & $0.00 \%$ & $0.00 \%$ & $0.00 \%$ & $0.00 \%$ & $0.00 \%$ \\
\hline Clostridiaceae & $0.43 \%$ & $0.89 \%$ & $0.06 \%$ & $0.46 \%$ & $0.23 \%$ & $0.10 \%$ \\
\hline Comamonadaceae & $0.16 \%$ & $0.43 \%$ & $0.00 \%$ & $0.00 \%$ & $0.23 \%$ & $0.07 \%$ \\
\hline Coriobacteriaceae & $1.05 \%$ & $4.33 \%$ & $23.53 \%$ & $1.84 \%$ & $6.36 \%$ & $2.70 \%$ \\
\hline Corynebacteriaceae & $0.03 \%$ & $0.00 \%$ & $0.00 \%$ & $0.00 \%$ & $0.00 \%$ & $0.00 \%$ \\
\hline Defluviitaleaceae & $0.01 \%$ & $0.00 \%$ & $0.00 \%$ & $0.01 \%$ & $0.00 \%$ & $0.00 \%$ \\
\hline Desulfovibrionaceae & $1.74 \%$ & $0.13 \%$ & $0.02 \%$ & $2.81 \%$ & $0.41 \%$ & $0.12 \%$ \\
\hline Eggerthellaceae & $0.01 \%$ & $0.01 \%$ & $0.01 \%$ & $0.01 \%$ & $0.14 \%$ & $0.11 \%$ \\
\hline Enterobacteriaceae & $0.73 \%$ & $3.37 \%$ & $0.92 \%$ & $0.38 \%$ & $0.17 \%$ & $0.30 \%$ \\
\hline Enterococcaceae & $0.00 \%$ & $1.98 \%$ & $0.17 \%$ & $0.00 \%$ & $0.34 \%$ & $0.03 \%$ \\
\hline Erysipelotrichaceae & $0.02 \%$ & $0.31 \%$ & $0.00 \%$ & $0.11 \%$ & $0.01 \%$ & $0.00 \%$ \\
\hline Erwiniaceae & $0.00 \%$ & $0.04 \%$ & $0.00 \%$ & $0.01 \%$ & $0.00 \%$ & $0.00 \%$ \\
\hline Eubacteriaceae & $1.65 \%$ & $0.50 \%$ & $0.01 \%$ & $3.60 \%$ & $0.09 \%$ & $0.20 \%$ \\
\hline Fusobacteriaceae & $0.00 \%$ & $0.00 \%$ & $0.00 \%$ & $0.57 \%$ & $0.07 \%$ & $0.13 \%$ \\
\hline Gracilibacteraceae & $0.00 \%$ & $0.00 \%$ & $0.04 \%$ & $0.00 \%$ & $0.00 \%$ & $0.00 \%$ \\
\hline Lachnospiraceae & $9.51 \%$ & $12.36 \%$ & $0.52 \%$ & $6.54 \%$ & $1.19 \%$ & $1.43 \%$ \\
\hline Lactobacillaceae & $0.10 \%$ & $0.18 \%$ & $0.02 \%$ & $0.03 \%$ & $0.02 \%$ & $0.00 \%$ \\
\hline Leuconostocaceae & $0.00 \%$ & $0.00 \%$ & $0.00 \%$ & $0.00 \%$ & $0.00 \%$ & $0.70 \%$ \\
\hline Listeriaceae & $0.00 \%$ & $0.01 \%$ & $0.00 \%$ & $0.00 \%$ & $0.00 \%$ & $0.00 \%$ \\
\hline Morganellaceae & $0.02 \%$ & $0.00 \%$ & $0.00 \%$ & $0.01 \%$ & $0.00 \%$ & $0.00 \%$ \\
\hline Nocardiaceae & $0.00 \%$ & $0.00 \%$ & $0.00 \%$ & $0.00 \%$ & $0.00 \%$ & $0.02 \%$ \\
\hline Oscillospiraceae & $0.00 \%$ & $0.10 \%$ & $0.00 \%$ & $0.00 \%$ & $0.03 \%$ & $0.00 \%$ \\
\hline Odoribacteraceae & $0.03 \%$ & $0.00 \%$ & $0.00 \%$ & $0.00 \%$ & $0.00 \%$ & $0.00 \%$ \\
\hline Paenibacillaceae & $0.00 \%$ & $0.10 \%$ & $0.00 \%$ & $0.00 \%$ & $0.00 \%$ & $0.00 \%$ \\
\hline Peptococcaceae & $0.01 \%$ & $0.00 \%$ & $0.00 \%$ & $0.00 \%$ & $0.00 \%$ & $0.00 \%$ \\
\hline Porphyromonadaceae & $3.07 \%$ & $0.64 \%$ & $0.06 \%$ & $5.96 \%$ & $0.19 \%$ & $0.09 \%$ \\
\hline Prevotellaceae & $0.00 \%$ & $0.00 \%$ & $0.00 \%$ & $0.00 \%$ & $0.01 \%$ & $0.01 \%$ \\
\hline Pseudomonadaceae & $0.00 \%$ & $0.10 \%$ & $0.02 \%$ & $0.05 \%$ & $0.12 \%$ & $0.02 \%$ \\
\hline Pseudeurotiaceae & $0.01 \%$ & $0.00 \%$ & $0.00 \%$ & $0.00 \%$ & $0.00 \%$ & $0.00 \%$ \\
\hline Rikenellaceae & $0.16 \%$ & $0.10 \%$ & $0.20 \%$ & $0.05 \%$ & $0.53 \%$ & $0.14 \%$ \\
\hline Ruminococcaceae & $0.30 \%$ & $0.19 \%$ & $0.64 \%$ & $1.08 \%$ & $1.95 \%$ & $0.54 \%$ \\
\hline Selenomonadaceae & $46.96 \%$ & $0.62 \%$ & $0.01 \%$ & $55.13 \%$ & $0.12 \%$ & $0.01 \%$ \\
\hline Sphingobacteriaceae & $0.00 \%$ & $0.02 \%$ & $0.00 \%$ & $0.00 \%$ & $0.00 \%$ & $0.00 \%$ \\
\hline Streptococcaceae & $0.01 \%$ & $0.90 \%$ & $0.00 \%$ & $0.00 \%$ & $0.00 \%$ & $2.18 \%$ \\
\hline Sutterellaceae & $0.18 \%$ & $0.07 \%$ & $0.00 \%$ & $0.23 \%$ & $0.01 \%$ & $0.10 \%$ \\
\hline
\end{tabular}




\begin{tabular}{|c|c|c|c|c|c|c|}
\hline \multirow[b]{3}{*}{ Family } & \multicolumn{6}{|c|}{ Relative abundance } \\
\hline & \multicolumn{3}{|c|}{ Donor 1} & \multicolumn{3}{|c|}{ Donor 2} \\
\hline & $\begin{array}{l}\text { Contro } \\
1\end{array}$ & ICC & $\mathrm{MDC}$ & Control & ICC & $\mathrm{MDC}$ \\
\hline Thermoactinomycetaceae & $0.01 \%$ & $0.00 \%$ & $0.00 \%$ & $0.00 \%$ & $0.00 \%$ & $0.00 \%$ \\
\hline Unclassified & $0.73 \%$ & $0.53 \%$ & $0.10 \%$ & $0.70 \%$ & $0.14 \%$ & $0.11 \%$ \\
\hline Unclassified Actinobacteria & $0.00 \%$ & $0.03 \%$ & $0.00 \%$ & $0.00 \%$ & $0.00 \%$ & $0.00 \%$ \\
\hline Unclassified Bacteroidales & $0.00 \%$ & $0.00 \%$ & $0.00 \%$ & $0.02 \%$ & $0.00 \%$ & $0.00 \%$ \\
\hline Unclassified Betaproteobacteria & $0.00 \%$ & $0.01 \%$ & $0.00 \%$ & $0.00 \%$ & $0.00 \%$ & $0.00 \%$ \\
\hline Unclassified Burkholderiales & $0.00 \%$ & $0.05 \%$ & $0.00 \%$ & $0.00 \%$ & $0.01 \%$ & $0.00 \%$ \\
\hline Unclassified Clostridiales & $0.17 \%$ & $0.22 \%$ & $0.06 \%$ & $0.08 \%$ & $0.16 \%$ & $0.23 \%$ \\
\hline Unclassified Gammaproteobacteria & $0.02 \%$ & $0.01 \%$ & $0.01 \%$ & $0.00 \%$ & $0.00 \%$ & $0.00 \%$ \\
\hline Unclassified Rhodospirillales & $0.00 \%$ & $0.00 \%$ & $0.00 \%$ & $0.00 \%$ & $0.00 \%$ & $0.01 \%$ \\
\hline Veillonellaceae & $5.71 \%$ & $12.11 \%$ & $0.49 \%$ & $4.14 \%$ & $2.24 \%$ & $0.96 \%$ \\
\hline Victivallaceae & $0.00 \%$ & $0.00 \%$ & $0.00 \%$ & $0.00 \%$ & $0.00 \%$ & $0.03 \%$ \\
\hline Xanthomonadaceae & $0.00 \%$ & $0.01 \%$ & $0.00 \%$ & $0.00 \%$ & $0.02 \%$ & $0.06 \%$ \\
\hline
\end{tabular}


Table 5-A3. 16S RNA microbial analysis at family level in the descending colon for ICC and MDC of two biological replicates. A control sample was included where microbiota was given a commercial feed that contained isolated starch.

\begin{tabular}{|c|c|c|c|c|c|c|}
\hline \multirow[b]{3}{*}{ Family } & \multicolumn{6}{|c|}{ Relative abundance } \\
\hline & \multicolumn{3}{|c|}{ Donor 1} & \multicolumn{3}{|c|}{ Donor 2} \\
\hline & Control & ICC & MDC & Control & ICC & MDC \\
\hline Acidaminococcaceae & $1.72 \%$ & $0.47 \%$ & $0.61 \%$ & $0.83 \%$ & $0.09 \%$ & $0.68 \%$ \\
\hline Akkermansiaceae & $0.73 \%$ & $0.19 \%$ & $0.07 \%$ & $0.14 \%$ & $0.00 \%$ & $0.00 \%$ \\
\hline Alcaligenaceae & $0.00 \%$ & $0.03 \%$ & $0.01 \%$ & $0.00 \%$ & $0.01 \%$ & $0.02 \%$ \\
\hline Atopobiaceae & $0.00 \%$ & $0.00 \%$ & $0.00 \%$ & $0.01 \%$ & $1.56 \%$ & $0.20 \%$ \\
\hline Bacillaceae & $0.00 \%$ & $0.05 \%$ & $0.22 \%$ & $0.01 \%$ & $0.02 \%$ & $0.03 \%$ \\
\hline Bacteroidaceae & $10.64 \%$ & $4.02 \%$ & $7.78 \%$ & $10.67 \%$ & $1.36 \%$ & $2.20 \%$ \\
\hline Bifidobacteriaceae & $17.38 \%$ & $57.08 \%$ & $47.23 \%$ & $8.77 \%$ & $71.37 \%$ & $65.06 \%$ \\
\hline Brucellaceae & $0.01 \%$ & $0.02 \%$ & $0.01 \%$ & $0.00 \%$ & $0.00 \%$ & $0.00 \%$ \\
\hline Catabacteriaceae & $0.00 \%$ & $0.01 \%$ & $0.00 \%$ & $0.00 \%$ & $0.00 \%$ & $0.00 \%$ \\
\hline Caulobacteraceae & $0.00 \%$ & $0.00 \%$ & $0.00 \%$ & $0.00 \%$ & $0.00 \%$ & $0.01 \%$ \\
\hline Christensenellaceae & $0.00 \%$ & $0.03 \%$ & $0.03 \%$ & $0.00 \%$ & $0.00 \%$ & $0.01 \%$ \\
\hline Clostridiaceae & $0.89 \%$ & $1.70 \%$ & $1.39 \%$ & $1.02 \%$ & $0.23 \%$ & $0.47 \%$ \\
\hline Clostridiales Family XIII. Incertae Sed & $0.00 \%$ & $0.00 \%$ & $0.33 \%$ & $0.03 \%$ & $0.03 \%$ & $0.14 \%$ \\
\hline Comamonadaceae & $0.11 \%$ & $0.46 \%$ & $0.07 \%$ & $0.00 \%$ & $0.21 \%$ & $0.37 \%$ \\
\hline Coriobacteriaceae & $1.86 \%$ & $4.29 \%$ & $4.64 \%$ & $1.83 \%$ & $12.43 \%$ & $0.68 \%$ \\
\hline Corynebacteriaceae & $0.01 \%$ & $0.00 \%$ & $0.00 \%$ & $0.01 \%$ & $0.00 \%$ & $0.00 \%$ \\
\hline Defluviitaleaceae & $0.01 \%$ & $0.00 \%$ & $0.00 \%$ & $0.02 \%$ & $0.00 \%$ & $0.00 \%$ \\
\hline Desulfovibrionaceae & $2.43 \%$ & $0.32 \%$ & $0.13 \%$ & $2.97 \%$ & $0.45 \%$ & $0.81 \%$ \\
\hline Eggerthellaceae & $0.02 \%$ & $0.02 \%$ & $0.00 \%$ & $0.07 \%$ & $0.28 \%$ & $0.03 \%$ \\
\hline Enterobacteriaceae & $0.78 \%$ & $3.49 \%$ & $11.22 \%$ & $0.32 \%$ & $0.16 \%$ & $3.54 \%$ \\
\hline Enterococcaceae & $0.00 \%$ & $1.07 \%$ & $4.31 \%$ & $0.01 \%$ & $0.50 \%$ & $0.32 \%$ \\
\hline Erwiniaceae & $0.02 \%$ & $0.02 \%$ & $0.06 \%$ & $0.01 \%$ & $0.00 \%$ & $0.01 \%$ \\
\hline Erysipelotrichaceae & $0.01 \%$ & $0.20 \%$ & $0.09 \%$ & $0.07 \%$ & $0.03 \%$ & $0.00 \%$ \\
\hline Eubacteriaceae & $2.84 \%$ & $1.20 \%$ & $0.22 \%$ & $3.28 \%$ & $0.10 \%$ & $0.97 \%$ \\
\hline Fusobacteriaceae & $0.00 \%$ & $0.00 \%$ & $0.00 \%$ & $0.18 \%$ & $0.08 \%$ & $0.02 \%$ \\
\hline Gracilibacteraceae & $0.00 \%$ & $0.00 \%$ & $0.16 \%$ & $0.00 \%$ & $0.00 \%$ & $0.00 \%$ \\
\hline Heliobacteriaceae & $0.00 \%$ & $0.00 \%$ & $0.01 \%$ & $0.00 \%$ & $0.00 \%$ & $0.00 \%$ \\
\hline Lachnospiraceae & $12.68 \%$ & $10.42 \%$ & $6.52 \%$ & $6.38 \%$ & $1.41 \%$ & $6.27 \%$ \\
\hline Lactobacillaceae & $0.06 \%$ & $0.16 \%$ & $0.08 \%$ & $0.04 \%$ & $0.02 \%$ & $0.06 \%$ \\
\hline Listeriaceae & $0.00 \%$ & $0.01 \%$ & $0.01 \%$ & $0.00 \%$ & $0.00 \%$ & $0.00 \%$ \\
\hline Leuconostocaceae & $0.00 \%$ & $0.00 \%$ & $0.00 \%$ & $0.00 \%$ & $0.00 \%$ & $1.00 \%$ \\
\hline Methanobacteriaceae & $0.02 \%$ & $0.08 \%$ & $0.84 \%$ & $0.00 \%$ & $0.00 \%$ & $0.00 \%$ \\
\hline Morganellaceae & $0.01 \%$ & $0.07 \%$ & $0.28 \%$ & $0.00 \%$ & $0.00 \%$ & $0.09 \%$ \\
\hline Nocardiaceae & $0.00 \%$ & $0.00 \%$ & $0.00 \%$ & $0.00 \%$ & $0.00 \%$ & $0.02 \%$ \\
\hline Odoribacteraceae & $0.06 \%$ & $0.00 \%$ & $0.01 \%$ & $0.00 \%$ & $0.00 \%$ & $0.00 \%$ \\
\hline Oscillospiraceae & $0.19 \%$ & $0.16 \%$ & $0.19 \%$ & $0.23 \%$ & $0.05 \%$ & $0.38 \%$ \\
\hline Paenibacillaceae & $0.00 \%$ & $0.06 \%$ & $0.00 \%$ & $0.00 \%$ & $0.01 \%$ & $0.00 \%$ \\
\hline Pectobacteriaceae & $0.00 \%$ & $0.00 \%$ & $0.00 \%$ & $0.00 \%$ & $0.00 \%$ & $0.01 \%$ \\
\hline Peptococcaceae & $0.00 \%$ & $0.00 \%$ & $0.00 \%$ & $0.00 \%$ & $0.00 \%$ & $0.01 \%$ \\
\hline Phyllobacteriaceae & $0.00 \%$ & $0.00 \%$ & $0.01 \%$ & $0.00 \%$ & $0.00 \%$ & $0.00 \%$ \\
\hline Porphyromonadaceae & $2.89 \%$ & $1.03 \%$ & $1.36 \%$ & $4.20 \%$ & $0.37 \%$ & $0.85 \%$ \\
\hline Pseudomonadaceae & $0.00 \%$ & $0.13 \%$ & $0.03 \%$ & $0.02 \%$ & $0.38 \%$ & $0.30 \%$ \\
\hline
\end{tabular}




\begin{tabular}{|c|c|c|c|c|c|c|}
\hline \multirow[b]{3}{*}{ Rikenellaceae } & \multicolumn{6}{|c|}{ Relative abundance } \\
\hline & \multicolumn{3}{|c|}{ Donor 1} & \multicolumn{3}{|c|}{ Donor 2} \\
\hline & $0.21 \%$ & $0.76 \%$ & $1.32 \%$ & $0.11 \%$ & $1.70 \%$ & $0.70 \%$ \\
\hline Rhizobiaceae & $0.00 \%$ & $0.00 \%$ & $0.00 \%$ & $0.01 \%$ & $0.00 \%$ & $0.00 \%$ \\
\hline Ruminococcaceae & $0.36 \%$ & $0.47 \%$ & $1.84 \%$ & $1.08 \%$ & $2.77 \%$ & $1.70 \%$ \\
\hline Selenomonadaceae & $38.82 \%$ & $0.28 \%$ & $0.17 \%$ & $52.98 \%$ & $0.15 \%$ & $0.10 \%$ \\
\hline Sphingobacteriaceae & $0.01 \%$ & $0.04 \%$ & $0.02 \%$ & $0.00 \%$ & $0.01 \%$ & $0.00 \%$ \\
\hline Staphylococcaceae & $0.00 \%$ & $0.00 \%$ & $0.01 \%$ & $0.00 \%$ & $0.00 \%$ & $0.00 \%$ \\
\hline Streptococcaceae & $0.00 \%$ & $0.28 \%$ & $0.00 \%$ & $0.00 \%$ & $0.01 \%$ & $2.20 \%$ \\
\hline Streptomycetaceae & $0.00 \%$ & $0.01 \%$ & $0.01 \%$ & $0.00 \%$ & $0.00 \%$ & $0.00 \%$ \\
\hline Sutterellaceae & $0.34 \%$ & $0.10 \%$ & $0.13 \%$ & $0.48 \%$ & $0.02 \%$ & $0.28 \%$ \\
\hline Unclassified & $0.81 \%$ & $0.31 \%$ & $0.51 \%$ & $0.58 \%$ & $0.14 \%$ & $0.22 \%$ \\
\hline Unclassified Actinobacteria & $0.00 \%$ & $0.02 \%$ & $0.01 \%$ & $0.00 \%$ & $0.00 \%$ & $0.00 \%$ \\
\hline Unclassified Bacteroidales & $0.01 \%$ & $0.00 \%$ & $0.01 \%$ & $0.05 \%$ & $0.00 \%$ & $0.00 \%$ \\
\hline Unclassified Burkholderiales & $0.00 \%$ & $0.06 \%$ & $0.00 \%$ & $0.00 \%$ & $0.00 \%$ & $0.05 \%$ \\
\hline Unclassified Clostridiales & $0.36 \%$ & $0.40 \%$ & $0.46 \%$ & $0.11 \%$ & $0.28 \%$ & $1.59 \%$ \\
\hline Unclassified Gammaproteobacteria & $0.00 \%$ & $0.03 \%$ & $0.12 \%$ & $0.02 \%$ & $0.00 \%$ & $0.04 \%$ \\
\hline Veillonellaceae & $3.38 \%$ & $10.15 \%$ & $7.03 \%$ & $3.20 \%$ & $3.51 \%$ & $8.09 \%$ \\
\hline Victivallaceae & $0.00 \%$ & $0.00 \%$ & $0.01 \%$ & $0.02 \%$ & $0.01 \%$ & $0.04 \%$ \\
\hline Xanthomonadaceae & $0.01 \%$ & $0.01 \%$ & $0.01 \%$ & $0.00 \%$ & $0.00 \%$ & $0.05 \%$ \\
\hline Yersiniaceae & $0.00 \%$ & $0.00 \%$ & $0.01 \%$ & $0.00 \%$ & $0.00 \%$ & $0.01 \%$ \\
\hline
\end{tabular}





\section{Chapter 6}

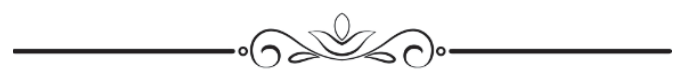

In-vitro colonic fermentation of kidney beans depend on cotyledon cells integrity and microbiota adaptation to the diet

This chapter is based on:

Ana M. Rovalino-Córdova, Vincenzo Fogliano, Edoardo Capuano. In-vitro colonic fermentation of kidney beans depend on cotyledon cells integrity and microbiota adaptation to the diet. Submitted for publication. 


\section{Abstract}

In the present study, we investigated the effect of cellular integrity on starch fermentation by gut microbiota. Cotyledon cells from red kidney beans with different levels of structural integrity were fermented in-vitro by microbial communities previously adapted to the conditions of ascending, transverse and descending colon. The effect of bacterial adaptation to substrate was assessed by using microbiota exposed to a diet rich in bean cells. Microscopy analyses indicate that cell integrity was maintained during fermentation suggesting that sample structural properties are an important factor for modulating substrate utilization. Moreover, adapted bacterial communities were more efficient in fermenting bean cells where higher amounts of butyrate were produced in all colon sections independently of sample integrity. Bacterial communities of the distal colon appeared to be the most efficient in carbohydrate degradation. This suggests that the relatively high protein fermentation observed in-vivo in the distal colon is due to carbohydrates depletion. 


\subsection{Introduction}

In the past few years, the large intestine has been recognized as one of the most metabolically active organs of the human body, where its dynamic microbial ecosystem is the main responsible of those functions. Considerable research was conducted in order to unravel the complex mechanism by which gut microbiota affect the host's health ${ }^{1}$. Several factors have been found to influence microbiota metabolic activity that include: host genetics, immunological factors, antibiotic usage and $\operatorname{diet}^{2}$.

Extensive studies were performed to elucidate the mechanism by which diet alters human microbiota. It has been suggested that factors such as the composition of the diet, habitual intake, acute compositional changes and nutrient availability impact the microbial community in the large intestine ${ }^{1,3}$. For instance, in a study performed by De Filippo, et $\mathrm{al}^{4}$ on European and rural African children large differences in their microbiota composition were found. African children microbiota was enriched with strains capable of hydrolyzing cellulose and xylan, that where completely lacking in European children. This was attributed to dietary differences since the African population consumed high concentrations of fiber, inferring that their microbiota evolved to maximize the energy intake from the nutrients available in their diet. In the same line, a recent study performed by Conterno, et $\mathrm{al}^{5}$ a difference in gut bacterial composition was found between lean and obese individuals. Such changes were attributed to dietary differences, where high-fat low-fiber diet had a dramatic impact on the gut microbiota variation. This indicates that the type of nutrients that escape digestion/absorption and reach the lower gut are key factors in the regulation of microbiota composition ${ }^{6}$. Thus, the intake of specific dietary ingredients is a viable mechanism to induce microbiota modulation ${ }^{7}$. That is why the consumption of specific substrates, collectively known as prebiotics, have been widely investigated and included in dietary guidelines for improving colonic health ${ }^{1}$.

Structural assembly of foods, i.e. the interaction of its constituents at different length scales is an important factor that determines not only the sensorial properties of foods but also its utilization by the human body. The relationship between food structure and nutrients digestibility has been investigated in the last years ${ }^{8-10}$. However, its influence during colonic fermentation is still largely unexplored. To our knowledge, only few studies had investigated the effect of food structure on colonic fermentation, mostly referring to molecular structural aspects of individual dietary components ${ }^{11,12}$ rather than to the complex food matrix systems ${ }^{13}$ as normally present in physiological conditions. In a recent study performed by our group, we 
determined that starch fermentation was delayed towards distal parts of the colon when entrapped within a plant tissue matrix as it occurs in red kidney beans. The magnitude of this effect decreased in time due to changes in microbiota composition caused by prolonged substrate exposure. Based on these findings we hypothesize that food matrix plays an important role in modulating the rate of starch fermentation and that colonic efficiency in macronutrients utilization is limited to substrate availability. In the present study, we used an in-vitro batch fermentation model inoculated with bacterial populations originating from that study to compare the fermentation pattern of bean cells with different levels of structural integrity. The influence of bacterial adaptation to substrate and its effects on fermentation were also explored to understand if food microstructure affects substrate utilization by microbiota even after adaptation to a bean diet. By using batch fermentation experiments, the kinetics of starch, protein and dietary fibre utilization was also assessed.

\subsection{Materials and methods}

\subsubsection{Materials}

Red kidney beans were purchased from the local supermarket (Wageningen, Netherlands). All chemicals were of analytical grade and obtained from Sigma Aldrich (St. Louis MO, USA) unless stated otherwise.

\subsubsection{Sample preparation}

Intact cotyledon cells (ICC) were isolated according to Rovalino-Cordova, et a ${ }^{10}$ with minor modifications. Briefly, Red kidney beans were soaked overnight in an ice bath and subsequently peeled and boiled for $1 \mathrm{~h}$. Cotyledons were mashed by gentle abrasion and fractionated by the use of a wet sieve shaker. Samples retained in a sieve with mesh size of $70 \mu \mathrm{m}$ were collected for further use and represented the ICC fraction. To obtain mechanically damaged cells (MDC), ICC integrity was mechanically disrupted by the use of a magnetic stirrer at high speed rate (1500 rpm) for $24 \mathrm{~h}$. Structural damage was assessed by the use of light microscopy.

\subsubsection{Preparation of faecal inoculum}

Human faecal inoculum was obtained after the stabilization of faecal sample in the simulator of the human intestinal microbial ecosystem $\left(\mathrm{SHIME}^{\circledR}\right)$ according to the protocol described by Koper, et $\mathrm{al}^{14}$. In short, three stage multi chamber reactor vessels were used to mimic the ascending, transverse and descending colon. Stabilized bacteria prepared from fresh faeces of 
two healthy volunteers (non-smoking healthy adults, consuming normal western diets and no antibiotic treatment at least 6 months before faecal donation) was placed in each of the vessels corresponding to the different colon portions. Bacteria was left for stabilization in the SHIME ${ }^{\circledR}$ system for 10 days prior inoculation of the penicillin bottles used in this study. During the stabilization period, microbiota was given a standard feed in which starch was readily available for its utilization. All the components present in this free starch feed and their concentration are described in Table 6-1 ${ }^{14,15}$. Subsequently, a set of penicillin bottles containing intact or mechanically damaged cells were inoculated with bacteria coming from either the ascending, transverse or descending colon. These treatments hereinafter will be identified as non-adapted ICC (NAICC) and non-adapted MDC (NAMDC).

Table 6-1. Composition of feed given to microbiota in the SHIME ${ }^{\circledR}$ system.

\begin{tabular}{c|c|c}
\hline Component & Free starch feed $\left(\mathbf{g ~ L}^{-1}\right)$ & Entrapped starch feed $\left(\mathbf{g ~ L}^{-\mathbf{1}}\right)$ \\
\hline Arabinogalactan & 1.2 & 0.72 \\
Pectin & 2.0 & 1.2 \\
Xylan & 0.5 & 0.3 \\
Glucose & 0.4 & 0.24 \\
Yeast extract & 3.0 & 1.8 \\
Special peptone & 1.0 & 0.6 \\
Mucin & 3.0 & 1.8 \\
L-Cysteine HCl & 0.5 & 0.3 \\
Starch & 4.0 & 0.0 \\
ICC & 0.0 & 4.0 \\
\hline
\end{tabular}

In a second stage, the microbiota present in the SHIME $^{\circledR}$ was given a diet that contained entrapped starch. For this, intact cells were included in the feed replacing free starch. The concentration of free starch diet constituents was modified in order to avoid over-dosing of protein and non-starch polysaccharides due to their presence in ICC. Microbiota in the SHIME ${ }^{\circledR}$ system was fed this starch entrapped diet for 12 consecutive days. Subsequently, a new set of penicillin bottles containing either intact or mechanically damaged cells were inoculated with these bacteria. These treatments hereinafter will be identified as adapted ICC (AICC) and adapted MDC (AMDC) respectively. For details on the microbiota composition of the inocula used, readers are referred to our previous study (Chapter 5). 


\subsubsection{In-vitro Fermentation}

Samples (NAICC, NAMDC, AICC and AMDC) were subjected to in-vitro fermentation using a modified version of the method described by Van Den Abbeele, et $\mathrm{al}^{16}$. ICC or MDC were weighed ( $6 \mathrm{~g} \mathrm{~L}^{-1}$ of starch dry basis) into penicillin bottles for each time point $(8,16,24,48$, $72,120 \mathrm{~h}$ ) analysed. Subsequently, a basal medium previously autoclaved $\left(2 \mathrm{~g} \mathrm{~L}^{-1} \mathrm{NaHCO}_{3} ; 2\right.$ $\mathrm{g} \mathrm{L}^{-1}$ yeast extract; $2 \mathrm{~g} \mathrm{~L}^{-1}$ peptone; $1 \mathrm{~g} \mathrm{~L}^{-1}$ mucin; $0.5 \mathrm{~g} \mathrm{~L}^{-1} \mathrm{~L}$-cysteine $\mathrm{HCl} ; 2 \mathrm{~mL} \mathrm{~L}^{-1}$ Tween 80; phosphate buffer $0.15 \mathrm{~mol} \mathrm{~L}^{-1}$ ) was added. Separate in-vitro colonic fermentations were performed for each of the three colon portions namely: ascending ( $\mathrm{pH}$ 5.6-5.9), transverse ( $\mathrm{pH}$ 6.1-6.4) and descending colon ( $\mathrm{pH}$ 6.6-6.9). All the experiments were conducted under anaerobic conditions by replacing $\mathrm{O}_{2}$ by $\mathrm{N}_{2}$ in a gas exchange system with 0.5 bar overpressure for 5 cycles.

On the day of inoculation, $7 \mathrm{~mL}$ aliquot was withdrawn from the SHIME ${ }^{\circledR}$ vessels and injected into its respective penicillin bottle in aseptic conditions. Samples were then incubated in an oven at $37^{\circ} \mathrm{C}$ with constant agitation ( $90 \mathrm{rpm}$ ) for up to $120 \mathrm{~h}$. At each time point analysed, its respective penicillin bottles were opened; centrifuged (10 min, $2000 \mathrm{x} \mathrm{g})$ and the pellet was separated from the supernatant. Samples were stored at $-20{ }^{\circ} \mathrm{C}$ until further analysis. The experiment was repeated following the same conditions for two biological donors. For all treatments, a time point zero was included in the measurement. The values obtained from this sample represented a base line and the contribution of the starting medium and inoculum.

\subsubsection{Cumulative Gas Production}

Cumulative gas production was measured by an adapted version of Theodorou, et $\mathrm{al}^{17}$. In this method, the gas volume was measured at fixed intervals by the use of a manometer and a syringe to measure the pressure and volume of gas respectively. This experiment was performed in triplicate for each biological donor.

The kinetics of gas fermentation was determined by the use of a monophasic exponential model $^{18,19}$ as follows:

$$
D M C V=\frac{A_{g}}{\left(1+\left(\frac{C}{t}\right)^{B}\right)}
$$


Where:

$\mathrm{DMCV}=$ Total gas $\left(\mathrm{mL} \mathrm{g}^{-1} \mathrm{DM}\right.$ sample) produced at time $\mathrm{t}$

$\mathrm{A}_{\mathrm{g}}=$ Asymptotic value for gas production $\left(\mathrm{mL} \mathrm{g}^{-1} \mathrm{DM}\right.$ sample)

$\mathrm{C}_{\mathrm{g}}=$ time at which half of the asymptotic value has been reached $(\mathrm{h})$

$\mathrm{t}=$ time $(\mathrm{h})$

$\mathrm{B}_{\mathrm{g}}=$ switching characteristics of the curve

Two additional parameters were calculated, the maximum rate of gas production $\left(\mathrm{R}_{\mathrm{M}}\right)$ and the time at which $\mathrm{R}_{\mathrm{M}}$ occurred ( $\left.\mathrm{T}_{\mathrm{RM}}\right)$ using the following equations ${ }^{19}$ :

$$
\begin{gathered}
R_{M}=\frac{\left(A_{g} \times\left(C_{g}\right)^{B_{g}} \times B_{g} \times T_{R M}^{\left(-B_{g}^{-1}\right)}\right.}{\left(1+\left(C_{g}^{B_{g}}\right) \times\left(T_{R M}^{-B_{g}}\right)\right)^{2}} \\
T_{R M}=C_{g} \times\left(\frac{B_{g}-1}{B_{g}+1}\right)^{\frac{1}{B_{g}}}
\end{gathered}
$$

\subsubsection{Short chain fatty acids (SCFA) quantification}

Supernatants collected after fermentation were analysed for SCFA composition following the protocol described by Guo, et $\mathrm{al}^{20}$. Briefly, centrifuged and filtered supernatants were combined with an internal standard (2-ethylbutyric acid in $0.3 \mathrm{M} \mathrm{HC}$ and $0.9 \mathrm{M}$ oxalic acid) prior SCFA analysis. Acetic, propionic, butyric, valeric, iso-butyric and iso-valeric solutions (0.01-0.45 $\mathrm{mg} / \mathrm{mL}$ ) were prepared for identification and quantification. The measurement was performed using a Shimadzu GC-2014 gas chromatograph (Kyoto, Japan) equipped with a Flameionization gas detector (FID), a capillary fatty acid-free Stabilwax-DA column $(1 \mu \mathrm{m} \times 0.32 \mathrm{~mm}$ x $30 \mathrm{~m}$ ) (Restek, Bellefonte, PA, USA) and a split injector. Nitrogen was used as the carrier gas and the temperature of the injector and detector were 100 and $250^{\circ} \mathrm{C}$ respectively. The ratio between branched and linear fatty acids (BCR) and the total SCFA production was calculated according to Warren, et al ${ }^{12}$.

\subsubsection{Nitrogen content by Dumas combustion method}

Protein content in the fermented samples was determined by Dumas combustion method in a flash EA 1112 NC analyser (Thermo fisher scientific Inc., Waltman, USA) following the 
Chapter 6

manufacturers protocol. Fermented samples were combusted using helium as a carrier gas, Dmethionine was used for the calibration curve and cellulose as a control. A factor of 6.25 was employed to convert the nitrogen content in the sample to protein.

\subsubsection{Total starch and dietary fibre determination}

Starch and total dietary fibre was quantified by the use of Total Starch Assay Procedure (amyloglucosidase/ $\alpha$-amylase) and Total Dietary Fibre methods, Megazyme Inc. (Bray, Ireland) respectively according to the manufacturer's instructions. Prior performing the analysis, ICC structure was mechanically disrupted to avoid underestimation of the studied components.

\subsubsection{Dry matter content}

A known amount of sample was left overnight at $105^{\circ} \mathrm{C}$ in an incubator until constant weight to determine the dry matter content of all samples investigated.

\subsubsection{Light and Scanning electron microscopy}

Changes in sample microstructure during fermentation were monitored by light and scanning electron microscopy (SEM). The analyses were done using the methods described by RovalinoCordova, et $\mathrm{al}^{10}$.

\subsubsection{Statistical analysis}

Data for cumulative gas production was the result of the mean from three replicates per biological donor. All the other analyses were performed in duplicate per donor. The parameters of significance from all the results was evaluated using the statistical software SAS, version 9.4 (SAS institute Inc., NC, U.S.A.). N-way ANOVA was performed using the GLM procedure, individual means were compared using the Tukey's test $\left({ }^{*} p<0.05\right)$. The main effects studied were cells integrity, colon region, bacterial adaptation and biological donor.

\subsection{Results and Discussion}

\subsubsection{Cumulative gas production after the utilization of ICC and MDC by microbiota} during in-vitro fermentation

$\mathrm{H}_{2}$ and $\mathrm{CO}_{2}$ are primary products of carbohydrate fermentation together with SCFA ${ }^{21}$. Therefore, gas production could be used as an indicator of dietary fibre fermentation in the 
colon. The kinetics of gas production of ICC and MDC with adapted and non-adapted bacteria are shown in Table 6-2. Significant differences were observed between the samples, with higher gas production obtained for MDC compared to ICC. The maximum rate of gas formation reached by NAICC took place after $23 \mathrm{~h}$, which was more than three times longer than for NAMDC. This suggests that the substrate structure plays a role in the kinetics of gas production. It could be speculated that due to structural damage, cellular contents were more exposed to colonic microbiota hereby facilitating fermentation. Studies conducted on mango, banana and carrots showed that cell integrity was a determinant factor in the rate of fermentation since larger particle sizes (clusters of intact and broken cells) showed higher amounts of gas production than individual and undamaged cells ${ }^{22,23}$. Differences were also observed between the colon regions $\left({ }^{*} \mathrm{p}<0.05\right)$. For all parameters tested, the rate of gas production followed the order descending $>$ transverse $>$ ascending. In-vivo studies indicate that the proximal colon is the most active site of carbohydrate fermentation and thus of gas production ${ }^{24,25}$. However, our experimental set-up suggests that the low activity observed in-vivo for the distal region is rather due to carbohydrate depletion than to a lower microbial efficiency in fermenting carbohydrates. When microbiota from the three colon portions were given the same substrate concentration, the distal part appeared to be the most active site. Our results go in accordance to what have been previously reported by Bauer, et $\mathrm{al}^{19}$ when fermenting different types of fibres using a pig inoculum.

In addition, significant differences in gas production were observed between the two types of bacteria utilized in this study. Adapted microbiota (i.e. exposed to ICC for 12 days prior batch inoculation) showed a significantly higher gas production compared to its non-adapted counterpart. This type of bacteria was not only producing higher amounts of gas but also at a faster rate, with the maximum amount of gas occurring $5.8 \mathrm{~h}$ after the start of fermentation. This could be caused by the shift in microbiota population observed in our previous study (Chapter 5) due to bean cells supplementation. Prolonged diet exposure could also produce changes on gene expression by which metabolic pathways could be altered ${ }^{26}$. It is important to mention that an increase in the rate of gas production was observed for the adapted microbiota independently of the changes on the structural properties of the samples utilized (ICC, MDC).

As for the donors, statistical differences were observed only in DMCV where inoculum from donor 2 produced more gas. No differences were observed for C, Rm and TRm between the donors suggesting that the fermentation kinetics between both of them was similar differing only in the amount of gas produced. Microbial inter-individual variation has been investigated 
by Turnbaugh, et $\mathrm{al}^{27}$. They found that despite of the high diversity of bacterial phylotype present among individuals there was a great resemblance in the microbial genes involved in various important metabolic functions. Therefore, despite the variation in microbiota population, large similarities in substrate utilization were found when providing microbiota with the same diet.

Interestingly, it was observed that several interactions between main factors were statistically significant. For instance, the amount of gas produced in the descending colon for adapted bacteria was higher than when fermented with non-adapted microbiota. A similar situation occurred when mechanically damaged cells were fermented with the descending colon microbiota. The interaction between the four parameters (structure, bacteria, donor and colon region) was also found to have statistical meaning. For all parameters tested, the interaction of all factors was important and contributed to the changes observed during in-vitro fermentation. 
Table 6-2. Kinetic parameters for gas production upon fermentation of NAICC, NAMDC, AICC and AMDC. For clarity of representation, only the mean values are reported.

\begin{tabular}{|c|c|c|c|c|}
\hline Variable & $\begin{array}{c}\text { DMCV } \\
\left(\mathrm{mL} \mathrm{g}^{-1} \mathrm{DM}\right)\end{array}$ & $\begin{array}{c}\mathbf{C} \\
(\mathrm{h})\end{array}$ & $\begin{array}{c}\mathbf{R m} \\
\left(\mathrm{mL} \mathrm{h}^{-1}\right)\end{array}$ & $\begin{array}{l}\text { TRm } \\
\text { (h) }\end{array}$ \\
\hline \multicolumn{5}{|l|}{ Structure } \\
\hline Intact & $57.213^{\mathrm{a}}$ & $9.764^{\mathrm{a}}$ & $8.716^{\mathrm{a}}$ & $23.131^{\mathrm{a}}$ \\
\hline Broken & $73.331^{\mathrm{b}}$ & $9.274^{\mathrm{b}}$ & $9.274^{b}$ & $7.695^{\mathrm{b}}$ \\
\hline Probability & $<0.0001$ & $<0.0001$ & $<0.0001$ & $<0.0001$ \\
\hline MSD & 3.200 & 2.753 & 2.753 & 2.076 \\
\hline \multicolumn{5}{|l|}{ Colon region } \\
\hline Ascending & $36.137^{\mathrm{a}}$ & $10.801^{\mathrm{a}}$ & $14.937^{\mathrm{a}}$ & $3.682^{\mathrm{a}}$ \\
\hline Transverse & $60.289^{\mathrm{b}}$ & $20.167^{b}$ & $14.607^{\mathrm{a}}$ & $17.559^{\mathrm{b}}$ \\
\hline Descending & $99.389^{\mathrm{c}}$ & $27.588^{c}$ & $7.554^{\mathrm{b}}$ & $24.999^{\mathrm{c}}$ \\
\hline Probability & $<0.0001$ & $<0.0001$ & $<0.0001$ & $<0.0001$ \\
\hline MSD & 4.715 & 4.055 & 5.073 & 3.058 \\
\hline \multicolumn{5}{|l|}{ Bacteria } \\
\hline Adapted & $77.038^{\mathrm{a}}$ & $31.748^{\mathrm{a}}$ & $6.106^{\mathrm{a}}$ & $24.952^{\mathrm{a}}$ \\
\hline Non-adapted & $53.506^{\mathrm{b}}$ & $7.290^{\mathrm{b}}$ & $18.626^{\mathrm{b}}$ & $5.875^{\mathrm{b}}$ \\
\hline Probability & $<0.0001$ & $<0.0001$ & $<0.0001$ & $<0.0001$ \\
\hline MSD & 3.200 & 2.753 & 3.443 & 2.076 \\
\hline \multicolumn{5}{|l|}{ Donor } \\
\hline 1 & $58.089^{\mathrm{a}}$ & $20.516^{\mathrm{a}}$ & $11.933^{\mathrm{a}}$ & $14.876^{\mathrm{a}}$ \\
\hline 2 & $72.454^{\mathrm{b}}$ & $18.522^{\mathrm{a}}$ & $12.799^{\mathrm{a}}$ & $15.951^{\mathrm{a}}$ \\
\hline Probability & $<0.0001$ & 0.1518 & 0.6151 & 0.303 \\
\hline MSD & 3.200 & 2.753 & 3.443 & 2.076 \\
\hline \multicolumn{5}{|l|}{ Interactions } \\
\hline $\mathrm{S}^{*} \mathrm{C}$ & $<0.0001$ & $<0.0001$ & 0.2384 & $<0.0001$ \\
\hline $\mathrm{S} * \mathrm{~B}$ & 0.1091 & $<0.0001$ & 0.214 & $<0.0001$ \\
\hline $\mathrm{C} * \mathrm{~B}$ & $<0.0001$ & 0.0006 & $<0.0001$ & $<0.0001$ \\
\hline$B * D$ & 0.0008 & 0.6634 & 0.2310 & 0.0009 \\
\hline$C^{*} \mathrm{D}$ & $<0.0001$ & 0.0044 & 0.3692 & 0.1626 \\
\hline$S * D$ & 0.0040 & 0.6733 & 0.0562 & 0.0005 \\
\hline $\mathrm{S}^{*} \mathrm{C} * \mathrm{~B} * \mathrm{D}$ & $<0.0001$ & $<0.0001$ & 0.0021 & $<0.0001$ \\
\hline
\end{tabular}

Different superscript letters within each treatment denote significance level ${ }^{*} \mathrm{p}<0.05$. DMCV $=$ cumulative gas production during $72 \mathrm{~h}$ of fermentation, $\mathrm{C}=$ Time at which half the asymptotic has been reached, $\mathrm{Rm}=$ maximum rate of gas production, $\mathrm{TRm}=$ time of maximum rate of gas production, $\mathrm{MSD}=$ minimum significant difference. Main factors analysed are indicated as follows: $\mathrm{S}=$ structure, $\mathrm{C}=$ Colon, $\mathrm{B}=$ type of bacteria, $\mathrm{D}=$ donor.

\subsubsection{Starch utilization by intestinal microbiota}

The rate of starch utilization by microbiota was monitored for up to $120 \mathrm{~h}$ after inoculation. Fig. 6-1illustrates the portion of starch left unfermented in NAICC, NAMDC, AICC and AMDC from ascending (a), transverse (b) and descending (c) colon. It is evident from the graph that there are large differences in starch fermentation between NAMDC and NAICC, where the 
Chapter 6

former showed higher fermentation levels than the latter. This variation was clearly observed in all the colon segments during the first $20 \mathrm{~h}$ of incubation. However, as fermentation continued, such differences were no longer detected for the ascending and transverse colon, whereas they persisted in the descending region even after $40 \mathrm{~h}$ of in-vitro incubation.

a)

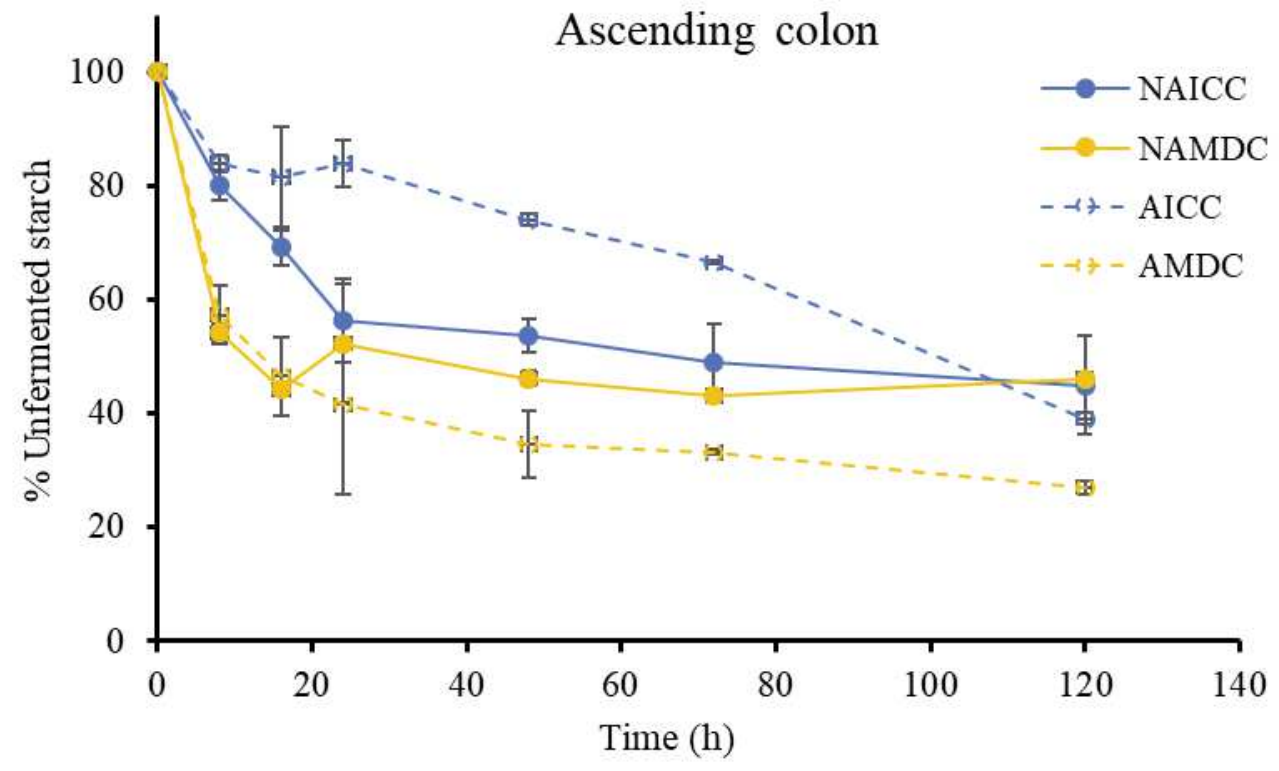

b)

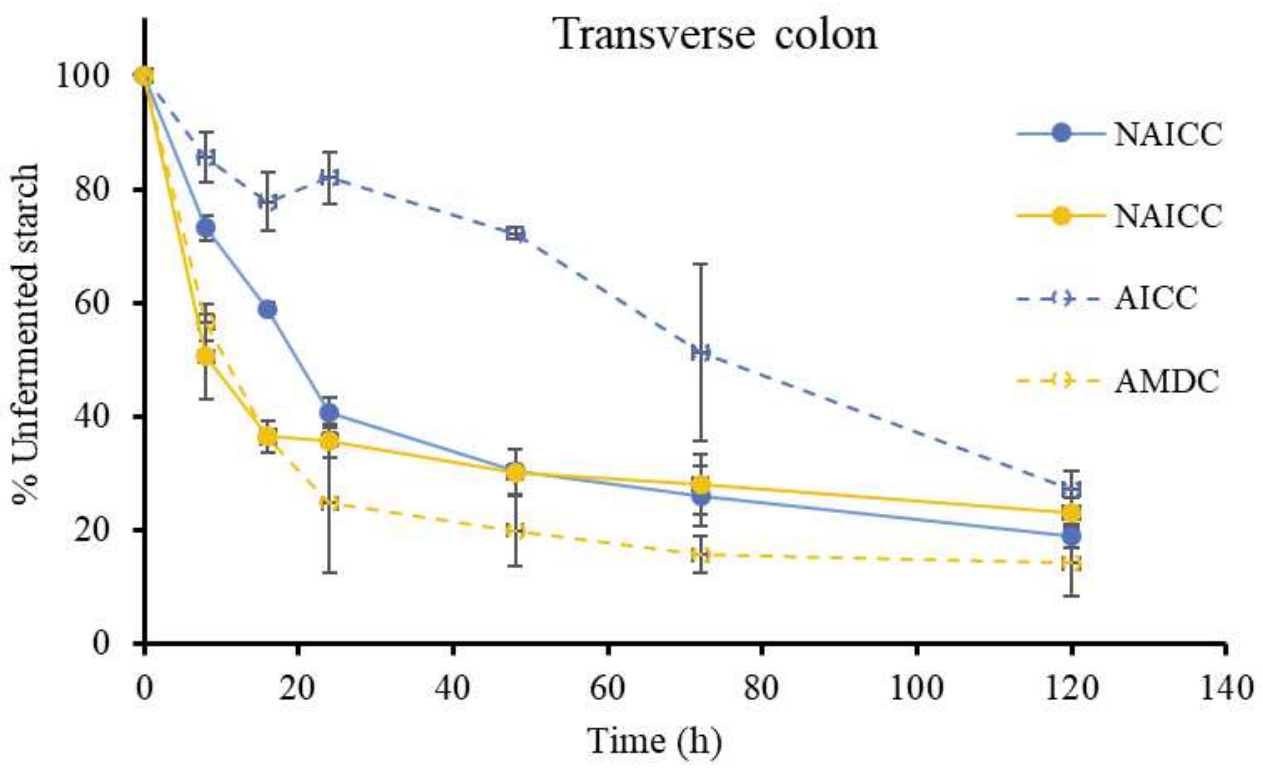


c)

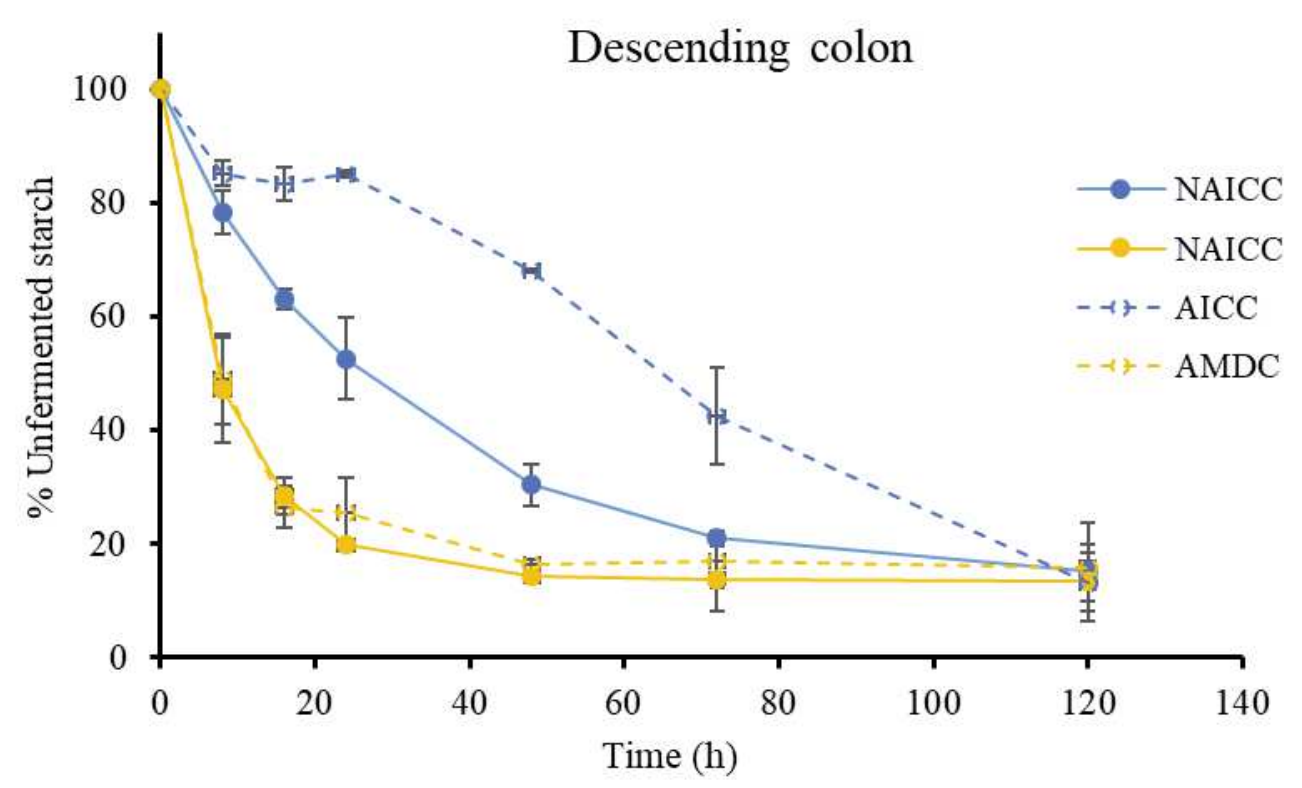

Fig. 6-1. Starch fermentation kinetics of NAICC, NAMDC, AICC and AMDC on ascending (a), transverse (b) and descending (c) colon. Error bars denote standard deviation between two biological donors. NAICC $=$ intact cotyledon cells inoculated with non-adapted bacteria, $\mathrm{NAMDC}=$ mechanically damaged cells inoculated with nonadapted bacteria, $\mathrm{AICC}=$ intact cotyledon cells inoculated with adapted bacteria, AMDC= mechanically damaged cells inoculated with adapted bacteria.

Differences were also observed when comparing starch fermentation by microbiota either adapted or not to bean cells. Contrary to our expectations, the amount of starch fermented in AICC was markedly reduced than to what obtained for NAICC. Less than $20 \%$ of the starch present in AICC was degraded during the first $20 \mathrm{~h}$ of fermentation compared to nearly $60 \%$ obtained for NAICC. As fermentation proceeded, the amount of starch in AICC gradually decreased until reaching values comparable to what obtained for NAICC. A similar trend was observed in the three colon portions. Interestingly, this behaviour could not be observed for AMDC in any of the colon segments since its fermentation pattern resembled to that of NAMDC.

Light and scanning electron microscopy were employed to get a qualitative impression of the samples structure and starch degradation during the course of in-vitro fermentation. In general, the three colon regions showed a similar trend in starch consumption and structure degradation (data not shown). However, only samples fermented in the DC are shown in Fig. 6-2 and Fig. 6-3 since in this colon region the structural changes were more evident than in the other two regions. Despite of the extensive fermentation treatment, it can be seen that NAICC and AICC maintained their structural integrity even after $72 \mathrm{~h}$ of incubation. This demonstrates that cell integrity has the potential to resist not only intestinal digestion ${ }^{8-10}$ but also microbial degradation. Light micrographs also evidence heterogeneity in starch utilization among 
individual cells. This behaviour has been already observed in the small intestine and is likely related to $\mathrm{CW}$ porosity resulting in different levels of starch accessibility to bacteria. Differences in the microstructural properties of ICC were observed between the two types of microbial inoculum utilized. ICC containing unfermented starch granules were present in large amounts in AICC after $48 \mathrm{~h}$ of fermentation. Whereas at $72 \mathrm{~h}$, it appears as if higher amounts of debris were present in AICC compared to NAICC. For the treatments where cell integrity was disrupted (NAMDC, AMDC) no apparent differences were observed between microbiota adapted or not adapted to bean cells (data not shown). Therefore, only one set of images was utilized to illustrate the changes in fermentation for both treatments. For these samples, starch granules could only be identified after $8 \mathrm{~h}$ of fermentation; their presence at a later stage was not clearly visible.
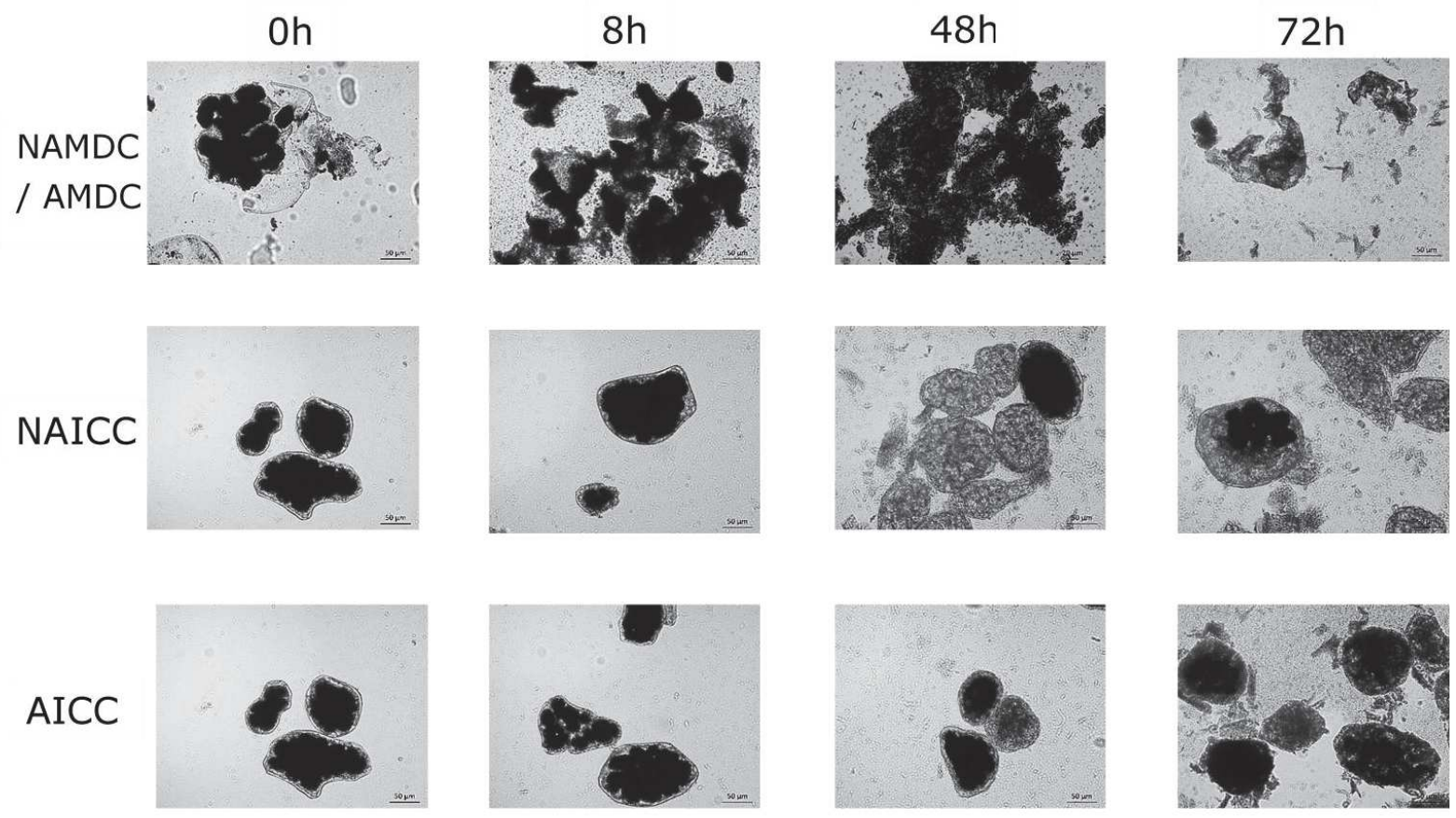

Fig. 6-2 Light micrographs of NAMDC, AMDC, NAICC and AICC at 0, 8, 48 and 72 h of in-vitro fermentation in the descending colon. Samples were stained with potassium iodide to highlight the presence of starch. For all samples, micrographs were taken using 20x magnification lens. NAICC $=$ intact cotyledon cells inoculated with non-adapted bacteria, NAMDC $=$ mechanically damaged cells inoculated with non-adapted bacteria, $\mathrm{AICC}=$ intact cotyledon cells inoculated with adapted bacteria, $\mathrm{AMDC}=$ mechanically damaged cells inoculated with adapted bacteria.

SEM micrographs depicted in Fig. 6-3 allow the identification of structural differences in the CW of samples treated with adapted and non-adapted microbiota. In general, it was observed that the adapted microbiota was able to consume higher amounts of CW material compared to its non-adapted counterpart. This could be appreciated by the large crevices and irregular 
surface found in AICC compared to the holes of small diameter (approximately $1.5 \mu \mathrm{m}$ ) encountered in NAICC.
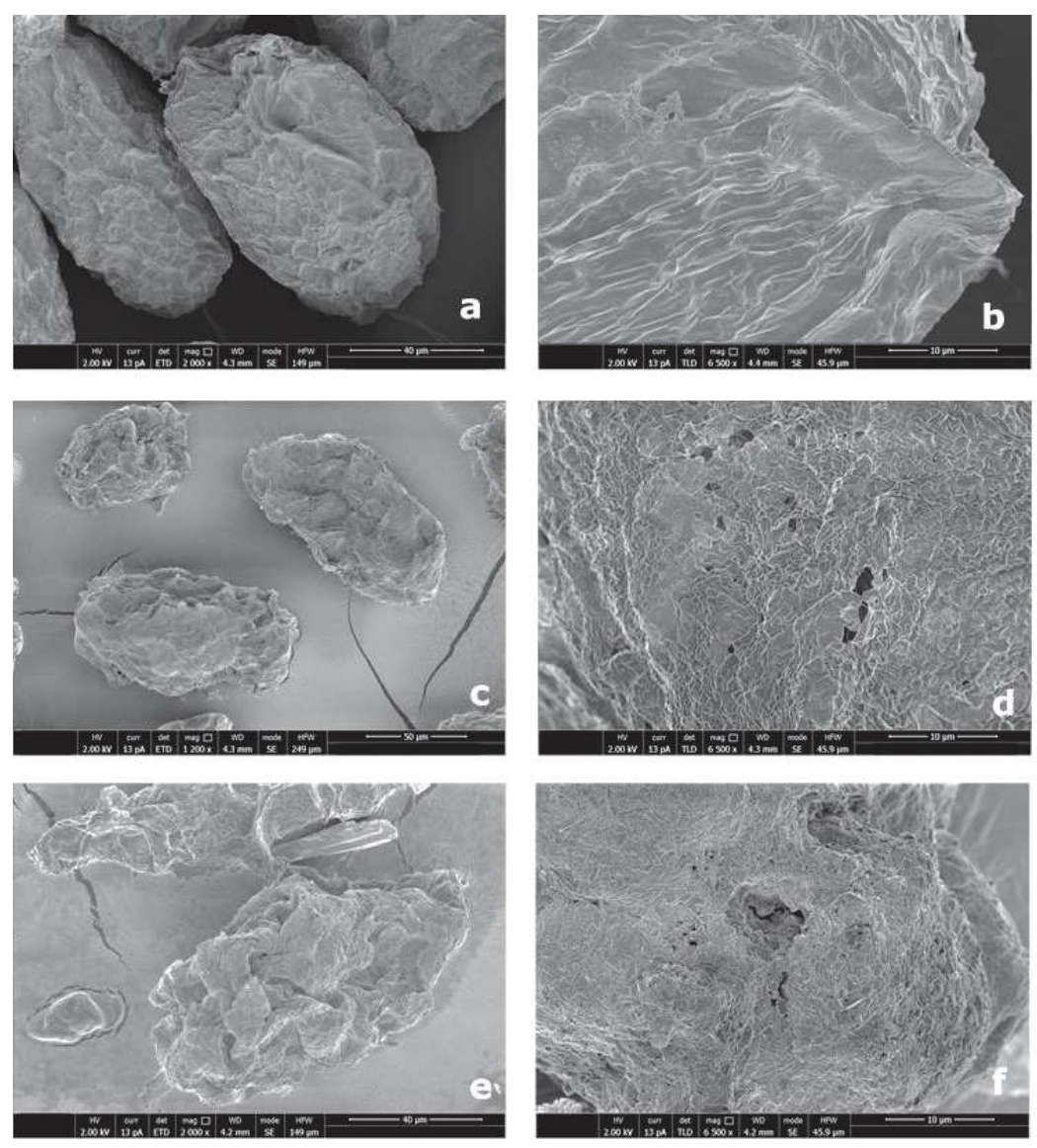

Fig. 6-3. SEM micrographs of NAICC (c, d) and AICC (e, f) after $72 \mathrm{~h}$ of in-vitro colonic fermentation in the descending colon. Unfermented samples $(\mathrm{a}, \mathrm{b})$ were used as control to highlight the changes produced during fermentation. Right column indicate a higher magnification of the micrographs shown in the left column.

When comparing starch fermentation between colon regions, it was found that the microbiota present in the descending colon fermented the largest amount of starch independently of the treatments studied. The efficiency of starch fermentation followed the order descending $>$ transverse $>$ ascending colon. These results reinforced what previously discussed about the higher gas production of the microbiota present in the descending portion. In addition, it is important to point out that for all treatments investigated, starch was not fermented further than $80 \%$. Thus, the difference between the treatments relied in the rate at which this level was reached. Further research is needed to clarify what are the causes that prevent residual starch from being fermented. We infer that the factors responsible for this incomplete fermentation could be related to structural properties of the starch granule (e.g. crystallinity, level of packing of amylose or amylopectin side chains) or protein-starch interactions. However, variations in microbial activity due to the absence of an absorption step to get rid of the metabolites formed by microbiota cannot be ruled out. 


\subsubsection{Macronutrients utilization during in-vitro fermentation}

The concentration of unfermented starch, protein and fibre was analysed after $72 \mathrm{~h}$ of in-vitro fermentation. Compositional differences were observed between the treatments when compared to the unfermented samples (Fig. 6-4). For all samples, the amount of residual starch was lower and statistically different respect to the one present in the unfermented sample. This behaviour was similar in all colon regions. Furthermore, AICC samples contained the highest amount of unfermented starch, being the ascending colon (Fig. 6-4 a) the region with less starch utilization. A similar pattern was observed for proteins where all treatments showed a lower amount of proteins when compared to the control $(* \mathrm{p}<0.05)$. In regard to fibre content, the control showed significant variation only for NAICC and NAMDC where higher concentrations of the nonstarch polysaccharide were recovered. As for samples treated with adapted bacteria, lower amounts of fibre were quantified specially for AICC suggesting that this type of microbiota was more prone to fibre utilization. The present findings illustrate the differences in nutrient degradation due to microbiota adaptation. In first place, and as mentioned before, adapted bacteria produced higher amounts of gas compared to its non-adapted counterpart. This increment in gas production could not be explained by starch degradation since this microbiota showed a delayed consumption as described before. Therefore, other nutrients should have been degraded in larger extents to produce those levels of gas. That was the case of fibre, since lower amounts of unfermented material were recovered for AMDC and AICC after $72 \mathrm{~h}$ of incubation. We can therefore infer that microbiota adaptation to encapsulated starch made them more efficient in fibre degradation than when starch was supplied in a high available form. Starch was still degraded to a large extent by microbiota adapted to bean cells but its fermentation was delayed. This behaviour could also be observed by SEM micrographs (Fig. 6-3) since there is a difference in cells appearance when incubated with these two types of bacteria as described previously. We believe that the structural organization of foods entering the colon may be a determinant factor that will influence the hierarchy of substrate utilization by colonic microbiota. Hierarchical utilization of fermentable substrates have only been assessed in terms of molecular characteristics of the substrate that might have an effect in fermentation ${ }^{28}$. However, to the best of our knowledge, the influence of food structure in substrate utilization has not been mentioned before.

Secondly, in the case of proteins the amount left unfermented did not show striking differences among the treatments as the ones observed for starch and fibre. With the exception of AMDC in the ascending colon, all the other treatments showed no significant difference in their protein 
content after $72 \mathrm{~h}$ of fermentation. Hence, we could infer that protein fermentation was not directly affected by microbiota adaptation. This is a reasonable outcome considering that the vast majority of bacteria present in the large bowel have predominantly saccharolytic metabolism, therefore carbohydrate availability is one of the most important factors that determine bacterial activity ${ }^{2}$.

Finally, we observed that cell integrity played an important role for starch degradation independently of the type of bacteria used. This was not the case for protein and fibre since no statistical differences were found between ICC and MDC. When checking the efficiency of each colon portion, it was observed that the descending colon was the region with highest starch degradation. While for fibre, the three regions showed no significant difference after post-hoc analysis. Interestingly, in the case of protein, the descending colon (Fig. 6-4 c) was found to be the region in which the least amount of protein was fermented. Protein fermentation is known to occur predominantly in the distal colon and has been associated with health related issues such as irritable bowel syndrome and cancer ${ }^{29,30}$. Therefore, identifying mechanisms to produce lower protein degradation might be of enormous relevance. In this study, by providing equal amounts of substrate to the three colon regions we have shown that microbiota present in the distal portion is not inherently more efficient in fermenting proteins. It is very likely that the high protein fermentation observed in-vivo is due to carbohydrate depletion. 
a)

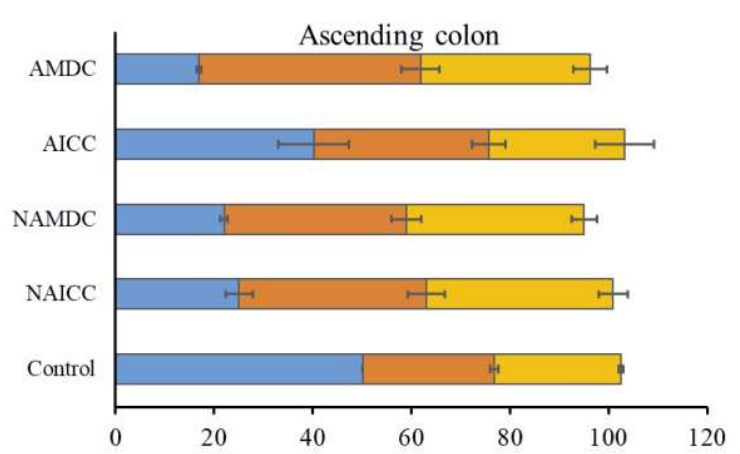

b)

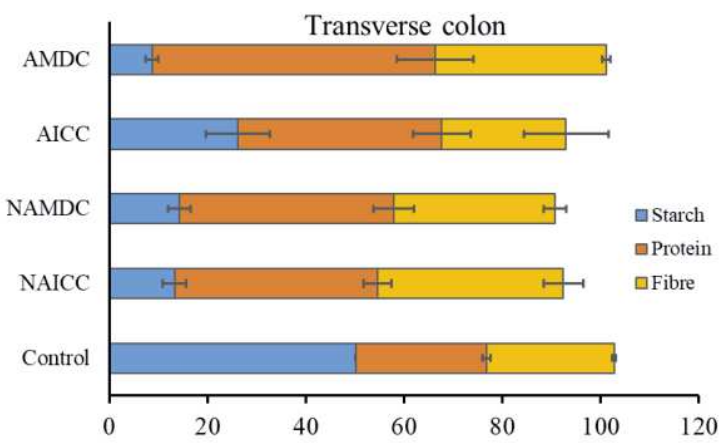

c)

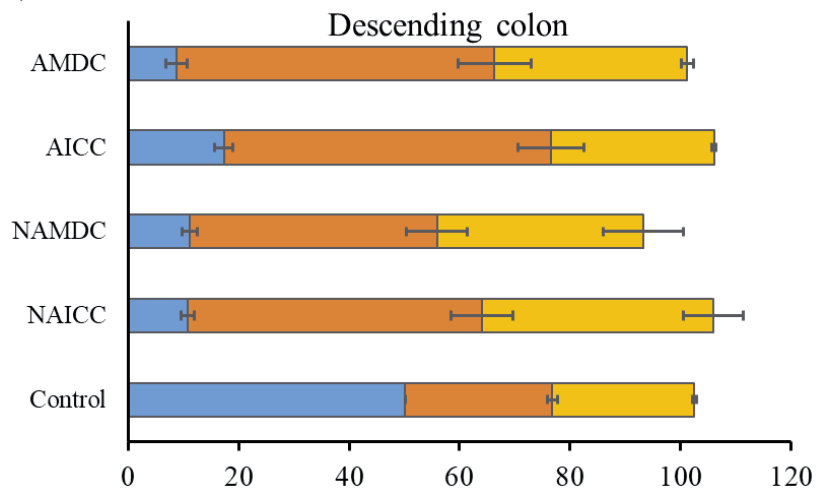

Fig. 6-4. Compositional changes in starch, protein and fibre after $72 \mathrm{~h}$ of in-vitro colonic fermentation in NAICC, NAMDC, AICC and AMDC in ascending (a), transverse (b) and descending (c) colon. A control sample with no fermentation was included for comparison. Error bars denote standard deviation between two biological donors. NAICC $=$ intact cotyledon cells inoculated with non-adapted bacteria, $\mathrm{NAMDC}=$ mechanically damaged cells inoculated with non-adapted bacteria, $\mathrm{AICC}=$ intact cotyledon cells inoculated with adapted bacteria, $\mathrm{AMDC}=$ mechanically damaged cells inoculated with adapted bacteria. The abundance of these components was determined experimentally for this reason in some cases the sum of these values does not sum exactly $100 \%$.

\subsubsection{SCFA, BCR and $p H$ in intact and broken cotyledon cells}

The distribution of acetic, propionic and butyric acid after $72 \mathrm{~h}$ of colonic fermentation are depicted in Fig. 6-5, whereas their absolute concentrations are reported in Table 6-3. Acetic, propionic and butyric acid are the most abundant metabolites produced during fermentation ${ }^{31}$. For all colon regions, acetic was the SCFA present in highest concentrations, followed by propionic and butyric acid. Several studies have found that the molar ratio of acetic: propionic: butyric acid is 60:20:20, respectively ${ }^{24}$. In the present study, this ratio was not observed in all treatments since higher propionic acid concentrations were obtained for NAMDC in the ascending and transverse colon. Such discrepancy might be due to the type of microbiota present and substrate availability. Non-adapted microbiota had high abundance of Bacteroides, a type of bacteria that has been recognized as propionate producers ${ }^{32}$. Even though NAICC was also inoculated with the same type of microbiota, it is likely that substrate accessibility favoured propionate production in NAMDC. 
When checking the efficiency of the three colon portions, we found that the concentration of SCFA was the highest when fermented by the microbiota adapted to the descending colon as observed in Table 6-3 $\left({ }^{*} \mathrm{p}<0.05\right)$. Interestingly, the highest amount of butyric acid was also produced by the descending colon microbiota. This metabolite has been found to be important for promoting large bowel health ${ }^{33}$ since it is the preferred energy substrate for colonocytes ${ }^{34}$. MDC lead to higher butyric acid production compared to ICC, probably due to a better starch accessibility for the microbiota since it is known that this fatty acid is produced from fermentation of $\operatorname{starch}^{35}$. For the other two SCFAs, no statistical differences were found in the concentration of acetic and propionic acid between transverse and descending colon while the ascending region produced the least amount of them. When testing for statistical significance between substrates, it was observed that butyric acid production was the only fatty acid influenced by cell structure.

Furthermore, adapted bacteria were able to produce higher amounts of butyric acid for all colon sections independently of the substrate structure. Significant differences were found in all SCFA, showing that adapted bacteria were more efficient in organic acid production. Interindividual variations also played a role in the distribution of SCFA produced. Microbiota from donor 2 generated lower amounts of acetic acid and significantly higher quantities of butyric acid. However, no differences between the two donors were observed for the total SCFA produced. 

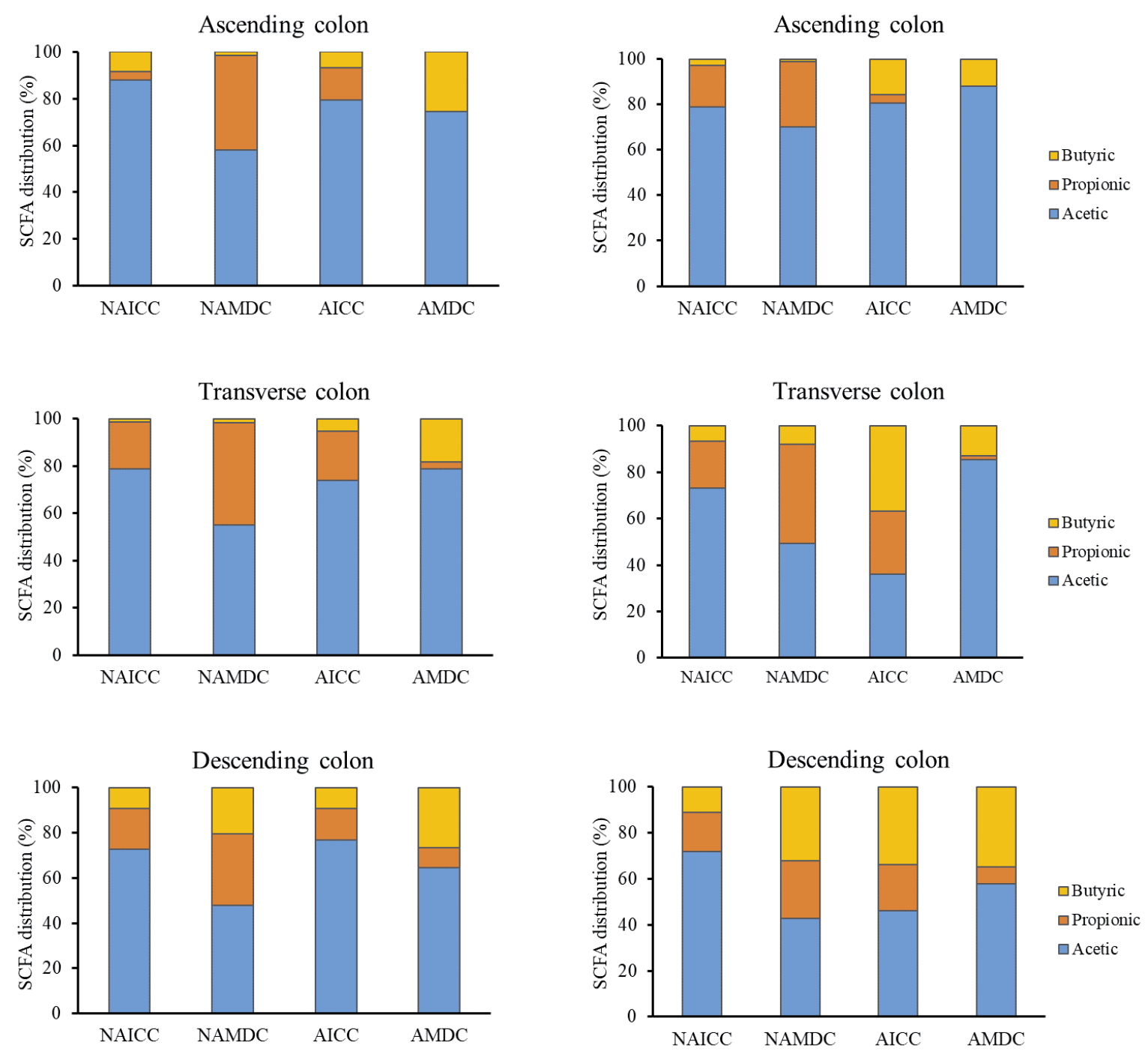

Fig. 6-5. Distribution of acetic, butyric and propionic acid in NAICC, NAMDC, AICC, AMDC after $72 \mathrm{~h}$ of invitro fermentation. Left column and right column indicate the SCFA distribution of donor 1 and 2 respectively in ascending transverse and descending colon. $\mathrm{NAICC}=$ intact cotyledon cells inoculated with non-adapted bacteria, $\mathrm{NAMDC}=$ mechanically damaged cells inoculated with non-adapted bacteria, $\mathrm{AICC}=$ intact cotyledon cells inoculated with adapted bacteria, $\mathrm{AMDC}=$ mechanically damaged cells inoculated with adapted bacteria.

Table 6-3 also depicts the branched chain ratio (BCR). This factor is an indication of the ratio between linear and branched chain fatty acids. BCR was expressed as acetic acid equivalents $\left(\mathrm{AAE} \mathrm{g}^{-1} \mathrm{DM}\right)$ to normalise all SCFA in terms of their carbon content ${ }^{19}$. Interestingly, it was observed that for adapted bacteria this value was lower than for its non-adapted counterpart. Such results indicate that these type of bacteria were not only capable of producing higher amounts of fatty acids but they were particularly able of generating linear organic acids, something that has been demonstrated to be beneficial for gut health since branched chain fatty acids are specific products of fermentation of certain amino acids ${ }^{29}$. 
As mentioned in section 6.2.5, each colon region had a different $\mathrm{pH}$ value in order to mimic physiological conditions during fermentation. After $72 \mathrm{~h}$ of incubation, the $\mathrm{pH}$ was measured in order to observe changes due to fermentation. Statistical differences were observed between ICC and MDC where the latter reached lower $\mathrm{pH}$ values that are normally associated to a more active fermentation ${ }^{24}$. The type of bacteria and biological replicates also showed statistical differences. For the former, adapted bacteria gave rise to higher $\mathrm{pH}$ levels the same as for donor 2. While for the colon sections, the three of them differed in $\mathrm{pH}$ values even after $72 \mathrm{~h}$ of fermentation indicating that there was a good buffering capacity of the medium ${ }^{22}$. 
Table 6-3. Mean values of SCFA, BCR and $\mathrm{pH}$ after $72 \mathrm{~h}$ of in-vitro colonic fermentation of NAICC, NAMDC, AICC and AMDC by microbiota from different colon sections and either adapted or not to a bean diet.

\begin{tabular}{|c|c|c|c|c|c|c|}
\hline \multirow[t]{2}{*}{ Variable } & $\begin{array}{c}\text { Acetic } \\
\text { acid }\end{array}$ & $\begin{array}{l}\text { Propionic } \\
\text { acid }\end{array}$ & $\begin{array}{c}\text { Butyric } \\
\text { acid }\end{array}$ & $\begin{array}{r}\text { Total } \\
\text { SCFA }\end{array}$ & \multirow{2}{*}{\multicolumn{2}{|c|}{$\begin{array}{c}\text { BCR } \\
\left(\mathrm{mg} \mathrm{AAE} \mathrm{g} \mathrm{g}^{-1} \mathrm{DM}\right)\end{array}$}} \\
\hline & \multicolumn{4}{|c|}{$\left(\mathrm{mmol} \mathrm{g}{ }^{-1} \mathrm{DM}\right)$} & & \\
\hline Structure & & & & & & \\
\hline Intact & $1.693^{\mathrm{a}}$ & $0.431^{\mathrm{a}}$ & $0.294^{\mathrm{a}}$ & $2.583^{\mathrm{a}}$ & $0.048^{\mathrm{a}}$ & $4.973^{\mathrm{a}}$ \\
\hline Broken & $1.723^{\mathrm{a}}$ & $0.458^{\mathrm{a}}$ & $0.443^{b}$ & $2.789^{\mathrm{a}}$ & $0.047^{\mathrm{a}}$ & $4.820^{\mathrm{b}}$ \\
\hline Probability & 0.7553 & 0.2105 & $<0.0001$ & 0.0827 & 0.8507 & 0.0132 \\
\hline MSD & 0.197 & 0.042 & 0.019 & 0.235 & 0.006 & 0.118 \\
\hline
\end{tabular}

Colon region

$\begin{array}{ccccccc}\text { Ascending } & 1.401^{\mathrm{a}} & 0.255^{\mathrm{a}} & 0.161^{\mathrm{a}} & 1.946^{\mathrm{a}} & 0.052^{\mathrm{a}} & 4.468^{\mathrm{a}} \\ \text { Transverse } & 1.721^{\mathrm{b}} & 0.519^{\mathrm{b}} & 0.267^{\mathrm{b}} & 2.769^{\mathrm{b}} & 0.047^{\mathrm{a}} & 4.859^{\mathrm{b}} \\ \text { Descending } & 2.002^{\mathrm{b}} & 0.559^{\mathrm{b}} & 0.678^{\mathrm{c}} & 3.433^{\mathrm{c}} & 0.044^{\mathrm{a}} & 5.363^{\mathrm{c}} \\ \text { Probability } & <0.0001 & <0.0001 & <0.0001 & <0.0001 & 0.0733 & <0.0001 \\ \text { MSD } & 0.292 & 0.062 & 0.029 & 0.348 & 0.009 & 0.175\end{array}$

Bacteria

$\begin{array}{ccccccc}\text { Adapted } & 1.934^{\mathrm{a}} & 0.279^{\mathrm{a}} & 0.517^{\mathrm{a}} & 2.865^{\mathrm{a}} & 0.038^{\mathrm{a}} & 4.961^{\mathrm{a}} \\ \text { Non-adapted } & 1.482^{\mathrm{b}} & 0.609^{\mathrm{b}} & 0.219^{\mathrm{b}} & 2.508^{\mathrm{b}} & 0.058^{\mathrm{b}} & 4.832^{\mathrm{b}} \\ \text { Probability } & <0.0001 & <0.0001 & <0.0001 & 0.0045 & <0.0001 & 0.0330 \\ \text { MSD } & 0.197 & 0.042 & 0.019 & 0.235 & 0.006 & 0.118\end{array}$

Donor

$\begin{array}{ccccccc}1 & 1.826^{\mathrm{a}} & 0.459^{\mathrm{a}} & 0.307^{\mathrm{a}} & 2.705^{\mathrm{a}} & 0.045^{\mathrm{a}} & 4.811^{\mathrm{a}} \\ 2 & 1.590^{\mathrm{b}} & 0.429^{\mathrm{a}} & 0.430^{\mathrm{b}} & 2.612^{\mathrm{a}} & 0.050^{\mathrm{a}} & 4.982^{\mathrm{b}} \\ \text { Probability } & 0.0021 & 0.1512 & <0.0001 & 0.2044 & 0.1130 & 0.0070 \\ \text { MSD } & 0.197 & 0.042 & 0.019 & 0.235 & 0.006 & 0.118\end{array}$

Interactions

$\begin{array}{ccccccc}\mathrm{S}^{*} \mathrm{C} & <0.0001 & <0.0001 & <0.0001 & <0.0001 & <0.0001 & 0.0263 \\ \mathrm{~S} \mathrm{~B} & <0.0001 & <0.0001 & 0.0004 & 0.1943 & 0.0070 & 0.0017 \\ \mathrm{C} * \mathrm{~B} & 0.8651 & <0.0001 & <0.0001 & 0.1575 & 0.0049 & 0.1810 \\ \mathrm{~B} \text { D } & <0.0001 & 0.0002 & 0.2516 & <0.0001 & 0.1737 & 0.8973 \\ \mathrm{C} * \mathrm{D} & 0.0082 & 0.9668 & <0.0001 & 0.2503 & 0.0193 & 0.6942 \\ \mathrm{~S} \mathrm{D} & <0.0001 & 0.2885 & <0.0001 & 0.0012 & <0.0001 & 0.9419 \\ \mathrm{~S}^{*} \mathrm{C}^{*} \mathrm{~B}{ }^{*} \mathrm{D} & 0.0003 & 0.0001 & <0.0001 & 0.0033 & 0.0004 & 0.5935\end{array}$

Different superscript letters within each treatment denote significance level $* \mathrm{p}<0.05$. Main factors analysed are indicated as follows: $\mathrm{S}=$ structure, $\mathrm{C}=\mathrm{Colon}, \mathrm{B}=$ type of bacteria, $\mathrm{D}=$ donor.

\subsection{Concluding remarks}

The results obtained in the present study indicate a clear impact of microbiota community on nutrients utilization in beans. Microbial adaptation to a bean diet was shown to produce changes in bean cells fermentation. Modulation and changes in the microbiota composition were not the only factors determining the rate and extent of nutrients utilization. In particular, we showed 
here that the degree of cell integrity modulates the potential beneficial (or detrimental) effects of microbial activity by changing the relative accessibility of fermentable substrates to microbiota. The descending colon is the most active section of the large bowel in fermenting plant components. The experimental set-up employed in the present study helped also in understanding that the microbiota present in the distal part of the colon are particularly efficient in producing beneficial metabolites such as butyric acid. These findings could be employed as basis to design intelligent food structures that target the delivery of prebiotics, like resistant starch, to the distal parts of the colon.

\subsection{Acknowledgements}

We thank Max Van Schaijk for conducting part of the experimental work utilized this study. This research was supported by a grant from the Ecuadorian Secretary of Higher Education, Science, Technology and Innovation. 


\section{References}

1. De Preter V, Hamer HM, Windey K, Verbeke K. The impact of pre- and/or probiotics on human colonic metabolism: Does it affect human health? Mol Nutr Food Res. 2011;55(1):4657.

2. Macfarlane GT, Macfarlane S. Fermentation in the human large intestine: Its physiologic consequences and the potential contribution of prebiotics. J Clin Gastroenterol. 2011;45(3):120-127.

3. Wong J, Souza R, Kendall C, Emam A, Jenkins D. Colonic Health: Fermentation and short chain fatty acids. J Clin Gastroenterol. 2006;40(3):235-243.

4. De Filippo C, Cavalieri D, Di Paola M, et al. Impact of diet in shaping gut microbiota revealed by a comparative study in children from Europe and rural Africa. Proc Natl Acad Sci. 2010;107(33):14691-14696.

5. Conterno L, Fava F, Viola R, Tuohy KM. Obesity and the gut microbiota: Does up-regulating colonic fermentation protect against obesity and metabolic disease? Genes Nutr. 2011;6(3):241-260.

6. Ercolini D, Fogliano V. Food Design to Feed the Human Gut Microbiota. J Agric Food Chem. 2018;66(15):3754-3758.

7. Holscher HD. Dietary fiber and prebiotics and the gastrointestinal microbiota. Gut Microbes. 2017;8(2):172-184.

8. Berg T, Singh J, Hardacre A, Boland MJ. The role of cotyledon cell structure during in vitro digestion of starch in navy beans. Carbohydr Polym. 2012;87(2):1678-1688.

9. Dhital S, Bhattarai RR, Gorham J, Gidley M. Intactness of cell wall structure controls the in vitro digestion of starch in legumes. Food Funct. 2016;7(3):1367-1379.

10. Rovalino-Córdova AM, Fogliano V, Capuano E. A closer look to cell structural barriers affecting starch digestibility in beans. Carbohydr Polym. 2018;181:994-1002.

11. Rumpagaporn P, Reuhs BL, Kaur A, Patterson JA, Keshavarzian A, Hamaker BR. Structural features of soluble cereal arabinoxylan fibers associated with a slow rate of in vitro fermentation by human fecal microbiota. Carbohydr Polym. 2015;130:191-197.

12. Warren FJ, Fukuma NM, Mikkelsen D, et al. Food Starch Structure Impacts Gut Microbiome Composition. mSphere. 2018;3(3):1-13.

13. Venkatachalam M, Kushnick MR, Zhang G, Hamaker BR. Starch-entrapped biopolymer microspheres as a novel approach to vary blood glucose profiles. $J$ Am Coll Nutr. 2009;28(5):583-590.

14. Koper JEB, Loonen LMP, Wells JM, Troise AD, Capuano E, Fogliano V. Polyphenols and Tryptophan Metabolites Activate the Aryl Hydrocarbon Receptor in an in vitro Model of Colonic Fermentation. Mol Nutr Food Res. 2019;63(3):1-9.

15. Molly K, Vande Woestyne M, Verstraete W. Development of a 5-step multi-chamber reactor as 
a simulation of the human intestinal microbial ecosystem. Appl Microbiol Biotechnol. 1993;39:254-258.

16. Van Den Abbeele P, Kamil A, Fleige L, Chung Y, De Chavez P, Marzorati M. Different Oat Ingredients Stimulate Specific Microbial Metabolites in the Gut Microbiome of Three Human Individuals in Vitro. ACS Omega. 2018;3(10):12446-12456.

17. Theodorou MK, Williams BA, Dhanoa MS, McAllan AB, France J. A simple gas production method using a pressure transducer to determine the fermentation kinetics of ruminant feeds. Anim Feed Sci Technol. 1994;48(3-4):185-197.

18. Debersaques FMA, Groot JCJ, Cone JW, Lantinga EA, Williams BA. Multiphasic analysis of gas production kinetics for in vitro fermentation of ruminant feeds. Anim Feed Sci Technol. 2002;64(1):77-89.

19. Bauer E, Williams BA, Bosch MW, Voigt C, Mosenthin R, Verstegen MWA. Differences in microbial activity of digesta from three sections of the porcine large intestine according to in vitro fermentation of carbohydrate-rich substrates. J Sci Food Agric. 2004;84(15):2097-2104.

20. Guo B, Oliviero T, Fogliano V, Ma Y, Chen F, Capuano E. Gastrointestinal bioaccessibility and colonic fermentation of fucoxanthin from the extract of the microalga Nitzschia laevis. $J$ Agric Food Chem. 2019.

21. Coles LT, Moughan PJ, Darragh AJ. In vitro digestion and fermentation methods, including gas production techniques, as applied to nutritive evaluation of foods in the hindgut of humans and other simple-stomached animals. Anim Feed Sci Technol. 2005;123-124 Pa:421-444.

22. Low DY, Williams BA, D'Arcy BR, Flanagan BM, Gidley MJ. In vitro fermentation of chewed mango and banana: Particle size, starch and vascular fibre effects. Food Funct. 2015;6(8):2464-2474.

23. Day L, Gomez J, Øiseth SK, Gidley MJ, Williams BA. Faster fermentation of cooked carrot cell clusters compared to cell wall fragments in vitro by porcine feces. $J$ Agric Food Chem. 2012;60(12):3282-3290.

24. Cummings JH, Pomare EW, Branch HWJ, Naylor CPE, MacFarlane GT. Short chain fatty acids in human large intestine, portal, hepatic and venous blood. Gut. 1987;28(10):1221-1227.

25. Jorgensen H, Jensen BB. the Effect of Dietary Fiber on Digestibility, Microbial Activity, and Microbial Gas Production in Various Regions of the Gastrointestinal Tract of Pigs. Vith Int Symp Dig Physiol Pigs, Proceedings, Vols 1 2. 1994;60(80):273-276.

26. Turnbaugh PJ, Ridaura VK, Faith JJ, Rey FE, Knight R, Gordon JI. The Effect of Diet on the Human Gut Microbiome: A Metagenomic Analysis in Humanized Gnotobiotic Mice. Sci Transl Med. 2009;1(6):1-10.

27. Turnbaugh PJ, Hamady M, Yatsunenko T, et al. A core gut microbiome in obese and lean twins. Nature. 2009;457(7228):480-484.

28. Tian L, Bruggeman G, van den Berg M, et al. Effects of pectin on fermentation characteristics, carbohydrate utilization, and microbial community composition in the gastrointestinal tract of weaning pigs. Mol Nutr Food Res. 2017;61(1):1-10. 
Chapter 6

29. Windey K, de Preter V, Verbeke K. Relevance of protein fermentation to gut health. Mol Nutr Food Res. 2012;56(1):184-196.

30. David LA, Maurice CF, Carmody RN, et al. Diet rapidly and reproducibly alters the human gut microbiome. Nature. 2014;505(7484):559-563.

31. Morrison DJ, Preston T. Formation of short chain fatty acids by the gut microbiota and their impact on human metabolism. Gut Microbes. 2016;7(3):189-200.

32. Macfarlane T, Gibson G. Carbohydrate fermentation, Enegry transduction and gas metabolism in the human large intestine. In: Mackie R, White B, eds. Gastrointestinal Microbiology. Vol 1. East Lansing: Chapman \& Hall; 1997:269-318.

33. Bird AR, Conlon MA, Christophersen CT, Topping DL. Resistant starch, large bowel fermentation and a broader perspective of prebiotics and probiotics. Benef Microbes. 2010;1(4):423-431.

34. Hosseini E, Grootaert C, Verstraete W, Van de Wiele T. Propionate as a health-promoting microbial metabolite in the human gut. Nutr Rev. 2011;69(5):245-258.

35. Macfarlane S, Macfarlane GT. Regulation of short-chain fatty acid production. Proc Nutr Soc. 2003;62(1):67-72. 
Chapter 7 .02060

General Discussion 


\subsection{Introduction}

Food structure is nowadays recognized as an important factor for modulating nutrients bioaccessibility. In plant tissues, the intricate network of cell walls resistant to digestion in the small intestine of humans results in low digestibility of the nutrients encapsulated within them. Up to know, most of the research performed on nutrients digestibility in plant tissues were either limited to a pure description of the observed phenomena or to providing very simplified explanations that were unable to offer an accurate overview of all the important aspects involved. Therefore, the overall aim of this thesis was to identify those key factors limiting the digestibility and fermentability of nutrients when entrapped within a plant tissue matrix. Cotyledon cells from red kidney beans were used as model systems to study the digestibility of its nutrients, with special emphasis on starch. The present chapter intends to discuss the main findings obtained in this study (Fig. 7-1) and to offer a broader perspective about the implications, relevance, challenges and future developments in this field. 
Table 7-1. Summary of the main results obtained in this thesis.

$\underline{\text { Starch and protein digestion }}$

- Understand the influence of cell wall and

- Cell wall is permeable to digestive cytoplasmic matrix in starch digestion.

\section{(Chapter 2)}

- Determine the effects of cell wall confinement in protein digestion. (Chapter 3)

\section{$\underline{\text { Mechanism of starch hydrolysis }}$}

- Investigate the physical and kinetic processes involved in starch digestion when confined within cell wall matrix. (Chapter 4)

- Enzymatic hydrolysis of starch takes place within cotyledon cells after enzyme diffusion through cell wall pores.

- $\alpha$-amylase binding to cell wall layer

- Difference in $\alpha$-amylase concentration between the bulk and within intact cotyledon cells (catalytically active enzymes).

\section{Colonic fermentation of bean cells}

- Study the fate of intact bean cells along the large intestinal tract.

$$
\text { (Chapter 5) }
$$

- Understand the role of food matrix in starch fermentation and colonic efficiency.
(Chapter 6)

- Cell wall entrapment delays starch fermentation towards distal parts of the colon.

- Food structure modulates the utilization of substrates present in the diet.

- Structural integrity of intact cotyledon cells is preserved after colonic fermentation.

- Microbiota present in distal colon showed highest efficiency in cell wall utilization.

- Microbial adaptation to substrate is affected by structural properties of the matrix. 


\subsection{Role of the cell walls in limiting digestion}

In bean cells, the presence of an intact cell wall (CW) made up of non-starch polysaccharides (NSP) that entraps nutrients reduces the rate of protein and starch digestion. This phenomenon was already described by others in the past, but a consensus was not yet reached regarding CW permeability to digestive enzymes. Part of the uncertainty arose because most of the studies claiming that the $\mathrm{CW}$ is permeable to enzyme diffusion were performed using samples treated with harsh mechanical processes to reduce their particle size which questioned the effect of such treatments on the integrity of the cells ${ }^{1}$. In addition, some of those studies have used very low or sometimes even no mixing regimes when conducting in-vitro experiments. In the present study, we isolated intact cotyledon cells to ensure that the results obtained after in-vitro digestion were performed in samples with homogeneous conditions (intact cells). Microscopy techniques were employed to obtain qualitative evidence of the cells integrity using dyes to localize the different cell components. Furthermore, appropriate mixing conditions were applied without compromising the samples structural integrity. In such a way, it was possible to demonstrate that starch could be hydrolysed in-vitro despite of being entrapped within an intact $\mathrm{CW}$, indicating the permeability of $\mathrm{CW}$ to digestive enzymes (Chapter 2). Nevertheless, the degree of $\mathrm{CW}$ permeability was shown to be one of the factors that limits the digestibility of starch in this system. Modulating CW permeability alters the rate of starch (and possibly protein) digestion as we demonstrated by digesting intact cells pre-treated with a mixture of $\mathrm{CW}$ degrading enzymes that increased $\mathrm{CW}$ porosity. These results together with the qualitative evidence provided in chapter 4 about pancreatic amylase accumulation within intact cells during digestion, demonstrate that $\mathrm{CW}$ in legumes serve as a physical barrier that limits the access of digestive enzymes to the intracellular environment. As consequence, a delay in starch hydrolysis occurs due to the lower concentration of enzymes present within intact cells during digestion compared to those present in the bulk. Interestingly, this delay is not only caused by the barrier effect exerted by the $\mathrm{CW}$, but it is also due to the interactions between $\alpha$-amylase with some NSP components of the CW. These interactions were previously described by Dhital, et $\mathrm{al}^{2}$ when hydrolysing free starch granules in the presence of cellulose and wheat bran.

By using the mathematical model described in Chapter 4, the effect of CW-amylase interaction was assessed by calculating the concentration of $\alpha$-amylase within intact cells (indicated as $\mathrm{Ce}_{\text {in }}$ in chapter 4) if no adsorption processes were present. In this calculation, the size of the enzymes was considered as the only factor limiting its diffusion through the $\mathrm{CW}$, neglecting their electrical charge. In Fig. 7-1 a simulation of the change in $\alpha$-amylase concentration within intact 
bean cells in presence or absence of interactions with the $\mathrm{CW}$ is depicted. The figure shows a fast and steep increase in $\alpha$-amylase concentration since the very first minutes of digestion in the absence of interactions between amylase and the CW. This is also reflected by the value obtained for the hindrance coefficient (indicated as $\mathrm{kd}_{\mathrm{e}}$ in Chapter 4) which was calculated to be three orders of magnitude higher than what obtained when $\mathrm{CW}$ interactions were considered. A higher concentration of catalytically active enzymes within intact cells will result in a faster rate of starch digestion producing a large impact on the glycaemic index of foods.

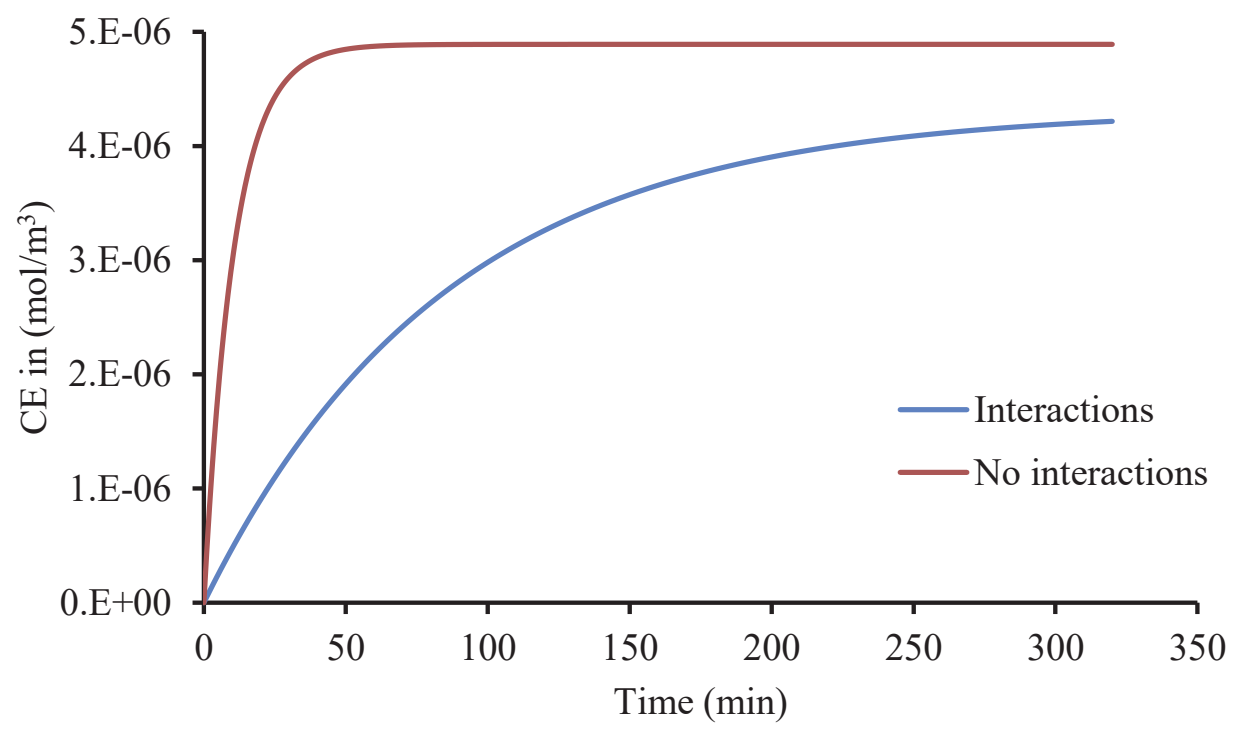

Fig. 7-1 Estimation of $\alpha$-amylase concentration within intact cotyledon cells in the presence (blue line) or absence (orange line) of adsorption interactions between the enzymes and the CW.

All in all, it could be stated that the $\mathrm{CW}$ is a powerful barrier that modulates the passage of digestive enzymes. This effect is achieved due to its unique structural properties that limits diffusion by the combined effect of electrostatic interactions with $\alpha$-amylase (and very likely other digestive enzymes) and its constricted porosity. It is important to mention that the nature of $\alpha$-amylase interactions with CW constituents are not catalytic site mediated. This explains why in mechanically damaged cells starch is extensively digested despite of having the same concentration of $\mathrm{CW}$ components present in the system.

\subsection{Are there any additional roles played by the cell wall?}

The strong barrier effect exerted by the $\mathrm{CW}$ is perhaps the most evident factor limiting the digestibility of nutrients in plant cells. However, $\mathrm{CW}$ presence could also reduce nutrients digestibility through other mechanisms. One of them consists in preserving the integrity of the cytoplasmic matrix formed by proteins and starch (Chapter 3). This is particularly important 
for starch digestion due to the unique architecture of bean cells where starch granules are immersed in a proteinaceous matrix. Therefore, for starch, the cytoplasmic matrix serves as an extra protective layer that delays its degradation during in-vitro digestion. The influence of protein matrix was already described for other plant-based tissues, such as sorghum, when starch digestibility in samples of different particle size was investigated ${ }^{3}$. Until know, this effect was only described in plant tissues where a strong interaction between starch granules and proteins were known such as those occurring in sorghum and maize, however our findings have shown that this principle could be extended to a larger group of matrices. Furthermore, it was interesting to observe that the interactions between proteins and starch in the cytoplasmic matrix of bean cells did not affect the digestibility of both molecules in the same way, since the presence (or absence) of starch granules in the cytoplasmic matrix had no effect in protein digestion (Chapter 3). In Chapter 3 we also highlighted another potential role of the $\mathrm{CW}$, demonstrating that the reduced digestibility observed for proteins in intact beans was also related to their molecular confinement within the packed intracellular environment. Molecular confinement may have repercussions on protein digestibility due to the impairment of its unfolding upon thermal treatments (Chapter 3). But it could also facilitate protein crosslinking and aggregation when harsh thermal treatments are applied that also has detrimental repercussions in digestibility. It is important to mention that the effect of molecular confinement is not limited to proteins. Differences in the extent of starch swelling during gelatinization have been observed between samples where starch granules are entrapped within a CW matrix compared to isolated starch granules ${ }^{4}$.

\subsection{An integrated look at the effect of intact $\mathrm{CW}$ on nutrients digestibility}

In this section, we will provide an integrated description of the effect of the $\mathrm{CW}$ on starch digestibility based on the findings described in chapter 2, 3 and 4. Starch digestion is an enzymatic reaction where $\alpha$-amylase increases the rate of starch conversion into low molecular weight dextrins. This reaction is generally expressed by the equation depicted in Fig. 7-2, where E represents the enzyme; $\mathrm{S}$ the substrate; ES the enzyme-substrate complex and $\mathrm{P}$ the products formed. In this section, such equation is used to illustrate how intrinsic and extrinsic factors related to starch entrapment within an intact $\mathrm{CW}$ affects starch digestibility.

As described in Chapter 4, the digestion of starch entrapped within an intact CW matrix could be described as the succession of three events: enzyme diffusion through stagnant layer and $\mathrm{CW}$, the conversion of starch into hydrolysis products and the transport of the hydrolysates 
from the intracellular environment to the intestinal lumen. Each of these events is affected directly or indirectly by the presence of (an intact) CW. The diffusion of enzymes from the bulk to the cytoplasm is governed by $\mathrm{CW}$ properties and external factors of the system. Both effects modulate the concentration of the enzyme, E, available for starch hydrolysis in the equation presented in Fig. 7-2. In the case of the $\mathrm{CW}$, its physical (porosity) and electrostatic (adsorption) properties are the factors responsible of limiting the access of digestive enzymes. The reduction in starch hydrolysis is the direct consequence of this restriction since only a fraction of enzymes (those who managed to diffuse through the $\mathrm{CW}$ ) were found to be catalytically active during hydrolysis. Furthermore, an intact $\mathrm{CW}$ preserves the integrity of the intracellular matrix which represents an extra barrier that limits the digestion of $\alpha$-amylase. On the other hand, the external factors refer to other characteristics of the system that are not influenced directly by the CW presence and are related to the viscosity, mixing conditions and enzyme concentration of the system. This part of the reaction has been found to be affected by the initial enzyme concentration and the amount of $\mathrm{CW}$ material since the affinity between the two is limited to the binding sites available in the CW. Thus, in an in-vivo scenario, factors such as gastric emptying, other diet components and rheological properties of the chyme could also influence the diffusion of enzymes through the $\mathrm{CW}$.

The second step needed for starch hydrolysis to take place is the formation of a stable enzymestarch complex, ES. Hence, all the factors that affect the formation of such complex could delay or inhibit hydrolysis. There is no question about the fact that individual molecular characteristics of starch and proteins can affect their digestibility. The amylose: amylopectin ratio in starch and the disulphide bonds for proteins are one of various factors that could modulate the affinity of the enzyme to the target molecular bonds hereby limiting catalytic action of enzymes. In the intact cell system, confinement produced by the presence of an intact $\mathrm{CW}$ facilitates the interaction between molecules and its physical presence will serve as a protective layer that mitigate the effects of thermal treatments which induce changes in the molecules facilitating their digestibility. Therefore, the $\mathrm{CW}$ has influence in the preservation of those intrinsic properties of the molecules that make them resistant to digestion. As discussed in the previous section, the $\mathrm{CW}$ plays a fundamental role in reducing the digestibility of starch and proteins either directly by limiting the access of enzymes or indirectly by preserving the cytoplasmic matrix. Therefore, structural features of the $\mathrm{CW}$, such as porosity and thickness, could make a large difference in modulating the properties of the entire system. In turn, it is evident that $\mathrm{CW}$ characteristics are dependent of the processing methods applied. If this 


\section{Chapter 7}

attempts against the integrity of the cells (e.g. milling), there will be considerable implications in all the other factors that will have repercussions in nutrients digestibility.

Finally, the rate of glucose appearance in the blood would depend on the rate of diffusion of starch hydrolysis products from their site of generation (i.e. inside intact cells), to the epithelial cells lining the small intestinal mucosa. The rate of diffusion of those products from the cells towards the exterior or bulk phase could be modulated by external factors such as the viscosity and the mixing conditions applied to the medium and not by the presence of the $\mathrm{CW}$ due to the small molecular weight of the hydrolysates and the absence of electrical interactions between them with CW constituents (Chapter 4).

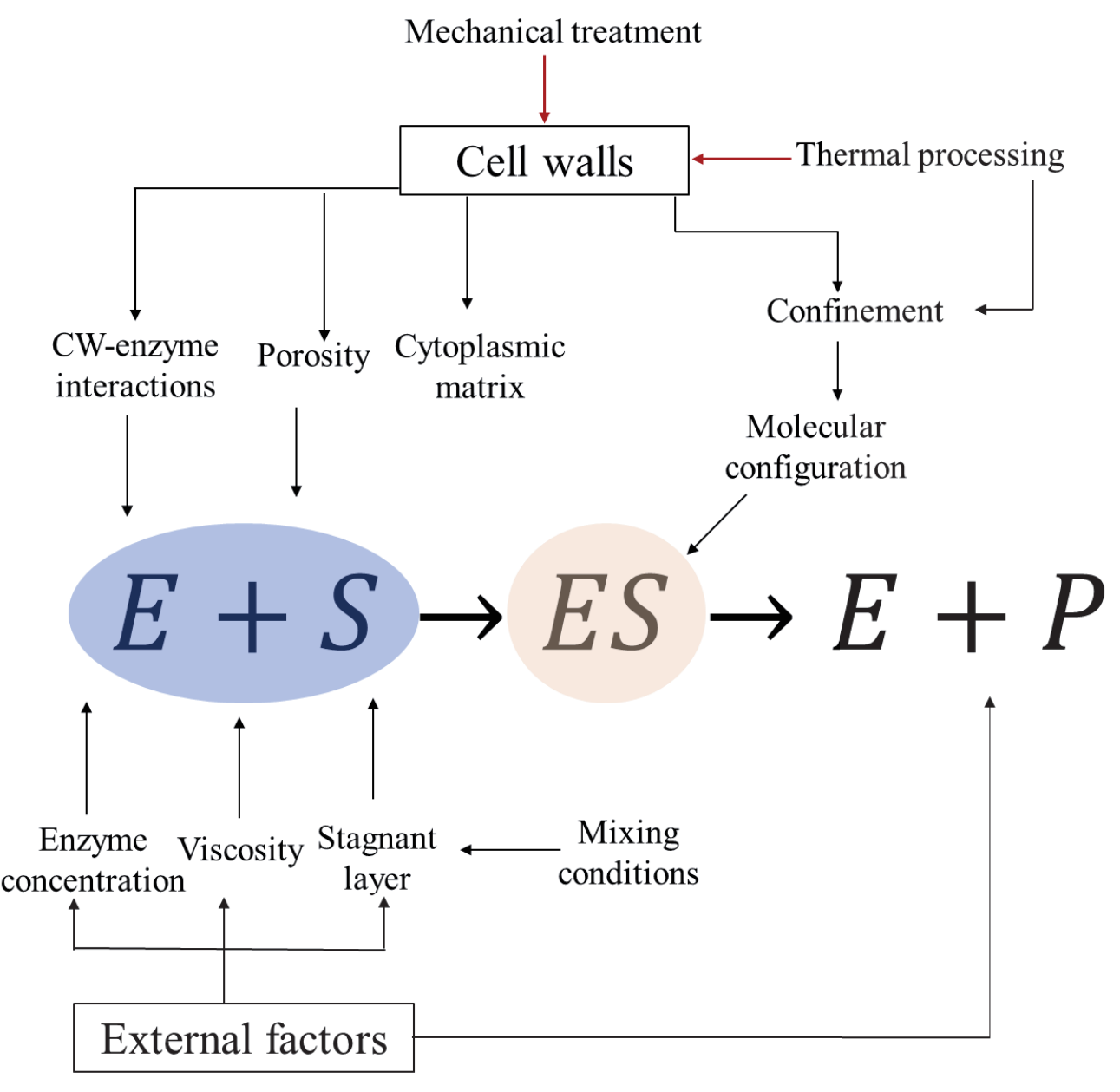

Fig. 7-2. Schematic representation of the factors affecting starch digestion when encapsulated within intact bean cells. $\mathrm{E}=$ enzyme; $\mathrm{S}=$ substrate; $\mathrm{ES}=$ enzyme-substrate complex; $\mathrm{P}=$ product formation.

\subsection{Cell wall encapsulation limits nutrients accessibility for microbiota utilization}

Similar to what occurs during gastro-intestinal digestion; structural characteristics of foods also influence microbiota fermentation in the colon. The first obvious reason for that, which is 
evident from the results reported in chapter 2 and 3, is that the level of $\mathrm{CW}$ integrity determines the amount of intracellular nutrients that escapes digestion in the small intestine and is delivered to the colon. Apart from this "indirect" effect, another factor with perhaps more direct influence could be related to the specific structure of the plant matrix. In chapters 5 and 6 , we have demonstrated that the diet composition is not the only factor capable of modulating intestinal microbiota and its metabolism; but food structure also plays a role in this respect. Previous studies had already shown that the presence of different types of dietary fibre in the diet modulates the fermentability of individual polysaccharides due to a hierarchical order of fermentation ${ }^{5}$. However, very scarce information was found regarding the fermentability of starch entrapped within plant-tissue matrix. In some studies, a delay in starch fermentation was observed as consequence of encapsulation of starch in polysaccharides resistant to digestion ${ }^{6,7}$. Yet, nothing was known about the fate of individual cells along the whole colonic tract and its utilization by microbiota present in the three colon regions. We decided to fill that knowledge gap by studying the fermentability of intact and mechanically damaged cells using static and dynamic in-vitro fermentation tools. By comparing two different structural matrices with the same compositional characteristics it was possible to observe changes in microbial metabolism due to substrate availability. In samples that contained encapsulated starch, a higher NSP fermentation was observed since bacteria needed to degrade the CW to a certain extent before getting access to starch. SEM images allowed the visualization of micron size holes created by the bacteria for such purposes. This shows that intact cells are not only resistant to small intestinal digestion ${ }^{8}$ but also to colonic fermentation.

In both, batch and SHIME ${ }^{\circledR}$ fermentation experiments the amounts of microbial metabolites formed from mechanically damaged cells was higher than what obtained from its intact counterpart. This indicates that the structure plays an important role in substrate utilization by microbiota. It is a logic outcome to obtain more metabolites produced by mechanically damaged cells due to the larger availability of substrate. In physiological conditions, this might not be the case since mechanically damaged cells would reach the colon almost depleted of starch. For our experiments, we decided not to pre-digest bean samples prior fermentation to isolate the effect of the structural organization (intact vs. mechanically damaged cells) from those occurring when different amounts of nutrients are delivered to the colon due to variations in digestibility. In this way, it was also possible to observe that during the first days of fermentation cellular entrapment delayed starch utilization towards distal portions of the colon. Furthermore, batch fermentation experiments allowed us to understand that the reduced 
fermentation of polysaccharides (and consequently the increased protein fermentation) that is observed in-vivo in the distal parts of the colon is due to polysaccharide depletion and not to microbiota inefficiency. In general, these experiments showed us that the role of food structure should not be neglected when studying the fermentation mechanism of the diet in the colon. The fermentability patterns of individual fibres give insights of what will happen in ideal conditions that are generally not occurring in human (or animal) colonic fermentation processes due to the complex matrices present in foods. Furthermore, it is very likely that the fermentation kinetics of other macromolecules, such as proteins, could follow a behaviour similar to that observed for starch with a steady degradation by colonic microbiota due to matrix constraints.

\subsection{Methodological aspects}

This section will describe the main features, challenges and limitations of the most important methodologies used in this thesis.

\subsubsection{In-vitro digestion model}

In-vitro digestion models are widely used to test the digestibility of foods in a relatively simple and inexpensive way. There are several types of in-vitro methods available; they range from rather simple static systems where only the biochemical processes involved in digestion are reproduced to more complex dynamic or semi-dynamic models in which other aspects of the digestive processes are also represented (e.g. absorption, peristalsis, flow of food and digestive secretions). In the present thesis, a static in-vitro digestion model was chosen for studying the digestibility of protein and starch encapsulated within a CW matrix. The choice of a static model was driven by the fundamental nature of the study and the fact that we aimed at understanding the digestion mechanism of a complex matrix. The selection of a rather simple digestion model allowed us to understand all the factors inherent to the plant tissue matrix that played a role in its digestion. This would have been impossible when using an in-vivo model where many factors cannot be controlled, and the digested sample could not be monitored. Furthermore, we opted for a static rather than a dynamic model because we were not specifically interested in an accurate prediction of starch digestibility (which requires the accurate replication of physiological conditions) but we were more interested in the comparison between samples with different structural organizations that could be achieved using a simpler model with a considerable saving of resources. In addition, even though dynamic systems can reproduce more accurately physiological conditions, most of them have been validated using specific food products raising the question if they might be useful for other systems with different rheological 
properties $^{9}$. It is important to mention that even though the selected digestion method was not replicating exactly what occurring at physiological conditions, it still contained the main processes taking place in the human or animal digestive system due to the utilization of the newly developed INFOGEST model. This simulated in-vitro digestion model is comprised of a series of steps that represent the oral, gastric and intestinal phases in which constant ratios of meal to enzymes, salts, bile acids etc. are used at each step of digestion. The method was developed using as a reference the current state of knowledge on in-vivo digestion conditions but employing widely available instrumentation and chemicals and represents the most successful attempt to develop a standardized, consensus model of in-vitro small intestinal digestion $^{10}$.

Comparing the results obtained in our study to those obtained by other research groups was somehow challenging. In some cases, and despite of several methodological differences, similar trends for digestion kinetics ${ }^{1,11}$ were obtained. However, in other cases, large discrepancies were observed like in the case of the study of Dhital, et $\mathrm{al}^{12}$ who concluded that the $\mathrm{CW}$ of legumes was impervious to the access of digestive enzymes. We believe that there are some key aspects responsible for obtaining such contradictory results. They are related to sample processing, type of enzymes and their concentration, and in-vitro mixing conditions. Regarding sample processing, it is evident that changes in the $\mathrm{CW}$ properties (e.g. integrity) will alter the digestibility of starch and proteins contained in the matrix as already discussed in previous sections. Therefore, cooking beans for short periods of time or at low temperature may result in a partial gelatinization of starch or an incomplete solubilization of pectin (present in the middle lamella between two adjacent cells) which influences CW permeability.

Enzyme concentration is another factor that can explain discrepancies of our results with those of others since it will determine the rate of hydrolysis. This is particularly important for starch, due to the affinity between $\alpha$-amylase and the CW. At low enzyme concentrations, most of the enzymes present in the system will be adsorbed by the CW surface almost depleting it of free enzymes capable of catalysing starch hydrolysis ${ }^{2}$. Furthermore, if proteolytic enzymes are not employed in the in-vitro method, the digestibility of starch could be hindered even further due to the intactness of the cytoplasmic matrix as explained in Chapter 3. The decision of including enzymes that mimic the function of those present at the brush border is another point of attention. This is sometimes done to better mimic the physiological conditions where starch hydrolysis is simultaneously completed by the activity of brush border enzymes. In this study, we decided not to include such enzyme(s) directly during the simulated digestion because it 
might also affect the degradation of starch. Usually for in-vitro systems brush border enzymes are replaced by amyloglucosidase from Aspergillus niger which has a different optimal $\mathrm{pH}$ than that of porcine $\alpha$-amylase. Therefore, if both enzymes are used simultaneously, a compromise in their optimal $\mathrm{pH}$ must be achieved to ensure proper activity of the two of them. Furthermore, fungal amyloglucosidase has been found capable of utilizing starch as substrate that could result in higher amount of starch hydrolysed ${ }^{13}$. Even though in-vivo evidence has indicated the presence and activity of brush border enzymes in the digesta ${ }^{14}$, very little is known about the concentration of these enzymes not bound to the membranes of epithelial cells and catalytically active in starch degradation.

Finally, another important but rather underestimated aspect is represented by the mixing conditions employed while conducting in-vitro digestion experiments. As shown in Chapter 4, the mixing regime is one of the factors that limits digestion because it affects the transport of $\alpha$-amylase through the combined stagnant and CW layer. When no agitation is applied, a considerable contribution of the stagnant layer is expected hampering enzyme-substrate contact. If, on top of that, low concentration of amylase is used, the digestion process will take a considerable amount of time before starch hydrolysis products are detectable. This could provide misleading information appearing as if no digestion is taking place. However, when given enough time to overcome the stagnant layer resistance, starch (and other nutrients) hydrolysis will eventually occur. To prove this, an experiment was performed on intact cells using low concentration of enzymes $(0.5 \mathrm{U} / \mathrm{mg}$ starch $)$ with mixing and non-mixing conditions. As seen in Fig. 7-3, the amount of starch hydrolysed in samples that were incubated with mixing conditions was twice as high compared to those in which mixing was absent at all time points analysed. Furthermore, by extending the incubation time to $200 \mathrm{~min}$, an increase in starch hydrolysis could be observed in both samples despite of their mixing conditions.

All the factors mentioned above are important to consider in the design of digestion experiments for complex matrices as those present in legumes. A clear and detailed explanation of the methods employed could also help understand the different results obtained between research groups. 


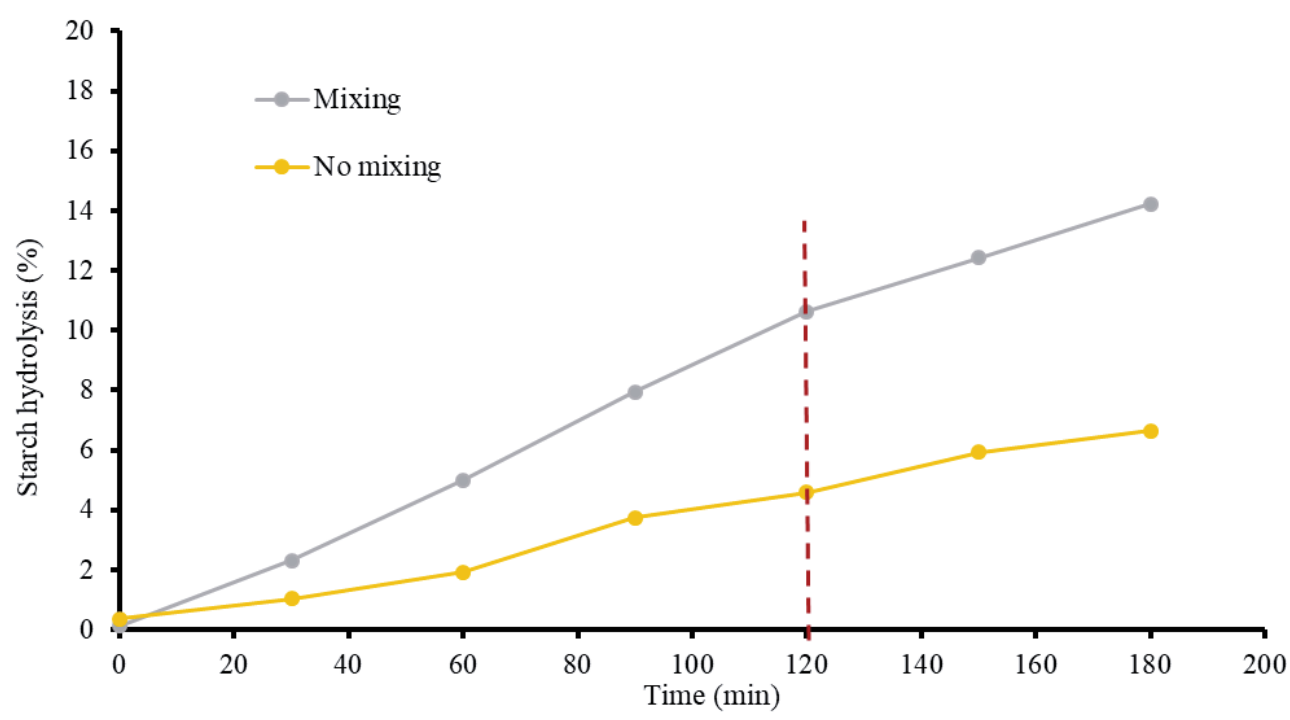

Fig. 7-3. In-vitro digestion kinetics of starch in intact cells from red kidney beans with and without mixing conditions during the experiment. The dashed red line indicates the end of the intestinal digestion phase in the invitro model employed.

\subsubsection{In-vitro Fermentation models}

As what occurs with digestion models, in-vitro fermentation could also be studied using static (batch), dynamic and semi-dynamic systems. The difference between these models resides in the accuracy of representing physiological conditions (substrate replenishment, continuous fermentation of the three colon portions), the duration of the experiments and the control of the fermentation parameters (anaerobiosis, gas production, absorption of metabolites) ${ }^{15}$. In this thesis, we used both batch and semi-dynamic models to get insights about the fermentation of starch encapsulated within beans CW. The use of these two systems allowed us to answer different research questions that otherwise would have not been possible by using only one model. These questions were related to understanding the influence of food structure in colonic fermentation, cell integrity and microbiota composition.

The SHIME ${ }^{\circledR}$ model was employed to determine the fate of starch fermentation along the three portions of the colon when entrapped within a $\mathrm{CW}$ matrix. It is important to mention that this system was originally developed to study the metabolic behaviour of microbiota and not for understanding how structural aspects of foods could modulate their response. That is why, in most of the cases, the system is fed with purified powdered compounds that could be easily dissolved and pumped from one reactor to another. In our case, we used a suspension of either intact or mechanically damaged bean cells. Therefore, the main challenge was related to preserving structural integrity of the samples while providing proper mixing conditions and ensuring no blockage of the system while conducting the experiment. Even though mixing by 
means of a magnetic stirrer (which is the mixing condition provided by the SHIME ${ }^{\circledR}$ model) has been found to affect cells integrity ${ }^{12}$, particle size analysis showed no changes in the distribution of intact cells size due to stirring in our fermentation experiments probably due to the low mixing rate utilized. Overall, the $\mathrm{SHIME}^{\circledR}$ system represents a valuable tool to investigate different aspects of fermentation that would not be possible to study otherwise. These are related to understanding the effect of prolonged diet exposure to asses changes in the microbiota composition and gaining insights about the fate of nutrients through the different colonic portions. In this study, by use of the semi-dynamic SHIME ${ }^{\circledR}$ model we could identify different fermentation patterns due to structural changes in the matrix in terms of starch utilization (distal portions of the colon) and microbiota metabolism. However, we do believe that there are several aspects of the model that deserve attention and optimization. One of them is related to the absence of a system that reproduce the metabolites absorption by the colon epithelium. This typically results in the accumulation of microbial metabolites in the distal portions of the colon making it difficult to estimate the net metabolites production in each compartment. Furthermore, this lack of absorption does not simulate the actual exposure of bacteria to nutrients or waste products, which may produce alterations in their metabolism.

In the case of batch fermentation model, this tool was useful to provide insights about cells integrity during fermentation. Due to the flexibility of the system it was possible to use a different mixing condition than stirring during sample incubation. This allowed us to investigate the changes in intact cells structure due to microbiota fermentation. Furthermore, batch fermentation was also useful to determine the efficiency of each colon portion when given equal amounts of substrate. This was achieved by inoculating the system with microbiota previously equilibrated in the SHIME model and adapted to the different colon segments. The main challenge found when conducting these experiments arise in the relatively long period of time needed for samples fermentation (especially for intact cells). Five days of fermentation were required to reach a plateau in gas production, this was more than twice of what other authors have described ${ }^{16}$ for other plant tissues.

\subsubsection{Mathematical modelling}

Mathematical models are important tools in science that aid in understanding the mechanism of a physical system. By using mathematical simulations, physical phenomena can be described and quantified allowing us to have a better overview of the system's behaviour and the individual contribution of the factors involved in it. Furthermore, these tools are useful to 
predict the behaviour of a physical system and are a good option for understanding systems that are very difficult to reproduce experimentally in a laboratory setting. These characteristics made it very suitable for exploring complex mechanisms such as those taking place during the digestion of plant tissue matrices. So far, several models have been proposed to describe starch digestibility data, but such models are of empirical or semi-empirical nature, often based only in reaction kinetics (first order or double exponential kinetics). In all these models, the effect of the food matrix (or food structure) is hidden in the estimated values of the apparent kinetic parameters ${ }^{17,18}$. From our knowledge, the model proposed in this thesis is the first to offer a mechanistic approach to understand the effect of cell wall entrapment in starch digestion. One of the most important assets of our model relies in the possibility of predicting changes in starch digestion when the food matrix or digestive conditions are altered, which is not possible when using empirical models ${ }^{19,20}$. The model is accurate enough to describe the role played by the CW during starch digestion, but we believe there are still possibilities of improvement. Perhaps one of the most evident could be related to model starch degradation when the reaction velocity is not comparable to Vmax (substrate depletion). In this case, other factors such as the cytoplasmic matrix (protein and starch interactions) will have a more predominant role and should be quantified independently. In our study, this effect was included in $\alpha$-amylase catalytic constant that was determined experimentally by us. We decided to use this approach since this was the first attempt to describe the system in a mechanistic way and some simplifications had to be done to develop the model. Overall, we believe that the mathematic description provided in this thesis is a good starting point to understand the phenomena occurring during digestion of macromolecules entrapped in plant tissues.

\subsection{Knowledge utilization}

This thesis provides fundamental knowledge about the complex interaction between food structure and digestion. Using individual cells as the smallest unit in plant tissue allowed us to understand all the different factors involved in the digestibility of macronutrients encapsulated within CW matrices. We believe that all the knowledge gathered in this thesis provides an important contribution to science and could be used for different applications; some of them will be discussed in this section. 


\subsubsection{Applicability in food technology}

\section{Understanding other plant matrices}

Even though structural differences exist between plant tissues of different origin, there are key factors applicable to all matrices that play an important role in determining the extent of macronutrients digestion. These are related to $\mathrm{CW}$ properties (porosity, thickness) and cytoplasmic matrix architecture. The individual properties of each matrix will determine the rate and extent of nutrients digestion. However, by using the mathematical model developed in this thesis, starch (and other nutrients) digestibility could be predicted by knowing specific aspects of the plant matrix such as CW thickness and porosity. For instance, the digestibility of nutrients in cereal matrices can be predicted using this approach. The architecture of cereals cell wall (which has negligible amounts of pectin) makes individual cell isolation a very complicate and cumbersome process. We have tried to isolate individual cells from sorghum with unsuccessful results since a low yield of material was collected and contained a mixture of broken and intact cells as seen in Fig. 7-4. Recently, Bhattarai and others ${ }^{21}$ developed a method for isolating individual cells from cereal sources. This method, besides of being complex and time consuming, was also not able to successfully provide intact cells since the presence of partially broken and fragmented cells was unavoidable due to the similar size in the isolation range of single intact cells. Hence, the mathematical model could be of great use in this situation to understand the mechanism of starch (and other nutrients) hydrolysis in these matrices.

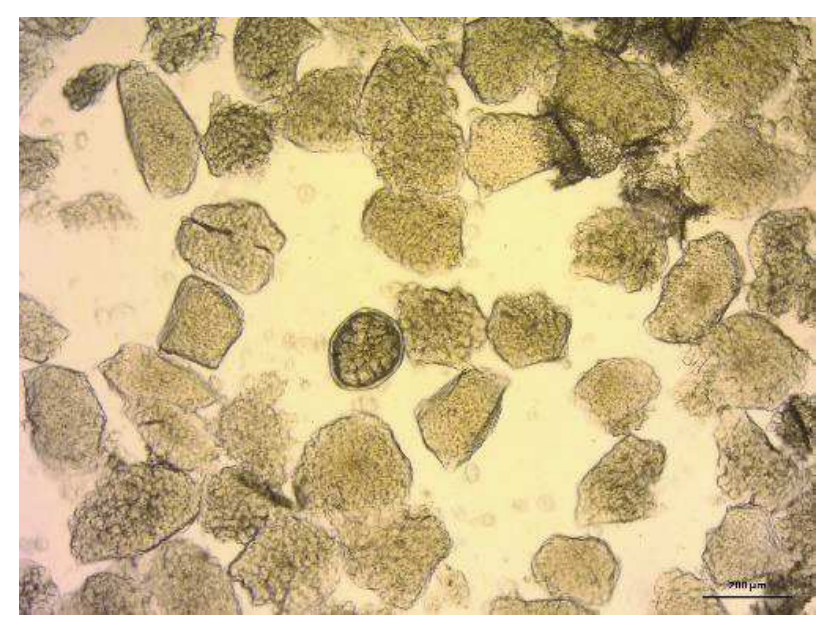

Fig. 7-4. Light micrograph of isolated intact cells from cooked sorghum. Cell isolation was done after gentle abrasion of cooked sorghum endosperm followed by sieving in a wet sieve shaker. Despite of the extensive separation treatment, isolation of intact cells could not be obtained since free starch granules and broken cells could be identified in the micrograph. 
Due to the large incidence of metabolic disorders and obesity worldwide, in the last years a reduction in starch digestibility of foods has been focus of attention. Starch is a macromolecule that besides of providing energy, possesses techno-functional properties that have been widely exploited by the food industry. Therefore, the need of finding strategies to reduce or delay its digestibility has been of great concern for researches and industry. In that respect, and based on the evidence found in this thesis, plant cell encapsulation has a lot of potential since it is one of the most efficient ways to delay starch digestion but also to deliver part of it towards the large intestine for colonic fermentation. In the past, several strategies to reduce starch digestion were explored such as the use of starch granules with different structural and molecular properties (e.g. porosity, amylose content) or the application of mild thermal treatments to limit its degree of gelatinization. However, the practical implications of these strategies are limited especially for products of human consumption since thermal processes applied during food preparation will compromise those effects. Lately, other ways of inhibiting starch digestion have been proposed such as the use of polyphenols, to inhibit the activity of amylolytic enzymes. In-vitro experiments conducted using these compounds have proven their effectiveness in reducing the digestibility of starch rich matrices such as bread ${ }^{22}$. However, very high concentrations of purified phenolic compounds have been found necessary to achieve amylase inhibition that could not be provided by the concentrations of phenolic compounds naturally present in the diet. Furthermore, due to the nature of the inhibition (catalytic site mediated), in-vitro experiments might not be a good representation of physiological conditions in terms of additional pancreatic enzymes secretion as a physiological response of enzyme inhibition. This will not occur in case of starch entrapment by plant tissues since the mechanism behind the reduction in digestibility is not directly related to kinetic aspects of amylases but on the structural aspects of the $\mathrm{CW}$ encapsulating material. The resistance of plant tissue to digestion has already being demonstrated by few researchers proving again that they are very effective tools to delay starch hydrolysis and delivering substrates for microbial fermentation in the gut $^{8,23}$.

\section{Implications for food design}

The resistance of starch encapsulated within intact bean cells makes them interesting ingredients for manufacturing starchy foods with a lower glycaemic index. The versatility and strength of legumes cells allows the production of bean flour that could be incorporated into 
bread formulations as a partial replacer of cereal flour. Fully substitution of cereal flour by bean flour will not be desirable since organoleptic properties of the bakery products will be compromised. It is important to mention that to fully exploit this encapsulation strategy to produce low glycaemic index ingredients beans need to be subjected to thermal treatments before their conversion into flour to preserve their cellular integrity and subsequently the protective effect on starch. Milling of the bean cotyledons before thermal treatments will result in breakage of the cells with partial loss of the encapsulation effect. Furthermore, this encapsulation strategy can be extended to other grains, e.g. cereals and be exploited to produce bakery products with lower GI. This could be achieved by using flour made up of larger particles (cell clusters), i.e. containing a large fraction of intact cells. However, the reduction in starch digestion will largely depend on intrinsic properties of the matrix like cell wall thickness and composition.

The cytoplasmic matrix of legumes is not only constituted by starch since (depending on the source) proteins and fats are also present. In the case of proteins, higher digestibility levels are desirable due to their essential role in human and animal physiological processes and since its fermentation in the large intestine is considered to have detrimental effects on health. Therefore, the knowledge gathered in this thesis could also be used to find strategies for increasing proteins digestibility. In this respect, we can infer that increasing the fraction of broken cells would increase protein digestibility. Another option could be increasing the pore size in plant tissues $\mathrm{CW}$, which can be obtained by means of processing. However, this effect has been recently shown to be relatively less important for protein digestibility in intact cells ${ }^{24}$. Unfortunately, due to the simultaneous presence of starch and proteins in many staple grains, it is not possible to obtain a high digestibility for protein without increasing that of starch. Consequently, a balance must be reached to take advantage of this natural encapsulating system without affecting protein intake.

\section{Applicability in human and animal nutrition}

We believe that all the findings described in this thesis could be utilized by other fields of science besides Food Technology. The first and foremost field that can benefit from this knowledge is human (and animal) nutrition. Even though the food matrix is recognized as a factor that modulates the rate and extent of nutrients absorption, this concept is not entirely implemented in nutrition research. This could be clearly observed in intervention studies where the role of food structure is normally not considered. An accurate description of the structural 
details of plant materials present in dietary interventions will facilitate the interpretation of invivo trials that otherwise might provide counterintuitive results leading to inappropriate conclusions. In a similar fashion, the plant tissue structure should be considered as a relevant factor in the design of dietary interventions because its presence would determine the amount of nutrients and bioactive compounds that are absorbed. Moreover, since the nutrients that escape digestion in the small intestine are delivered to the colon; the structure of foods must also be considered for the design and interpretation of results in those studies aiming at investigating the link between plant tissues and microbiota since substrate utilization largely depends on the architectural composition and the interactions among the constituents of the matrix. Furthermore, it is important to consider that the presence of $\mathrm{CW}$ in plant tissues will not only hinder nutrients bioaccessibility but also will determine the degree at which they are affected by thermal treatments as what observed with proteins denaturation in Chapter 3 . Thus, providing details on the way foods are processed in combination with information regarding its structural properties will further help understanding the observed outcomes.

Moreover, the increasing evidence about the importance of food structure (as those provided in this thesis) in digestion should motivate nutritionists and dieticians to modify dietary guidelines and recommendations. Recently, a study published by Capuano, et $\mathrm{al}^{25}$ demonstrated that the caloric content of foods is affected by structural properties of the food matrix. In this study, the authors demonstrated that the digestibility factor normally employed for calculating the metabolizable energy provides an overestimation of the caloric content in foods rich in plant tissue matrices. Therefore, dietary guidelines should stress the importance of food structure and recommend the consumption of a diverse diet not only in terms of nutritional composition but also in structural properties. This will allow the consumers to make more conscious choices and hopefully shift their diets to more healthy alternatives.

\subsection{Future research}

In this thesis, we have used a multidisciplinary approach to understand the effects of plant tissue encapsulation in digestion and fermentation. The efforts made have brought new insights about the most important aspects that govern this effect. However, we believe that there is still plenty of space for optimization and research to bring more lights into understanding the system at its fullest. In this section, we will discuss some of the things that we consider worth exploring. 


\subsubsection{Validation of the mathematical model and extrapolation to other matrices}

We are confident that the model described in chapter 4 is one of the strongest contributions of this thesis to the scientific world. However, we believe that there is still room for improvement to increase its robustness. This could be achieved by validating the model with additional invitro data using different legume sources (i.e. samples with different $\mathrm{CW}$ composition and permeability), different mixing regimes or rheological properties of digesta.

Furthermore, even though the model presented here is limited to intact cells, it can be used as a starting point to describe more complex plant matrices, like cell clusters where encapsulated and non-encapsulated starch structures occur simultaneously. But also, the same approach based on Fickean diffusion can be applied to other types of structural barriers to starch (e.g. gluten network in pasta or bread) or even different types of nutrients digestibility (e.g. proteins, fats).

\subsubsection{Role of oral processing and salivary $\alpha$-amylase}

One of the few studies that addressed the effect of oral processing of legumes on starch digestibility was mainly focussed on the mechanical process of mastication and its influence in digestion due to differences in the bolus particle size ${ }^{26}$. In this study, the authors concluded that the textural properties of legumes (after cooking) have a large effect on the particle size distribution of the bolus and, in turn, on starch digestion by pancreatic amylase. However, the effect of salivary amylase was excluded from that research since bolus samples were prewashed before in-vitro digestion. It is generally accepted that the activity of salivary $\alpha$-amylase is not limited to the few minutes that food resides in the oral cavity. Instead, this enzyme has been found to be active for around $30 \mathrm{~min}$ after it reaches the gastric phase until the $\mathrm{pH}$ drops to values inferior to $3.0^{27}$. This gives salivary $\alpha$-amylase enough time to hydrolyse substantial amounts of starch present in the chyme. A recent study using wheat bread nicely demonstrates this issue since up to $80 \%$ of starch was hydrolysed in the first 30 minutes of gastric digestion ${ }^{28}$. In the case of plant tissues, very little is known about the effect of $\mathrm{CW}$ encapsulation on digestion of starch by salivary amylase. We believe that understanding how encapsulated starch is digested by salivary amylase would be of huge importance since this will determine the amount of starch reaching small intestine already pre-digested. Furthermore, it would also be interesting to determine if $\mathrm{CW}$ encapsulation serves as a protective layer that could extend amylase activity in the stomach for longer periods of time. 


\subsubsection{Effect of digesta rheological properties}

Another aspect that might be worth exploring is how physical factors like the viscosity of the intestinal lumen affects digestibility of starch within intact cells. Viscosity has been widely used as a strategy to reduce starch digestibility where some NSP, like $\beta$-glucan, has been recognized for such properties ${ }^{29}$. However, most of the studies that have been performed to understand the effect of lumen viscosity have used systems in which the natural entrapment of starch has been lost. In some of these studies, it has been concluded that viscosity reduces starch digestibility, however maintaining high viscosity levels in the system is only possible at low shearing rates (below physiological values) ${ }^{30}$. While in other cases, it was found that the interactions between some NSP and $\alpha$-amylase were more efficient in reducing starch digestibility than viscosity itself $^{31}$. Furthermore, it was found that starch granules contribute to the viscosity of the lumen content since a decrease in viscosity has been observed as digestion proceeds and the granules integrity are lost. This is an interesting finding worth to explore using intact cells since no contribution to viscosity from starch itself is expected due to $\mathrm{CW}$ encapsulation. Moreover, we believe that by increasing the viscosity of the chyme, the effect obtained by the stagnant layer will also increase not only for enzyme diffusion but perhaps also for the diffusion of starch hydrolysis products out of the cells delaying even further starch digestion and absorption. 


\section{References}

1. Berg T, Singh J, Hardacre A, Boland MJ. The role of cotyledon cell structure during in vitro digestion of starch in navy beans. Carbohydr Polym. 2012;87(2):1678-1688.

2. Dhital S, Gidley MJ, Warren FJ. Inhibition of $\alpha$-amylase activity by cellulose: Kinetic analysis and nutritional implications. Carbohydr Polym. 2015;123:305-312.

3. Wong JH, Lau T, Cai N, et al. Digestibility of protein and starch from sorghum (Sorghum bicolor) is linked to biochemical and structural features of grain endosperm. J Cereal Sci. 2009;49(1):73-82.

4. Edwards CH, Warren FJ, Campbell GM, et al. A study of starch gelatinisation behaviour in hydrothermally-processed plant food tissues and implications for in vitro digestibility. Food Funct. 2015;6(12):3634-3641.

5. Tuncil YE, Nakatsu CH, Kazem AE, et al. Delayed utilization of some fast-fermenting soluble dietary fibers by human gut microbiota when presented in a mixture. J Funct Foods. 2017;32:347-357.

6. Warren FJ, Fukuma NM, Mikkelsen D, et al. Food Starch Structure Impacts Gut Microbiome Composition. mSphere. 2018;3(3):1-13.

7. Rose DJ, Keshavarzian A, Patterson JA, Venkatachalam M, Gillevet P, Hamaker BR. Starchentrapped microspheres extend in vitro fecal fermentation, increase butyrate production, and influence microbiota pattern. Mol Nutr Food Res. 2009;53:121-130.

8. Edwards CH, Grundy MM, Grassby T, et al. Manipulation of starch bioaccessibility in wheat endosperm to regulate starch digestion, postprandial glycemia, insulinemia, and gut hormone responses: a randomized controlled trial in healthy ileostomy participants. Am J Clin Nutr. 2015;102(4):791-800.

9. Dupont D, Alric M, Blanquet-Diot S, et al. Can dynamic in vitro digestion systems mimic the physiological reality? Crit Rev Food Sci Nutr. 2019;59(10):1546-1562.

10. Minekus M, Alminger M, Alvito $\mathrm{P}$, et al. A standardised static in vitro digestion method suitable for food - an international consensus. Food Funct. 2014;5(6):1113-1124.

11. Pallares Pallares A, Alvarez Miranda B, Truong NQA, et al. Process-induced cell wall permeability modulates the: In vitro starch digestion kinetics of common bean cotyledon cells. Food Funct. 2018;9(12):6544-6554. 
12. Dhital S, Bhattarai RR, Gorham J, Gidley M. Intactness of cell wall structure controls the in vitro digestion of starch in legumes. Food Funct. 2016;7(3):1367-1379.

13. Pazur J, Ando T. The Action of an Amyloglucosidase of Aspergillus on Starch and Maltooligosaccharides *. J Biol Chem. 1959;234(8):1966-1971.

14. Martens BMJ, Flécher T, de Vries S, Schols HA, Bruininx EMAM, Gerrits WJJ. Starch digestion kinetics and mechanisms of hydrolysing enzymes in growing pigs fed processed and native cereal based diets. Br J Nutr. 2019:1-29.

15. Payne AN, Zihler A, Chassard C, Lacroix C. Advances and perspectives in in vitro human gut fermentation modeling. Trends Biotechnol. 2012;30(1):17-25.

16. Low DY, Williams BA, D’Arcy BR, Flanagan BM, Gidley MJ. In vitro fermentation of chewed mango and banana: Particle size, starch and vascular fibre effects. Food Funct. 2015;6(8):2464-2474.

17. Edwards CH, Warren FJ, Milligan PJ, Butterworth PJ, Ellis PR. A novel method for classifying starch digestion by modelling the amylolysis of plant foods using first-order enzyme kinetic principles. Food Funct. 2014;5:2751-2758.

18. Goñi I, Garcia-Alonso A, Saura-Calixto F. A starch hydrolysis procedure to estimate glycemic index. Nutr Res. 1997;17(3):427-437.

19. Li H, Dhital S, Gidley MJ, Gilbert RG. A more general approach to fi tting digestion kinetics of starch in food. Carbohydr Polym. 2019;225:1-9.

20. Butterworth PJ, Warren FJ, Grassby T, Patel H, Ellis PR. Analysis of starch amylolysis using plots for first-order kinetics. Carbohydr Polym. 2012;87(3):2189-2197.

21. Bhattarai RR, Dhital S, Mense A, Gidley MJ, Shi YC. Intact cellular structure in cereal endosperm limits starch digestion in vitro. Food Hydrocoll. 2018;81:139-148.

22. Goh R, Gao J, Ananingsih VK, Ranawana V, Henry CJ, Zhou W. Green tea catechins reduced the glycaemic potential of bread: An in vitro digestibility study. Food Chem. 2015;180:203210.

23. Grundy MML, Carrière F, Mackie AR, Gray DA, Butterworth PJ, Ellis PR. The role of plant cell wall encapsulation and porosity in regulating lipolysis during the digestion of almond seeds. Food Funct. 2016;7(1):69-78.

24. Zahir M, Fogliano V, Capuano E. Effect of soybean processing on cell wall porosity and 
Chapter 7

protein digestibility. Food Funct. 2019:0-31.

25. Capuano E, Oliviero T, Fogliano V, Pellegrini N. Role of the food matrix and digestion on calculation of the actual energy content of food. Nutr Rev. 2018;76(4):274-289.

26. Pallares Pallares A, Loosveldt B, Karimi SN, Hendrickx M, Grauwet T. Effect of processinduced common bean hardness on structural properties of in vivo generated boluses and consequences for in vitro starch digestion kinetics. Br J Nutr. 2019;122(4):388-399.

27. Bornhorst GM, Singh RP. Bolus Formation and Disintegration during Digestion of Food Carbohydrates. Compr Rev Food Sci Food Saf. 2012;11(2):101-118.

28. Freitas D, Le Feunteun S, Panouillé M, Souchon I. The important role of salivary $\alpha$-amylase in the gastric digestion of wheat bread starch. Food Funct. 2018;9(1):200-208.

29. Kim HJ, White PJ. Impact of the molecular weight, viscosity, and solubility of $\beta$-glucan on in vitro oat starch digestibility. J Agric Food Chem. 2013;61(13):3270-3277.

30. Hardacre AK, Lentle RG, Yap S-Y, Monro JA. Does viscosity or structure govern the rate at which starch granules are digested? Carbohydr Polym. 2016;136:667-675.

31. Hardacre AK, Yap S-Y, Lentle RG, Monro JA. The effect of fibre and gelatinised starch type on amylolysis and apparent viscosity during in vitro digestion at a physiological shear rate.

Carbohydr Polym. 2015;123:80-88. 
Summary

$-92060$ 


\section{Summary}

The consumption of plant-based foods have been increasing in the last years. Such rise is related to health and environmental benefits provided by these food products. In this sense, legumes represent an important constituent of plant-based diets due to its high nutritional content which makes them a good option for replacing certain products of animal origin. One of the most interesting aspects of legumes are related to its low glycaemic index that have been shown to be beneficial for health, in particular to those segments of the population with metabolic disorders. It has been found that microstructural aspects of legumes are responsible of such effects since in these systems, starch is naturally encapsulated within a cell wall matrix of nonstarch polysaccharides. Therefore, it is essential to understand the mechanism by which those structures confer this low glycaemic index. Thus, in this thesis we have used red kidney beans as model systems to provide more insights about the role of plant-tissue structure in starch digestion.

In chapter 2, in-vitro digestion of cotyledon cells with different levels of cell wall integrity were tested in order to understand starch hydrolysis when entrapped within this matrix. Three levels of structural integrity were investigated. The first one comprised samples where intact cotyledon cells encapsulated starch as normally occurring in cooked beans. The second type of sample represented an intermediate level of cell integrity since the thickness and porosity of the cell wall was modified by enzymatic treatment without affecting the integrity of the cytoplasmic matrix. The third type of sample was made up of cells whose structure was completely disrupted by the effect of mechanical treatments. Results indicated that by decreasing cell intactness, the rate of starch digestion increased. Moreover, it was also found that the cytoplasmic matrix, constituted by starch embedded in a protein matrix, reduced further the accessibility of amylase affecting also the rate of starch digestion. Finally, it was confirmed that structural changes in intact cotyledon cells occurring during digestion had no effect in starch hydrolysis.

Since proteins were also encapsulated within a cell wall matrix, it was interesting to explore how its digestibility was affected by the physical entrapment (chapter 3 ). It was observed that cell wall encapsulation limited protein denaturation induced by thermal treatment causing a reduction in digestibility. High amounts of an indigestible protein fraction were identified when proteins were cooked during cell wall confinement. Disrupting cell wall integrity after applying thermal treatments did not increase the extent of protein digestion indicating the resistance of 
this fraction. Furthermore, opposed to what found for starch, protein digestion was found to be unaffected by the presence of starch granules in the cytoplasmic matrix.

In chapter 4, a mathematical model was developed to provide a mechanistic explanation about the digestibility of starch when confined within an intact cell wall matrix. The process behind the digestibility of starch entrapped in bean cells consisted of a series of steps that started with the diffusion of $\alpha$-amylase through the cell wall. It was found that the porosity and the interaction of amylase with cell wall constituents limited enzyme diffusion. As a result, lower amount of enzymes were available within the cell causing a reduction in starch digestion. The model was validated using in-vitro starch digestion data with very accurate results. This approach provided a useful tool to understand the effect of plant-tissue encapsulation in starch hydrolysis.

The following chapters of this thesis were designed to understand the effect of food structure in colonic fermentation. In chapter 5, the simulator of the human intestinal microbial ecosystem $\left(\mathrm{SHIME}^{\circledR}\right.$ ) was used to determine the fate of starch fermentation when entrapped within a cell wall matrix. The results indicate that during the first days of fermentation, encapsulation reduced the amount of starch fermentation compared to a sample where cell intactness was disrupted. However, after 12 days of fermentation, the amount of starch utilized by the microbiota was comparable to a sample devoided of cell wall entrapment. Furthermore, it was also observed that bean supplementation changed the composition of the microbiota present in the three colon regions where a higher relative abundance of Bifidobacterium was identified independently of the structural properties of the sample.

In chapter 6, by using a batch fermentation model, we studied the efficiency of the microbiota present in each colonic region and assessed the changes in fermentation due to microbiota adaptation to bean cells. For the former, by providing equal amounts of substrate to colonic microbiota it was possible to determine that bacteria present in the descending colon was the most efficient in fermenting carbohydrates. This indicated that the high amounts of protein fermentation observed in-vivo are probably due to carbohydrate depletion instead of a preference of microbiota to utilized protein. As for the later, the effect of microbial adaptation was studied by using inocula obtained from the SHIME ${ }^{\circledR}$ system before and after 12 days of exposure to intact bean cells. It was found that bacterial adaptation to substrate increased fermentation efficiency since higher amounts of gas were produced. However, it was found that 
Summary

structural integrity of bean cells affected the rate of starch utilization independently of the type of microbiota utilized.

Finally, in chapter 7 all the findings provided in this thesis were discussed. A summary of the most important results were stated together with an overview of their potential applicability by other scientific fields and industry. Furthermore, the methodological approach was evaluated and its limitations were described. This section ends with an overview of the ongoing challenges that could not be covered in this thesis and suggest a direction for future research. 


\section{Acknowledgements}

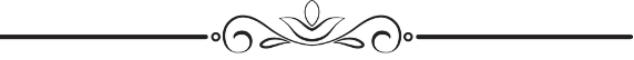





\section{Acknowledgements}

Before starting my PhD I knew that this experience was going to leave me lots of lessons. I was eager to learn and understand those aspects that make food science such a fascinating topic. Now, after four years I must say that my expectations were met. However, I never imagined that besides all these knowledge, my $\mathrm{PhD}$ life was going to give me the opportunity to meet so many people with whom I have shared this journey.

I would like to start acknowledging Edoardo and Vincenzo. Thank you very much for all your support during these years. I really appreciate the fact that you always gave me the freedom to choose how to conduct my research but were always there to find solutions when things were not going in the right direction. It was very easy working with both of you; your diligence and commitment really helped me especially in the last stretch of my $\mathrm{PhD}$.

Being part of FQD group has been a great pleasure. Sometimes I am impressed that despite of the size of the group and its multidisciplinary nature the working environment has always been very pleasant. Thanks to all staff members of FQD for the nice moments shared together during dinners, lab trips, lunch breaks and informal chats. It was a real pleasure to meet you all. In particular, I will like to acknowledge the support received from our secretaries Kim, Corinne and Lysanne. You truly make our life easier, thanks for taking care of all the administrative issues concerning our $\mathrm{PhD}$ life but also for cheering us up to keep us motivated during challenging times.

My gratitude goes also for all the technical support provided by Xandra, Charlotte, Mike, Erik, Frans and Geert. Erik, you were perhaps the person who helped me the most with my experiments during these years. Thank you a lot for always finding time in your busy agenda to help me. We had a very nice time even when conducting the smelly experiments in the SHIME. Charlotte and Mike, I enjoyed helping in the practical of the digestion course with you. We were a good team; I will miss working together with you!

I would like to thank all my fellow (past and present) $\mathrm{PhD}$ colleagues; it was really nice meeting and getting to know you all. In particular I would like to thank my friends Jonna and Mostafa with whom I have shared this PhD journey from the beginning. Ita, James, Faith, Ruth, Juliet and lately Elisa and Marianna I was really glad to find people with the same lunch timing than me and being part of the "late lunch group". Li, Ling and Chunyue I really appreciate your friendship and the time we spent together in conferences, $\mathrm{PhD}$ trips and during those long hours of lab work. A mis queridas amigas Latinas: Ornella, Fabiola, Sara, Araceli, Naomi y Lucía. Ha sido un placer enorme conocerlas y tenerlas como amigas durante estos años. Muchas gracias por hacerme sentir más cerca de casa, es increíble darse cuenta 
que tenemos tantas cosas en común a pesar de venir de países diferentes. Les deseo muchos éxitos en todos sus proyectos y espero verlas pronto.

Thanks a lot to my dear paranymphs Hannah and Lucía. I am really happy to have you by my side during my defence. Knowing you has been one of the great things of this $\mathrm{PhD}$ journey, both of you are brave and determined women so I am pretty sure you will achieve all what you wish in life.

To my MSc. and BSc. students: Florine, Katia, Rosanne, Lysanne, Wensi and Max thanks for your hard work and commitment to the project. I hope you have learned from me as much as I did from you. The outcome of this thesis is also yours.

Debo agradecer también a aquellas personas que son el pilar de mi vida: mi familia. Rocío y Bolívar, son los mejores padres que la vida me pudo dar. Gracias infinitas por su amor, el apoyo incondicional que he recibido por parte de ustedes es lo que me motiva a ser mejor cada día. Ojalá algún día pueda recompensar todo el sacrificio que han hecho por nosotros. María Elena: Creo que esta experiencia no hubiera sido la misma sin tu venida a Europa. Fue un año realmente especial en el que disfruté cada segundo de tu compañía. Eres una mujer muy sabia, te agradezco mucho por ser siempre mi cable a tierra. David: mi hermanito menor gracias por permitirme ser parte de tu vida a pesar de la distancia. Tu incondicionalidad y preocupación me han ayudado en los momentos en los que más lo he necesitado. Tengan presente que estoy muy orgullosa de ambos y mi cariño para ustedes es infinito. Para el resto de mi familia del Edificio Córdova y mi tía Elena: muchas gracias por estar tan al pendiente de mí, sepan que los llevo siempre en mi corazón y el cariño es mutuo.

Agradezco también a mi familia Aguirre Montesdeoca. El tiempo que compartimos juntos durante sus visitas alegraron mucho mis días. Mil gracias por estar pendientes de mí y por toda la rica comida ecuatoriana que nunca faltó en nuestra mesa.

Muchas gracias a mis amigas de toda la vida: Ligia, Stephanie y Carolina. Me queda claro que la distancia no es una excusa cuando la amistad es verdadera. Gracias por los mensajes de apoyo y por seguir en contacto todos estos años.

El agradecimiento más especial es para Víctor. Gracias por caminar junto a mí todo este tiempo, por celebrar mis logros y por secar mis lágrimas en los momentos difíciles. Tu alegría y optimismo han hecho de esta una experiencia que jamás olvidaré. Te amo infinitamente y estoy ansiosa de comenzar un nuevo capítulo en mi vida junto a ti. 
About the author

$-92000$ 



\section{Curriculum Vitae}

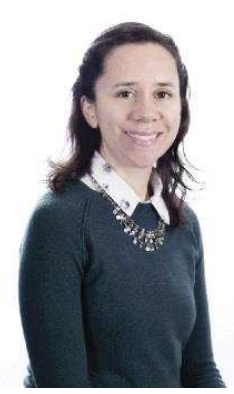

Ana Maria Rovalino Córdova was born in Quito-Ecuador on August $31^{\text {st }}, 1986$. She studied Food Engineering at Universidad San Francisco de Quito from which she graduated with honours (Cum Laude) in 2009. Afterwards she worked in the food industry for nearly two years before continuing with her MSc. studies. In 2012, she started her MSc. program in Food Technology at Wageningen University following Food Ingredient Functionality specialization. For her MSc. thesis, she studied the effect of pectin structure on fibre fermentability using rats as model systems at the Laboratory of Food Chemistry. As an internship, Ana worked in a project where the rheological behaviour at oil-water interphase of chemically modified dairy proteins was investigated in a joint collaboration between Food Physics and Food Process Engineering departments at Wageningen University. After obtaining her master's degree, Ana worked as research assistant at Food Process Engineering group under the supervision of Professor Karin Schroën. The focus of this project was related to understanding the interfacial interactions on droplet formation using microfluidic EDGE emulsification systems. In September 2015, Ana started her PhD project at Food Quality and Design group, Wageningen University. The results of her research are presented in this thesis. 


\section{List of publications}

This thesis:

- Ana M. Rovalino-Córdova, Vincenzo Fogliano, Edoardo Capuano. A closer look to cell structural barriers affecting starch digestibility in beans. Carbohydrate polymers. Volume 181, 2018.

- Ana M. Rovalino-Córdova, Vincenzo Fogliano, Edoardo Capuano. The effect of cell wall encapsulation on macronutrients digestion: A case study in kidney beans. Food Chemistry. Volume 286, 2019.

- Ana M. Rovalino-Córdova, Victor Aguirre Montesdeoca, Edoardo Capuano. A mechanistic model to study the effect of the cell wall on starch digestion in intact cotyledon cells. (Submitted for publication)

- Ana M. Rovalino-Córdova, Vincenzo Fogliano, Edoardo Capuano. Effect of bean structure on microbiota utilization of plant nutrients: an in-vitro study using the simulator of the human intestinal microbial ecosystem $\left(\right.$ SHIME $\left.^{\circledR}\right)$ (Submitted for publication)

- Ana M. Rovalino-Córdova, Vincenzo Fogliano, Edoardo Capuano. In-vitro colonic fermentation of kidney beans depend on cotyledon cells integrity and microbiota adaptation to the diet. (Submitted for publication)

Others:

- Sami Sahin, Olesya Bliznyuc, Ana M. Rovalino-Córdova, Karin Schroën . Microfluidic EDGE emulsification: the importance of interface interactions on droplet formation and pressure stability. Scientific reports. Volume 6, 2016.

- Claire C. Berton-Carabin, Anja Schroder, Ana M. Rovalino-Córdova, Karin Schroën and Leonard Sagis. Protein and lipid oxidation affect the viscoelasticity of whey protein layers at the oil-water interface. Eur. J. Lipid Sci. Technol. Volume $118,2016$. 


\section{Overview of completed training activities}

\section{Discipline specific activities}

\section{Courses}

- Reaction Kinetics in Food Science (VLAG, Wageningen-NL, 2016)

- Summer Course Glycoscience (VLAG, Groningen-NL, 2016)

- Advanced Food Analysis (VLAG, Wageningen-Netherlands, 2017)

- Microscopy and Spectroscopy in Food and Plant Sciences (EPS, VLAG, Wageningen-NL, 2017)

- Healthy Food Design (VLAG, Wageningen-NL, 2018)

Conferences and meetings

- International Conference on Food Digestion (COST INFOGEST, Rennes-FR, 2017)

- Food Structure and Functionality Symposium* (ELSEVIER, Montreal-Ca, 2018)

- EFFoST (ELSEVIER, Nantes-FR, 2018)

- Food Science Symposium* (FPH-FPE, Wageningen-NL, 2020)

\section{General Courses}

- PhD week (VLAG, Zwolle-NL, 2015)

- Introduction to R (VLAG, Wageningen-NL, 2017)

- Applied Statistics (VLAG, Wageningen-NL, 2017)

- The essentials of scientific writing and presenting (WGS, Wageningen-NL, 2018)

- Career perspectives (WGS, Wageningen-NL, 2018)

- Scientific artwork- Vector graphics and images (WUR Library, Wageningen-NL, 2019)

- Start to teach (WUR education support, Wageningen-NL, 2019)

\section{Optional activities}

- Preparation of research proposal (Wageningen-NL, 2015)

- PhD study tour (Italy, 2016)

- Preparing PhD study tour (Italy, 2016)

- PhD study tour (Australia, 2018)

- Meetings and colloquia (Wageningen, 2015-2019)

\footnotetext{
*Oral presentation
} 
The research described in this thesis was financially supported by a grant from the Ecuadorian Secretary of Higher Education, Science, Technology and Innovation.

Financial support from Wageningen University for printing this thesis is gratefully acknowledged.

Cover design by Frank López $\|$ Novotrendmedia

Printed by Digiforce $\|$ ProefschriftMaken 